\title{
THE MATERIAL ARCHITECT: PHYSICALLY ENGAGING THE DESIGN PROCESS
}

\author{
by \\ Michael S. Suriano \\ B. Arch Sc, Ryerson University, 2011 \\ A design thesis project \\ presented to Ryerson University \\ in partial fulfillment of the \\ requirements for the degree of \\ Master of Architecture \\ in the Program of \\ Architecture \\ Toronto, Ontario, Canada, 2013 \\ ๑) Michael S. Suriano 2013
}





\section{Author's Declaration}

I hereby declare that I am the sole author of this thesis. This is a true copy of the thesis, including any required final revisions, as accepted by my examiners.

I authorize Ryerson University to lend this thesis project to other institutions or individuals for the purpose of scholarly research.

I further authorize Ryerson University to reproduce this thesis project by photocopying or by other means, in total or in part, at the request of other institutions or individuals for the purpose of scholarly research.

I understand that my thesis may be electronically available to the public.

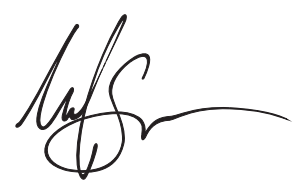

Michael S. Suriano 



\author{
Abstract \\ The Material Architect: \\ Physically Engaging the Design Process \\ M. Arch (2013) \\ Michael S. Suriano \\ Master of Architecture \\ Ryerson University
}

The contemporary architect operates within a profession which is detached from the physical processes undertaken during the making of architecture. The emergence of two-dimensional representation as the architect's primary mode of communication and design is deeply embedded within architectural praxis. The fundamental physical reality of architecture requires that the architect have an experientially based understanding of architecture's conceptual drivers.

This situation necessitates re-conceptualizing the process of creating architecture. By reverting to a tangibly based method of design the creation of representative and demonstrative artefacts can aid in developing a stimulating and exploratory design process. The proposed method of design imbues the designer with a direct corporal experience of architectural ideas heightening an awareness of existent and emergent complexities in manifesting architectural works. The maturation of an architectural intuition steeped in the material reality of architecture developed through the fabrication of architectural prototypes is a critical tool in the arsenal of the contemporary architect. 



\section{Acknowledgements}

First and foremost, I would like to offer my sincerest gratitude to my supervising professors, Dimitri Papatheodorou and Scott Sorli, for offering their insight, patience, and knowledge during the course of my thesis. Their ability to give guidance while allowing me the freedom to explore, create, and make on my own was invaluable. The enthusiasm and interest shown by both Dimitri and Scott ensured an environment where ideas flowed easily and endlessly without which this thesis would not be possible.

I am incredibly grateful to Vincent Hui who has undoubtedly helped shape and develop my academic and professional architectural career. His willingness to help, genuine interest, constructive criticism, and continuous availability were instrumental throughout the past five years. I am indebted to him for setting a high standard and providing the guidance and support to meet it.

Frank Bowen, Blain Evans, and all the DAS Fabrication Lab staff to whom I owe a great deal of appreciation for aiding in the design and construction of many of my prototypes and models. The generosity they have shown with countless hours of their time and in sharing their knowledge has expanded my education exponentially. For this I am ever grateful.

I would like to thank my friends and colleagues for their constant support throughout my academic career. I am grateful to them for providing me inspiration, motivation, and a helping hand when work slowed as well for all the input, comments, critiques, and discourse which have allowed me to develop as an architect and individual.

Lastly, but most importantly, I owe an unending gratitude to my family, my parents Mike and Paola Suriano, my brothers Alexander and Matthew, and Donna Behrouzian for all their patience, understanding, support, and unwavering belief. You are all the foundation on which I am built, one which never shifts, keeping me grounded and level in the most trying of times. Without your guidance, concern, and care none of this would have been possible. This thesis is for each of you. 



\section{Dedications}

To my parents Mike Suriano and Paola Bertoia-Suriano, my aunt Piera Canella, and my grandmother Luisa Bosa-Bertoia 



\title{
Table of Contents
}

\author{
iii Author's Declaration \\ $\checkmark$ Abstract \\ vii Acknowledgements \\ ix Dedications \\ xi Table of Contents \\ XV List of Figures \\ 02 Introduction \\ 10 Chapter 01: The Emergence of the Immaterial Architect \\ 20 Chapter 02: The Architect as Craftsman \\ $28 \quad$ 02.1: Heavy Light \\ 38 Chapter 03: The Human Experience \\ 44 Chapter 04: The Eternal Student \\ 52 Chapter 05: Tools of the Hand and Mind \\ 62 Chapter 06: Tectonics [Physical Engagement In] \\ 70 Chapter 07: A Manifesto of Making \\ 76 Chapter 08: Primitive Hut [Re]-Engaged \\ 82 08.1: Primitive Hut [Re]-Visited
}



96

102

108

124

130

148

162

170

176

180

212

ccxviii
Chapter 09: Possibilities of Knowing

09.1: Making Version 1: Genesis Through Making

09.2: Making Version 2: [Re]-Configuring the Artefact

09.3: Making Version 3: Building the Drawing

09.4: Making Version 4: [1:1]

09.5: Making Version 5: [Re]-Assembling Architecture

Chapter 10: A Manifesto of Architecture

10.1: Making Version 6

Chapter 11: Primitive Hut [Re]-Treat

11.1: Making Version 7

Conclusion

Bibliography 



\section{List of Figures}

Figure 01: MV1Detail

Source: Michael Suriano

Figure 02: Heavy-Light Form Disassembly

Source: Michael Suriano

Figure 03: Sanding Plaster Model Components Source: Michael Suriano

Figure 04: MV1Detail

Source: Michael Suriano

Figure 05: CNC Cutting Concrete Form

Source: Michael Suriano

Figure 06: Wood Weave Test Construction

Source: Michael Suriano

Figure 07: Heavy-Light Concrete Texture Detail Source: Michael Suriano

Figure 08: Heavy-Light Fissure Detail Source: Michael Suriano

Figure 09: Heavy-Light Hand Planing Formwork Source: Michael Suriano

Figure 10 : MV1 Model Components

Source: Michael Suriano

Figure 11: MV1 Model Assembly Detail

Source: Michael Suriano

Figure 12: MV1 Model Formwork Assembly

Source: Michael Suriano

Figure 13: MV1 Final Model

Source: Michael Suriano 
Figure 14: MV1 Connection Detail Source: Michael Suriano

Figure 15: Heavy-Light Component Assembly Source: Michael Suriano

Figure 16: Heavy-Light Concrete Dry Fit Test Source: Michael Suriano

Figure 17: Preliminary Sketch Source: Michael Suriano

Figure 18: Heavy-Light Form Source: Michael Suriano

Figure 19: Formwork Components Source: Michael Suriano

Figure 20: CNC Milling Formwork Source: Michael Suriano

Figure 21: Formwork Components Source: Michael Suriano

Figure 22: Formwork Construction Source: Michael Suriano

Figure 23: Formwork Construction Source: Michael Suriano

Figure 24: Formwork Construction Source: Michael Suriano

Figure 25: Skin Application Source: Michael Suriano

Figure 26: Multi-Curve Ply Detail Source: Michael Suriano

Figure 27: Skin Application Source: Michael Suriano

Figure 28: Formwork Assembly Source: Michael Suriano

Figure 29: Formwork Assembly Source: Michael Suriano 
Figure 30: Concrete Pour

Source: Michael Suriano

Figure 31: Removal of Components

Source: Michael Suriano

Figure 32: Form and Artefact

Source: Michael Suriano

Figure 33: Pin Connection Insert

Source: Michael Suriano

Figure 34: Base Construction

Source: Michael Suriano

Figure 35: Heavy-Light Final Installation

Source: Michael Suriano

Figure 36: Heavy-Light Concrete Lamp on Stained Hard Maple Base

Source: Michael Suriano

Figure 37: Heavy-Light Textural and Lighting Detail

Source: Michael Suriano

Figure 38: Concrete Formwork Detail

Source: Michael Suriano

Figure 39: MV1Detail

Source: Michael Suriano

Figure 40:Kolb’s Experiential Learning Diagram

Source: Michael Suriano

Figure 41: Heavy-Light Base Construction

Source: Michael Suriano

Figure 42: Manual Drafting Tools

Source: http://factory20.com/files/gimgs/1155_1797draftsmans-architects-draftingtable-wood4.jpg

Figure 43: Digital Drafting Tools

Source: http://www.jtbworld.com/images/acadarch_2012_content_search_1 large_1279x959.jpg

Figure 44: Manual Construction Tools

Source: http://sourcethestation.com/wp-content/uploads/2013/03/

Green_Roof_Workshop_Work_Benches.jpg 
Figure 45: Digital Fabrication Tools Source: http://lerablog.org/wp-content/uploads/2013/06/laser-cutting.jpg

Figure 46: Concrete Panel Textural Detail Source: Michael Suriano

Figure 47: MV4 Grasshopper Script Delaunay Triangulation Source: Michael Suriano

Figure 48: MV4 Concrete Panel Rhino 3D Model Source: Michael Suriano

Flgure 49: Mastercam X6 G-code Source: http://www.cimco.com/gfx/line-numbers.png

Figure 50: CNC Milled Multi-Ply Laminated Formwork Source: Michael Suriano

Figure 51: Finished Concrete Panel Source: Michael Suriano

Figure 52: CNC Milling Concrete Panel Mold Source: Michael Suriano

Figure 53: MV1 Detail Source: Michael Suriano

Figure 54: Drawing as notary during Construction Process

Source: Michael Suriano

Figure 55: MV4 Concrete Panels Curing Source: Michael Suriano

Figure 56: MV1 Detail Source: Michael Suriano

Figure 57: MV1 Detail Source: Michael Suriano

Figure 58: MV1Detail Source: Michael Suriano

Figure 59: Hut of the Colchians in Pontus Source: http://www.vitruvius.be/hutten.JPG 
Figure 60: Hut of the Phyrgians

Source: http://wnw.vitruvius.be/hutten.JPG

Figure 61: Laugier's Little Rustic Hut

Source: http://25.media.tumblr.com/832e6d3aea4dfe85efe9cded01b8b389/

tumblr_meq7c1LRQC1rwwinyol_1280.jpg

Figure 62: Caribbean Bamboo Hut Section, Elevation, and Plan

Source: http://classconnection.s3.amazonaws.com/192/flashcards/2809192/g

png/screen_shot_2013-02-19_at_30214_pm1361304147595.pn

Figure 63: Viollet-le-Duc's Primitive hut

Source: http://25.media.tumblr.com/tumblr_mlb18bpWqYlqzlcoro1_400.jpg

Figure 64: Corb's Primitive Temple

Source: Corbusier, L. (1923). Towards an Architecture. Los Angeles: Getty Research Institute.

Figure 65: Maison Domino

Source: http://classconnection.s3.amazonaws.com/1416/flashcards/678373/

png/presentation-013-008.png

Figure 66: Anatomy of a Dwelling

Source: http://arteria.ca/wp-content/uploads/2_Anatomy_of_a_Dwelling.jpg

Figure 67: Environmental Bubble

Source: http://wnw.architizer.com/blog/wp-content/uploads/2013/06/new10.j

$\mathrm{pg}$

Figure 68: MV1 Detail

Source: Michael Suriano

Figure 69: MV4 Mold Detail

Source: Michael Suriano

Figure 70: Making Versions Diagram

Source: Michael Suriano

Figure 71: MV1 in situ

Source: Michael Suriano

Figure 72: MV1Detail

Source: Michael Suriano

Figure 73: MV1-1.1

Source: Michael Suriano 
Figure 74: MV1-1.2

Source: Michael Suriano

Figure 75: MV1-1.3

Source: Michael Suriano

Figure 76: MV1-1.4

Source: Michael Suriano

Figure 77: MV1-2.1

Source: Michael Suriano

Figure 78: MV1-2.2

Source: Michael Suriano

Figure 79: MV1-2.3

Source: Michael Suriano

Figure 80: MV1-2.4

Source: Michael Suriano

Figure 81: MV2-2.5

Source: Michael Suriano

Figure 82: MV1-3.1

Source: Michael Suriano

Figure 83: MV1-3.2

Source: Michael Suriano

Figure 84: MV1-3.3

Source: Michael Suriano

Figure 85: MV1-3.4

Source: Michael Suriano

Fiugre 86: MV1-3.5

Source: Michael Suriano

Figure 87: MV1-3.6

Source: Michael Suriano

Figure 88: MV1-3.7

Source: Michael Suriano

Figure 89: MV1-4.1

Source: Michael Suriano 
Figure 90: MV1-4.2

Source: Michael Suriano

Figure 91: MV1-4.3

Source: Michael Suriano

Figure 92: MV1-4.4

Source: Michael Suriano

Figure 93: MV1 Detail

Source: Michael Suriano

Figure 94: MV1 Detail

Source: Michael Suriano

Figure 95: MV2-P1

Source: Michael Suriano

Figure 96: MV2-P2

Source: Michael Suriano

Figure 97: MV2-P3

Source: Michael Suriano

Figure 98: MV2-P4

Source: Michael Suriano

Figure 99: MV2-P5

Source: Michael Suriano

Figure 100: MV2-P6

Source: Michael Suriano

Figure 101: MV2-P7

Source: Michael Suriano

Figure 102: MV2-P8

Source: Michael Suriano

Figure 103: MV2-P9

Source: Michael Suriano

Figure 104: MV2-P10

Source: Michael Suriano

Figure 105: MV2-P11

Source: Michael Suriano 
Figure 106: MV2-P12

Source: Michael Suriano

Figure 107: MV2-P13

Source: Michael Suriano

Figure 108: MV2-P14

Source: Michael Suriano

Figure 109: MV2-P15

Source: Michael Suriano

Figure 110: MV2-P16

Source: Michael Suriano

Figure 111: MV2-P17

Source: Michael Suriano

Figure 112: MV2-P18

Source: Michael Suriano

Figure 113: MV2-P19

Source: Michael Suriano

Figure 114: MV2-DA1

Source: Michael Suriano

Figure 115: MV2-DA2

Source: Michael Suriano

Figure 116: MV2-DA3

Source: Michael Suriano

Figure 117: MV2-Cl

Source: Michael Suriano

Figure 118: MV2-C2

Source: Michael Suriano

Figure 119: MV2-C3

Source: Michael Suriano

Figure 120: MV2-C4

Source: Michael Suriano

Figure 121: MV2-C5

Source: Michael Suriano 
Figure 122: MV2-C6

Source: Michael Suriano

Figure 123: MV3 Mold Detail

Source: Michael Suriano

Figure 124: MV4 Detail

Source: Michael Suriano

Figure 125: Primary Model Sketch

Source: Michael Suriano

Figure 126: Primary Model Sketch

Source: Michael Suriano

Figure 127: Concrete Panel Model Sketch

Source: Michael Suriano

Figure 128: Concrete Panel Model Render

Source: Michael Suriano

Figure 129: Construction Drawing for Concrete Panels

Source: Michael Suriano

Figure 130: Grasshopper Surface Texture Explorations

Source: Michael Suriano

Figure 131: CNC Milling Concrete Form derived from Rhino Model Source: Michael Suriano

Figure 132: MV4 Detail

Source: Michael Suriano

Figure 133: MV4 Construction

Source: Michael Suriano

Figure 134: MV4-1Component Assembly

Source: Michael Suriano

Figure 135: MV4-1 Tools and Materials

Source: Michael Suriano

Figure 136: MV4-1Component Assembly

Source: Michael Suriano

Figure 137: MV4-1 Component Assembly

Source: Michael Suriano 
Figure 138: MV4-1 Component Assembly Source: Michael Suriano

Figure 139: MV4-1 Final Assembly Source: Michael Suriano

Figure 140: MV4-1 Completed Source: Michael Suriano

Figure 141: MV4-2 Concrete Mold Source: Michael Suriano

Figure 142: MV4-2 Mold Detail Source: Michael Suriano

Figure 143: MV4-2 Concrete Panel Source: Michael Suriano

Figure 144: MV4-2 Concrete Panel Detail Source: Michael Suriano

Figure 145: MV4-3 Concrete Mold Source: Michael Suriano

Figure 146: MV4-3 Mold Detail Source: Michael Suriano

Figure 147: MV4-3 Concrete Panel Source: Michael Suriano

Figure 148: MV4-3 Concrete Panel Detail Source: Michael Suriano

Figure 149: MV4-4 Concrete Mold Source: Michael Suriano

Figure 150: MV4-4 Mold Detail Source: Michael Suriano

Figure 151: MV4-4 Concrete Panel Source: Michael Suriano

Figure 152: MV4-4 Concrete Panel Detail Source: Michael Suriano

Figure 153: MV4-5 Concrete Mold Source: Michael Suriano 
Figure 154: MV4-5 Mold Detail

Source: Michael Suriano

Figure 155: MV4-5 Concrete Panel

Source: Michael Suriano

Figure 156: MV4-5 Concrete Panel Detail Source: Michael Suriano

Figure 157: MV4-6 Concrete Mold

Source: Michael Suriano

Figure 158: MV4-9 Mold Detail

Source: Michael Suriano

Figure 159: MV4-6 Concrete Panel

Source: Michael Suriano

Figure 160: MV4-6 Concrete Panel Detail

Source: Michael Suriano

Figure 161: MV4-7

Source: Michael Suriano

Figure 162: MV4-8

Source: Michael Suriano

Figure 163: MV4-9

Source: Michael Suriano

Figure 164: MV4-10

Source: Michael Suriano

Figure 165: MV4-11

Source: Michael Suriano

Figure 166: MV4-7 Detail

Source: Michael Suriano

Figure 167: MV4-8 Detail

Source: Michael Suriano

Figure 168: MV4-9 Detail

Source: Michael Suriano

Figure 169: MV4-10 Detail

Source: Michael Suriano 
Figure 170: MV4-11 Detail Source: Michael Suriano

Figure 171: MV1Detail Source: Michael Suriano

Figure 172: MV5 Making Diagram Source: Michael Suriano

Figure 173: Carpentry Genealogy Source: Michael Suriano

Figure 174: Masonry Geneaology Source: Michael Suriano

Figure 175: Textile Genealogy Source: Michael Suriano

Figure 176: Floor and Ceiling Condition Source: Michael Suriano

Figure 177: Wall Condition Source: Michael Suriano

Figure 178: Wall Condition Source: Michael Suriano

Figure 179: Wall Condition Source: Michael Suriano

Figure 180: Concrete Panel Wall and Wood Floor Connection Detail Source: Michael Suriano

Figure 181: Concrete Panel Wall Section Detail Source: Michael Suriano

Figure 182: Structural Steel Column Detail Source: Michael Suriano

Figure 183: Concrete Panel Wall Section Detail Source: Michael Suriano

Figure 184: Exterior Render 1 Source: Michael Suriano

Figure 185: Exterior Render 2 Source: Michael Suriano 
Figure 186: View towards Entrance Source: Michael Suriano

Figure 187: Interior Volume Source: Michael Suriano

Figure 188: Interior Volume Source: Michael Suriano

Figure 189: View towards Exterior Source: Michael Suriano

Figure 190: Roof Plan

Source: Michael Suriano

Figure 191: Plan

Source: Michael Suriano

Figure 192: Unfolded Section

Source: Michael Suriano

Figure 193: Elevations

Source: Michael Suriano

Figure 194: MV1Detail

Source: Michael Suriano

Figure 195: MV4 Detail

Source: Michael Suriano

Figure 196: Architecture of Thickness

Source: Michael Suriano

Figure 197: Architecture of Immediacy

Source: Michael Suriano

Figure 198: Architecture of Connection

Source: Michael Suriano

Figure 199: Materially based Architecture Typology Diagram

Source: Michael Suriano

Figure 200: MV4 Detail

Source: Michael Suriano

Figure 201: MV1 Detail

Source: Michael Suriano 
Figure 202: Making Version Diagram Source: Michael Suriano

Figure 203: Material Palette Source: Michael Suriano

Figure 204: Exploded Axonometric Component Diagram Source: Michael Suriano

Figure 205: Construction Process Diagram Source: Michael Suriano

Figure 206: Section and Details Source: Michael Suriano

Figure 207: [Re]-Treat Hut Plan Source: Michael Suriano

Figure 208: [Re]-Treat Courtyard Plan Source: Michael Suriano

Figure 209: [Re]-Treat Roof Plan Source: Michael Suriano

Figure 210: [Re]-Treat West Elevation Source: Michael Suriano

Figure 211: [Re]-Treat South Elevation Source: Michael Suriano

Figure 212: [Re]-Treat North Elevation Source: Michael Suriano

Figure 213: [Re]-Treat East Elevation Source: Michael Suriano

Figure 214: [Re]-Treat Approach Source: Michael Suriano

Figure 215: [Re]-Treat Courtyard Source: Michael Suriano

Figure 216: [Re]-Treat Entry Source: Michael Suriano

Figure 217: [Re]-Treat Hut Interior View Source: Michael Suriano 
Figure 218: [Re]-Treat Exterior Night View Source: Michael Suriano

Figure 219: MV1Detail

Source: Michael Suriano 


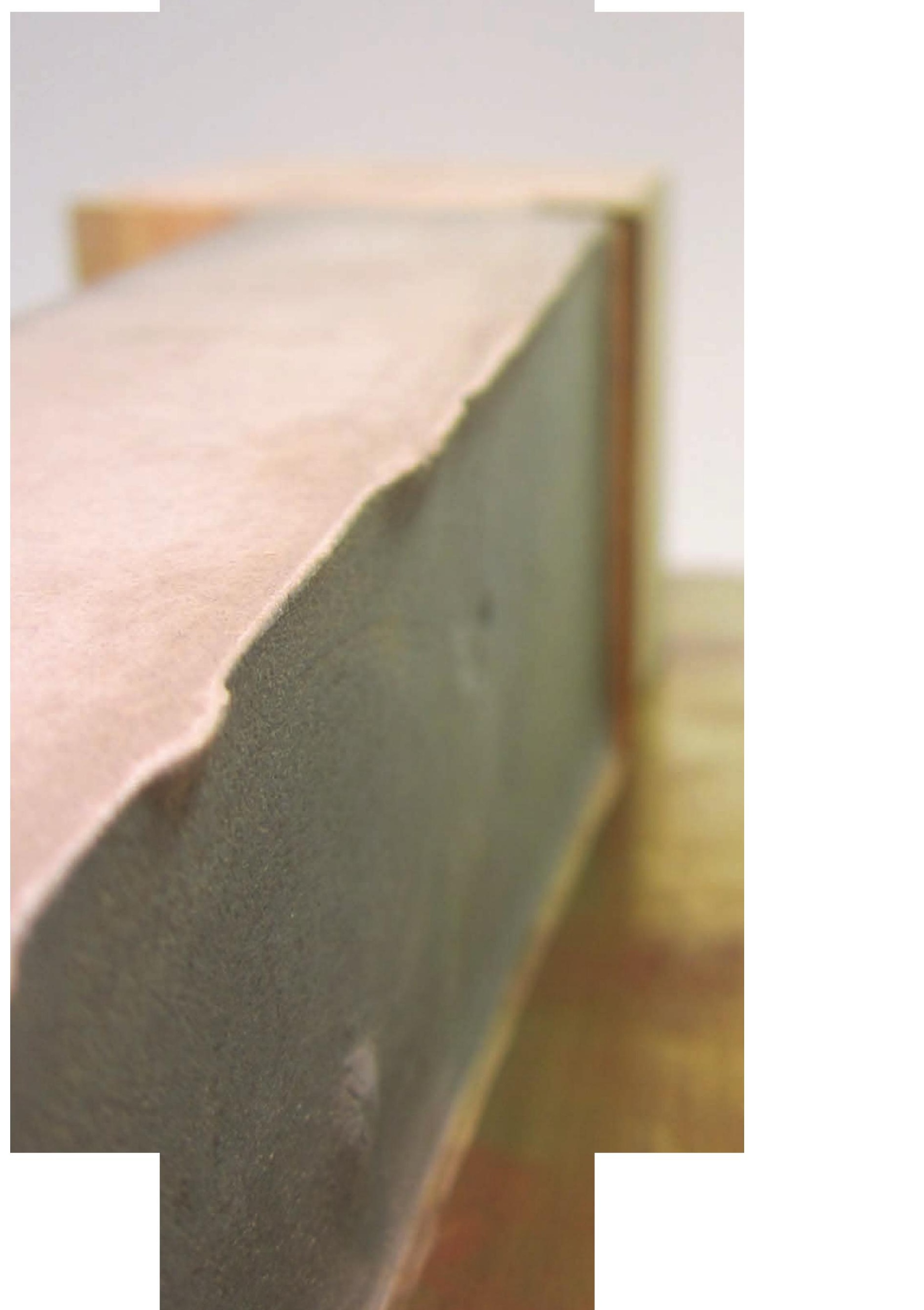




\section{Introduction}

Architectural prototypes are ideas given physicality; they are material expressions of thought birthed from the creative and playful desire to engage craft, making, and exploration in design. The ability of the prototype to be simultaneously abstract and definitive, expressing design ideas and concepts, lies in it's inherent tangible and haptic nature. Prototypes exist physically, and as such are subject to time and three-dimensional space; a key distinguishing feature from other modes of two-dimensional representations. Manually and digitally produced two-dimensional representations have the ability and benefit of being able to dictate and convincingly manipulate the way in which their viewers engage the subject matter. Conversely the architectural prototype does not have this ability and is therefore engaged in a far more honest and visceral manner, engaging the senses before being consciously examined. In Model Making Megan Werner Furthers this notion; “... the onus to construct view, to place one's eye and hand on the object, and take in its space, details, shape or texture - allows for an emotional relationship, a 
guttural connection, a feeling of investment..." (Werner, 2011, p. 9). The ability to transcribe thought, concept, and idea into physical form is an indispensable tool of the architectural design process, having a formative role in all procedural stages of design from the conception of an idea to the final presentation of an architectural product. With the advent of digital technologies and their ubiquitous integration into the architectural profession it is crucial that the art of physical prototyping not be cast aside or lost. Through the design, exploration and construction of physical models and prototypes, the architect gains insight into the design process in a manner which cannot be duplicated by either two-dimensional representation or three-dimensional computer modeling. The haptic nature of the act of physically making returns craft into the realm of architectural design reinforcing the physical essence of architecture.

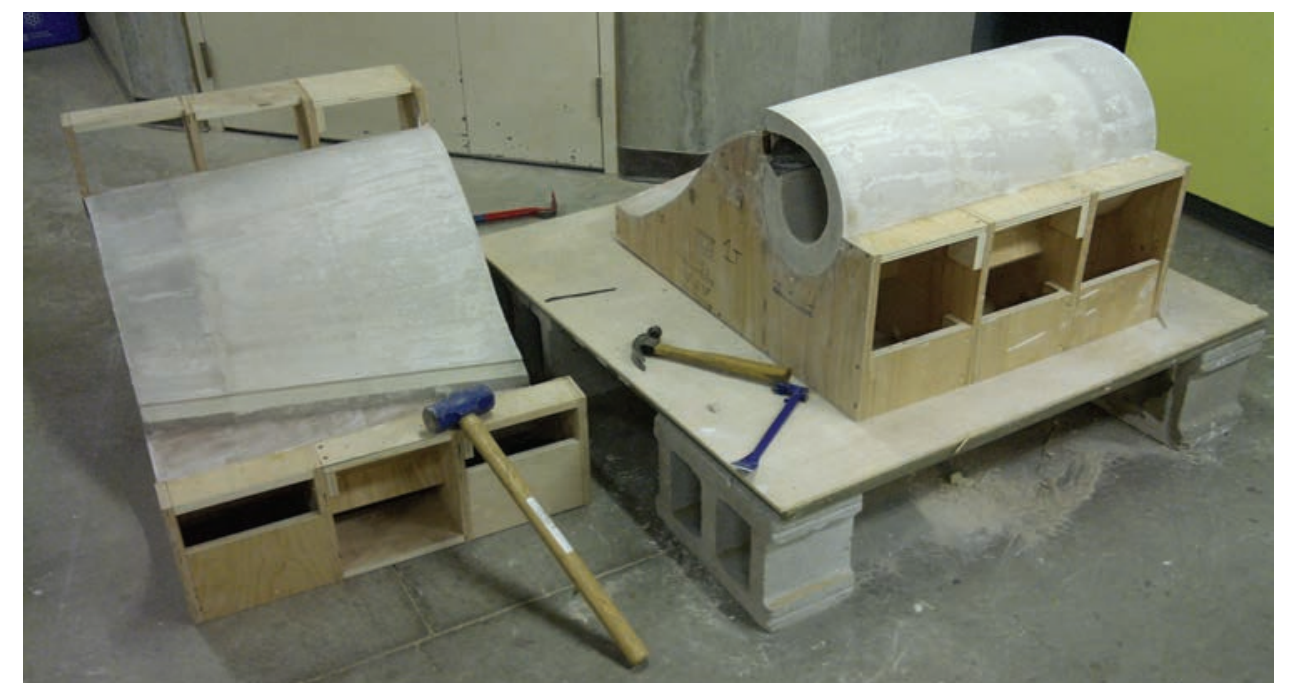

Imperative when exploring the importance which physical prototypes hold within the design process is that a definition be established which details their precise nature. At it's very essence, the architectural prototype is a tool of communication and definition. It is a tangible object employed as a means through which to express the intangible (Smith A. C., 2004, p. 93). This aspect of communication is a key component of the architectural prototype as it is through an idea's physical expression and the subsequent discourse and analysis surrounding the artefact that a growth and maturation of architectural understanding is enabled (Dunn, 2007, p. 13). While the breadth of architectural design occurs under the guise of representation, it is critical that the architect engage a design medium which diminishes the amount of
Figure 01: MV1Detail Figure 02: Heavy-Light Form Disassembly 
simulacra employed and shifts towards design processes which are materially founded. The creation of physical prototypes and artefacts as a means of working through a design, communicating ideas, and giving the ability to corporally connect and understand design potentialities and issues, responds to and respects the fundamental physical reality of architecture. A process of design which is steeped in making begins to substitute the tangible conditions of architecture for the virtual and simulated normative modes of representation which a solely two-dimensional design process entails. In the proposed method of design the architect is able to clarify and communicate design intentions, both to themselves and an exterior audience materially, allowing for a broader spectrum of communicative and definitive power in the prototype than accessible in virtualized representation.

Furthering the notion of the prototype as an indispensible tool is its ability to become the centre of the iterative process of architectural design. Miro, Carbonero and Coderch draw similarities between the physical model and the architectural diagram stating that the model "may undergo changes and adopt final solutions during the creative process that move far from the initial idea." (Coderch, Miró, \& Carbonero, 2010, p. 11). The creation of prototypical artefacts is by no means definitive as it presents a position in a particular instance in time during the journey of design development and offers communicative glimpses into the progress of a project or idea.

In so far as these elements of the architectural prototype are omnipresent there can be found a tripartite nature engrained within them. These present themselves through a physical model's ability to become an object or tool for design development, as an instrument employed to communicate and represent ideas, and as stand-alone objects pertaining to the idea which they represent embedded within their own artistic and aesthetic value (Coderch, Miró, \& Carbonero, 2010, p. 11). Through the creation of physical prototypes the architect can employ these inherent benefits, further emphasizing and solidifying the notion of the physical model as a vital component of contemporary architectural praxis.

By examining the historical prevalence of the architectural prototype it becomes readily apparent that models and representational objects have 
been pervasive throughout human history. While the existence of artefacts is ubiquitous, the context and cultural roles which they fulfilled have shifted over time. Smith details these roles in Architectural Model as Machine: A New View of Models from Antiquity to the Present Day explaining that the cultural function of models varied greatly between time periods. The Egyptian culture held a firm belief in the supernatural powers of the scaled representation, the Greeks created models as representations based on tradition, while the Romans equated models to machinery, and during the Renaissance models became symbolic entities for conceptualizing society (Smith A. C., 2004, p. 41). The physical prototype and model have been crucial elements in aiding humanity contextualize, understand, analyze, and revere the world. Architectural models are rooted in time and history, and while the cultural roles they fulfill in contemporary society may differ they remain a quintessential component in the communication and interpretation of critical concepts about the tangible fabric of our environment.

Due to the architectural prototype's tripartite generative nature and its iterative qualities its role as an indispensable instrument in the architectural design process should not be overshadowed by virtual means of design. Prototypes and models are employed as tools which, through the act of their construction and making, enable a fundamental understanding of architecture. They allow the architect the ability to tangibly engage many integral facets of architecture such as structures, construction processes, materiality, spatial relationships, and programming (Dunn, 2007, p. 19). In The Ecology of the Architectural Model Nick Dunn establishes a crucial role which physical artefacts play in contemporary architectural practice. Dunn states that it is through the prototype's ability to fluidly act as a 'tool of transmission' between a 'sender' and 'receiver' that dictates models as an invaluable instrument for instruction (Dunn, 2007, p. 20). While the proposed process of design through making advocates working with materials and processes which are as close as possible to the reality of the design, in certain instances the use of simulacra may be unavoidable. During the translation of immaterial concept to material artefact the designer/fabricator must be aware of the use of symbols and substitutions which can occur due to scalar issues during the process. The implementation of symbols can be read and understood in a subjective manner being open to multiple interpretations depending on the 
'receiver' (Dunn, 2007, p. 20). Overall, the success of the model as a communicative device is dependent on how successfully the representative symbols chosen by the design communicate their ideas and desired meanings (Dunn, 2007, p. 20). Through directly engaging the construction of architectural prototypes to inform the design process the architect can employ them as tools of understanding and knowledge generation prior to their use as machines of transmission. The designer who engages the seminal act of making benefits from the ability to physically explore architecture much earlier in the design process thus bringing to surface critical architectural issues such as materiality, components, and construction processes.

The existence of the prototype in three dimensions allows for a more robust understanding and engagement of its architecture than with two dimensional forms of imagery. Those who view and engage these physical constructs are able to perceive a greater spatial experience of the intended design which facilitates a less convoluted reading of the formal qualities of the architecture being presented (Dunn, 2007, p. 32). Akiko Busch explains the direct corporal relationship which can be formed with architectural prototypes;

"The world in miniature grants us a sense of authority; it is more easily manoeuvred and manipulated, more easily observed and understood. Moreover, when we fabricate, touch, or simply observe the miniature, we have entered a private affair; the sense of closeness, of intimacy is implicit." (Busch, 1991, p. 11).

The physical nature of the model allows the architect the opportunity and ability to convey and communicate their ideas in four dimension, both time and space $(x, y, z)$. Thus one's perception and ability to engage the artefact in multiple dimensions allows instantaneous access "to any part of a model and to both detailed as well as overall views." (Dunn, 2007, p. 25). Werner furthers this notion stating that the ability of an artefact, through its physicality, to react to environmental conditions such as materials to light, allows the prototype to be perceived in "innumerable and unpredictable ways" (Werner, 2011, p. 9). This interaction, enabled solely through the transformation of an idea into an object which tangibly exists, imbues the architectural model with a life like essence.

Critical to understanding the fundamental physical reality of 
architecture, the architect must engage the design and construction of prototypical artefacts during the design process. Craft and craftsmanship are integral facets of experience, understanding and learning about architecture. Richard Sennett, in his book The Craftsman believes that craftsmanship "...names an enduring, basic human impulse, the desire to do a job well for its own sake" (Sennett, 2008, p. 9) focusing on the "intimate connection between hand and head." (Sennett, 2008, p. 9). This follows closely with Immanuel Kant's observation two centuries ago whereby he concludes that "The hand is the window on to the mind." (Tallis, 2003, p. 4). Architectural prototypes and models allow the individual to experience, with a totality of the senses, the essence of the intended architectural work. Pallasmaa strengthens this notion in The Eyes of the Skin stating that;

"The hands are the sculptors eyes: but they are also organs for thought... The skin reads texture, weight, density and temperature of matter... The tactile sense connects us with time and tradition; through impressions of touch..." (Pallasmaa, The Eyes of the Skin: Architecture and the Senses, 2005, p. 56)

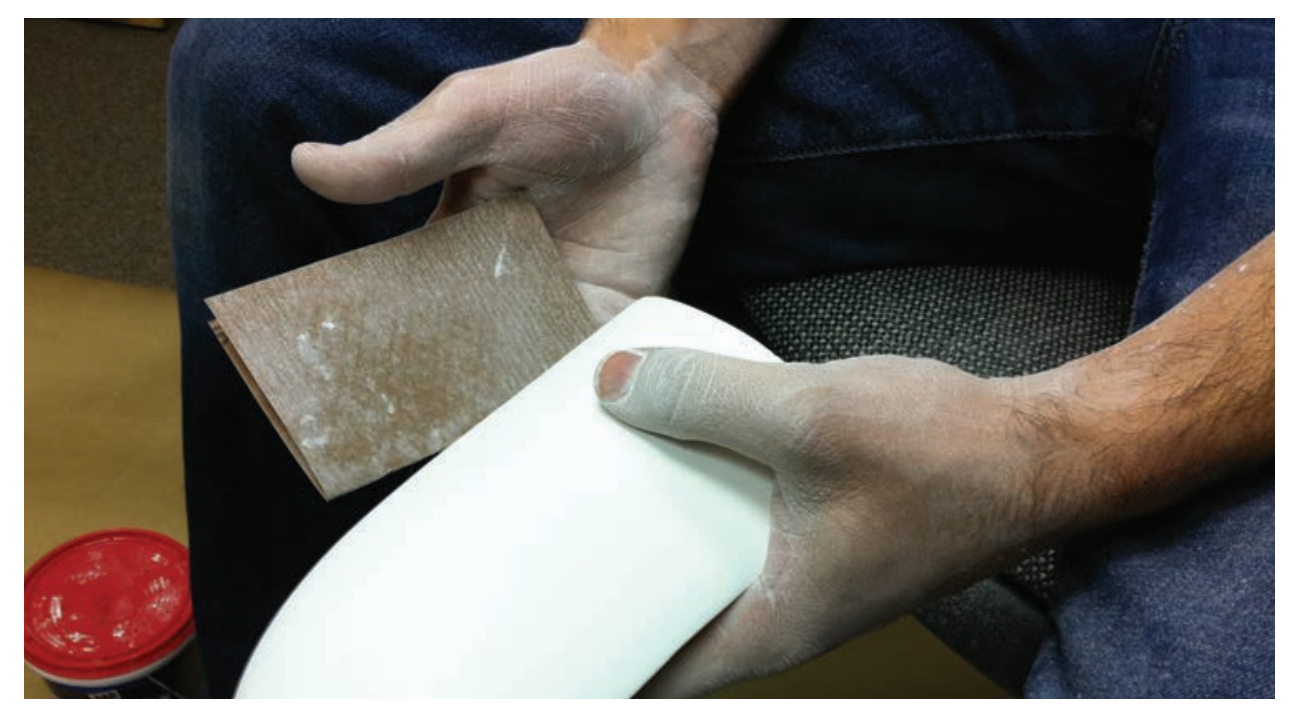

Here Pallasmaa notes that it is through shifting one's focus from the ocularcentrism which is dominant in contemporary architectural practice and by engaging architecture haptically that one is able to truly understand the object or artefact being designed, created and engaged.

Inherent to the act of making is the ability of the individual to connect an intangible thought or idea to a tangible materiality. Through making and
Figure 03: Sanding Plaster Model Components 
creating intimately with materials one elicits the use of their imagination and senses providing a perceptive and emotional engagement with the object (Jetsonen, 2001, p. 126). Furthermore, it allows opportunities for the architect to test material and tool limits offering a richness of information through direct experiences with the processes involved in creating architecture. The engagement of these critical facets of architecture can serve to strengthen the designer's sense of respect for the skill and craftsmanship which encompasses each architectural project. The ability to connect with architecture in a haptic manner, through the act of making, by physically working with one's hands and with materials is positioned as a crucially formative experience for architects.

The ubiquitous integration of technology within contemporary architectural praxis has had an effect on all aspects of architectural design and production. As it pertains to physical prototypes and models, the employment of three dimensional computer modeling and rapid prototyping technologies has expanded the exploration, development and communication of design information allowing more detailed and complex design to be examined (Mills, 2011, p. 116). Digital technologies allow mass amounts of previously incalculable information to be efficiently translated into a legible and constructible format. The availability of these amounts of data-sets and information has grand implications for the manner in which, and the methods by which, physical models are conceived of and crafted.

The ability of the architect to engage an intangible design and through the craft and construction of communicative devices symbolize, represent, and capture an idea is at the core of architectural praxis. It is critical, given the multiplicity of mediums through which an architect can explore design, that the medium be employed in a manner which reinforces the physical nature of architecture. Architectural prototypes and models, as physical projections of thought, are an indispensable tool through which to invite discourse and development. They are being positioned as key components of the iterative process of design, touching every stage of development from initial conception to final presentation. As the contemporary architectural profession finds itself in a stage of immateriality a critical reflection on the role which prototypes fulfill within the design process is seminal. 


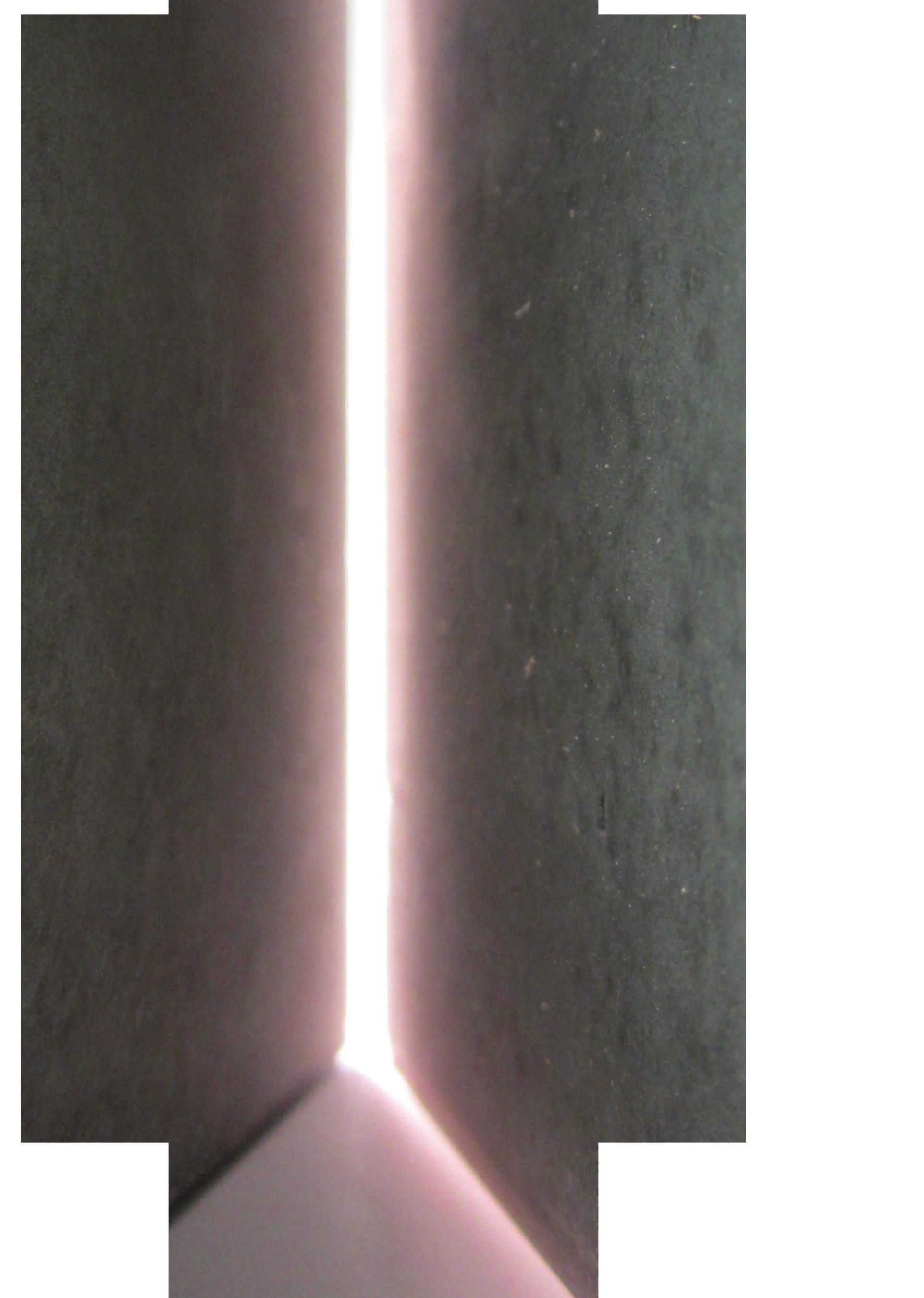




\section{The Emergence of the Immaterial Architect}

Critical to understanding the necessary tangible relationship that design through making evokes it is crucial that the evolution of the contemporary architectural profession be examined. The development of the practice of architecture and its concurrent split from engaging the tangible realm of the built environment is inherently tied to the rise of two-dimensional representation as the architect's primary mode of design communication. This deeply rooted ideology, which is widely held as the normative mode of contemporary architectural practice, can be traced through history to the late 13th century and the beginnings of the Italian Renaissance (Hill, 2005, p. 14).

Prior to this defining moment the craft of architecture was tied to the mason's guilds of the Middle Ages whereby the design and construction of architectural works occurred simultaneously through the accumulated effort of a team of knowledgeable and highly skilled craftsmen (Hill, 2005, p. 14). These anonymous individuals laboured together, manipulating materials and managing 
design decision ad hoc and in situ, with the aid of a master-builder who through coupling their knowledge of the construction process, their ability to organise labour, and their understanding of material processes were able to bring to fruition immensely complex architectural projects (Carranza, 2007, p. 153). During this epoch of physical engagement the making of a design and the making of a building ran congruently, a process of design which was inter twined with the physicality of materials, with information being passed orally from master-builder to craftsman without the need for drawn or written documentation (Starkey, 2005, p. 2). However, due to the intrinsic ties which existed between the architect (or master-builder) and manual labourers coupled with the inability to denote a constructed works authorship to any one particular individual, the perceived social status of the architect in pre-Renaissance social hierarchy was relatively low (Hill, 2005, p. 14).

These societal perceptions began to alter in the late 13th century with the emergence of the Italian Renaissance, during which the discipline of design began to fragment itself from the tangible realm of architecture (Carranza, 2007, p. 153). The removal of the architect from the process of building and their subsequent insertion into the intellectualised profession of architecture was due to the increasing authority of the drawing, or disegno, as the primary representational means of an idea (Hill, 2005, p. 14). The importance of the ability of the architect to draw forth from the realm of intangible thought a pure idea which could then be manifest through drawing stems from the Platonic theory of forms, in which the perfection of an idea can only exist in the intangible realm and once the idea becomes materialized or gains physicality its purity is consequently degraded (Thomas, 2007, p. 3). The authority of the idea over matter allowed drawing to cement itself as the new cornerstone of the architectural profession. The new status of drawing within the realm of architecture allowed the architect to claim sole authorship as the creator of a particular design, which was drawn from the intangible realm at a complete remove from the physicality of materials and the construction process (Hill, 2005, p. 14). The role of the architect, as form giver, lead to the privileging of form as the primary concern of the design profession over matter which symptomatically became secondary and superficial in design considerations (Thomas, 2007, p. 3). These elemental changes to the architectural profession demarcated the work of the architect as belonging to the realm of intellectual 
abstract thought represented through the projective medium of drawing. This established trends and modes of practice which would carry the architect and the architectural drawing into the upper echelons of the hierarchical professional practices.

Contemporary architectural practice has not strayed from these well-established roots which through their propagation over centuries have reinforced the role of the architect as a singular intellectual creator divorced from the tangible material processes of architecture. The split between the architect and the construction process deepened in the mid-nineteenth century with the transformation of the representational drawing into the legally binding contract document (Kolarevic B. , Information Master Builders, 2005, p. 58). This change preceded the introduction of the professional engineer and general contractor as mediating factors establishing further layers between the designer and the execution of their designs. Kolarevic details the consequences of this split;

"The architect's role on the construction site, instead of shaping the building (as master builders once did), became the contractual administration... The design was split from the construction, conceptually and legally. Architects detached themselves fully from the act of building, unintentionally giving up the power they once had, pushing design to a sideline, and setting the profession on a path of increasing irrelevance..." (Kolarevic B. , Information Master Builders, 2005, p. 58)

The expertise of the architect currently resides not in their ability to construct, but rather, in the authoritative role they play in providing information (through the medium of two-dimensional representation) which is essential in enabling cost estimation and construction (Sheil, Transgression from Drawing to Making, 2005, p. 22). A remove from the physicality of architecture was underscored by a decrease in the architect's on-site interaction with skilled craftspeople and builders. This further reduced their ability to engage in collaborative and verbal environments with individuals who make which consequently diminished the tacit knowledge of the architect in the processes of making and constructing (Sheil, Transgression from Drawing to Making, 2005, p. 22). Propagating this, the field of architecture has grown exponentially with the logistics entangled in operating a practice requiring that 


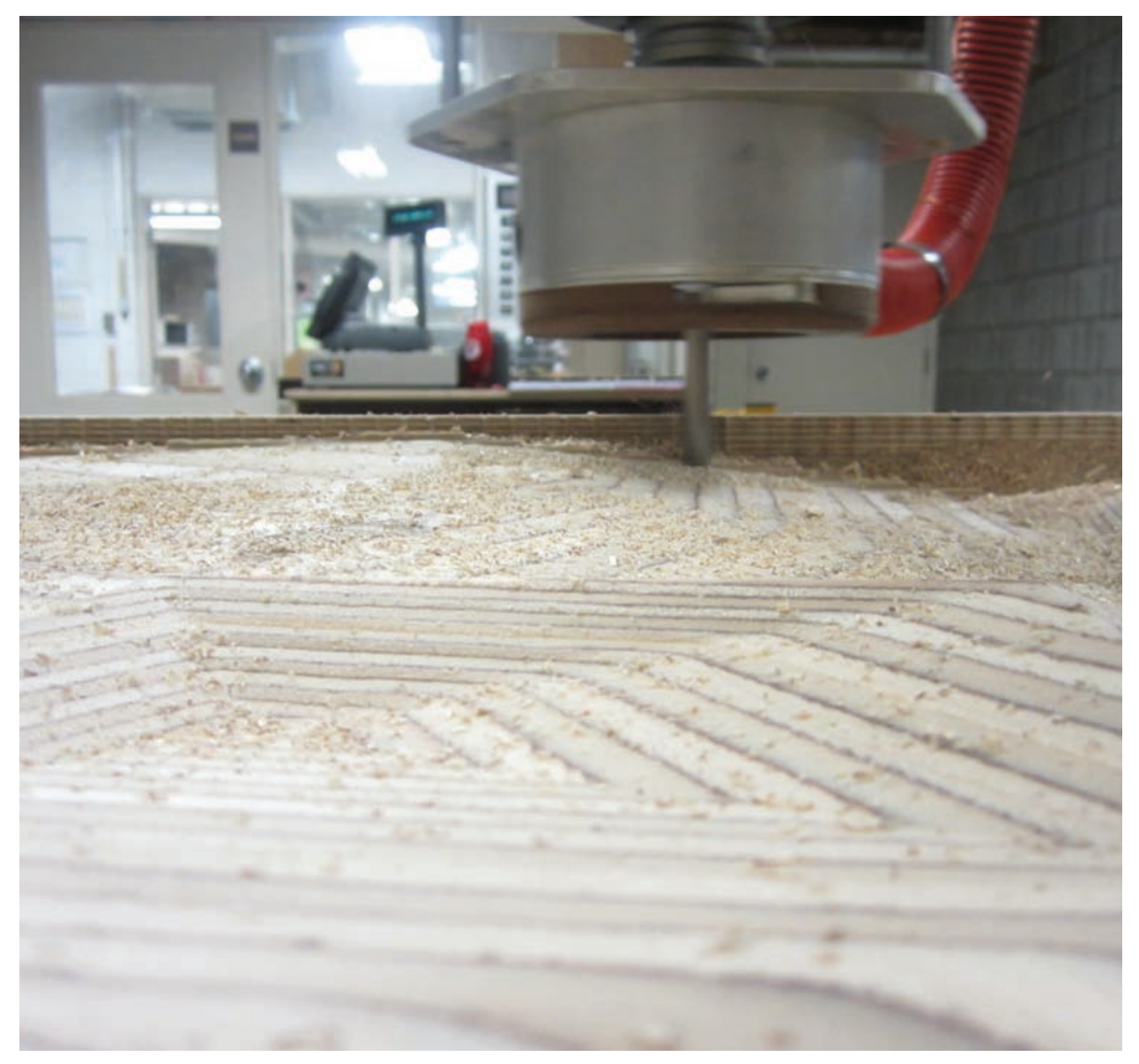

the architect continually exercise and have a working knowledge of a vast array of architectural products, governmental legislation, environmental issues, and so on; all information necessary in the production of the drawing. As the information required to design and construct drawings expanded the architectural profession suffered even further loss of knowledge and expertise in the process of making (Sheil, Transgression from Drawing to Making, 2005, p. 23).

With the advent of technologically based design processes and their ubiquitous employment in the architectural profession the once static drawing has become a tome of information with the potential capacity to carry within it a multiplicity of previously inaccessible information. While Computer-Aided Design software has given architects a means through which to organise and control the production of building, reinforcing the profession's authority over construction, there are inherent consequences in relying on a solely immaterial process of design (Carranza, 2007, p. 153). The continuous absorption by the 


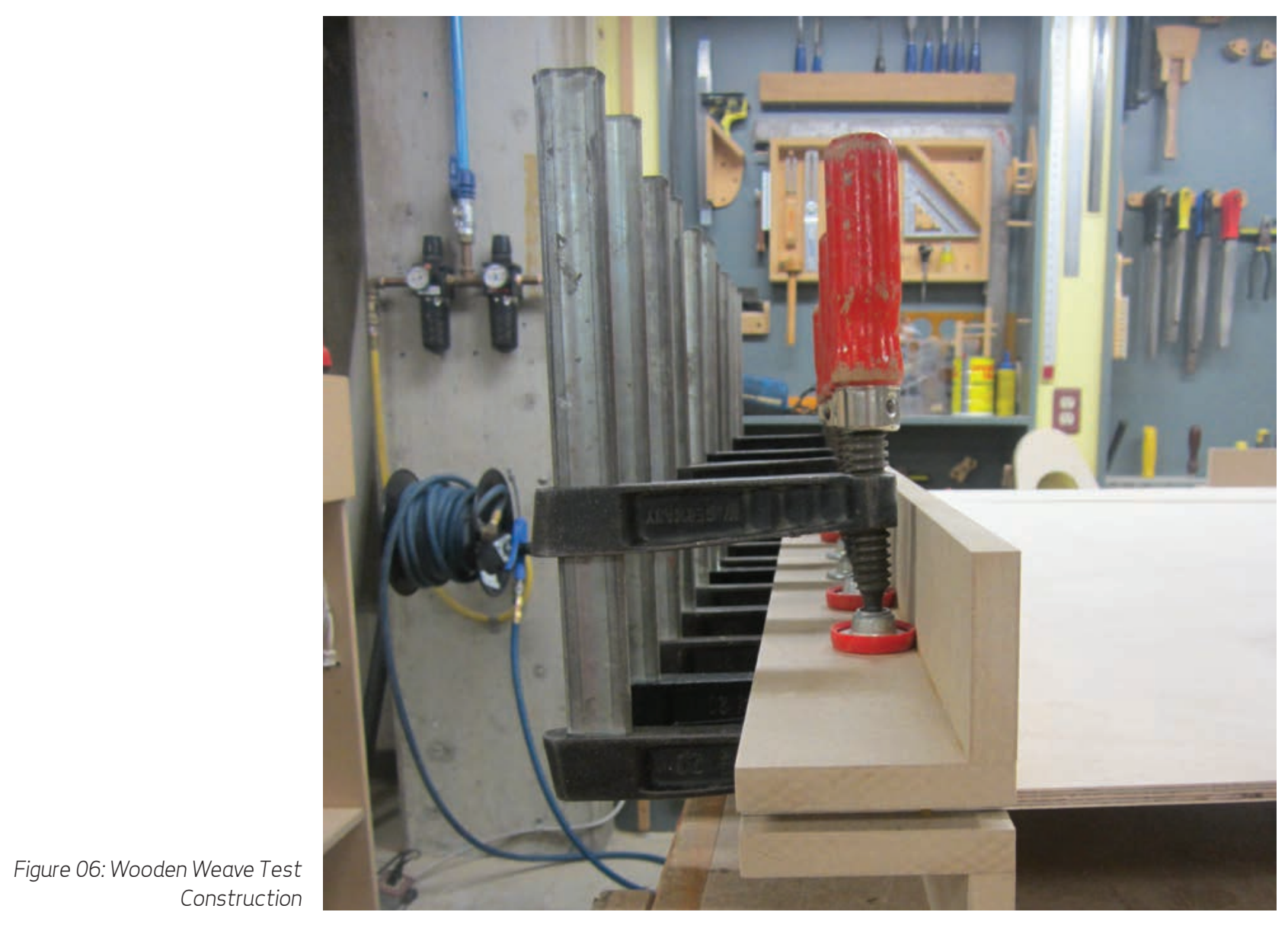

contemporary architectural profession of the realm of the two-dimensional representative image, which is detached from the physicality of the built environment, does not allow for an integrated and whole approach to architectural design as currently employed. A critical understanding of the role which technology plays within the process of making architecture, through the development of information used to guide physical machining and making processes, may serve to resolve the established disconnect. However, the contemporary virtualization of design brings with its implementation a host of symptoms which have formed a collective naiveté in architecture within the context of the technical and material foundations of the profession.

The current state of the architectural profession, where the immaterial and intangible dominate, necessitates a thorough examination of the methods and means by which the architectural community engages the design of the tangible, built environment. The ability to physically engage making within the design process proper will be positioned as a means through which the 
architect is able to wholly engage with prototypes and artefacts, ascertaining an understanding and knowledge which would otherwise be inaccessible through the virtualization of a design. The act of making, in every tangible sense of its meaning, provides the maker with a resource which has the ability to act concurrently as a mode of research, experimentation and innovation. The proposed method of design will call into question the fundamental basis upon which, since the Italian Renaissance, architects have practiced seeking to synthesise the contemporary conflicting intellectual and haptic realms. The architect must become an active participant in the process of design through making engaging intimately with constructive and material processes gaining expertise in the tactile and the physical. Through the physical engagement of a design via making the architect is able to ascertain particular modes of knowledge which are inseparable from each other and yet distinct in the manner in which they inform. 


"This intimate handling of the material, the sense of the presence of the maker in the artefact, had considerable consequences on the evocative power of the work and perhaps, by association, its emotional accessibility" (Shotton, 2007, p. 93) 


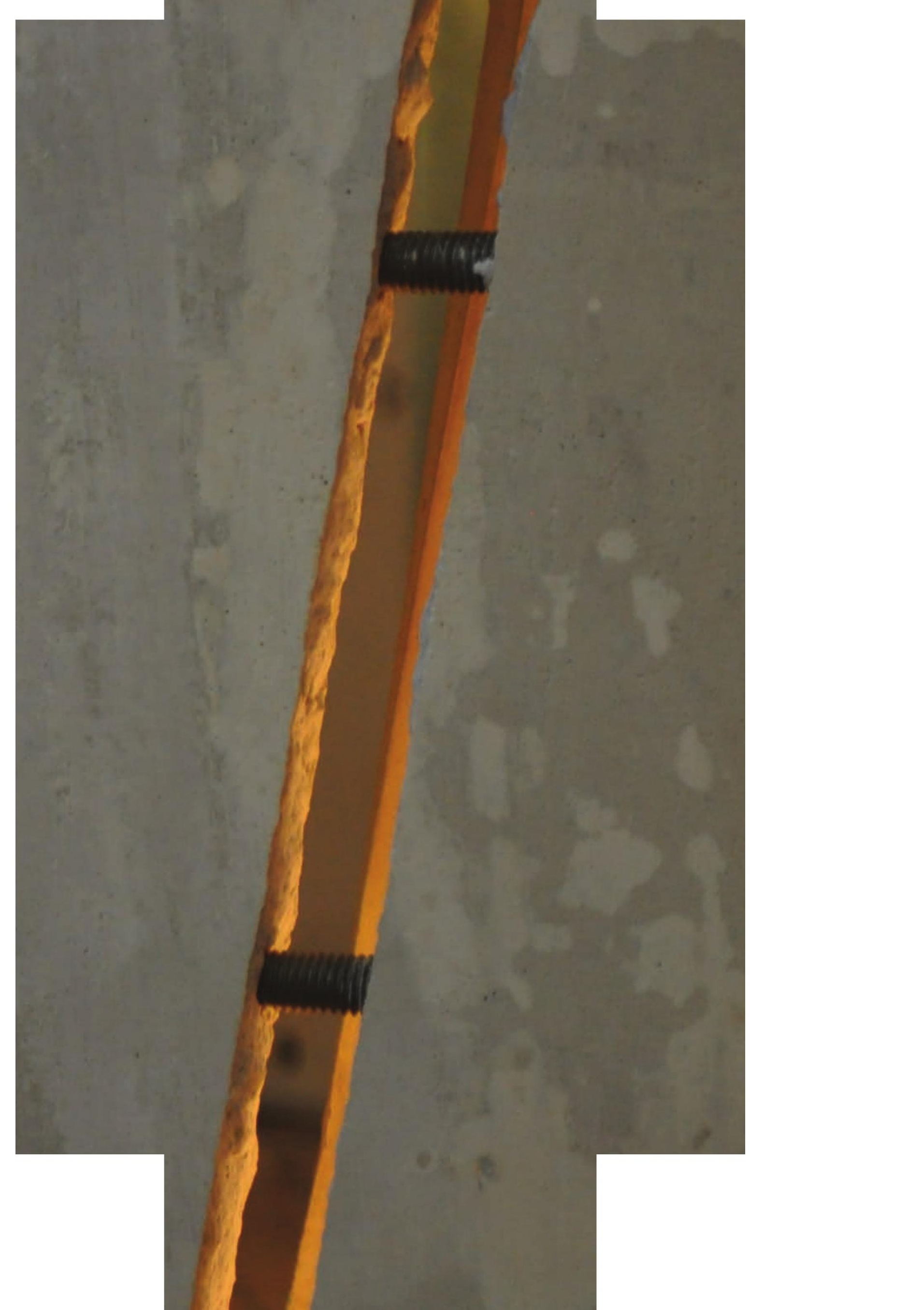




\section{The Architect as Craftsman}

Design "n. A plan or drawing produced to show the look and function or workings of a building, garment, or other object before it is made... $n$. The art or action of conceiving of and producing a plan or drawing of something before it is made... v. [with object] decide upon the look and functioning of (a building, garment or other object), by making a detailed drawing of it... v. Do or plan (something) with a specific purpose in mind.' (Oxford University Press, 2010)

Make 'v. Form (something) by putting parts together or combining substances; create... v. Alter something so that it forms (something else)... v. Cause (something) to exist or come about' (Oxford University Press, 2010)

Craft 'n. An activity involving skill in making things by hand... n. Work or objects made by hand... $n$. The skills in carrying out ones work... v. Exercise skill in making (an object), typically by hand.' (Oxford University Press, 2010) 
"It focuses on the intimate connection between hand and head. Every good craftsman conducts a dialogue between concrete practices and thinking; this dialogue evolves into sustaining habits, and these habits establish a rhythm between problem solving and problem finding." (Sennett, 2008, p. 9)

"An architect must be a craftsman. Of course any tools will do; these days, the tools might include a computer, an experimental model, and mathematics. However, it is still craftsmanship - the work of someone who does not separate the work of the mind from the work of the hand. It involves a circular process that takes you from the idea to a drawing, from a drawing to a construction, and from a construction back to idea." - Renzo Piano (Buchanan, 2003)

An intimate and sensual engagement of the process of design through the act of making requires a fundamental restructuring of the normative modes of practice and representational hierarchical structure which has been the historical foundation for contemporary architectural practice. The active engagement of making as a method through which to explore design aides one in becoming involved in processes that are able to impart tacit knowledge and expertise only accessible through an experientially based kinetic means of design. In order for a fullness of understanding around that which one is designing, the architect must wholly engage craft and making from the inception of a design idea through to its completion. This procedural shift can, in tandem with the ability of the designer to think through the act of making and craft, become the catalyst for a development and maturation of material thinking.

In the article Design as Research Brian Lawson notes that the means through which a designer can come to understand and gain knowledge about ideas which they have developed is not merely through an abstract method of research but is through relying on the processes of design, and by extension making, to impart crucial information. The process by which one is able to take a conceptual idea or artefact and through material processes transform it into a tangible artefact is an experience which will leave a lasting impression on the maker. This type of gained knowledge is what Donald Judd refers to as 'durable' knowledge, that is knowledge gained by engaging a process which 
Figure 07: Heavy-Light Concrete Texture Detail Figure 08: Heavy-Light Fissure Detail Figure 09: Heavy-Light Hand Planing Formwork

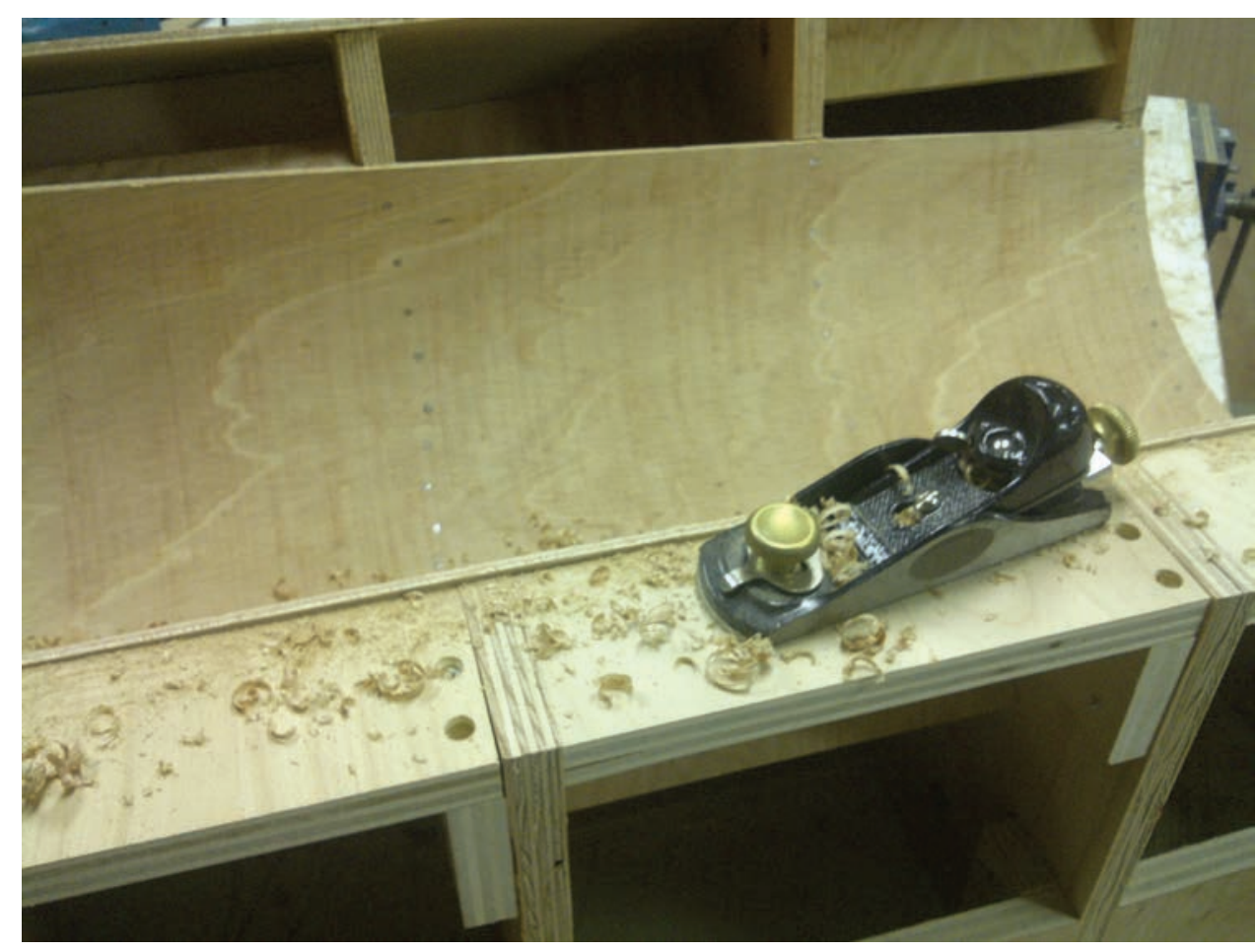

alters the 'material consciousness' of an individual allowing them to simultaneously interact with an objects materiality through both the visual and haptic senses (Poole, 2007, p. 107). These tangible experiences have the ability to modify a designer's perception in regards to the physical materialization of an idea due to the intense intellectual and manual labour that the act of creating entails.

Seminal to the process of design through making is the ability of the designer to engage their ideas sensuously, through the haptic senses, which are able to impart knowledge deeply embedded in material processes. The value of sensory information within an architectural design process is indispensable as it is through one's bodily identification with the surrounding environment that one is able to internalize and process information. The elemental link between an individual's mind and the built environment is corporal; intangible information and knowledge about the physical world is internalized by the hand endowing an awareness and consciousness which ultimately expands ones perception (Poole, 2007, p. 112). Re-affirming the crux of this statement, Alan Chandler in A Philosophy of Engagement: Developing a Strategic Ability through Direct Engagement with Material, Process and Collective Actions continues; "Architects seldom build their own work, but to begin an immersion into the act of building is the only means by which their line can become relevant and 
purposeful." (Chandler, A Philosphy of Engagement: Developing a Strategic Ability through Direct Engagement with Material, Process and Collective Action, 2007, p. 121). Within this context, Chandler refers to drawn lines as the intermediary between the intangible and tangible or thought and making. In this reflective process engaging the act of making allows the architect to better understand the drawn representation which further informs thought. The bodily identification of an architect with their work, and the retroactive effects this has on their understanding of the work, is crucial in their ability to endow future projects with the potential for a "meaningful exchange with others" (Poole, 2007, p. 112). Juhani Pallasmaa extends this notion further, reinforcing
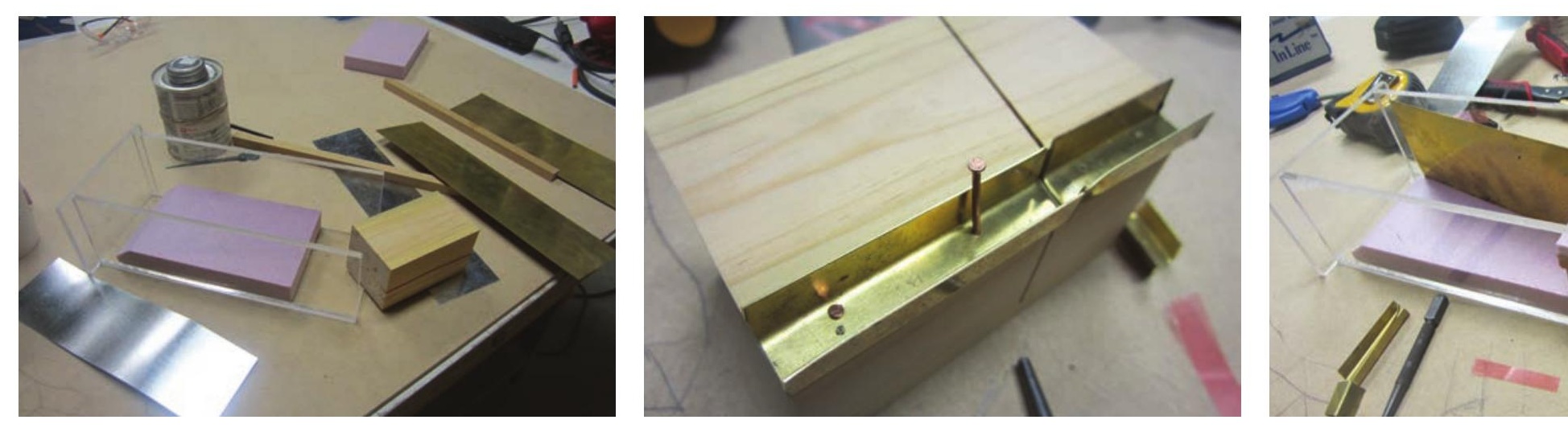

the importance of the bodily identification which is made through making, noting that "As the work interacts with the body of the observer, the experience mirrors the bodily sensations of the maker... architecture is Figure 10: MV1 Model Components Figure 11: MV1Model Assembly Detail Figure 12: MV1 Model Formwork communication from the body of the architect directly to the body of the person who encounters the work." (Pallasmaa, The Eyes of the Skin: Architecture and the Senses, 2005, p. 67). Once one is able to connect themselves corporally to their work they are then able to transfer this understanding and first-hand experience to their designs which will allow other individuals to engage and connect in a similar manner.

The initiation of a material based process of making from the onset of a design forces the designer to confront wholly and consciously the relationships between the intangible form or idea and the physical potentiality inherent in materials. This is an exercise which cannot be entertained solely in an intellectual manner; it must be thoroughly investigated through making, fabrication and craft (Thomas, 2007, p. 5). This method of engagement is able 
to reveal possibilities of knowing which are intertwined with sensory based and material based experiences (Gray \& Burnett, 2009, p. 2). The prototypes created within this process of design through making can also be utilized as means through which knowledge can be gained and a design stimulated. Kristina Niedderer, in her article Relating the Production of Artefacts and the Production of Knowledge in Research, explores this notion listing three distinct manners in which an object or artefact can be used to integrate tacit knowledge within the process of knowledge generation and knowledge communication (Niedderer, 2009, p. 65). Firstly, artefacts can be engaged with as input into the process of research and knowledge generation through their
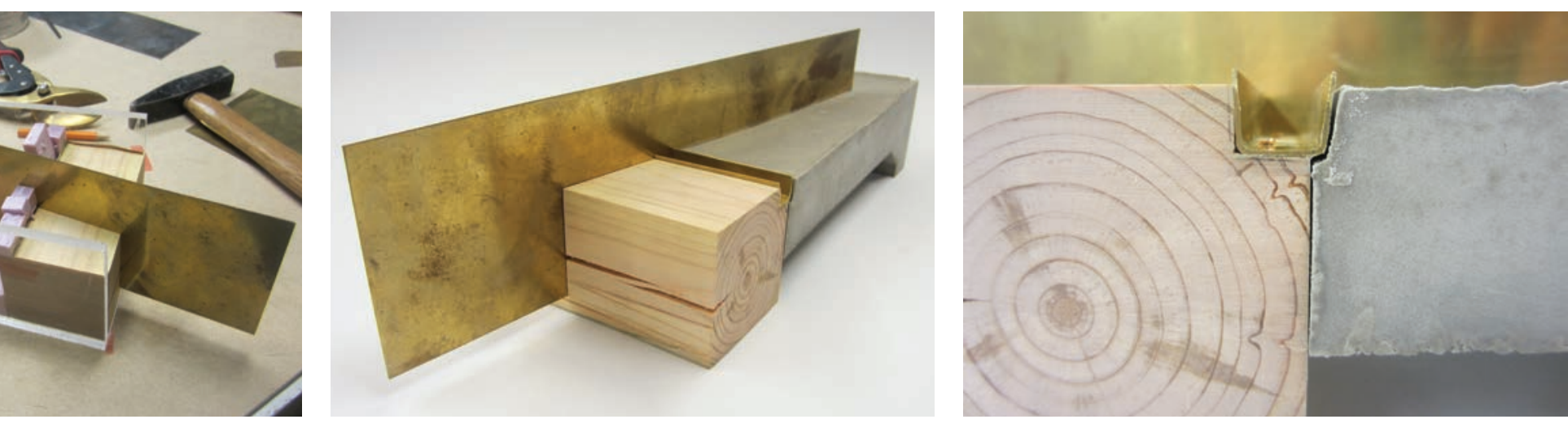

Figure 13: MV1 Final Model Figure 14: MV1 Connection Detail ability to act as a basis for the generation of research questions, they can provide data to be analyzed, and/or where no previous examples exist new artefacts can be created to commence the cycle (Niedderer, 2009, p. 65). Secondly, artefacts can be means through which knowledge can be generated as in their ability to test the viability of new processes and materials, and they can act as pieces of creative exploration in developing deeper understandings and analysis of concepts, objects, and materials (Niedderer, 2009, p. 65). Finally, artefacts can be utilized for output and communication of knowledge both as 'procedural knowledge' (that which can be read from the artefact resultant from material processes such as joints and markings) and in displaying results of experimentation and research (an object for demonstrating a problem, testing, creative exploration, and experience or aesthetics) (Niedderer, 2009, p. 65). Thus it becomes apparent that it is not only the act of making in and of itself which is critical to the design process but also the product of said act, through which, during its production and as a physical object post-production, can be a tangible artefact which can be 
engaged with to impart and convey knowledge.

Critical to engraining the process of making within the architect's mind is the fundamental reality that physical and tangible experiences inherently factor into the procedure the variable of time. This defining component of making is crucial in regards to the ability of the designer to form and retain 'durable' knowledge or memory as it relates to both the processes and methods by which an artefact is constructed and the physical material properties with which one must contend (Poole, 2007, p. 107). Milan Kundera, in his novel Slowness, details the affect which time and memory have on each other; "There is a secret bond between slowness and memory, between speed and forgetting... The degree of slowness is directly proportional to the intensity of memory; the degree of speed is directly proportional to the intensity of forgetting." (Kundera, 1995, p. 39) Reinforcing this sentiment in the article Pumping Up: Digital Steroids and the Design Studio, Scott Poole notes; "Making architecture... is incredibly slow work... its material form... develops, for the most part, through quiet reflection, with actions that move at the speed of lead. Paradoxically, it is not velocity but the ability to accustom oneself to working slowly within density that intensifies consciousness." (Poole, 2007, p. 112) The slowness which Kundera and Poole describe is at odds with the methods through which contemporary architectural practices function. Heavy reliance on CAD software and virtual simulation programs have suspended the time based reality in which design, and its resultant product, must function. This removal from reality, coupled with the image as the basis through which to design, inevitably leads to a lesser understanding of the artefact and calls into question the physical process involved in its materialization.

Intrinsically bound to the nature of design through making is the unavoidable failures which are a natural part of a tangible design process. The process of materializing an idea is something which encompasses a great deal of not knowing, and by virtue of this inherent quality, those engaged in this process are able to sensorially experiment and experientially discover, that is make known or reveal, tacit knowledge which would otherwise go unnoticed (Tonkwise, 2009, p. 1). While failure is often met with frustration, the architect-maker will undoubtedly understand much more about their design than had the process been perfect. The ability of the architect to recognize, 
understand and correct their material failings will undoubtedly lead to a much more successful result, albeit through a somewhat longer process (Thorton, 2005, p. 102). In discussing Diderot's Encyclopédie, Richard Sennett notes that "...trial and error was a guiding method of experimentation... the process of trial and error [was] following a path from many to fewer errors, a steady and progressive improvement through experiment." (Sennett, 2008, p. 96). While this method of physical engagement with design might at times seem tedious and arduous, it is through the repetitive elements and time based variables engrained within this process that enable the designer to engage in 'constructive concentration' with the work at hand (Poole, 2007, p. 108). Inlaid within this procedure is the informative ability that concurrently affects the efficiency of the task as one continues engaging it. Renzo Piano, in discussing his design process writes, "Our efficiency implies the complexity of doing and doing again. Galileo Galilei said something like provandi e riprovandi, which means trying and trying again. It is sort of a basic philosophy of experimental work." (Piano, 1994, p. 128) It is through experiencing the repetitive constructive act of making that the designer is able to impress upon their memory the intricate time-based sequential processes involved in materializing an idea (Poole, 2007. p. 108). The slow tangible engagement of an artefact or design allows a retention of its qualities which far outweigh those preserved through the virtualization of the thing. The quality of the retention and perception of a design necessitates a method of engagement which is inherently physical. 

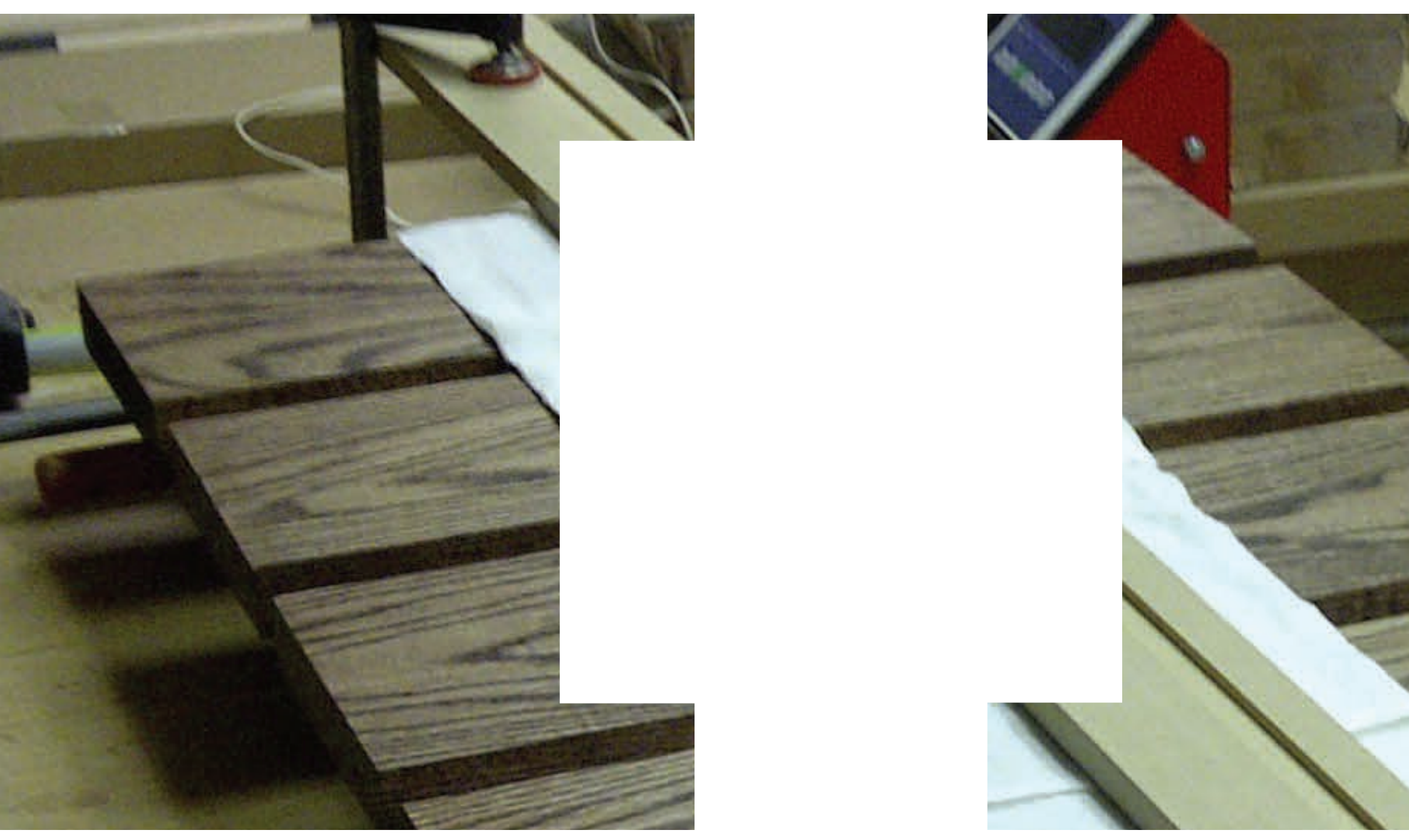


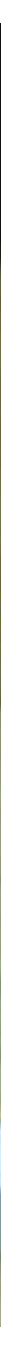




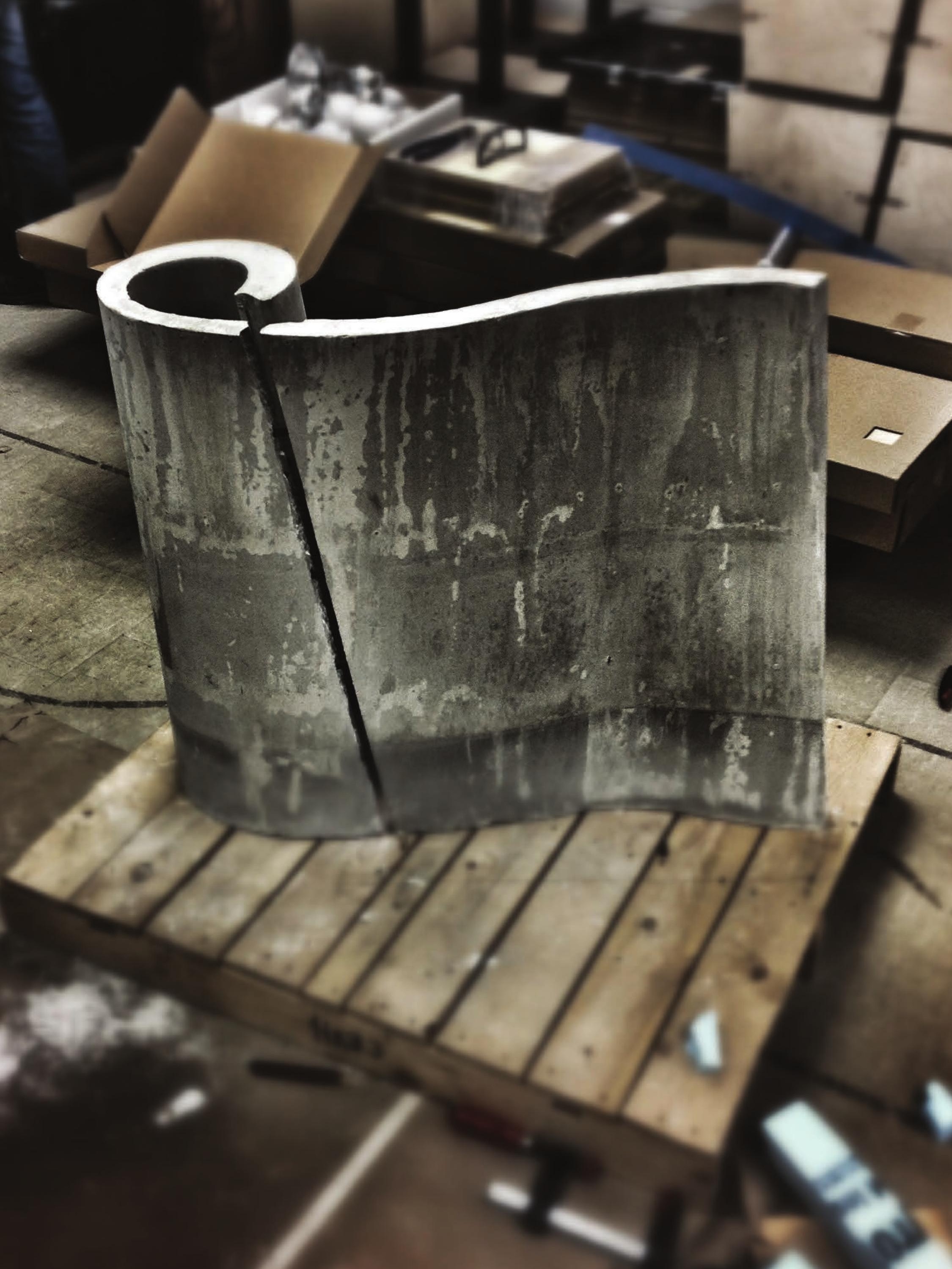


The experience which is derived from the intimate and tangible processes involved in the physical exploration of an architectural design is critical in imbuing the designer with a comprehensive understanding and working knowledge of the entire spectrum of work (both immaterial and material) involved in the realization of architectural undertakings. While the process of making can seem overtly effortful given the speed at which one may digitize a design, the knowledge which is gained by engaging physical creation is one which encompasses all aspects of a design, ranging from idea and form to matter, materiality, and construction processes. Engrained within the proposed experiential method of engaging architectural design are several crucial instances in which the process of making, the materials being manipulated, the tools engaged, and the designed artefact take on a generative role with respect to their ability to impart otherwise inaccessible tacit knowledge to the designer-maker.

While the Heavy Light installation is decidedly not a work of architecture it can be viewed as embodying many prominent issues with which architects engage. These issues, inherent to the physical manifestation of a designed artefact, can be paralleled (albeit at a much larger scale) to architectural decisions which occur during the process of design including issues of form, materiality, aesthetics, structure, and constructability. These architectural concerns when engaged with and understood through a corporal means aid the designer in forming a bodily understanding of and relationship with them.

Most notable within the Heavy Light installation, both in the finalized artefact and within the design process, was the opportunity to think through craft and materials as well as engage with the unavoidable notions of chance and failure in design. Critical in bridging the theoretical and physical divide in architecture, thinking through materials and craft allows one to make design decision in real time, ad hoc and in situ, drawing direct correlation to the material affects each architectural gesture entails. These issues, which are inherently applicable to the physical realm of architecture, necessitate that one is able to accept and design with them in mind.

Figure 15: Heavy-Light Component Assembly

Figure 16: Heavy-Light Concrete Dry Fit Test 


\section{Heavy-Light Design and Construction}

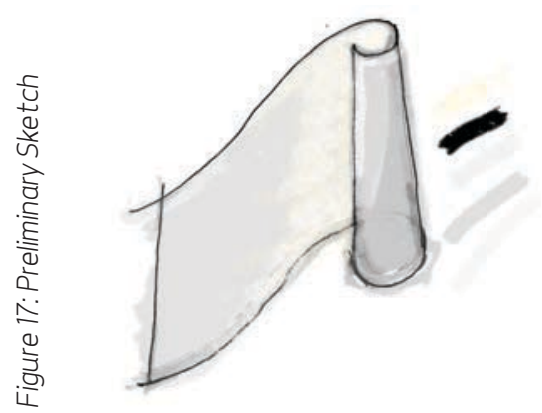

Manual Drafting

This preliminary phase of design sought to express the considered form of the artefact as a simple volume; an initial notation to the making process.
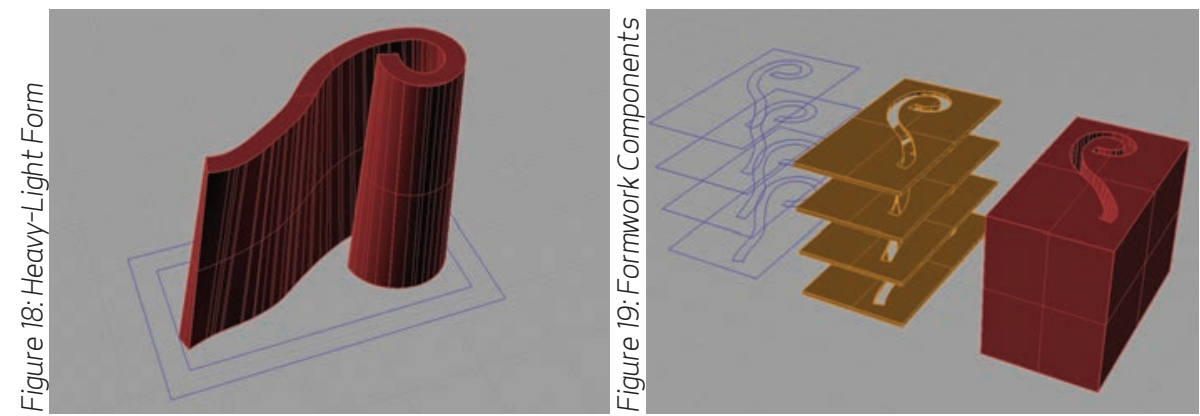

Digital Drafting

Given the complex double curvature of Heavy-Light virtual modeling was engaged with as a means of creating information for the subsequent phases of making. This three-dimensional model focused not on the artefact but rather the formwork which would be constructed to create it.
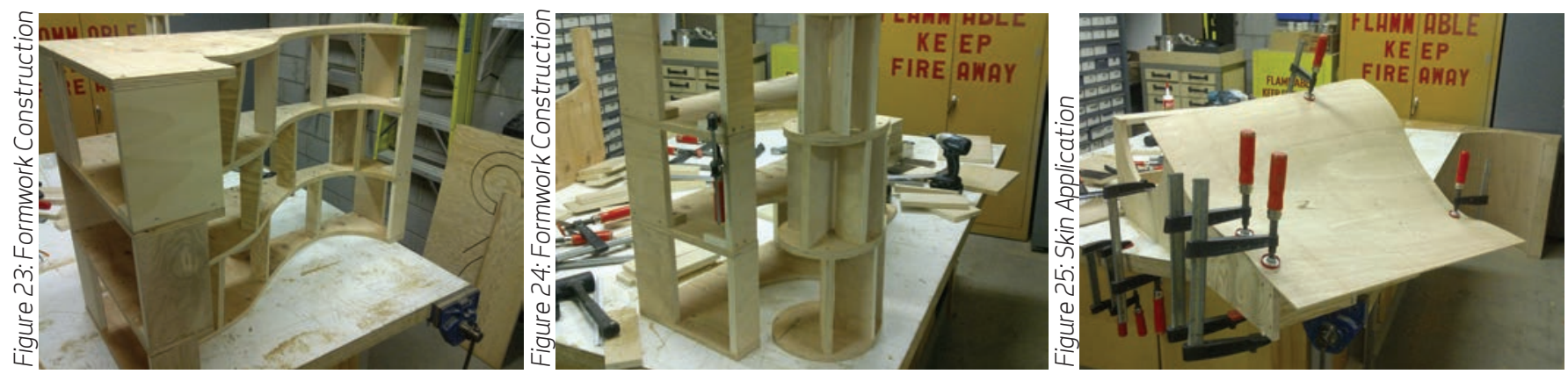

Structural Backing Assembly

The four sections of the formwork were further broken down into three separate components in order to allow a proper release of the form once the concrete had cured. These components were manually assembled with the installation of blocking in order to provide the proper height dimension as well as allowing a surface on which to adhere the skin.

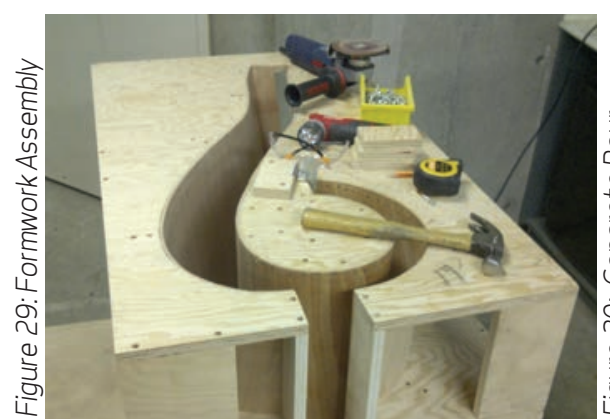

installed as a transition piece between two portions of the form in order to further express the construction process in the final artefact. This decision would unexpectedly alter the aesthetic of the entire project.
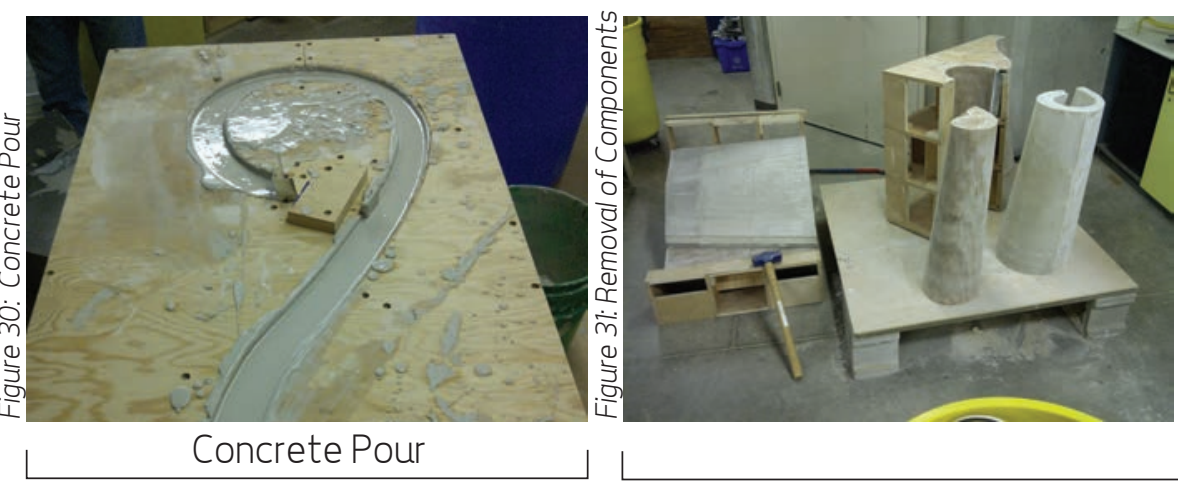

The mix used in this process was formulated by mixing three parts HYDROCAL Gypsum Cement and one part Portland cement. The primary ingredient was chosen as it is high strength cement utilized when pouring thin sculptural elements with intricate detail while the secondary ingredient was added to darken the colour of the cement. The entire pour consisted of three different batches of cement which are visible through colour variation in the final piece.

\section{L}

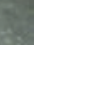




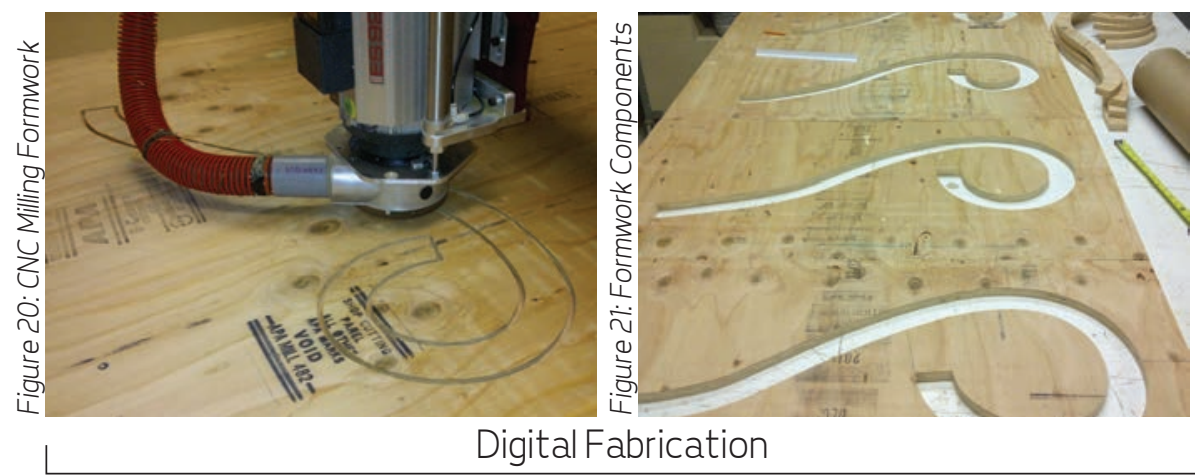

The information drawn from the three-dimensional model was converted through Mastercam X6 into $G$-code which in turn drove the CNC machine as it cut each sectional component of the formwork.
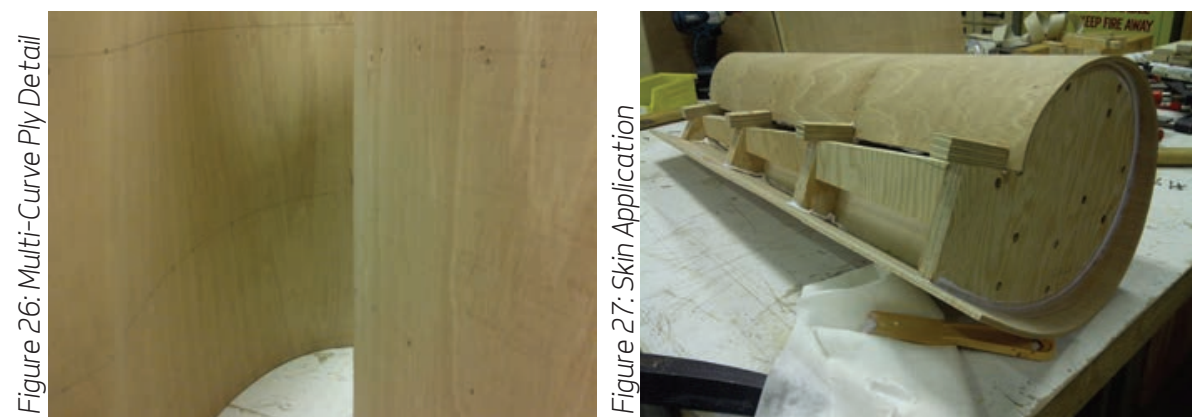

Skin Assembly

While the milled sections and the backing provided the rough shape of the Heavy-Light the fina dimensions, texture, and material qualities were finalized with the installation of a quarter inch thick multi-curve plywood skin. The plywood was attached to the form with glue as well as flat head copper finishing nails. The indentations left in the skin by driving the nails slightly past its surface were intentional as they would leave evidence of the construction process and craftsmanship in the final product.

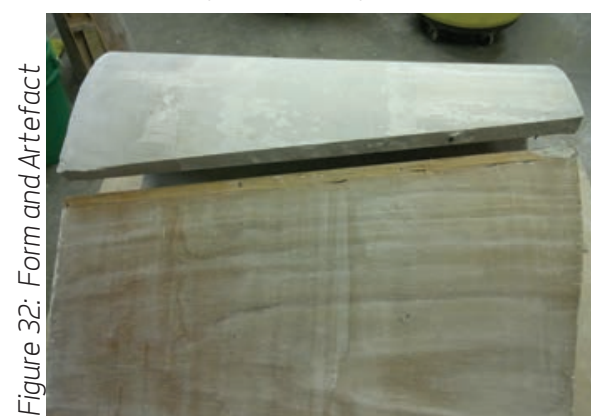

Formwork Disassembly

The form released relatively smoothly with the exception of the interior conical component which required greater force. Once disassembled the cement split along the wood transition pieces creating an irreproducible fissure. While this was immediately construed as a failure it was later converted into the primary strength of the artefact.

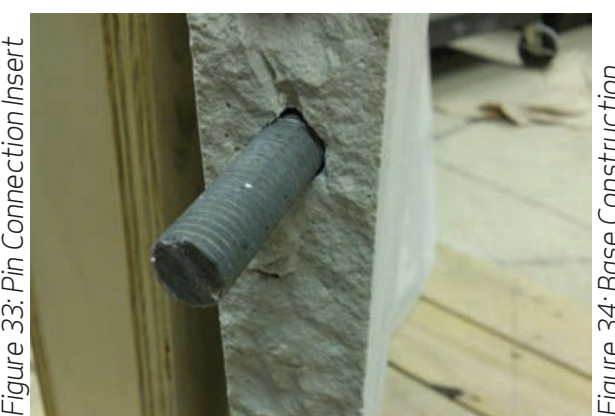

\section{Concrete Re-Assembly}

The two separate components were reassembled by inserting half-inch threaded rod into each end and dry fitting them together. Instead of attempting to conceal the fissure these rods were left exposed, expressing the break by separating the two components.
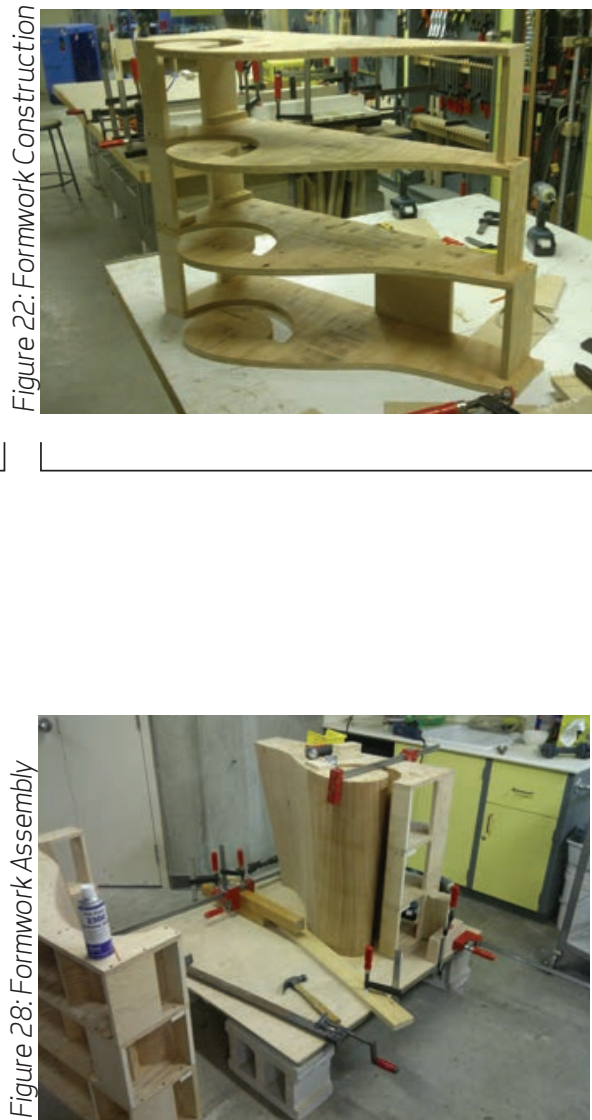

Formwork Assembly

Each finished piece of the form was anchored to one inch thick chipboard. The form was assembled upside down to prevent air from becoming trapped in the mold and to allow for a smoother form release. During this assembly a strip of half-inch thick wood was

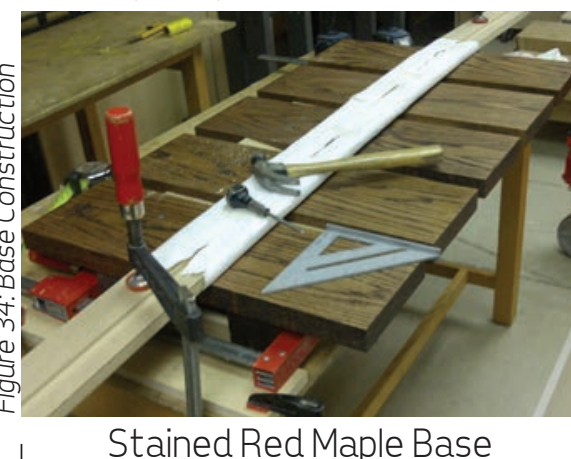

In order to contrast the textural and material qualities of the cement the base was constructed from mahogany stained red maple. The rich warm texture of the wood, as well as the 12 gauge flat head galvanized nails, provided a strong grounded base on which to display the Heavy-Light. This base was also constructed to act as a transferring platform. 


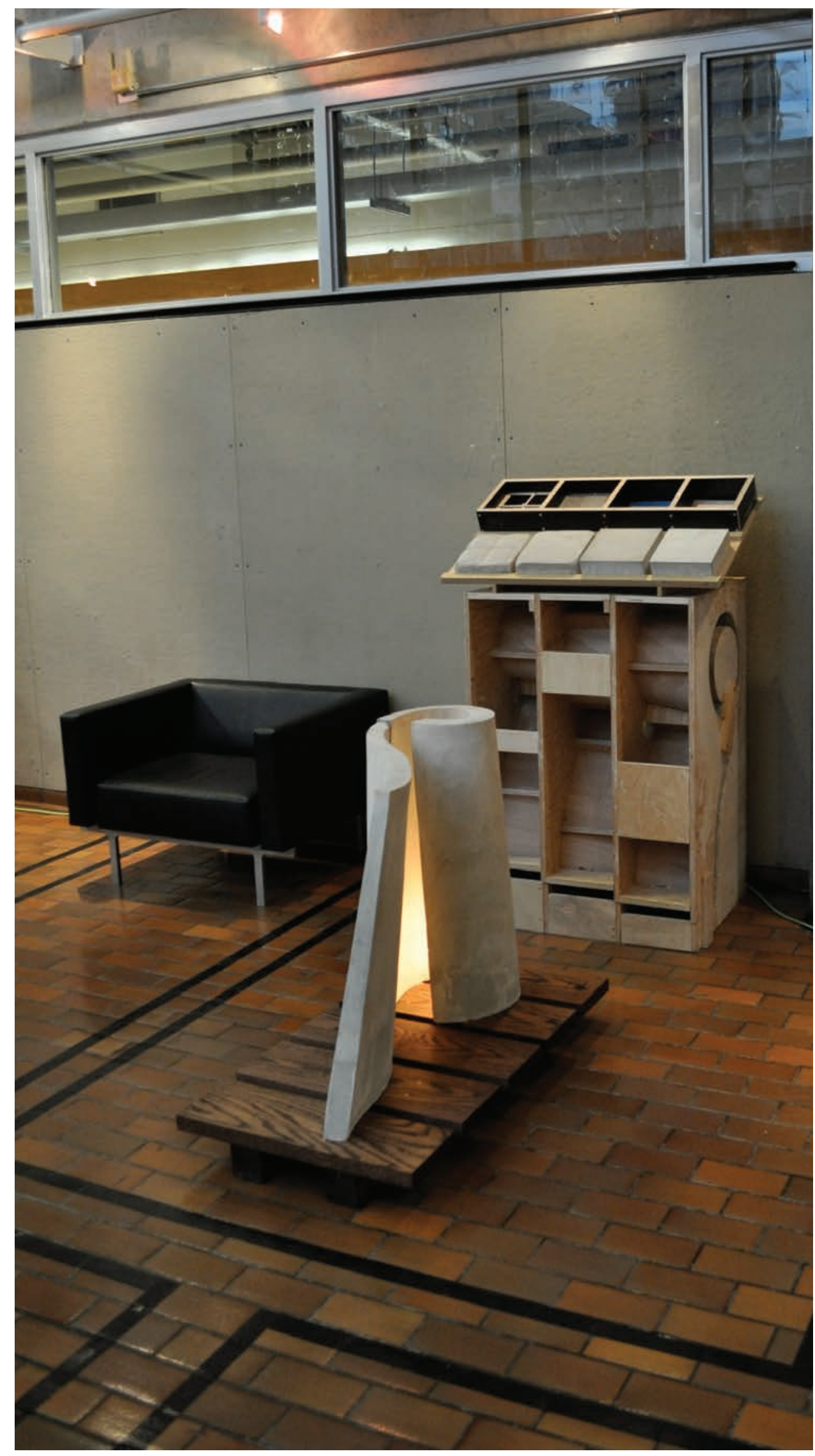

Figure 35: Heavy-Light Final Installation 


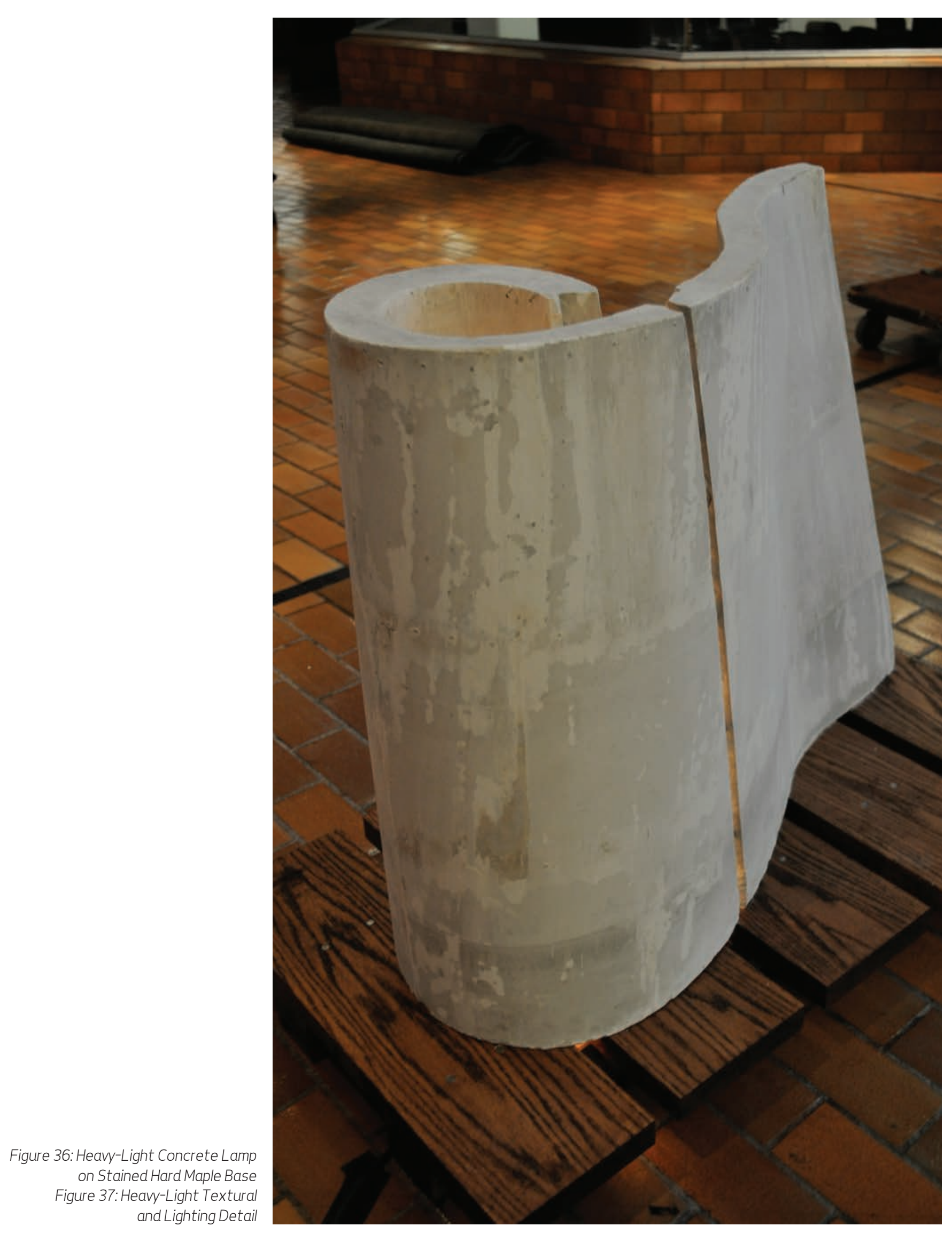




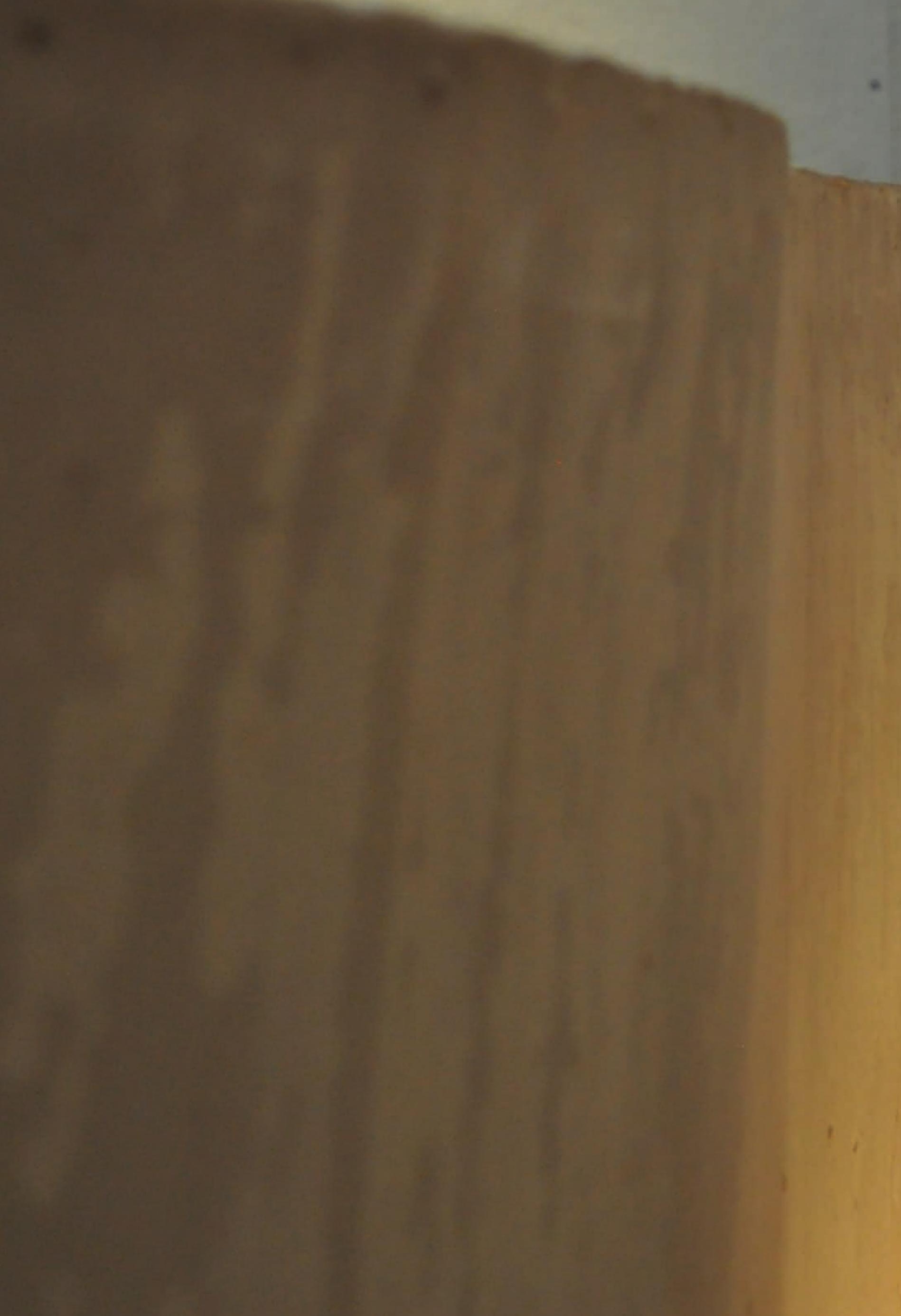


*

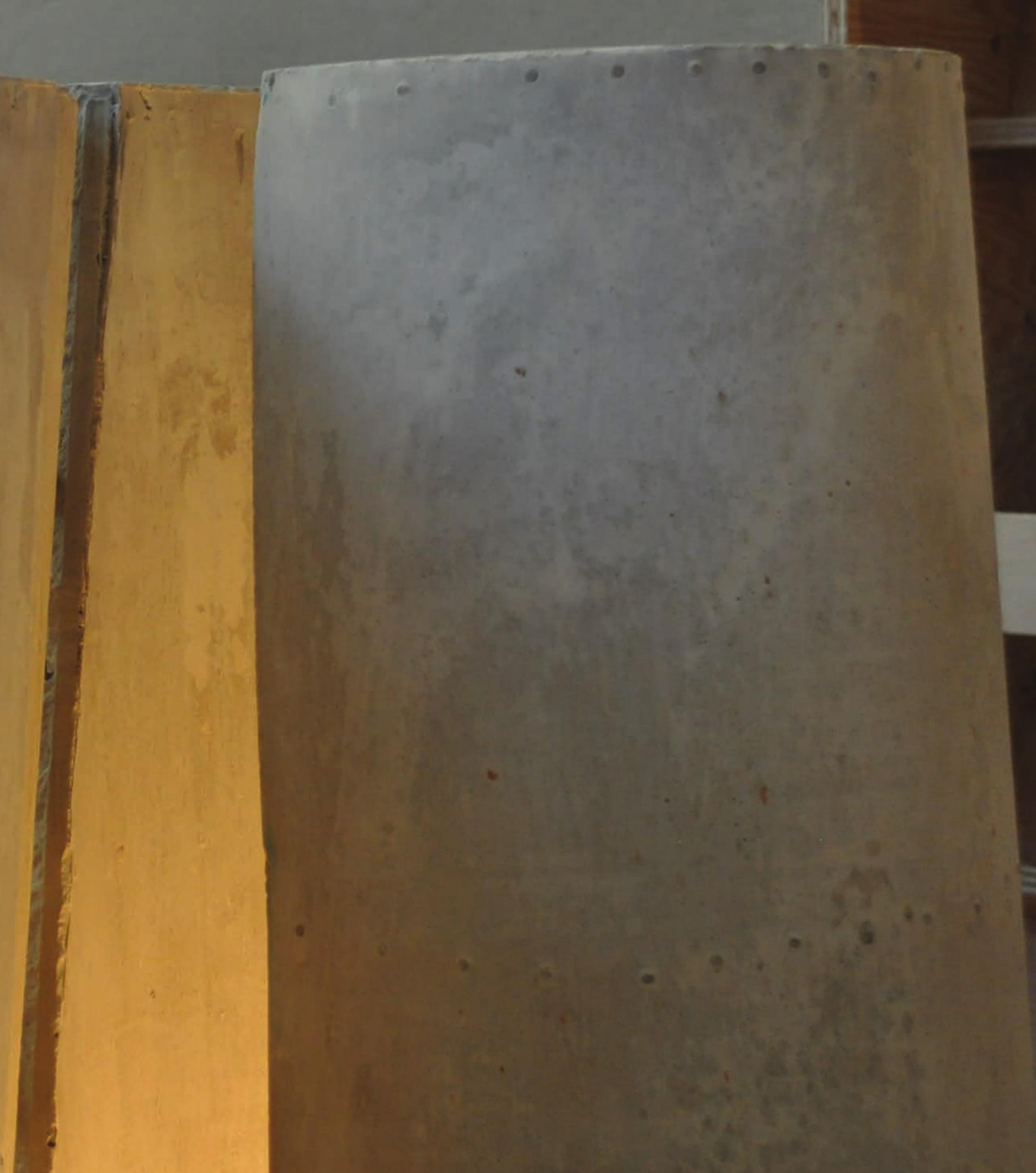




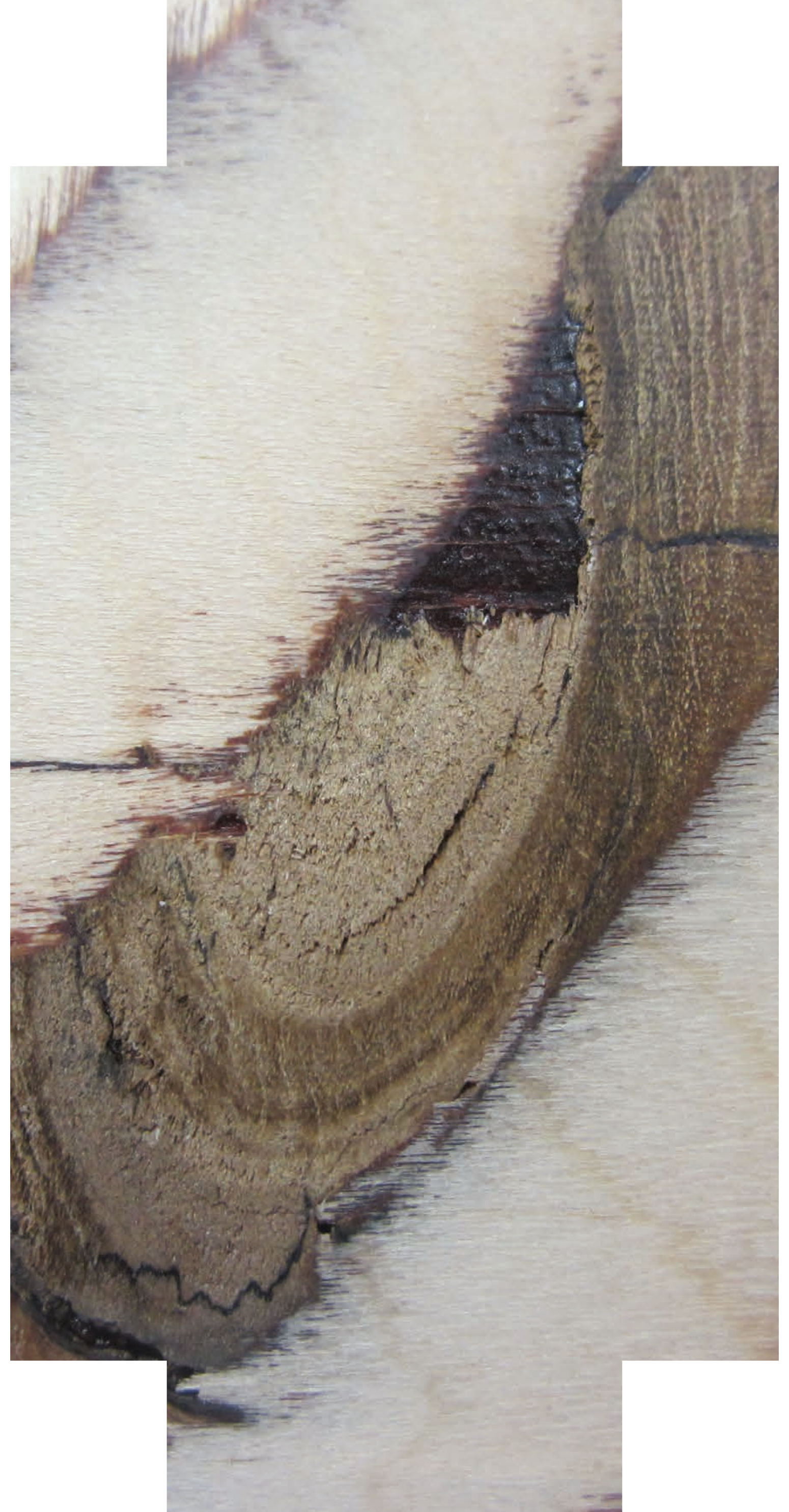




\section{The Human Experience}

"Art (creative practice) is now an increasingly acknowledge experiential mode of inquiry that... can reveal insights and understandings in ways that expand our capacities for "knowing." (Gray \& Burnett, 2009, p. 1)

Engrained within the notion of engaging design through the act of making is the corporal connection or the unique human condition through which one is able to experience in a whole or full manner. The ability of the architect to engage in this process first-hand, through bodily identification with the physicality of an object, is directly related to their ability to form a personal, intimate, and sensual knowledge of architecture. The formulation of new knowledge, through creative and physically engaged practices and processes stem from the notion, which laian Biggs sets forth in his dissertation Art in Research: Creative Practice and Academic Authority, that the production of knowledge is by its very nature experiential and performative (Biggs, 2009). This notion of performative action is expanded upon by Estelle Barrett who, 
through tracing the etymological roots of performance and performativity, concludes that this mode of knowledge production, encompassing the entirety of its actions and processes, is quintessentially generative (Barrett, 2010, pp. 1,2). The required physical input and resulting tangible output transforms the static concept of knowledge to one which is experiential, relying on interaction and action (Barrett, 2010, pp. 1,4).

Corporal identification and bodily understanding are inherently central to the hypothesis that the methods and means of design through making being proposed elicit a fuller and more embodied understanding of architectural works and processes. In the article Hapticity Vision, Juhani Pallasmaa states; "Our contact with the world takes place at the boundary line of the experiential self through specialised parts of our enveloping membrane." (Pallasmaa, Hapticity Vision, 2005, p. 137). Critical to this discourse is the understanding that the means through which one absorbs information pertaining to the enveloping physical world, in all its dimensions, is through ones haptic sense. J.J. Gibson provides a seminal definition of the haptic sense in The Senses Considered as Perceptual Systems noting that they are "The sensibility of the individual to the world adjacent to his body by the use of his body... an apparatus by which the individual gets information about both the environment and his body. He feels an object relative to the body and the body relative to an object." (Gibson, 1966, pp. 97-98). By engaging architectural design through making one is able to garner knowledge through the haptic senses by forming direct corporal relationship with the conceptual drivers of a design manifest in a tangible manner. Although this form of knowledge transfer seems to imply an unconscious or subliminal transaction the perception of an artefacts impact on one's body and one's bodily impact on the artefact is a result of a consciousness brought forth from the employment of one's physicality (Polanyi, 1968, p. 91). Michael Polanyi asserts that;

"Every deliberate act of consciousness, therefore, has not only an identifiable object as its focal point, but has also a set of subsidiary roots, inside our body. And this is where our body is related to our mind. As our sense organs - our nerves and brain, our muscles and memories - serve us to implement our conscious attention, our awareness of them enters subsdiarily into every meaningful entity which forms the focus of our attention." (Polanyi, 1968, p. 91) 
There exists within the proposed experiential method of engaging architectural design a direct continuity of knowledge and understanding which subsists between the made artefact (matter and material) and one's intellect (idea and form) through the connected medium of one's body. The position which Pallasmaa, Gibson, and Polanyi set forth recognizes and responds to the fundamental truth that architecture, embodied in the totality of it's concepts, theories, and manifestations, inherently deals with the built environment which is understood and absorbed through one's corporality. This condition, which is absent in two-dimensional architectural explorations (whether manual or digital), is critical in imbuing the architect with an experiential method of design which is intrinsically human.

The transformative act that is the process of making draws the architect closer, both physically and mentally, to their design bridging the schism that exists between idea and matter. The distanced observatory role which architects traditionally carry within the context of participating or performing built works is subsequently replaced through the intimate engagement of an artefact, with a heightened 'aesthetic awareness' which informs knowledge through action and interaction on and with idea and matter (Barrett, 2010, p. 1). The production of knowledge, through experiential and interactive procedures within design denotes a process of making which allows the designer the ability to engage intellectually with the artefact, or 'thinking with art' (Sutherland \& Acord, 2007, p. 125). Central to this argument which Sutherland and Accord propose in their article Thinking with Art: from Situated Knowledge to Experiential Knowing, is the ability of a designer to manually engage the creative process which cements and affirms their body as central to the experience of knowing. Tangible design processes act as a mediator between body and mind transforming the act of making or more generally experience into 'knowing' or knowledge (Sutherland \& Acord, 2007, p. 133). Furthermore this method of engagement is what Sutherland and Acord propose gives way to the conversion of situated knowledge into experiential knowing (Sutherland \& Acord, 2007, p. 125).

In repositioning the design process as inherently involving making there are afforded several critically reflective opportunities for the designer to engage with the artefact in the effort of establishing an informative discourse. 
The very nature of physically designing allows for the architect to draw information from both the physical object and the craft/processes of making during several vital instances. Carole Gray and Gordon Burnett note in their article Making Sense: An Exploration of Ways of Knowing Generated through Practice and Reflection in Craft that during the process of bringing to fruition an intended design one will fluidly develop a 'critical dialogue' with the artefact by entering frameworks of the unfamiliar (Gray \& Burnett, 2009, pp. 6,8). It is through these unknown, intimate, and experiential frames of reference, inclusive of the dialogues which they provoke, that Gray and Burnett believe lend heavily to the emergence and accessibility of multiple layers of previously inaccessible or unknowable information (Gray \& Burnett, 2009, p. 8). It is through engaging wholly with these material processes that the act of making itself becomes dually dynamic, in both its physical and intellectual senses, gaining the ability to inform and be informed in all of its layered complexities.

Providing a formative theoretical basis for the research undertaken by Gray and Burnett, Donald Schon delves deeper into the experientially based processes by which professionals gain knowledge through action. Within the context of design, the process of making implicitly denotes the formation of a communicative relationship between the individual engaging in the process, the act of creating and the artefact. Schon continues; "In a good process of design, this conversation with the situation is reflective. In answer to the situation's back-talk, the designer reflects in action on the construction of the problem, the strategies of action, or the model of the phenomena..." (Schon, 1983, p. 79). The primary dialogic occurrence takes place during the act of making, through which maker is able to connect corporeally with the conceptual drivers behind a design as well as the material and construction processes through which it is manifest. In considering the design process to be intrinsically experimental the designer, as acting mediator between the conceptual and tangible, will undoubtedly engage complex intellectual and physical processes during the construction of an artefact which will through reflective analysis further inform the intangible and tangible frameworks in which they function (Schon, 1983, p. 79). Serving as a catalyst for a self-contemplative and experiential method of knowledge acquisition, the design processes and artefacts employed become the guiding tools and foci for a cyclical input and output of crucial information. In his book, The Reflective 
Practitioner: How Professionals Think in Action, Schon details three distinct ways in which the act of experimentation within a design process, through the application and testing of ideas tangibly, can serve as vehicles for reflection both in and on one's actions. These design gestures, whether implemented in an intuitive or calculated manner, can be evaluated in relation to their desired outcomes, in what manner they infringe or are complacent with previously established frameworks, and in relation to the creation of further design issues or potentialities (Schon, 1983, p. 101). The uniquely physical iterative process which is engrained within design through making allows for the establishment of a referential method of design in which, through reflection on experiential and performative actions, the designer is able to critically develop conceptual and physical constructs tangentially.

Engaging architecture through the experience of designing and constructing prototypes affords the designer the opportunity to connect with architecture in a uniquely human fashion. The direct corporal relationships formed through the craft of making allows knowledge and information about one's design to presence themselves through a process which is inherently generative and experiential. In positioning the haptic engagement of architecture as central to the design process the physical qualities of architecture are continually being re-confirmed and cemented for the designer. In performing the act of making one is also able to engage the immaterial and material facts of a design in a critical dialogue. From this reflective discourse the architect is able to form a holistic and complete understanding which is based in the material and tangible realities of architecture. 


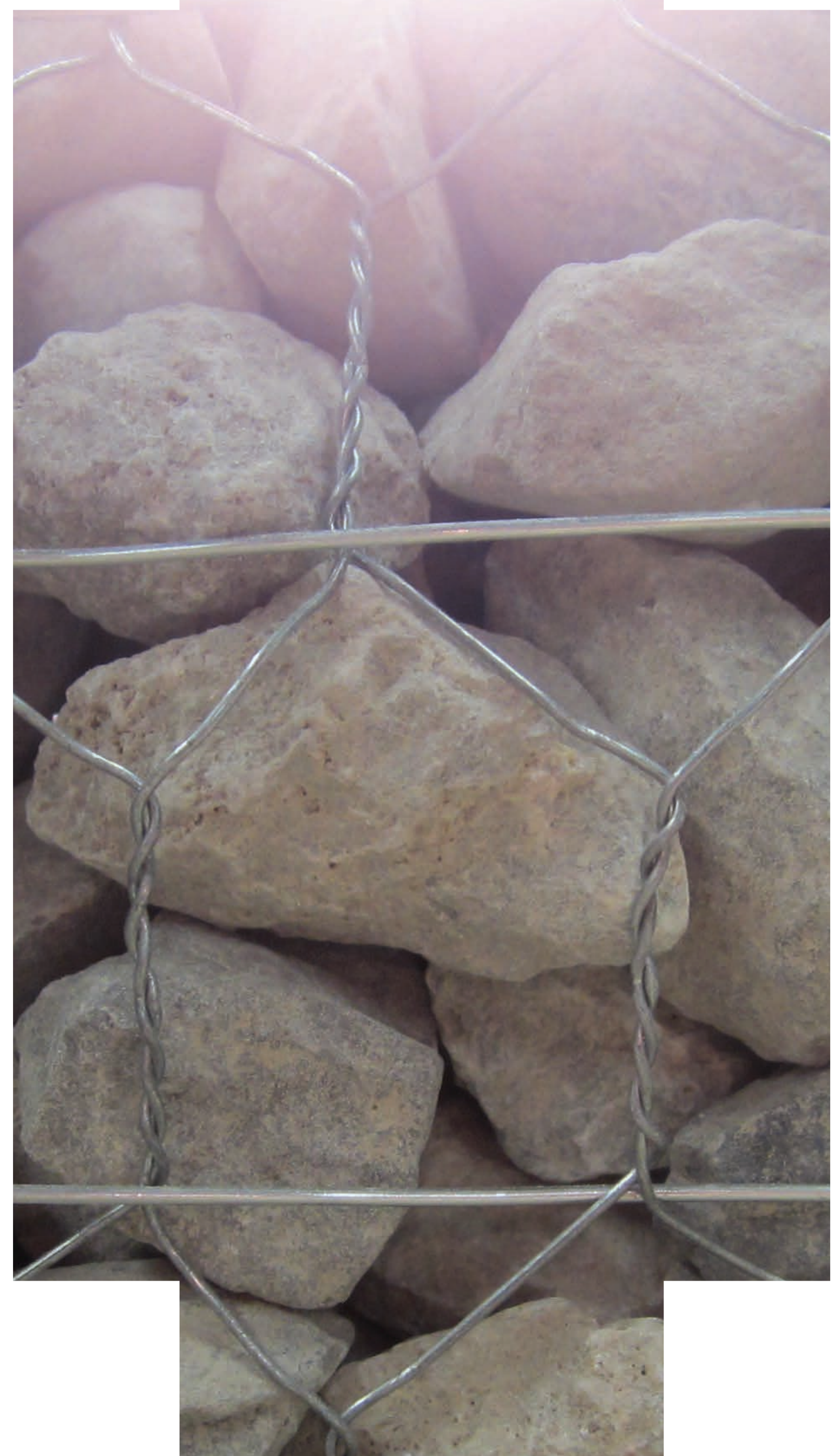




\section{chapter 04}

\section{The Eternal Student}

The basis for reconsidering the manner in which architecture is engaged with during the design process stems from a critical reframing in the role in which architects have been placed. Broadening the spectrum of the design process to position making as a central component entails a transformation on the part of the architect from physically static to physically active participant. Entailing this base shift implies that the active and participating architect engages the design through a process of making which inherently connects them with the material essence of their design. Intimately connecting with physical materials in a hands-on manner will provide a unique and irreproducible experience from which to draw critical information. The fundamental notion which serves as the cornerstone for design processes which are rooted in the intrinsic experiential qualities of architecture is interactivity. The ability for an architect to, in some manner, engage interactively with their design is indispensible as a means through which to elicit an experientially based method of information transfer. The construction of 
architectural prototypes is a process which tangibly engages the designer in an active manner, engendering them to use their physicality and senses as a means through which to elicit an informative experience and strengthen in a corporal fashion the driving architectural concepts behind a design. The importance of the prototype, architectural model, and physical artefacts lie in their tangible presence as they serve in connecting the architect to the design in a physical way while simultaneously and concretely bridging the divide between idea and matter, form and material. At their essence, the interactivity involved in the creation of such artefacts acts as a catalyst for the accessibility of information and knowledge.

The conceptual underpinnings for the proposed integrated method of an interactive and experiential mode of design stems from the work of several notable learning and educational theorists. Each of their learning models positions the human body and the ability to ascertain a tangible experience as the fundamental component in communicating and gaining knowledge. John Dewey, an American philosopher, psychologist and educational theorist, whose work dates to the early 20th century details experience as the basis for genuine education which provides a decisive position from which to consider its application to architectural design processes. In his 1938 publication Experience and Education Dewey posits a key fundamental component for his philosophy is the notion that "there is an intimate and necessary relation between the processes of actual experience and education" (Dewey, Experience and Education, 1938, p. 7). It should be noted that while Dewey states that experience is the basis for education not all experiences are educational and thus proposes that it is in fact the quality of the experience which is critical in determining its educational properties. At its essence, the quality of the making/fabricating experience should be as follows; the designer tangibly engages materials and material processes in creating an artefact and has a direct intimate experience, the designer digests this experience and as a result any subsequent experiences are affected by it indicating that information and knowledge has been accrued. Here Dewey states that there are two conditions, continuity and interaction, which should be considered when establishing the ability of an exhibition to impart an informative and educative experience. According to Dewey, the notion of continuity is imbued with the idea that for an experience to be educational it must, in some manner, 
stimulate the active participant yielding new knowledge which can be added to that which previously exists. Dewey notes, “...every experience both takes up something from those which have gone before and modifies in some way the quality of those which come after." (Dewey, Experience and Education, 1938, p. 27). Building upon this is Dewey's principle of interaction of which he states that, "An experience is always what it is because of a transaction taking place between an individual and what, at the time, constitutes his environment." (Dewey, Experience and Education, 1938, p. 41). Integral to applying this model to the architectural design process is the notion that the designer must engage in some physical manner with the prototype or model in order to garner a positive educational experience. The inability of the designer to interact physically negates the informative and knowledge yielding intention of the experiential exploration. Recognizing that the physical experience of making within the design process can lead the architect to a cycle of problem and inquiry which builds upon itself further encourages a self-motivated process of exploration and discovery. These conditions which Dewey presents lend themselves heavily in reinforcing the need for a means through which designers may actively and physically interact with the architectural ideas and concepts in order to stimulate and foster a process which promotes the transfer of information and knowledge through interactivity and experience.

Further anchoring experience as an essential and critical component to the learning process is an educational theory established by David A. Kolb, an American educational theorist, entitled the Experiential Learning Model. Kolb's position defines learning as "the process whereby knowledge is created through the transformation of experience. Knowledge results from the combination of grasping and transforming experience." (Kolb, 1984, p. 41). The Experiential Learning Model was conceived of as a cyclical process revolving around four distinguishing instances each positioned as a means of either grasping or transforming experience. The two primary means of grasping experience according to Kolb's model are Concrete Experiences and Abstract Conceptualizations, while transforming experience occurs through Reflective Observation and Active Experimentation. Within this model Concrete Experiences serve as the primary means of gathering direct information and is considered the most physically active component of the process. This information is then processed through Reflective Observation which entails 
analyzing one's experience. This knowledge can then become the basis for Abstract Conceptualizations which brings together past and present experiences in order to form ideas for future ones. Establishing conclusions through this method allows the individual the ability to physically test them through Active Experimentation which then continues the model's cyclical nature. The formal qualities of the Experiential Learning Model have a very direct application to the integration of tangible design methods within the architectural design process. The cyclical nature of the ELM model speaks heavily to the iterative nature of architectural design, the active and experiential components to the fabrication of physical artefacts for study, and the reflective and conceptual instances to the theoretical and conceptual drivers. Kolb's model provides a solid and standard basis from which engaging design through the construction of prototypes and artefacts can be viewed as an indispensable and formative process in architectural design.

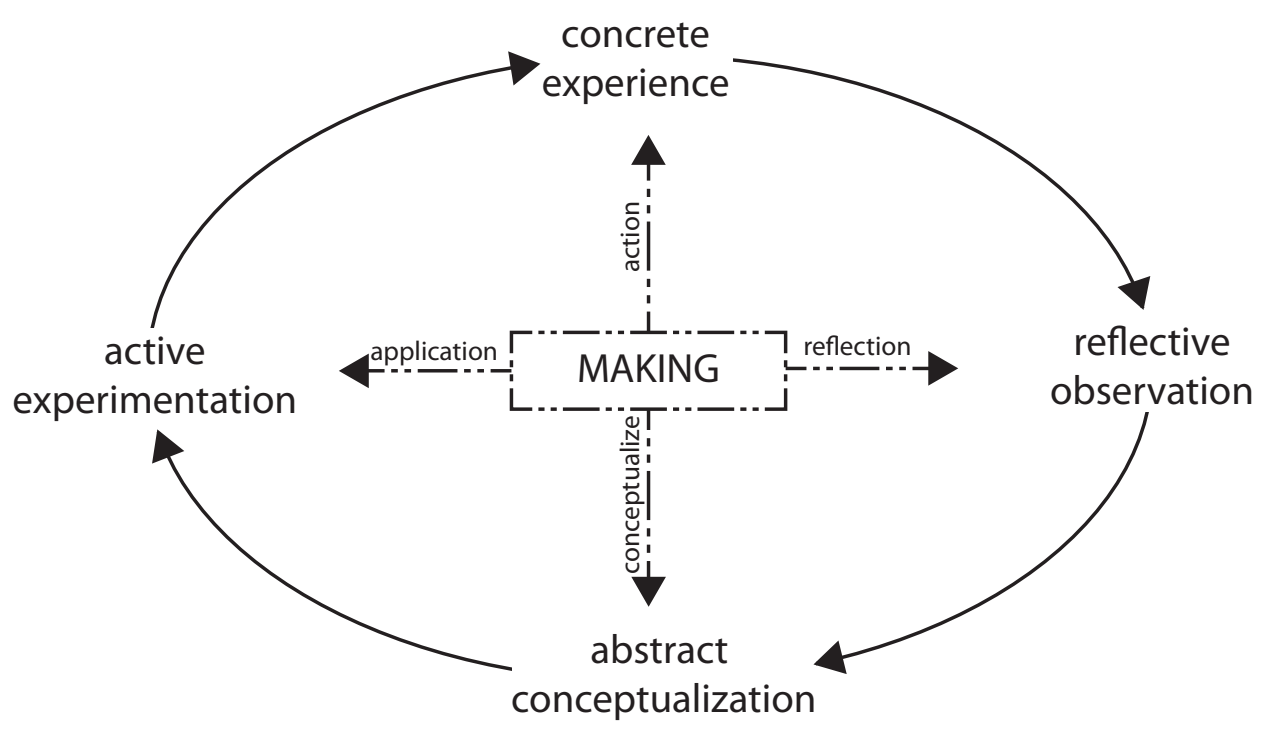

Building upon Dewey's concept of a self-motivated method of learning Figure 40:Kolb's Experiential Learning Diagram and serving to further solidify the necessity of interactivity and experience as an indispensable condition for architectural design processes to successfully impart knowledge and information is the Constructivist Theory of Learning developed by George Hein. This model posits that it is the individual's ability to connect theoretical concepts to physical constructs through tangible engagement and conscious reflection that imbues the experience of making with generative informational qualities. Hein's Constructivist Theory states that "learning requires the active participation of the learner in both the way 
that the mind is employed and in the product of the activity, the knowledge that is required." (Hein, 1998, p. 34). Critical to this position are two notions, firstly, that the individual must assume an active role in acquiring knowledge through engagement and secondly that the knowledge accrued in this fashion is subjective, being given meaning solely through the interpretation of the active participant. Within this model, learning is considered to be an active process, pursued by the individual in an interactive manner with the artefact and environment. It is thus critical that the architect take on an active role in the making/fabrication of their designs. Hein cements this notion stating that it is critical for participants to "use both their hands and minds, to interact with the world, to manipulate it, to reach conclusions, experiment, and increase their understandings or ability to make generalizations about the phenomena with which they engage." (Hein, 1998, p. 34). It must be noted that not only is Hein arguing for the physical engagement of the architect, but also that the experience ascertained through the exploratory apparatus allow the designer to consciously draw conclusions and create meaning from the experience. The connection between the hand and the mind, the immaterial and material is at the core of the Constructivist Theory.

Each of these historically established and widely implemented models of learning focus on the physical nature of the individual as the critical component of learning. While they independently approach learning from different vantages the ability to tangibly engage the subject of desired knowledge is a necessity to gaining lasting and durable information. Dewey, Hein and Kolb have established that drawing a connection both physically and mentally, that is creating a situation in which one may employ both body and mind simultaneously, is paramount. Implementing these models into the process of design for an architect has the ability to garner a holistic, full and experiential method of design exploration. Critical to this understanding is the notion that architecture inherently deals with the tangible and material fabric of the world. It is rooted, even at a conceptual and theoretical level, in issues pertaining to the built environment. Thus, it is crucial that as technology and virtualization become wholly integrated into the practice of architecture, inclusive of the prevalent fetishism of the image as a total embodiment of architecture, that contemporary architectural praxis not relinquish its rootedness in the physical and material constructs of the profession. 
Embedded in this position is the notion that the experience of architecture, the innately human experiences ascertained through our senses and physicality, is what gives meaning to architectural works. As such it is an absolute necessity that architecture in its totality, as ideas, concepts, forms, theories, materials, and processes be engaged with tangibly so that a whole and tactile understanding can be ascertained. If the architect looks solely to mediated interfaces to attempt to understand the totality of architecture one would be ignoring its defining fundamental truth. 



\section{Tools of the}

\section{Hand and Mind}

Architecture begins in the mind. It is within this organic tool of the human body that the spark of imagination and creativity connect immaterial ideas and material concepts in a desire to create. At this particular instance in time the imagined architecture exists immaterially, as affected by nothing other than unfiltered thought, with the ability to transform simply through the power of will. Thus begins a process of employing an endless array of tools in the hope of exploring, developing, examining, and communicating the complexity of this thought. This process has the possibility of being endless and yet in its endless complexity the tools through and with which a designer selects to materialize this thought have deeply resounding affects.

The range of tools available to the architect is infinite. They may be as simple as a finger drawing in soil, a hammer and nail, a compass and scale or as complex as Building Information Modeling systems, parametric design programs, and rapid prototyping machines. They may be virtual and representative, two-dimensional or three-dimensional, or tangible and material. 

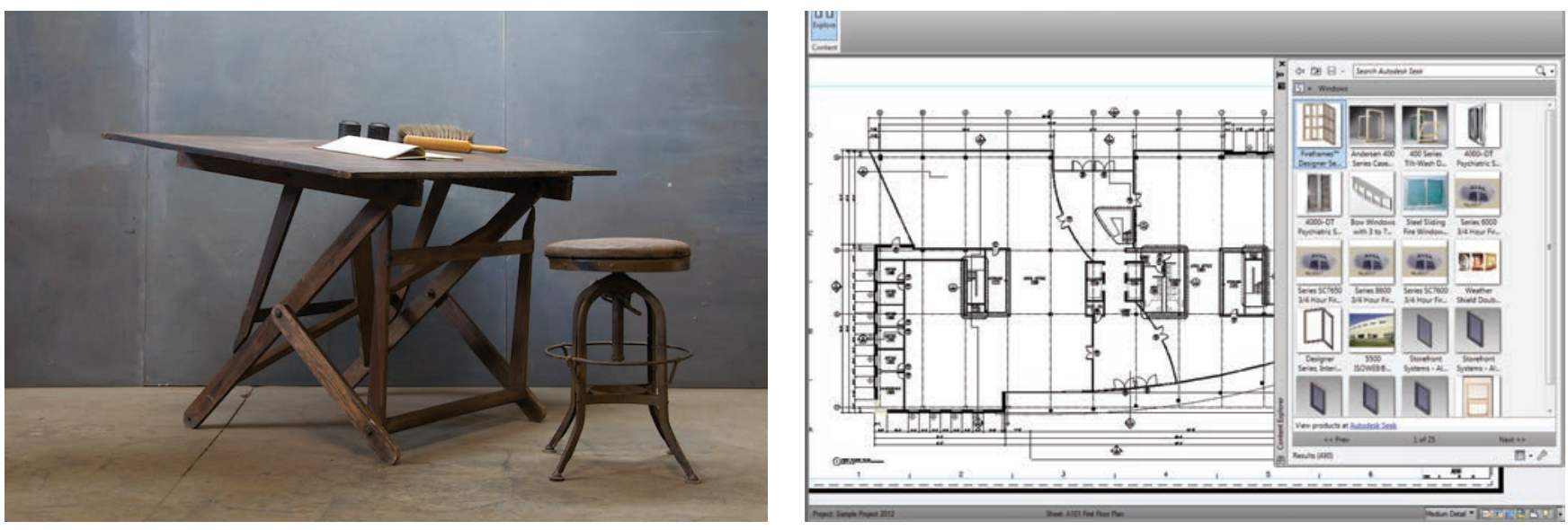

The selection of a particular typology of tools to engage with must be regarded within the design process not as an end (as the common employment of novel Figure 42: Manual Drafting Tools Figure 43: Digital Drafting Tools representational technology might suggest), but rather a means through which to skillfully engage an architectural thought.

Interestingly, the wake of these choices of means is far ranging and non-linear. The type of imagined architecture can affect the appropriateness of tools selected, the tool selected and its employment can affect the imagined architecture, both can experientially affect the architect. This cyclical process of cause and effect is integral to the development of the design, the designer, and their tools.

In so far as the type of tools chosen through which to explore an architectural idea are important, so to are the means by which architecture is explored are critical. The fundamental physical reality of architecture, being its existence in both time and space through materials, necessitates a process of design which is steeped in these integral facets.

The exploration and employment of tools and technologies (both manual and digital) in the process of making physical architectural prototypes has the ability to have resounding effects on the architect. By engaging making as a primary means of design, inclusive of the craft and craftsmanship which this entails, qualitative and quantitative information about the created artefact is made knowable to the designer through the employment of tools for making.

The primary tool of an architect is corporal (the mind and the hand) 

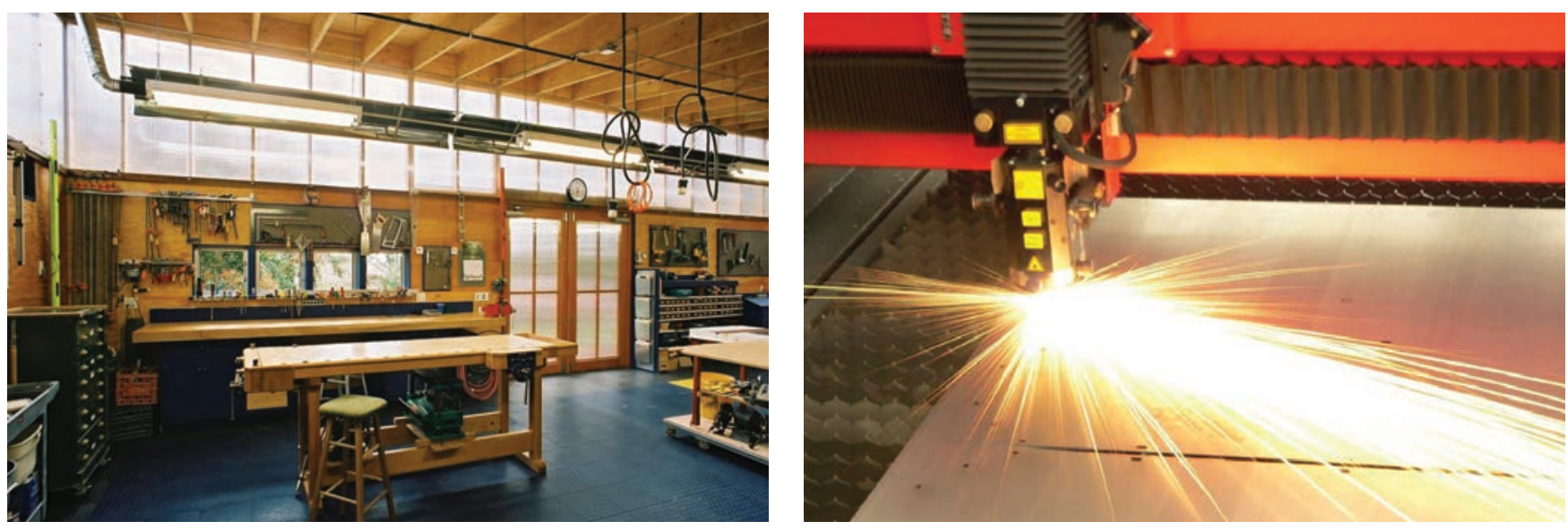

Figure 44: Manual Construction Tools Figure 45: Digital Fabrication Tools through which information can be simultaneously received and communicated. The physical external tool, regardless of its formal abilities, is a static object which once engaged with tangibly can be understood as an extension of the self through which information about the making process and its inherent architectural qualities can be expressed and understood. This notion of incorporation (as prescribed by Merleau-Ponty in Personal Knowledge: Towards a Post-Critical Philosophy and Polanyi in The Tacit Dimension) details the phenomena by which the sensory perception of the designer extends to include the physical essence of the tool (Tonkwise, 2009, p. 8). The development of this condition of knowing is intuitive and experiential, demanding that the user engages directly with the making processes in order ascertain knowledge about the artefact being created, the process of its creation, and its material base. The information acquired through this process of making and through the physical engagement with tools is both empirical and phenomenological. The tools, acting as an extension of the sensory system of the designer, can allow a corporal and tacit understanding of the inlaid properties of a chosen material as well as the effect of design decisions.

"...we are absorbed in something, no longer self-aware, even of our bodily self. We have become the thing on which we are working." (Sennett, 2008, p. 174)

Working through tools in fashioning materials into architectural constructs can also lead to processes of discovery and development of an architectural intuition which would have otherwise been unknowable. While the gamut of tools available for making architectural prototypes is vast there are often instances in which architects are inspired to design and create or appropriate 


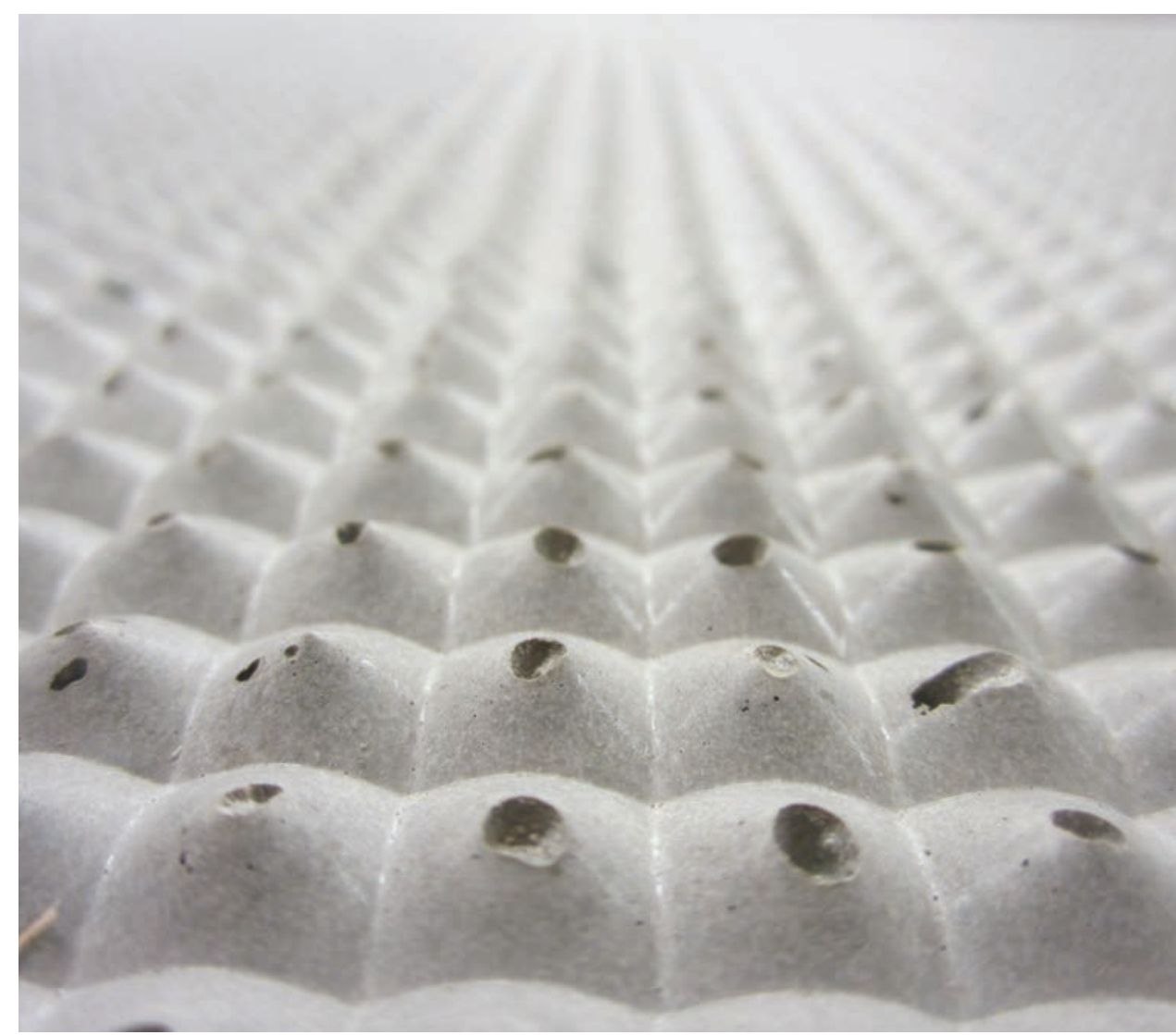

tools which suit the intended need (Smith M. , 2008, p. 227). Engaging the making of tools as a by-product of the making of prototypes allows the architect the ability to gain a detailed understanding and insight into not only the product of their efforts, but also the processes by which architectural concepts are materialized. In these critical instances architects role as designers takes on a tripartite nature (architect/craftsman/toolmaker) which can be crucial in understanding and expressing architecture as a materially based practice founded in a physical reality.
Figure 46: Concrete Panel Textural Detail
Figure 47:MV4 Grasshopper Script Delaunay Triangulation Figure 48: MV4 Concrete Panel Rhino 3D Model

Figure 49: Mastercam X6 G-code
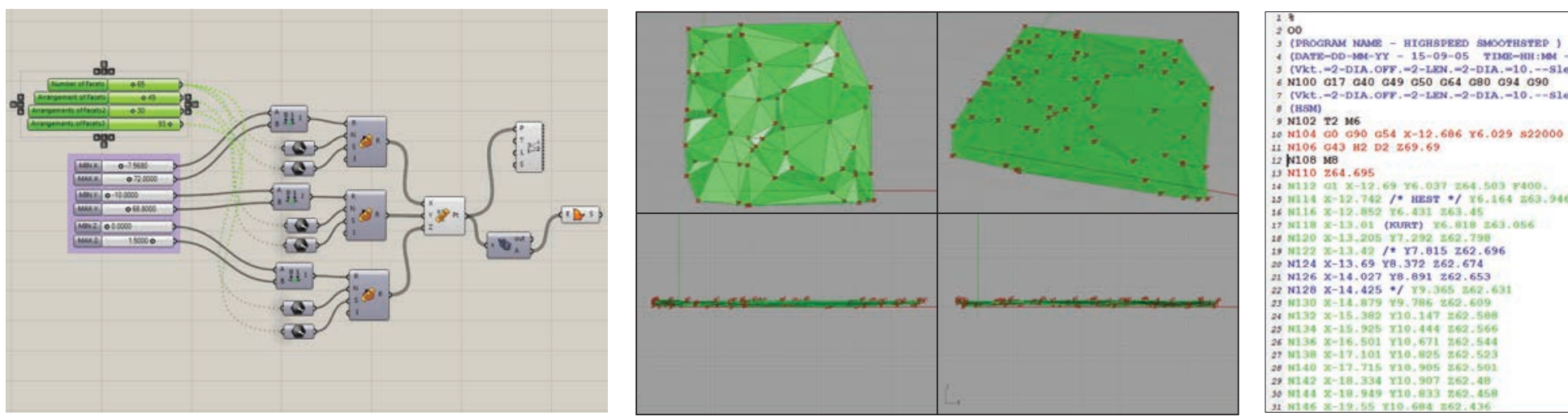
While establishing a relationship between the engagement of manual tools and the making process is relatively straight forward (as the architect is physically crafting the materials) the integration of digital fabrication and rapid prototyping technologies into the making process presents a complex condition. While the virtualization of design has led to the schism which currently exists within contemporary architectural praxis advancements in the manufacturing and fabrication industries coupled with the developments in CAD software seek to reverse this established trend. This has given rise to digital craft (Kolarevic B. , 2008, p. 120). This type of craftsmanship is a result of advancements in CAD software which allows the architectural drawing the ability to contain within it information which is directly employed in controlling digital fabrication processes. The making of the drawing and the making of the building are now intrinsically connected and can be explored through the fabrication of complex prototypical artefacts. The complexity and precision with which the architect is now able to construct prototypes allows for a method of design through making previously unattainable. In the section entitled 'Destiny of Innovation' in Manufacturing Material Effects, Chris Sharples notes:

"Problem solving at this level of complexity is something that has been lacking in the way people have been working. When we used to build models, we tended to build them as representational devices. Now, we actually have to think about how to make that model, and at what scale we are making that model, and how that model references other scales. These tools are critical! They are critical to the design process." (Kolarevic B. , Manufacturing Material Effects, 2008)

This form of digital making repositions the architect within an architecture that is fundamentally a material practice, reinforcing the inherent connectivity between material and form (Kolarevic B. , 2008, p. 120). A direct corporeal connection between the architect and the material process of architecture in digital making is severely mediated through drawing and fabrication software and technologies. This issue can be somewhat resolved depending on the type of tools a designer chooses to make with.

When selecting what type of tools to engage with when digitally making prototypes it is important that one understands the benefits and limitations 
Figure 52: CNC Milling Concrete Panel

Mold

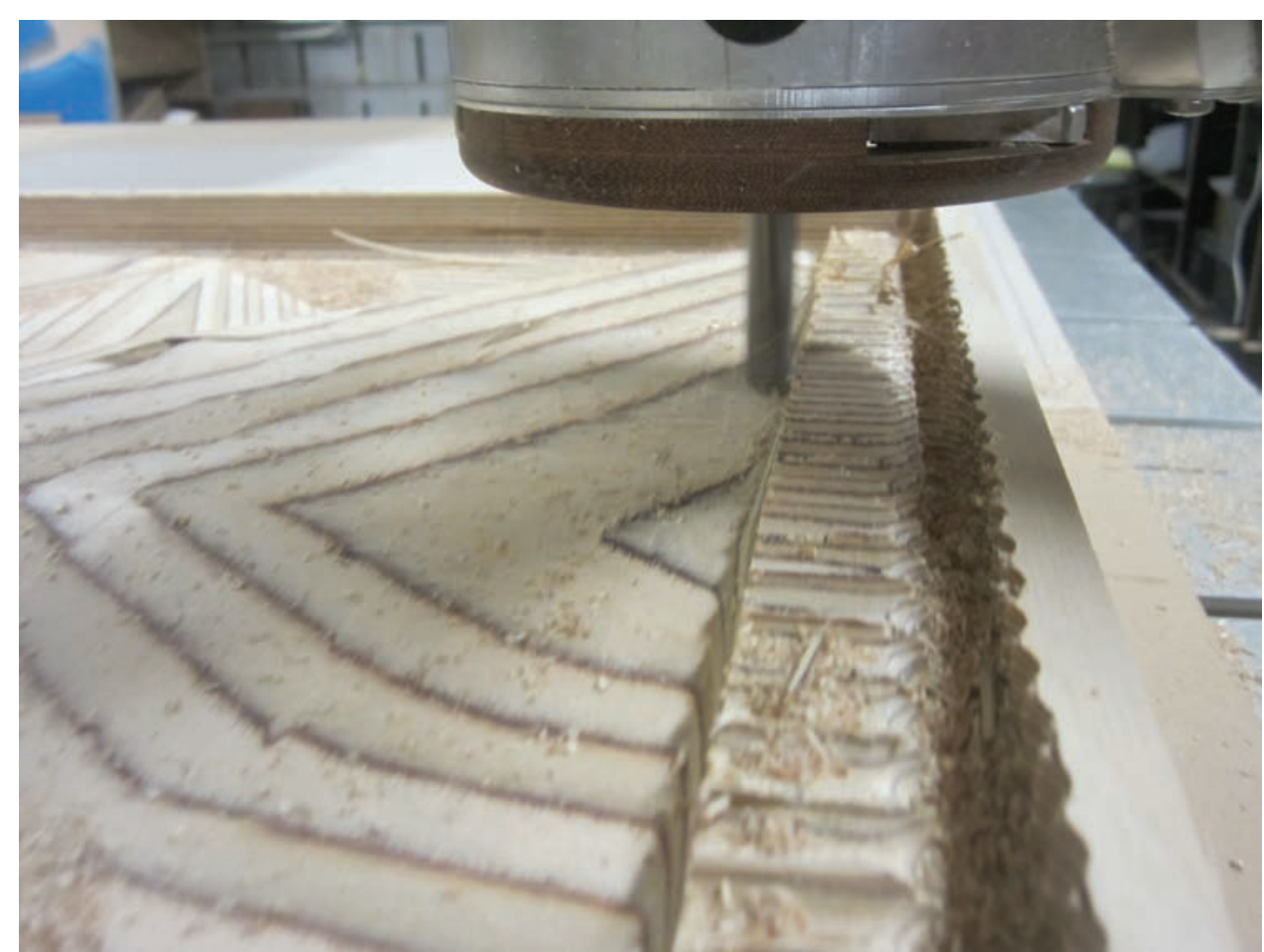

which each typology of tool brings. There currently exist two types of rapid prototyping machines; CNC (Computer Numerical Control) machines and 3D Printers. Each functions under similar conditions whereby the architect designs the prototype in either two or three dimensions digitally and according to what type of machine is selected draws out the required information which would allow the rapid prototyping machine to function.

CNC machines employ a process of machining which is subtractive. They can be outfitted with a variety of different heads which allow for a wide range of capabilities such as milling, sawing, cutting, drilling, and pressing. These processes are controlled by a type of software (such as MasterCamX) which translates the vector, mesh or nurbs based information into tool-paths or $\mathrm{G}$-code which the CNC machine is able to precisely follow. These machines have the ability to not only make scaled models and prototypes, but are also actively used in the production of full scaled custom building components (Krasny, 2008, p. 174). These types of rapid prototyping machines are able to work with a spectrum of materials such as woods, plastics, and metals. This availability of materials along with the precision and complexity which are easily executed with these prototyping machines allows the architect a detail method through which to explore the material qualities of their design. 
Inherent in the process through which these machines function is the fact that while they can be used to produce scaled replicas of form they are most often used for exploring architectural components. This means that while the CNC machines fabricate components they often still require a great deal of manual assembly which allows the designer a complex and intimate experiential understanding of the construction processes undertaken in the materialization of a given design. Issues of scale and speed also make this type of rapid prototyping attractive. They are able to produce artefacts and components which allow the designer the ability to discover at full-scale hidden complexities within a design. The speed at which CNC machining can fabricate also allows the feasible prototyping of artefacts in an iterative, exploratory, and communicative design process.

3D printing is also often employed as a tool for rapidly manifesting architectural ideas. There are however, several notable differences between $3 \mathrm{D}$ printing and CNC machining which make 3D printing a poor choice for engaging architectural design as a materially based craft. 3D printing is an additive process and as such is severely restricted in the selection of materials available for production and is usually limited to plastics and starch powders which respond well to the additive process. There also exist several scalar restraints which relegate the prototypes produced by $3 \mathrm{~d}$ printers to the realm of representation. The objects which are created in this process are bound by the maximum allowable size of the printing machine and must be adjusted in order to allow for minimum tolerances and structural stability of thin parts, thus when printing full examples of architecture the designer must skew the proportions of a project in order to allow the machine the ability to function. It is also important to note that while the artefacts created may appear completed (albeit generally from a homogeneous material) they are unable to impart information into their construction processes. 3D printing gives the designer the illusion that the object is complete and yet disregards the material basis of architecture as well as the inlaid construction processes (Poole, 2007, p. 110). 3D printing as a means of engaging architecture materially through making is not suitable for forming a complete understanding and privileges, much like two-dimensional representations, the form of a design while ignoring other fundamental architectural truths. 
Engaging tools when undertaking the making of architectural prototypes is a necessary part of the making process. These tools may range from simple to complex and may be manual or digitally driven. Regardless of the tools chosen it is critical that the designer consider how the employment of the tool will affect their understanding of the architecture being created and whether it will transmit reliable information or falsify the reality of the works. In so far as architectural prototypes are exploratory and communicative the tools which are chosen or created to manifest a work should be equally enlightening. Tools should become extensions of the self connecting the material of the architectural work to the primary tool of understanding and experience, the designer's corporeality. 


\section{chapter 06}

\section{Tectonics \\ [Physical Engagement In]}

Tectonic 'adj. 1650's "of or relating to building," from Late Latin tectonicus, from Greek tektoniko "pertaining to building," from tekton (genitive tektonos) "builder, carpenter," from Proto-Indo-European root "tek- "to make"' (Harper, Tectonic)

The drawn line is an imposter, a stand in, the ultimate architectural symbol. Whether the line is drawn manually or digitally it exists solely for the purpose of expressing the existence of something else. The ubiquity with which this representational construct is employed as the primary means through which to explore design and understand architectural ideas has led to an impoverishment of the architectural profession's technical and tectonic heritage (Gregotti, 1996, pp. 98-9). In order to make an architecture physically feasible the designer must have an intimate understanding of the techniques and materials employed in construction, along with an in depth understanding of how an architectural drawing translates to a built construct (Hill, 2005, p. 16) The architect of the image is functioning at a disconnect from the tectonic 
reality which encompasses all architectural endeavours. Found in the etymological root of the word tectonic is the Proto-Indo-European root tekwhich means "to make" (Harper, Tectonic). Thus the ability of the architect to understand and experience the design of architecture through making is critical in their ability to convey design comprehensively through representational means.

'Lines are the intermediaries between 'thought' and 'making', and their significance as substitute for matter needs to be understood. Architects seldom build their own work, but to begin an immersion into the act of building is the only means by which their line can become relevant and purposeful." (Chandler, A Philosphy of Engagement: Developing a Strategic Ability through Direct Engagement with Material, Process and Collective Action, 2007, p. 121)

In his article Building the Drawing, Jonathan Hill appropriates the psychoanalytical construct of the 'transitional object' in order to illustrate the detrimental affects that can occur when solely focusing on the drawing as the principle means of knowing and exploring architecture (Hill, 2005, p. 16). A transitional object is used to describe a phenomenon in psychology whereby the adoption of an artefact by a child is employed as a stand-in for particular attachments and relationships with the child's mother (Winnicott, 1971). The transitional object is found within a transitional space which exists between the psychic and external (or conceptual and material) reality of the mother-child relationship. When a healthy relationship is maintained with this object (stuffed toy, blanket, etc..) the child is able to wean itself from both the mother (material reality) and the transitional object, asserting them as independent entities with a full understanding of both material reality and the proper role of the transitional object (Winnicott, 1971). If the child is unable to properly understand the role which transitional objects are intended to fulfill the symptomatic outcome according to Elizabeth Wright can be "the fixed delusion which may turn the transitional object into that permanent security prop, the fetish, both in the Freudian sense (it disguises the actuality of lack) and in the Marxian sense (it functions as a commodity that supplies human want)." (Wright, 1984, p. 93)

The diminishing relationship between the architect and an intimate 
understanding of the tectonics of architectural works has come as a by-product of the heavy reliance by the contemporary architect on virtualized means of design. The intention of these methods, acting as the transitional object between the psyche of the architect and the material reality of architecture, have become both fixated upon and fetishized in contemporary architectural culture. Engaging making and the tectonic qualities which are inherently embedded in architectural works is an experiential vehicle through which the designer can develop a broad understanding of the processes which are necessary in the realization of a project. During the process of making the normative mode of architectural practice is restructured (Chandler, A Philosphy of Engagement: Developing a Strategic Ability through Direct Engagement with Material, Process and Collective Action, 2007, p. 121). The drawing takes on a secondary role to making, not driving the process but rather being employed as an explanatory device or notary describing how the artefact is to be constructed. The creation of exploratory artefacts as an integral component of the design process aids in repositioning and rebalancing the scale of contemporary design. Making is able to provide an equilibrium that is essential to successfully understanding, designing, and communicating architecture as physical craft.

"In my view, the best designers know how things work, how they are made, how materials behave and their qualities. They produce buildings of elegance and grace where the concept, the materials and the details are in harmony." (Thornton, 2005, p. 100)

Figure 54: Drawing as notary during Construction Process

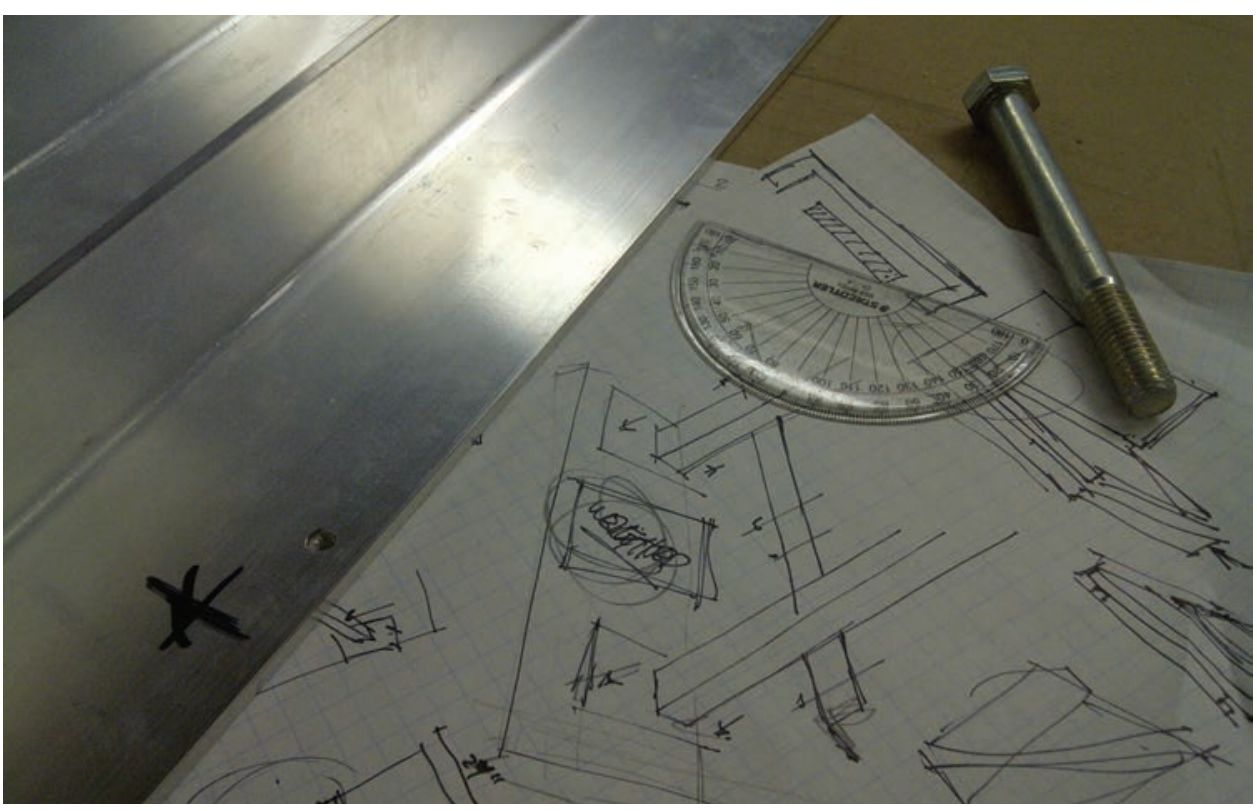


The creation of prototypical artefacts entails a direct corporal experience with the making process. Depending on the type of prototype being constructed, at what scale, and with what materiality the processes involved in its realization can be close to those experienced during the construction of a building, albeit in a controlled environment. This experience is fundamental in developing an understanding of the underlying rationale in material and construction practices and processes. The knowledge acquired through the experience of making can then be subsequently applied to future works and design decisions. For example, if a designer were to make with concrete as a material through which to explore a particular design then they would necessarily engage a majority of the processes involved with when pouring concrete for full-scale construction. The architect-maker would have direct experience with the different material processes involved such as; mixture ratios, add-mixtures, textural effects, designing and building formwork, curing temperatures and times, structural strengths, form limitations, addition of tensile members (re-bar), etc. This process also enlightens the designers as to the difficulty of realizing design decisions, shedding light on the consequences which even small decisions and alterations to a design can have on the construction process. It is through the making process that one is able to fully appreciate the difficulty of construction and apply the connection between the drawn line and the built construct.

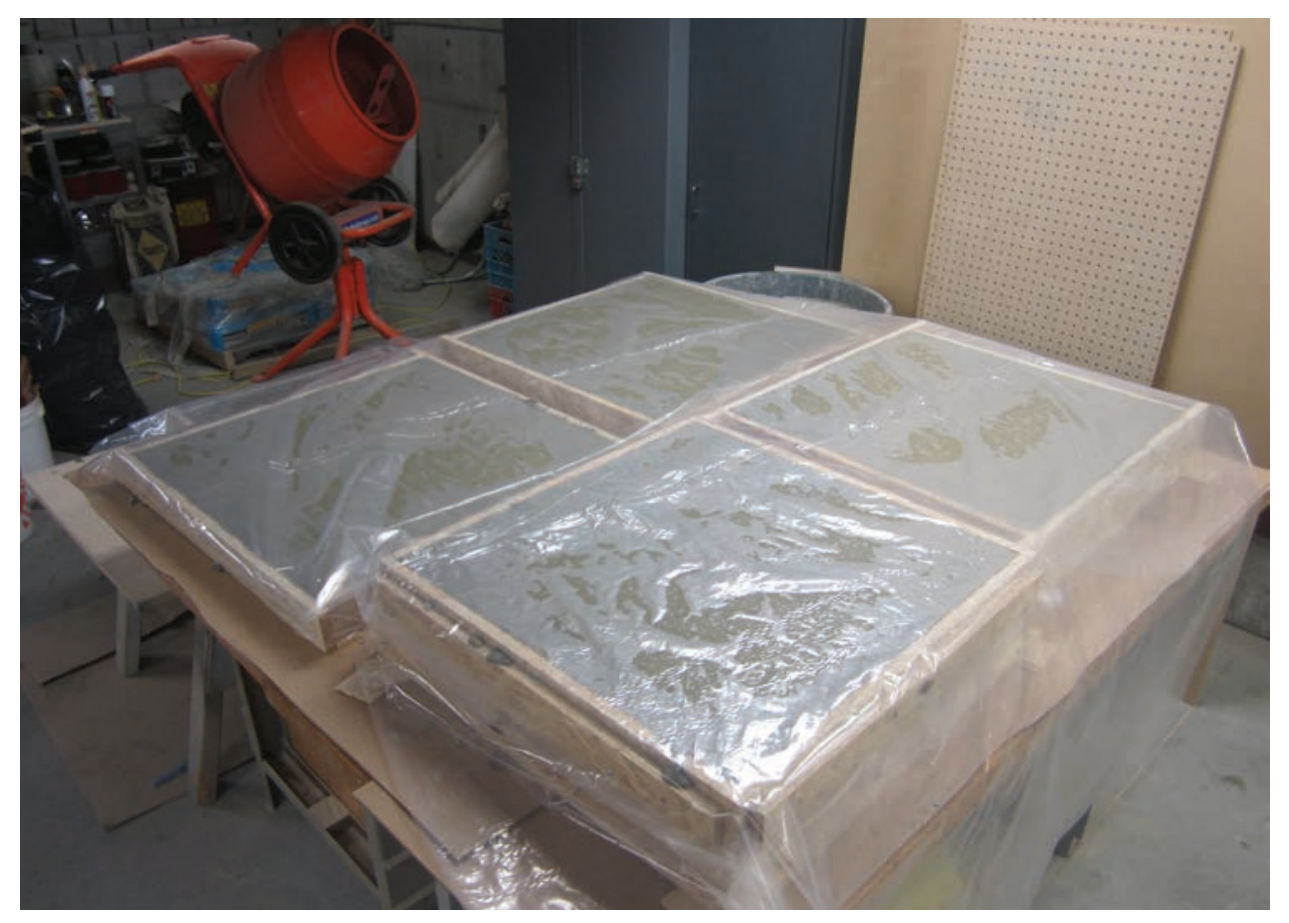

Figure 55: MV4 Concrete Panels Curing 
By engaging making as a critical design tool the designer is able to expose themselves to a wide variety of material and construction processes necessary in the realization of a project. Gaining an experiential knowledge through the materially intimate act of making allows the architect the ability to create a corporally based mental history of architectural tectonics. Designing architecture through making is a means through which architects are able to "generate essential experiences of material structures in order to gain experiential and durable knowledge and to aid in re-investing this knowledge and experience when it is needed." (Chandler, A Philosphy of Engagement: Developing a Strategic Ability through Direct Engagement with Material, Process and Collective Action, 2007, p. 121). This type of experiential knowledge is quantity and quality driven, thus the larger the breadth of exposure the larger the experiential knowledge from which to design (Thornton, 2005, p. 102). The development of a mental material library from which to inspire future creative processes is critical in the development and maturation of an architectural method of thinking which is based on the material essence of architecture.

Practicing a method of engaging with and thinking about architecture which is materially based is a critical component of constructing methods of designing architecture which are tectonically founded. The concept of material thinking is one which has remained relatively abstract evading a concise definition. Alan Young, in an editorial for Studies in Material Thinking, simply describes material thinking as thinking about materials. He goes on to note that it is in contemplating the nature of materials, their qualities, how they exists naturally and artificially, and how one is able to work with and through them that categories a type of thinking which is materially based (Young, 2011, p. 1). Dually important is the reciprocal manner in which the materials that the architect chooses to engage with are able to affect the creative process of design in ways which are both knowable and unknowable (Young, 2011, p. 1). Developing this type of thinking and design practices within contemporary architectural praxis, a profession which is heavily reliant on mediated forms of design, requires a methodology of working which favours direct and sensual experiences of the materials and processes which make architecture possible. In her article Material Thinking as Document, Nancy De Freitas notes that material thinking as a skill "is acquired experientially, through practice and 
contemplation... from the handling and forming of materials..." (De Freitas, 2009, p. 1). The architectural discourse occurring mentally within this process of design privileges the material qualities over formal and requires an ever expanding experiential mental library from which to draw and create.

Establishing this critical material discourse in which the designer engages particular materials during making, responding to their properties and allowing their properties to inform design, is a departure from normative design procedures. The consumption of the architectural image, both in exploring and communicating design, occurs rapidly and visually through a medium which is silent in its expressive qualities (Young, 2011, p. 3). The viewer of these images reacts instantly, gathering information in quick glances about a work which is intended to be experienced, making crucial judgements based on an ocularcentric reading. Exploring design physically and communicating architectural ideas through making establishes a dialogue which occurs between designer, materials, and design simultaneously through a full experiential spectrum. The internal discourse which then surrounds these informative artefacts can occur in a dynamic omni-directional fashion.

Incorporating making into the design process as a tangible means of exploring and communicating architecture allows for a renewed and corporally based understanding of architectural tectonics. Physically engaging these inherently material conditions early on in the design of a project affords the designer the ability to carefully and thoughtfully construct an architecture which centers on the fundamental premise of its physical and material reality. Over time, as the architect continually engages making through a variety of different works, their mental repertoire for tectonics increases allowing an ever expanding experiential mastery of the material properties through and from which architecture is constructed. 



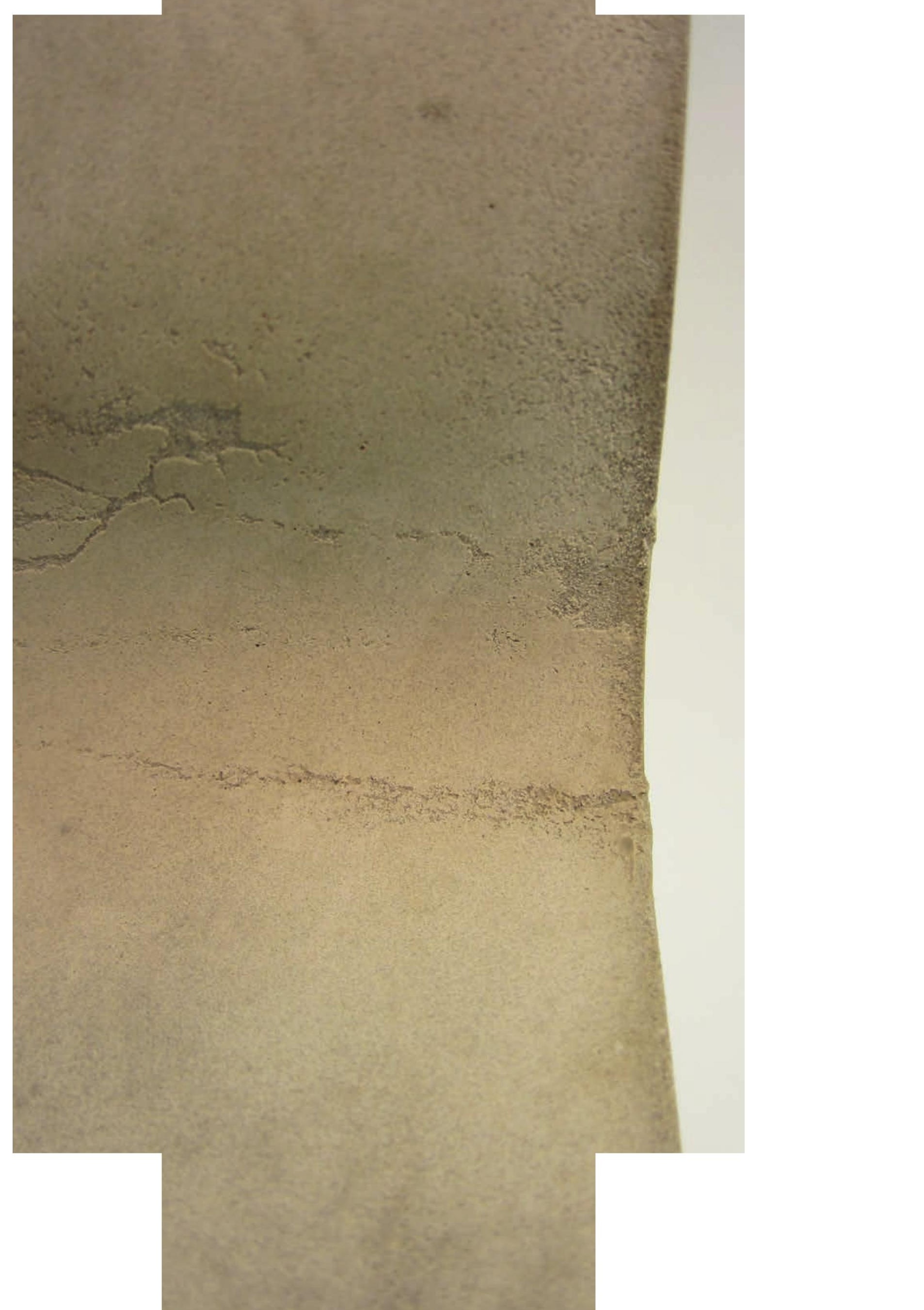




\section{A Manifesto of Making}

The divergence of architectural design from the material foundations of architecture has been established as both a historical and contemporary trend being continually furthered by the ubiquity with which virtual and representational methods of design are integrated into architecture. This thesis is proposing that architects engage a design process which is at its core inherently material based by engaging making as a primary method of design. This can be demonstrated through the creation of prototypical artefacts which employ materials and methods of construction that are as close to reality as possible. These artefacts can be both abstract and definitive, informing design through the materially informative basis of architecture. 
occurs when understanding and engaging design through a materially based lens. 'Thinking within architecture' and 'thinking about architecture' are two radically different things. Frascari continues;

"... the capacity of the architect pre-rationally to make sense of the actions, emotions and sensations of others (users and builders) depends on embodied simulation, a functional mechanism through which the actions, emotions or sensations start their internal representations of the body states that are associated with these architectural stimuli, as if they were engaged in a similar action or experiencing a similar emotion or sensation... this emotional way of conceiving and building architecture, the crucial element of response consists of the activation of embodied mechanisms encompassing the simulation of actions, emotions and corporeal sensation..." (Frascari, Splendor and Miseries of Architectural Construction Drawings, 2010, p. 110)

It is by engaging architecture as a maker that the architect is able to achieve a state of thinking within architecture enabling a total corporeal and mental involvement with design. Designing architecture through the role of both architect and craftsman increases the potency and degree to which tacit knowledge and emotive understanding is transferred acting as a trigger for a full and total architectural experience.

The proposed method of design will engage a process which is liberated from a strictly representational method of design, being substituted instead with a tangible and materially based methodology of design. Engaging architecture in this manner restructures the contemporary means of design to a more physically rooted sense of architecture which allows design opportunities to develop through engaging making as a primary exploratory device.

Understandably, there are many restrictions which can prevent a designer from fully engaging design development solely through the lens of making. The normative representational and virtualized modes of design have become established within the profession because of their quickness and versatility in developing and expressing complex design gestures. It should be noted that while this thesis intends to position design as necessitating physical engagement there are no false pretenses to the efficiency and ease 
which virtual tools of representation provide architects.

In responding to this procedural issue, which is deeply embedded within contemporary architectural praxis, it is important that a framework be established through which to guide the design through making processes. These Strategies of Making are prescriptive in regards to the process of design and can be implemented in all areas of architectural design, exploration, and expression.

\section{Strategies of Making}

\section{Design with your hands and mind.}

Engage making as a fundamental means of design exploration.

Designing architecture requires one to think both with and through one's hands and mind. Architectural design is not only highly intellectualized and theoretical but also material, construction, and craft based. It is the mastery and marriage of these two inseparable realms that dictate the quality of the work accomplished. Engaging making as a fundamental means of design exploration ensures a holistic and well rounded approach to creating architecture which is fundamentally based on the material reality of the profession.

\section{Real Materials}

Use materials which are the materials being suggested.

Through creating and designing architecture physically one is able to engage materials as informative and exploratory devices in the design process. As architecture is fundamentally a physical practice and in all facets based within the built environment it is critical that designing architecture begin with materials. Materials should not be secondary and supplementary to form; rather they should inspire and drive architectural design.

\section{Real Construction}

Use methods of construction which are the appropriate construction methods being suggested

Architecture is our built environment. As such it is integral that the architect has a tangible understanding of the processes and procedures involved in its construction. The tacit knowledge deeply embedded within 
the craft of construction can only truly be understood and drawn out through its intimate engagement. Starting design through the lens of the maker allows the constructive forces involved in architecture to become repositioned as central to an architecture's development. This ensures that the product of such efforts will inherently integrate and respond to both the simple and complex architectural detailing gestures engrained within a design. Concurrently, the designer will develop an understanding and appreciation of the labour involved in the realization of their creative efforts.

\section{Real Scale}

Work at a scale which allows the desired design intentions to be fully expressed, understood, and communicated.

Designing architecture and working at a scale which allows a full resolution and comprehension of a design is critical to engaging making as a developmental tool for architecture. With the advent, implementation, and ubiquitous use of virtualized design software the ability to work through a scale-less unrealistic mediated interface has disintegrated the tangible relevance of the drawn line. By re-integrating scale into design through the medium of making the designer becomes acutely aware of the major effects minute changes can mean for a design. Making at a legible scale also imbues the designer with an experience of the qualities of their design (both procedural and final) which can be conferred as relatable to both the builder and end-user experience.

\section{Push Materials and Tools}

Employ making as a means of exploring the boundaries of the intended design by pushing material and tool limits.

The exploratory nature of design through making allows the architect the ability to approach presupposed and intended tool and material limitations inquisitively. In reconsidering and re-evaluating the manner in which materials and tools are employed in architectural design and production the architect-maker is able to position themselves at the center of architectural fabrication, bridging the gap between designing and making. The innovative processes, procedures, and products which are resultant can be incorporated into existing frameworks of making to spur and further architectural discourse. Engaging making in this light can be difficult as the designer must not only explore, but also restructure how 
tools and materials are being employed and why they are being used in such a manner.

Through integrating the aforementioned Strategies of Making into the workflow of design the architect will have the opportunity to develop both their understanding of architecture and the design being constructed in a full and holistic manner. The knowledge generated from engaging this process of design will allow the architect to rapidly expand their experience of architecture through a haptic and tangible means while developing a vast mental repertoire for integration into future architectural endeavours. 


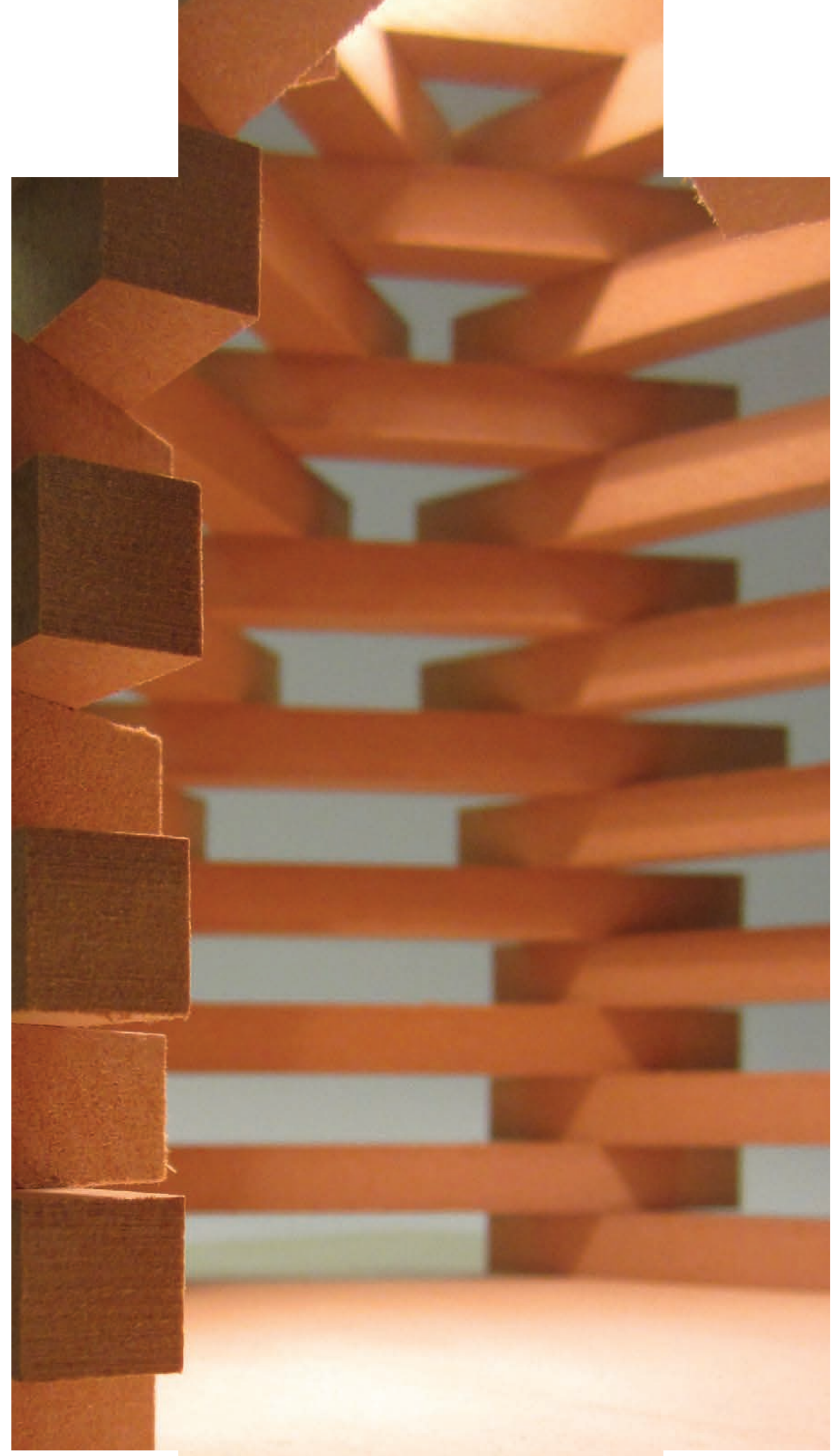




\section{Primitive Hut [Re]-Engaged}

Prototype 'n. c.1600, from the French prototype, from Medieval Latin prototypon, from Greek prototypon "a first or primitive form," properly neuter singular of prototype "original, primitive," from protos "first" + typos "impression"' (Harper, Prototype)

The primitive hut does not exist. It is a fabrication, purposefully made up as a means of designing a construct suited to exploring, discovering and communicating an idea. This fictional architecture has been historically drawn upon as an explanatory and communicative tool through which to demonstrate a genealogy of architectural origins. In exploring the concept of the primitive hut the many authors who have employed this theoretical construct seek to define a measure of authenticity in the origins of the built shelter while imbuing the hut with their personal architectural theories. The versatility of the primitive hut as a concept has allowed its appropriation in communicating a vast and varied spectrum of architectural theory. 
Despite the breadth and diversity of ideas which the hut has been employed to communicate there exist particular thematic conditions within the ever changing narrative of the hut which provide a foundation and continuity between each individual version. Deeply engrained within the accounts of each of the primitive huts is the important role which making and materiality have in defining architecture. Each of the stories of the hut, from Vitruvius to Le Corbusier, describe in detail the process of making and constructing the huts and the vernacular materials which have been harvested to give physicality to their designs. The active participation of the makers in this process of designing and building, whether simply for shelter from the elements as in Vitruvius and Laugier's account or in defining one's orderly role in nature as Le Corbusier details, is telling of the intimate and sensual connectivity necessary in the process of creating architecture. Even in tracing the theoretical roots of architecture, a genealogy of its origins, compositional components, or building elements each narrative explores architecture as being rooted in the built environment, as a by-product of man's physical interactions with materials. Quite simply; people make their architecture.

The relationships which have been established in the primitive hut narratives are direct. They connect mankind with materials and through the intimate act of making a typology of architecture is manifest. Vernacular materials are employed with vernacular building methods in response to local conditions (whether they are climactic, political, religious, etc.) in order to produce a construct which best suits the needs of the individual or community. In the primary version of the primitive hut, Vitruvius describes a process of design based on the builder's desire to ameliorate their own huts, engaging building as a means of iteratively exploring design through making. Vitruvius' primitive architects explore the concept of shelter through the construction of full-scale prototypical architecture. These builders, along with those in subsequent primitive hut narratives, are involved in a process which connects form and matter simultaneously through the intimate handling of materials.

While each of these narratives differ in their intended reading, the primitive hut in each serves as a prototype, the first or original, through which architectural ideas and discourse can be manifest. The processes of design which have been established as being fundamental to the primitive hut 
narratives are heavily echoed in a method of design which explores architecture through making. These critical elements which tie together the conceptual and material realms of architecture through the medium and efforts of the human body imbue the architect-maker with a unique and irreproducible architectural experience. The etymological roots of the word prototype, which the making of is being positioned as a critical component of design, draws similarities to the conceptual underpinnings of the primitive hut narrative and the integration of prototypical artefacts in the design process. While the concept of a prototype or prototyping may have connotations which can signify the quantitative and empirical development of an artefact for manufacturing purposes its etymology points to a broader definition and thus application. The word prototype as applied and understood in this thesis came into existence circa the 1600's from the French prototype, based on the Medieval Latin and Greek prototypon or prototypes meaning "a first, original or primitive form" with protos- meaning first and -typos meaning impression (Harper, Prototype).

The significance of understanding and interpreting the root of prototype is two-fold. Firstly, it signifies that constructed artefacts as prototypes are not an end in themselves but are rather part of a continuous and iterative process of making and discovery which govern design. They are by no means definitive and are representational of a particular instance in time during the journey of design giving communicative glimpses into an otherwise silent process. Much like the primitive hut narratives, the construction of prototypical artefacts in the design process draws into existence a construct which can be exploratory and communicative. Secondarily, inlaid within both the nature of the primitive hut (as a concept) and the making of prototypical artefacts is the ability for these constructs to act as a tool for thinking about architecture. Thinking about and discovering architecture in this light during the design process (as matter, form, and matter transformed) allows the designer the ability to consciously confront the physicality of architecture, considering its origins as a materially based tectonic craft.

In exploring the integration of making as a critical design process the fictional construct of the primitive hut will be utilized in continuing an existent and legible framework for provoking architectural discourse. The huts simplicity 
of program and richness in architectural conditions make it an ideal means through which to actively engage design through making. Furthermore, the physical function of the hut, of separation from natural conditions, is being considered as analogue to the contemporary state of the architect who fulfils a role in design which acts autonomously from the fundamental material nature of architecture, sheltered in a hermetic state. The Primitive Hut [Re]-Engaged, inclusive of its materiality, architectural conditions, and tectonics will become an exploratory and communicative tool, reframing the role which making fulfills in the architectural design process. 


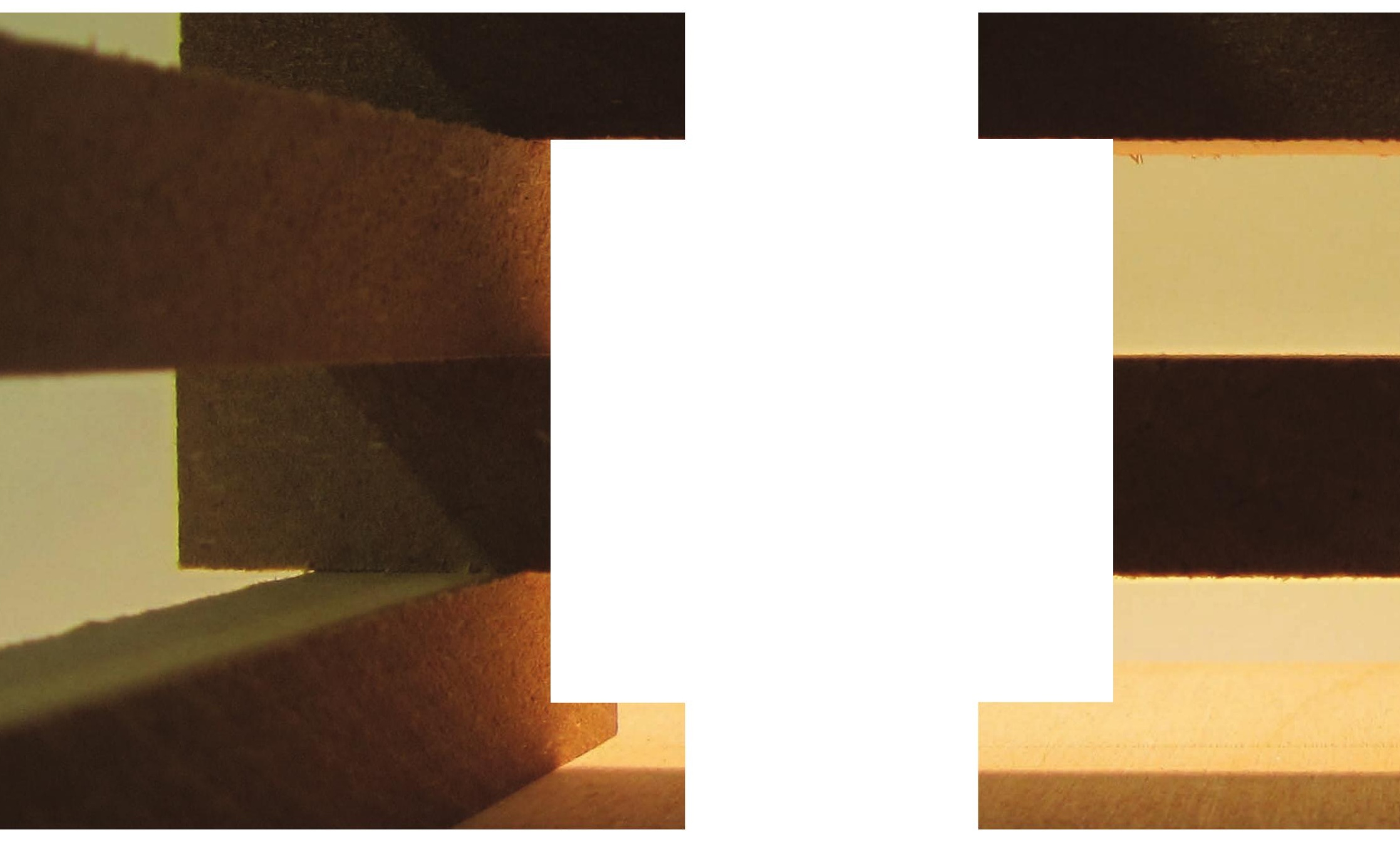


\section{chapter 08.1}

\section{Primitive Hut [Re]-Visited}




\section{Marcus Vitruvius Pollio}

Located in the second chapter entitled 'The Origin of the Dwelling House' in The Ten Books on Architecture, Vitruvius' account of the primitive hut begins as a fictional tale of the origins of gathering and dwelling. The discovery of fire, acting as a catalyst for the gathering of primitive man, development of language, and social interaction leads to man distinguishing themselves from animals through their ability to manipulate and construct their environment with ease. Vitruvius'details a process of design and construction which is inherently iterative and tectonically based on the local materials and functionality of program. The design process in this primitive hut narration is driven by the desire of the primitive man in ameliorating their huts. Vitruvius notes:

"and since they were of an imitative and teachable nature, they would daily point out to each other the results of their building, boasting of the novelties in it; and thus, with their natural gifts sharpened by emulation, their standards improved daily" (Vitruvius, 1999, p. 39)

The primitive builders which Vitruvius describes (he goes on to distinguish between two typologies of shelter based on differing geographical locations implying the vernacular) function in a physically iterative design process working at full-scale and non-representationally. The design decisions which they make are done as a product of the local materials which they select to build with and the construction processes inherent to them. As they engage craft in making their shelters, primitive man gains the innovative insight, experience, and ability required in materializing architecture. 

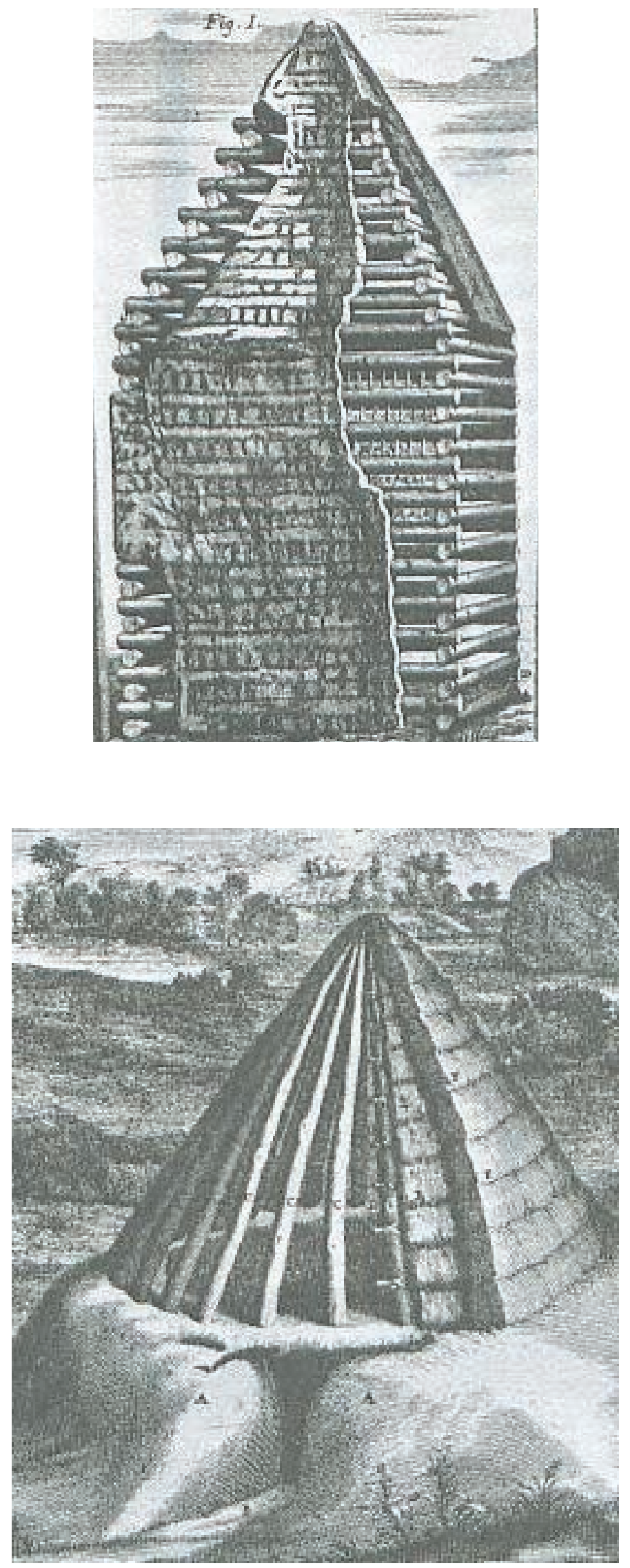


\section{Marc-Antoine Laugier}

"Let us never lose sight of our little rustic hut." (Laugier, 1977, p. 12)

Marc-Antoine Laugier recounts his version of the hut by creating a story centered on primitive man's desire for protection from the elemental forces of nature. Dubbed the 'little rustic hut', Laugier's primitive man seeks to impress his ingenuity over the shortcomings provided for him by nature by constructing for himself a place of shelter. In this account of the primitive hut, Laugier details how man gathered fallen materials and began building a structure which was comprised of the essential elements of architecture; column, entablature, and pediment. It is in this 'little rustic hut' that Laugier describes an architecture of perfection, creating an idealized model to trace the lineage of all architecture.

"All the splendors of architecture ever conceived have been modeled on the little rustic hut I have just described. It is by approaching the simplicity of this first model that fundamental mistakes are avoided and true perfection is achieved." (Laugier, 1977, p. 12)

Through his story of the hut, Laugier is establishing a prototypical typology from which one is able to measure authenticity and correctness in architecture. For Laugier the presence of the components which he deems critical to architecture signals a completeness and perfection of the work. Within this narrative, Laugier positions the primitive man once again as maker, constructing the 'little rustic hut' by organizing and connecting fallen branches developing a rational and order for architecture, a primitive tectonic. 


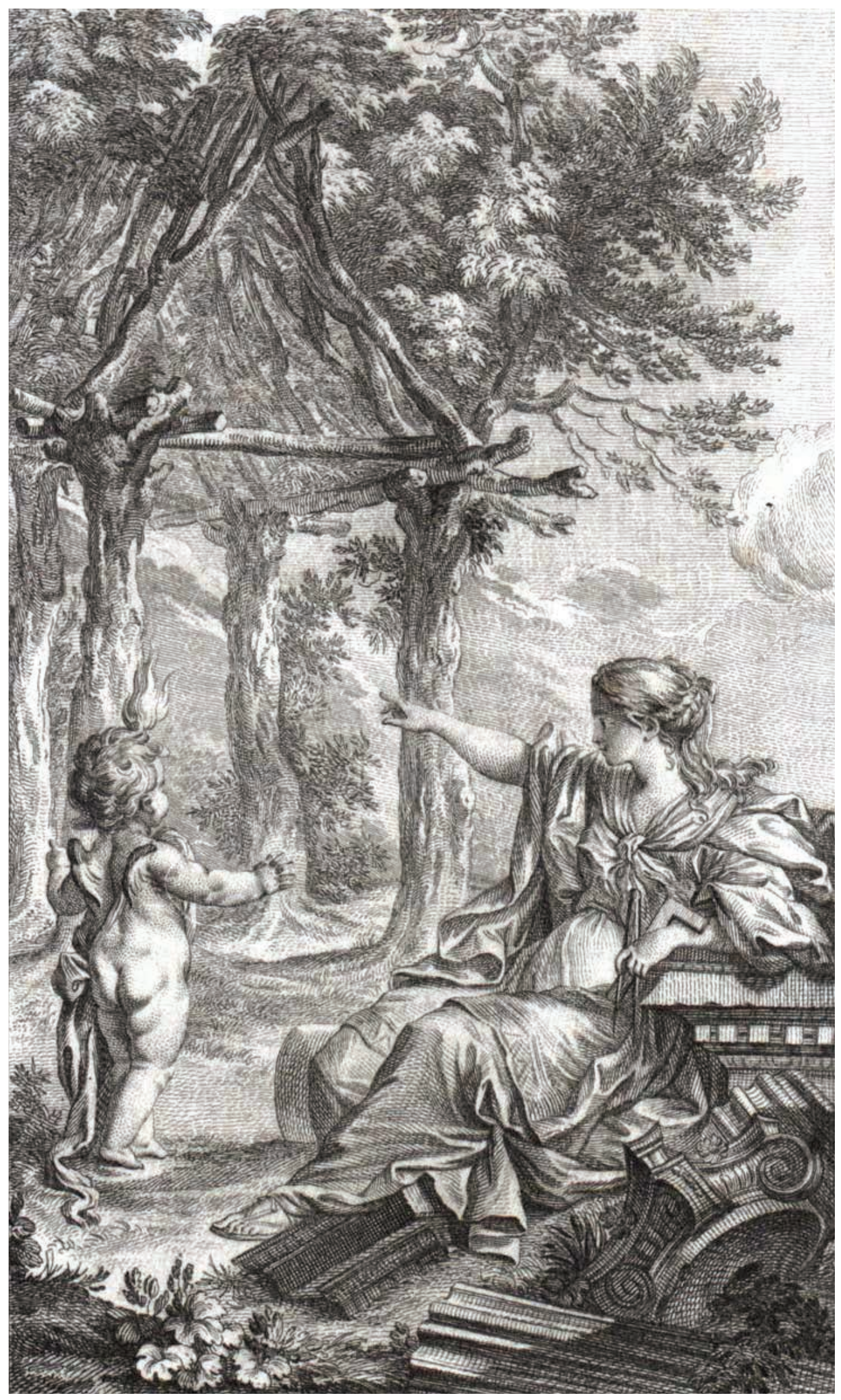




\section{Gottfried Semper}

In his works The Four Elements of Architecture (1851) and Der Style (1860) Gottfried Semper takes a different approach in establishing primitive hut narrative than his predecessors. Semper's hut is based on a native Caribbean bamboo hut which was displayed at the Great Exhibition of 1851 in London (Semper, Style: Style in the Technical and Tectonic Arts; or, Practical Aesthetics, 2004, p. 666). This primitive hut, while out of context and separate from its geographical and climactic drivers, provided Semper with the architectural conditions from which he was able to explore his four elements of architecture. These varying conditions of stereotomics, ceramics, textiles, and tectonics (represented by the floor, hearth, wall, and roof) are employed as analog to a range of architectural building practices (Semper. The Four Elements of Architecture, 1989, pp. 102-3).

"...not a figment of the imagination but a highly realistic example of a wooden structure taken from ethnology." (Semper, Style: Style in the Technical and Tectonic Arts; or, Practical Aesthetics , 2004, p. 666)

In selecting the Caribbean hut as a tool through which to exemplify a purity and authenticity in his four elements, Semper is grounding the essence of his work in a tangible construct. This hut, more than the previous narratives, emphasises the built conditions of architecture over the narration of the story. Semper details what he believes to be the essential architectural elements (floor, hearth, wall, and roof) in a manner which is simultaneously and directly translatable to material form and conceptual architectural theory. 

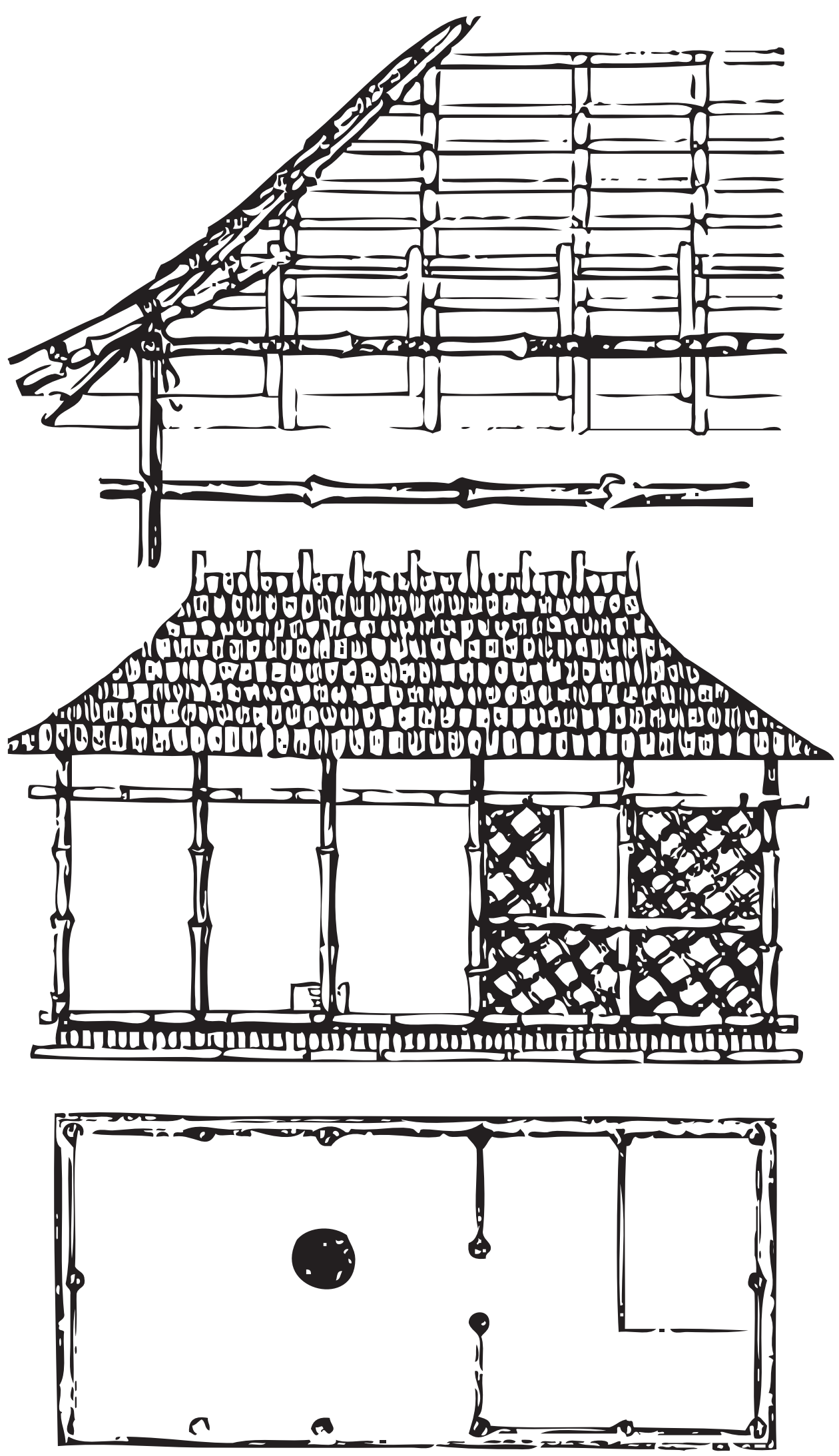


\section{Eugène Viollet-le-Duc}

In his novel Histoire de L'Habitation Humaine, Eugene Voillet-le-Duc approaches the concept of the primitive hut through an extensive and creative narrative. Voillet-le-Duc's two main characters, Epergos and Doxius, encounter different groups of people in varying stages of development aiding them in constructing bigger and more complex shelters. Epergos, much to the continual chagrin of Doxius, imparts knowledge which advances the methods of construction and material assembly unto each of the individuals and communities they encounter that are in need. Viollet-le-Duc also emphasises the iterative nature of making architecture in these narratives, stressing the importance of employing technological advancements.

"Epergos, covered with sweat and dirt, then rests by his companion Doxius. "Why," says the latter, "thus run counter to things as they are? Wouldst thou be for teaching the birds how to make their nests, the beavers to build themselves huts different from those they are accustomed to make? Why alter the Creator's work?"

"Who knows!" answers Epergos: "let us return here in a hundred thousand day, and we shall see whether these creatures have forgotten my instructions and live as they were living yesterday. If so, then I am wrong in meddling with their affairs, and I have not found what I have been seeking; but if they have profited by my suggestions, - if the huts we see then are better made than these, I have been successful, for in that case these creatures are not mere animals." (Viollet-le-Duc, 1876, p. 7)

The architecture which results from Epergos' instruction is rooted in deriving architectural form from the available materials and methods of construction. The underlying concept which is present in Viollet-le-Duc's narratives is that architecture is materially and structurally based, with form being determined by the tectonics and logical system of construction inherent in the chosen materials. In these narratives Epergos develops architecture through making in an effort to show primitive man a new tectonic and hoping that an iterative process of development and design through making will occur, working both with and through the materials present in order to discover and create previously unknown forms. 


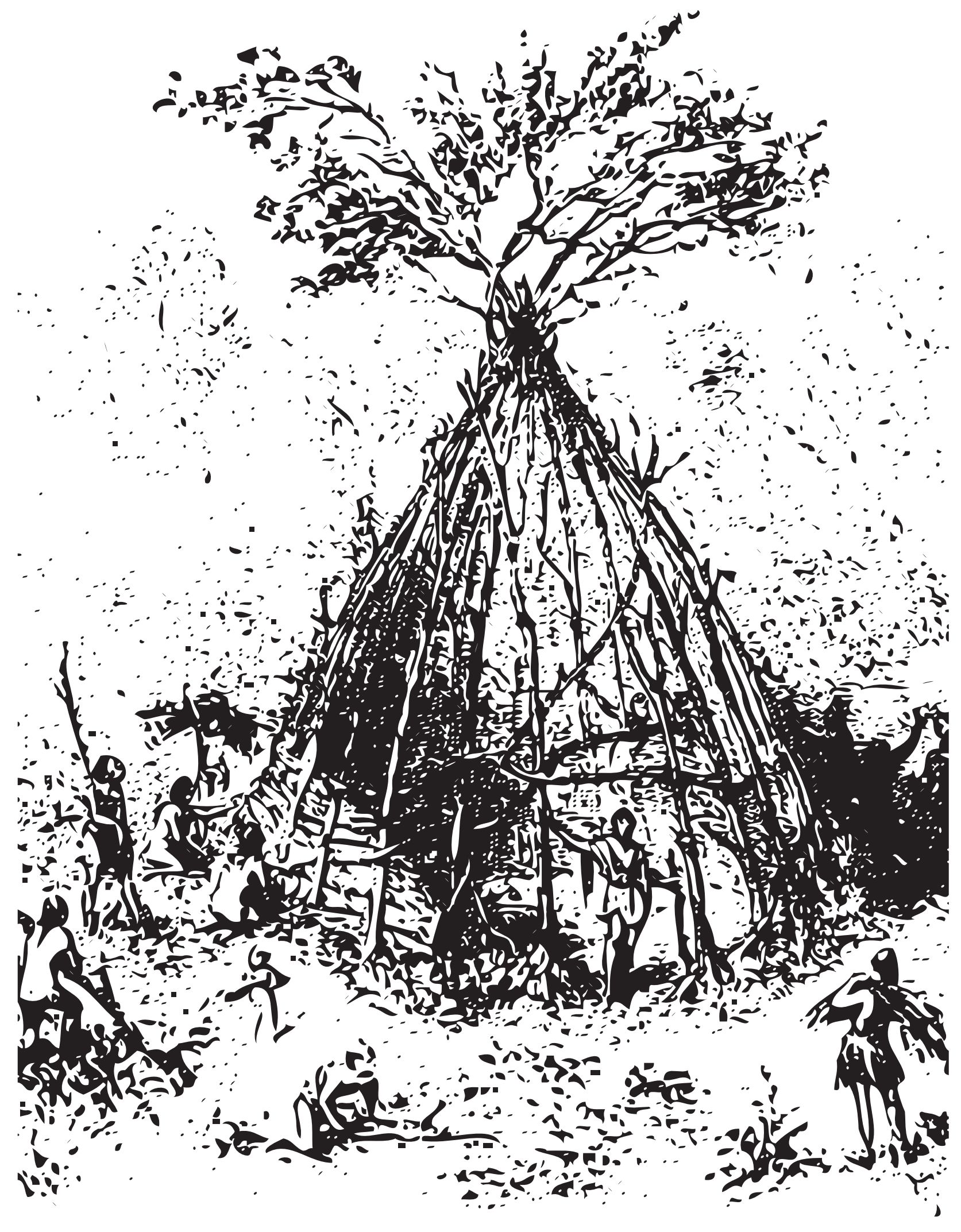




\section{Le Corbusier}

Presented within the chapter of his book, Vers un Architecture, entitled 'Regulating Lines', Le Corbusier's narrative of the primitive temple (altered from the iconic notion of the hut) begins by asserting the dominance that primitive man has over nature. It is man who chooses their building site, fells and clears the trees, leveling the ground. After establishing a tabula rasa upon which to construct primitive man lays down regulating and geometries whose simple mathematics will govern this design juxtaposing it with the disorder which nature presents. The primitive man uses his body as units of measurements ensuring it is to his scale, a human scale with which he can connect. Le Corbusier's man collects wood and materials from the forest and builds his temple in accordance with rationality;

"To build well and distribute his labor, to guarantee the solidity and utility of the work, he took measurements, he introduced a module, he regulated his labor, he introduced order. For all around him the forest is in disorder, its vines, bushes, and tree trunks obstruct him and forestall his efforts." (Corbusier, 1923)

This narrative of the primitive hut focuses on the ability of primitive man's self separation and domination over natural conditions. While this is done through strict governing rational Corb's man is still intimately engaged with the making process. It is through establishing a connection between his body, the temple, and the materials that he is able to construct an appropriate design.

Le Corbusier's primitive temple can be seen as a precursor to his Five Points of Architecture, as detailed in his written works L'Esprit Nouveau and Vers Une Architecture. These Five Points, which echoed the rationality of his primitive temple, drafted the typology for an architecture which culminated in his design of the Maison Domino. This prototypical plan, which went on to inform much of Corb's work, can be interpreted as a modernist approach to the primitive hut, adding to the hut's established historical narrative but responding to architectural concerns embedded in the early 20th century. 

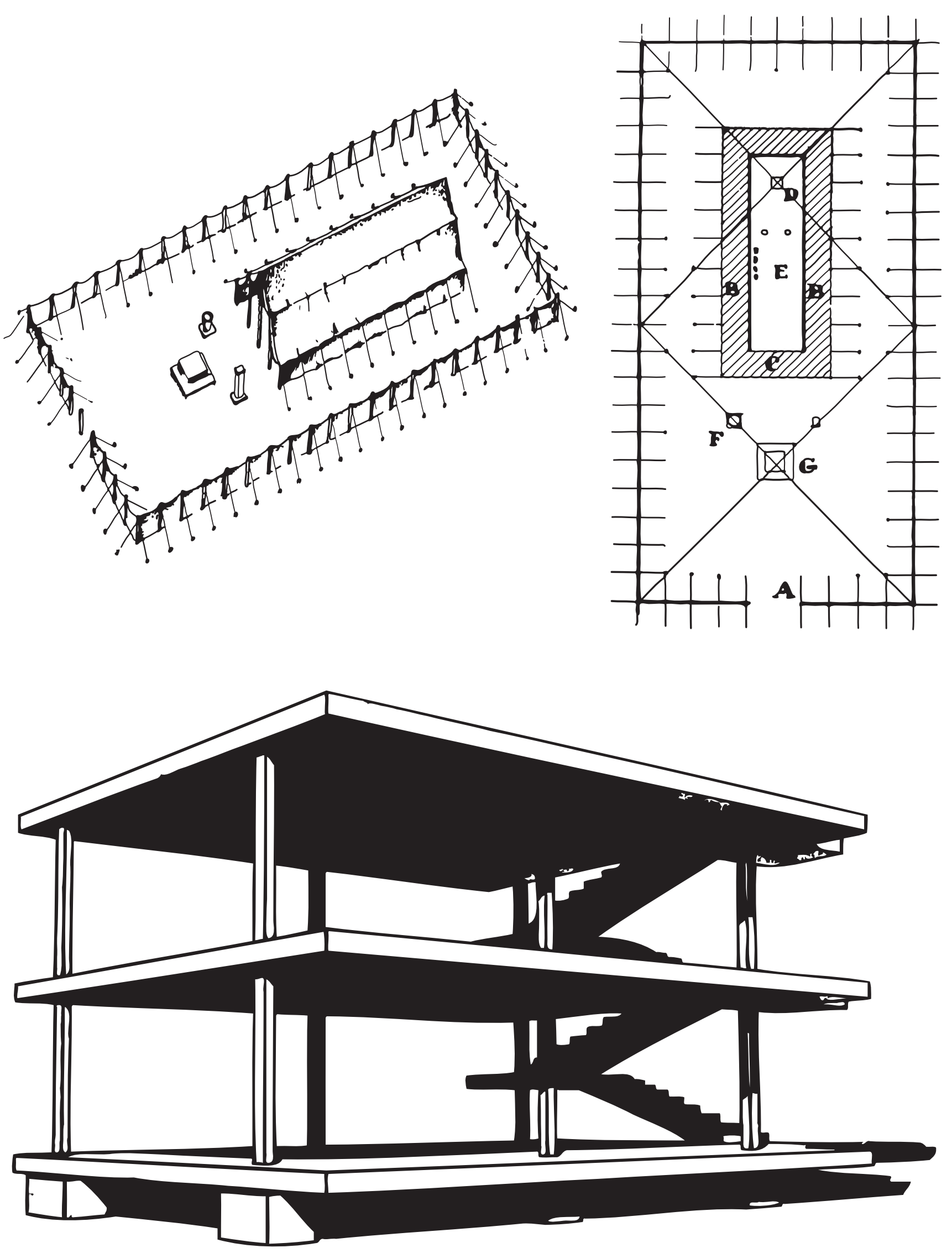


\section{Reyner Banham as illustrated by Francois Dallegret}

In the article "A Home is Not a House", Renyer Banham begins developing his position for a primitive hut as a response to the integration and reliance of modern architecture on systems of comfort, reconsidering the influence this has on architectural typology and form. Banham recalls the iconic image of the campfire as the primary comfort system, noting that "...the space around a campfire has many unique qualities which architecture cannot hope to equal, above all, its freedom and variability." (Banham, 1965, p. 75). It is within architecture's ubiquitous building systems, akin to the contemporary campfire, that Banham believes modern architecture can find an unprecedented versatility of form.

"...when it contains so many services that the hardware could stand up without any assistance from the house, why have a house to hold it up?" (Banham, 1965, p. 70)

Through illustrating "A Home is Not a House", Fancois Dallegret gave form to Banham's architecture; one based on building and comfort systems through which contemporary architecture functions. Eschewing the architectural envelope and connotations of shelter, Dallegret's 'Environmental Bubble' and 'Anatomy of a Dwelling' illustrations embody an architecture which, according to Banham, is based on the freedom which contemporary building systems allow. Within this discourse, Banham and Dallegret present the architect as maker of environments and systems allowing the replacement of the architectural envelope with far more adaptive and fluid forms. 

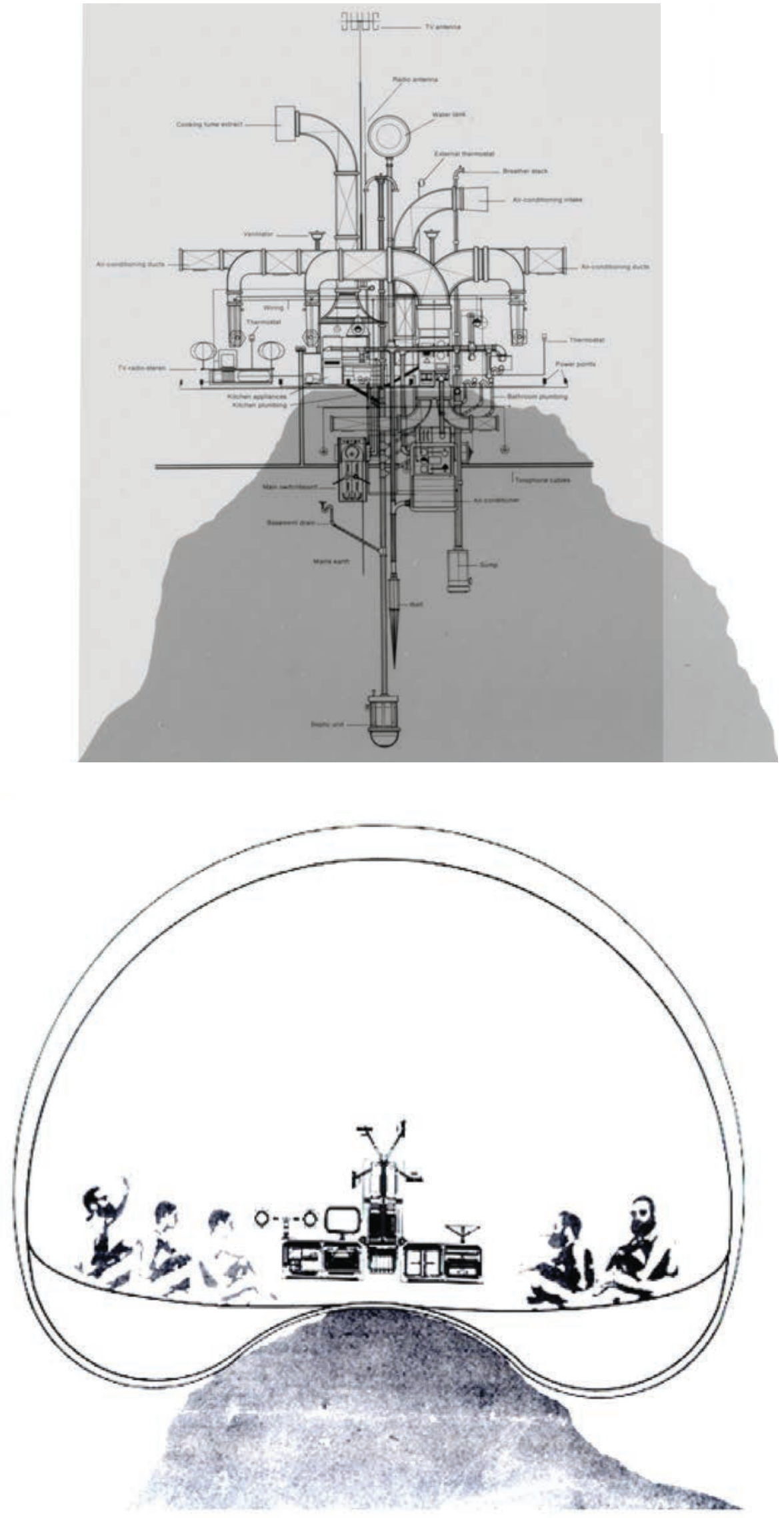


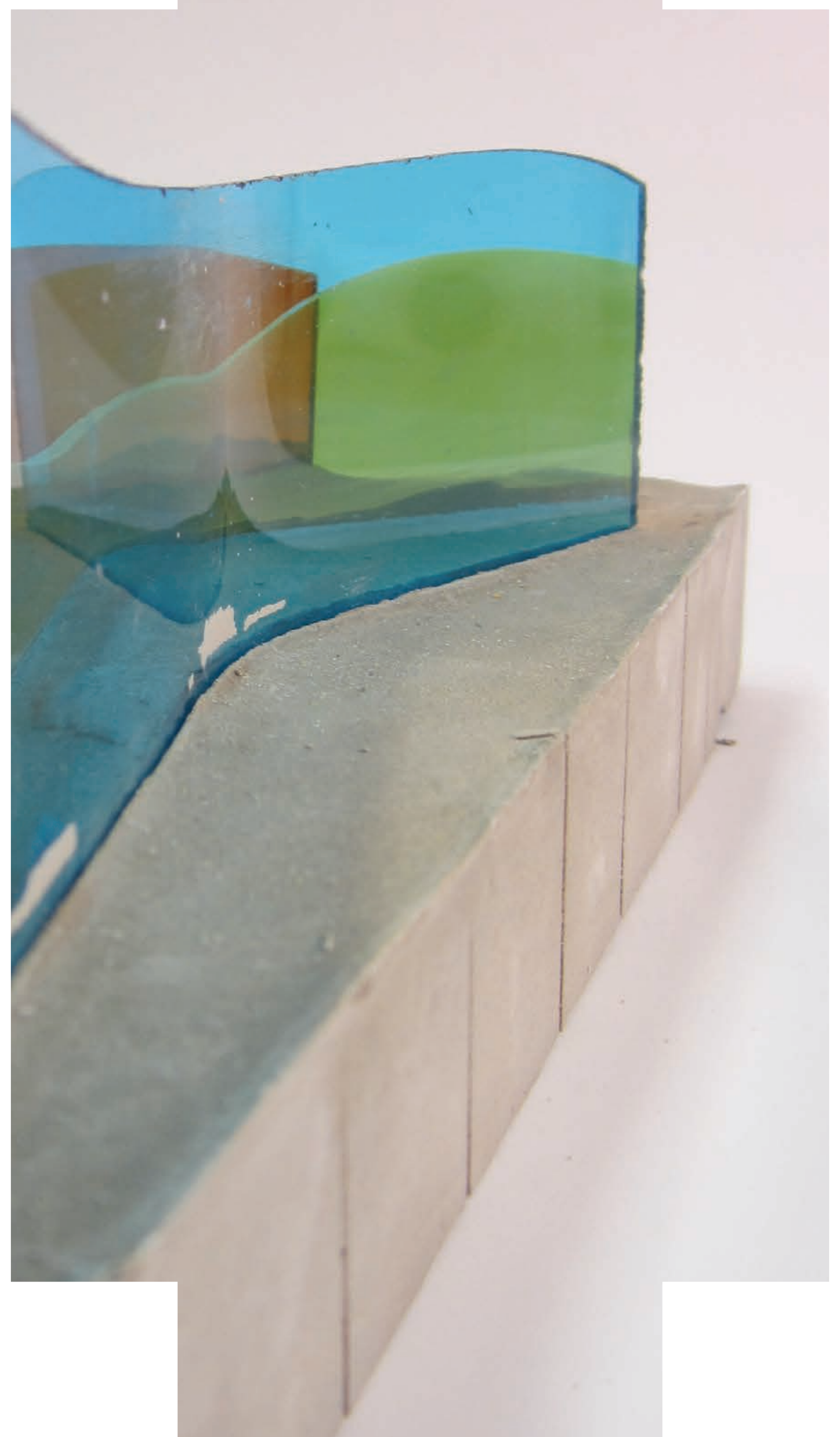




\section{chapter 09}

\section{Possibilities of Knowing}

In commencing the design of the Primitive Hut [Re]-Engaged a process of design was employed which suspended virtualized methods of architectural development in favour of a methodology which positioned making as the primary means of exploration. This centralized the physical creation of prototypical artefacts in the design process in an attempt to produce exploratory and demonstrative artefacts which would stimulate a holistic process of design. Subsequently, this would occur through an experiential making process through which an understanding of the Primitive Hut [Re]-Engaged could develop both consciously and unconsciously. The subsequent process of design through making was governed by several strategies as detailed in the previous chapter (Ch. 07: A Manifesto of Making). These strategies were employed to test design decisions tangibly and reveal unforeseen design opportunities unique to the creative process of making. 
including; engaging making as the fundamental means of design exploration, using materials which were as close to (if not the) materials being suggested, using methods of assembly which were as close to (if not the) appropriate methods, working at a scale which allowed the desired design intentions to be expressed fully, and engaging making as a means of exploring design boundaries by pushing material and tool limits. The produced prototypical artefacts were further explored post-production through photography and collage to provide insight into inherent design opportunities which may have been overlook during the making process.

The succeeding versions of making (entitled Making Version \#) were developed fluidly over time in relation to the making process in order to draw out and develop a conceptualized design for the Primitive Hut [Re]-Engaged. Each making version was an integral component of the whole project, with each subsequent version only being realized and created in response to the one previous to it. Interestingly, while a bulk of the design decisions during the making process were consciously decided upon, the amount of information which was gathered tacitly through a kinetic means of design and subsequent analysis was far greater. Making versions one through five are direct responses to the procedural design issues identified in the bulk of this thesis, while making version six responds to the architectural manifesto preceding it which explores an architectural typology and position steeped in a design methodology which centralizes making as a developmental machine. 


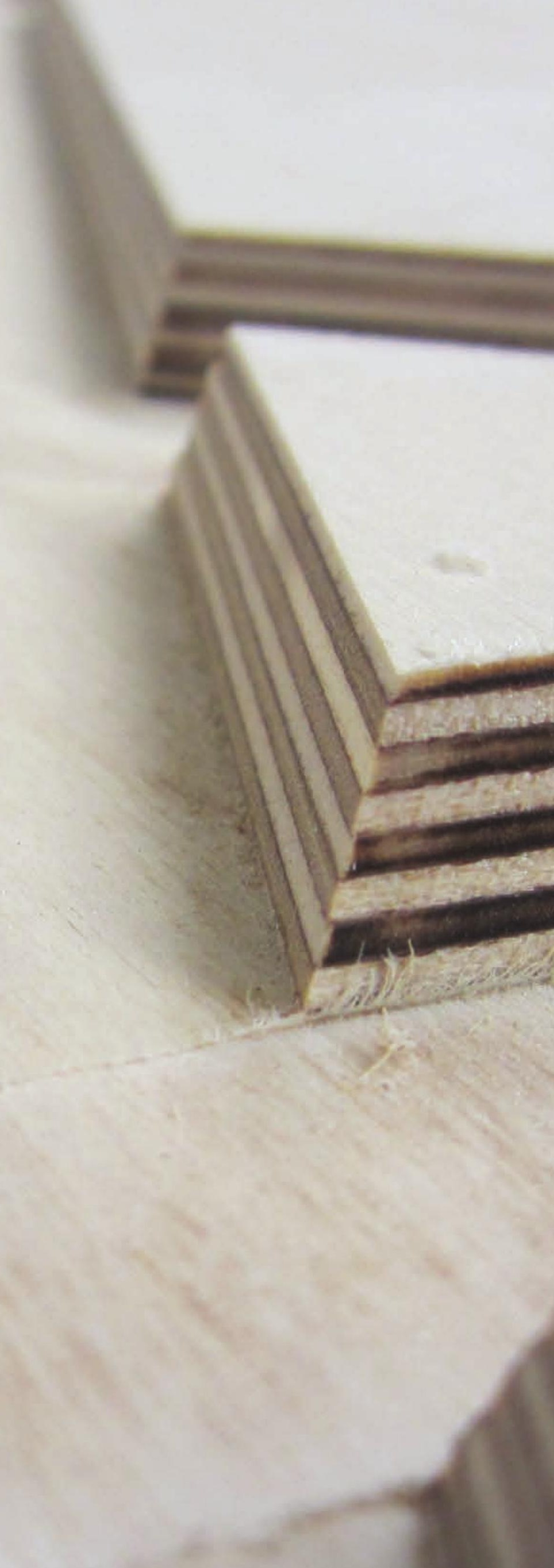


Making Versions
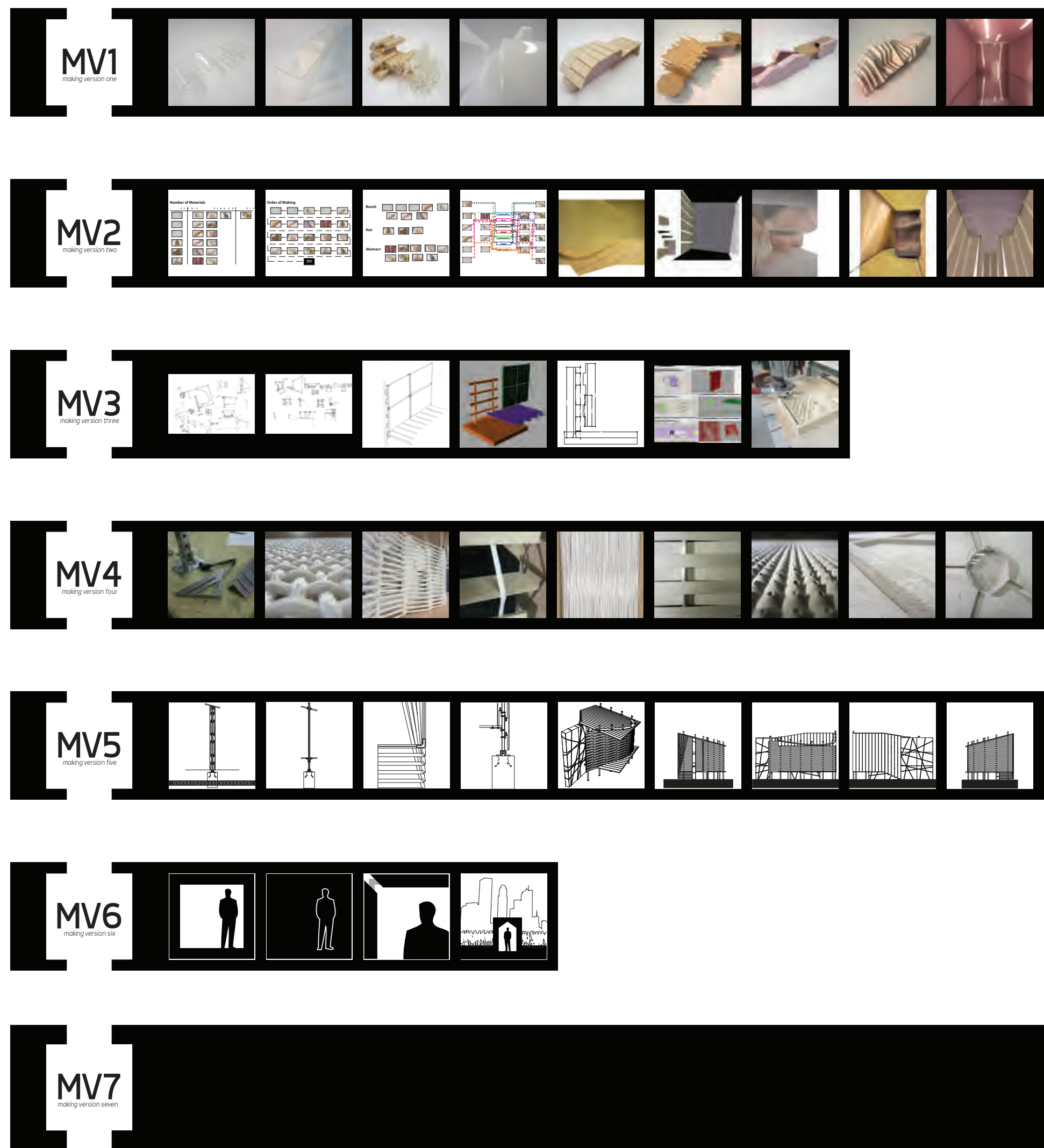

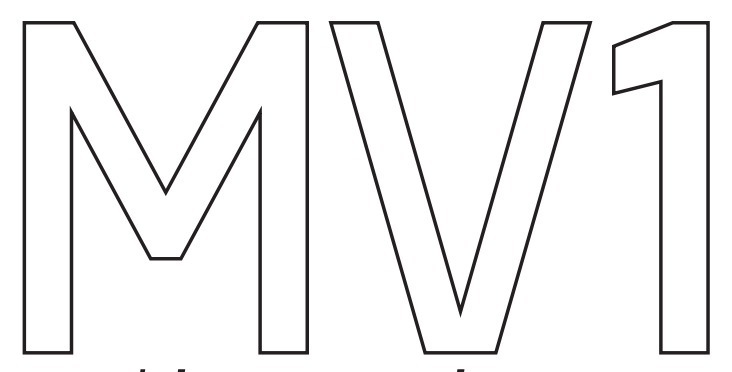

making version one 


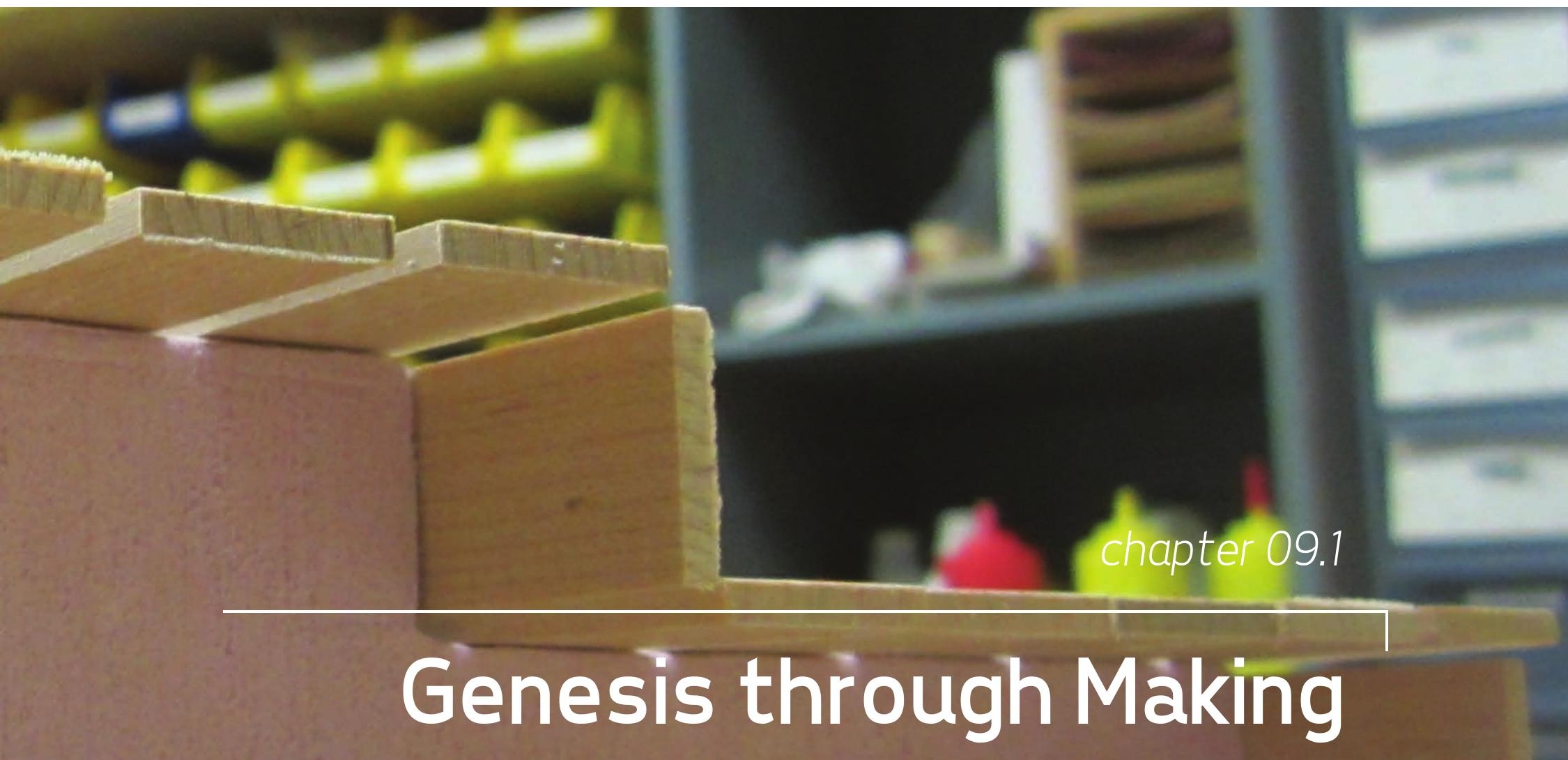



Making Version 1: Genesis through Making engaged making as the initial means of commencing the design process for the Primitive Hut [Re]-Engaged. The construction of architectural artefacts (both formal and abstract) was undertaken as a way to engage with a materially based process of design and explore various architectural conditions and the inherent material properties in which they are founded. These artefacts (Figure 73-92) were made as a means of developing exploratory and communicative tools for analysis both during and after the creative process. They were developed free from the typological and programmatic restraints of form driven design rather exploring the manner in which matter and its properties are able to contain architecture within them. These physical models are further explored and analyzed in the subsequent sections of the design component of this thesis. 
MV1 series one
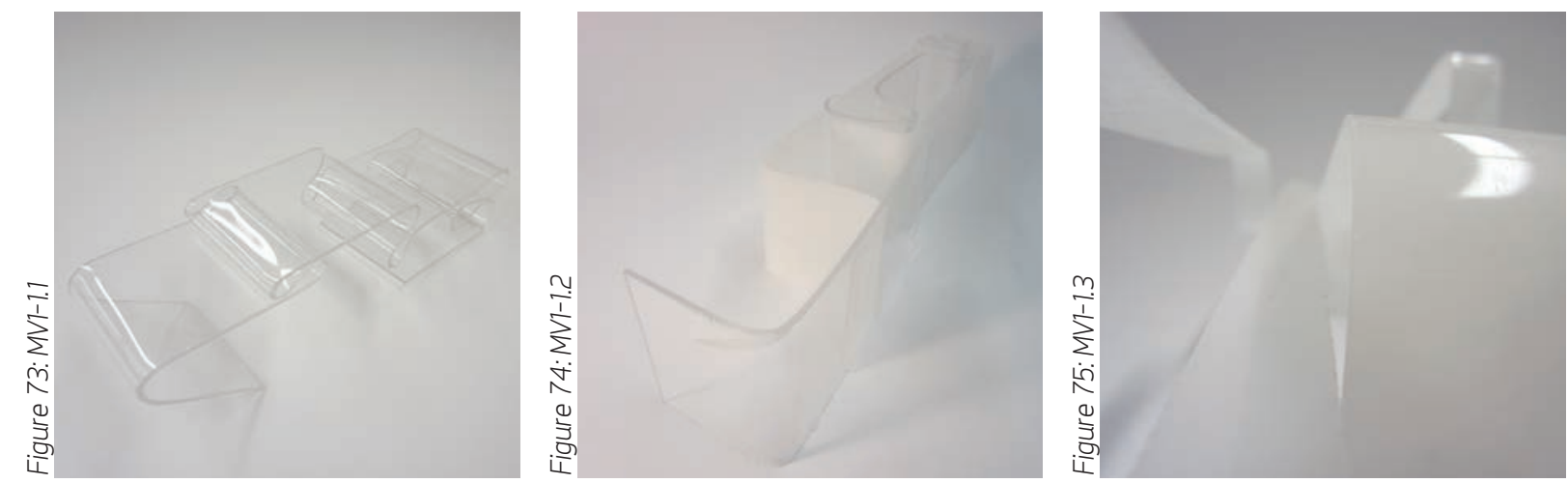

MV1 series two
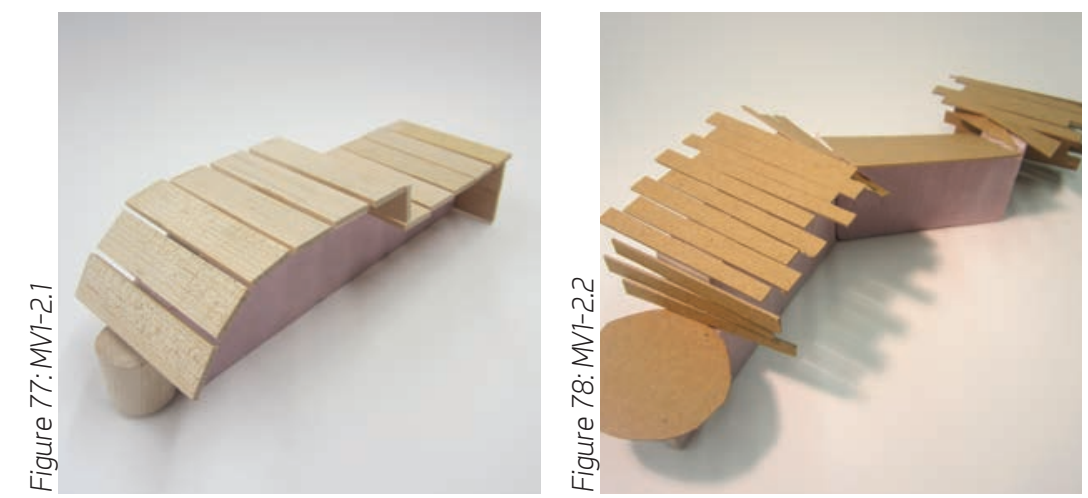

MV1 series three
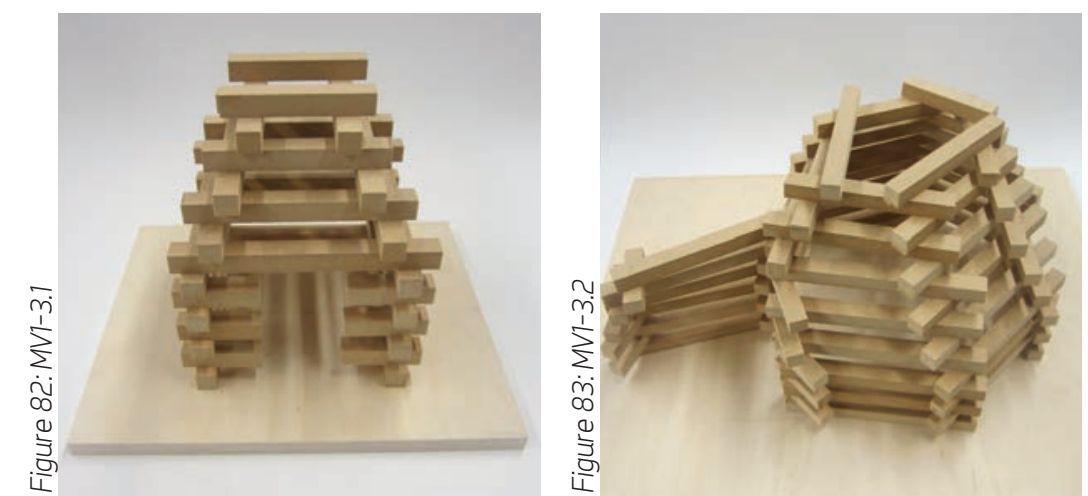

MV1 series four
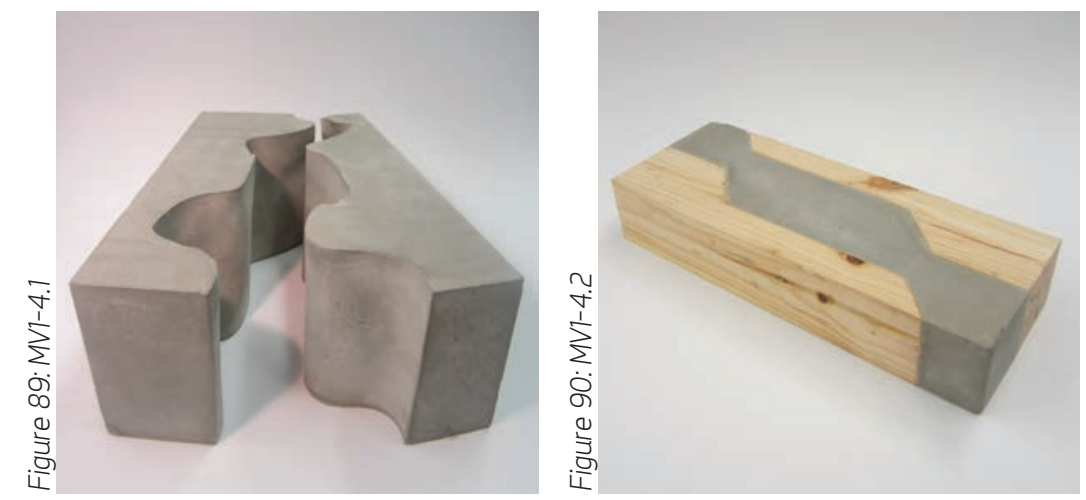

m.
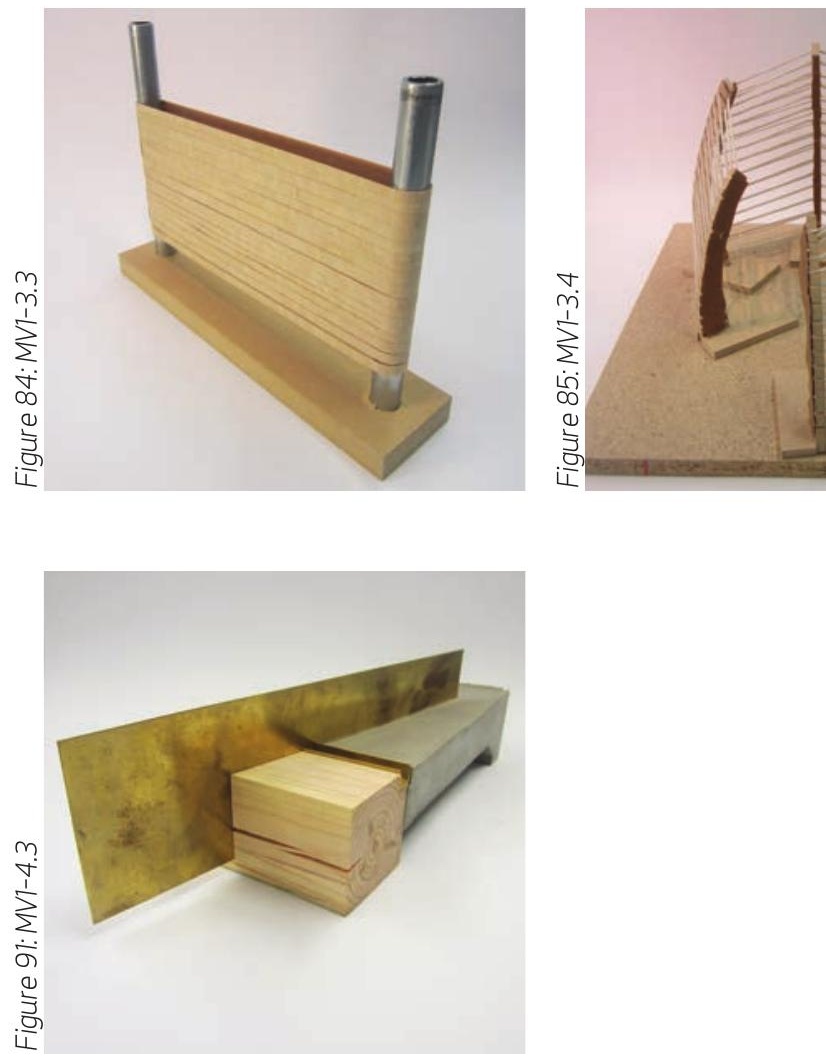


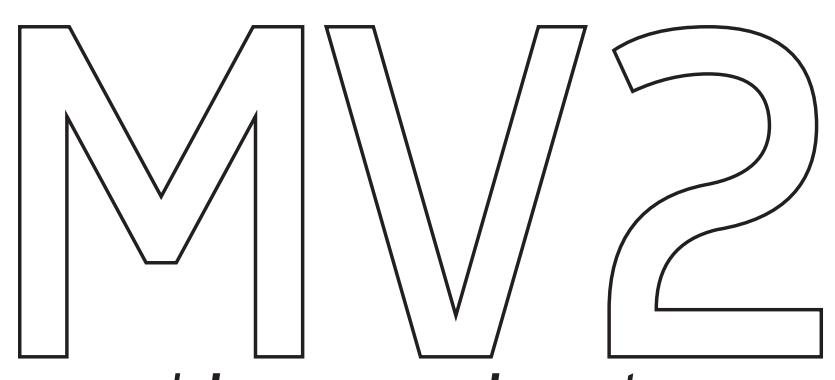

making version two 


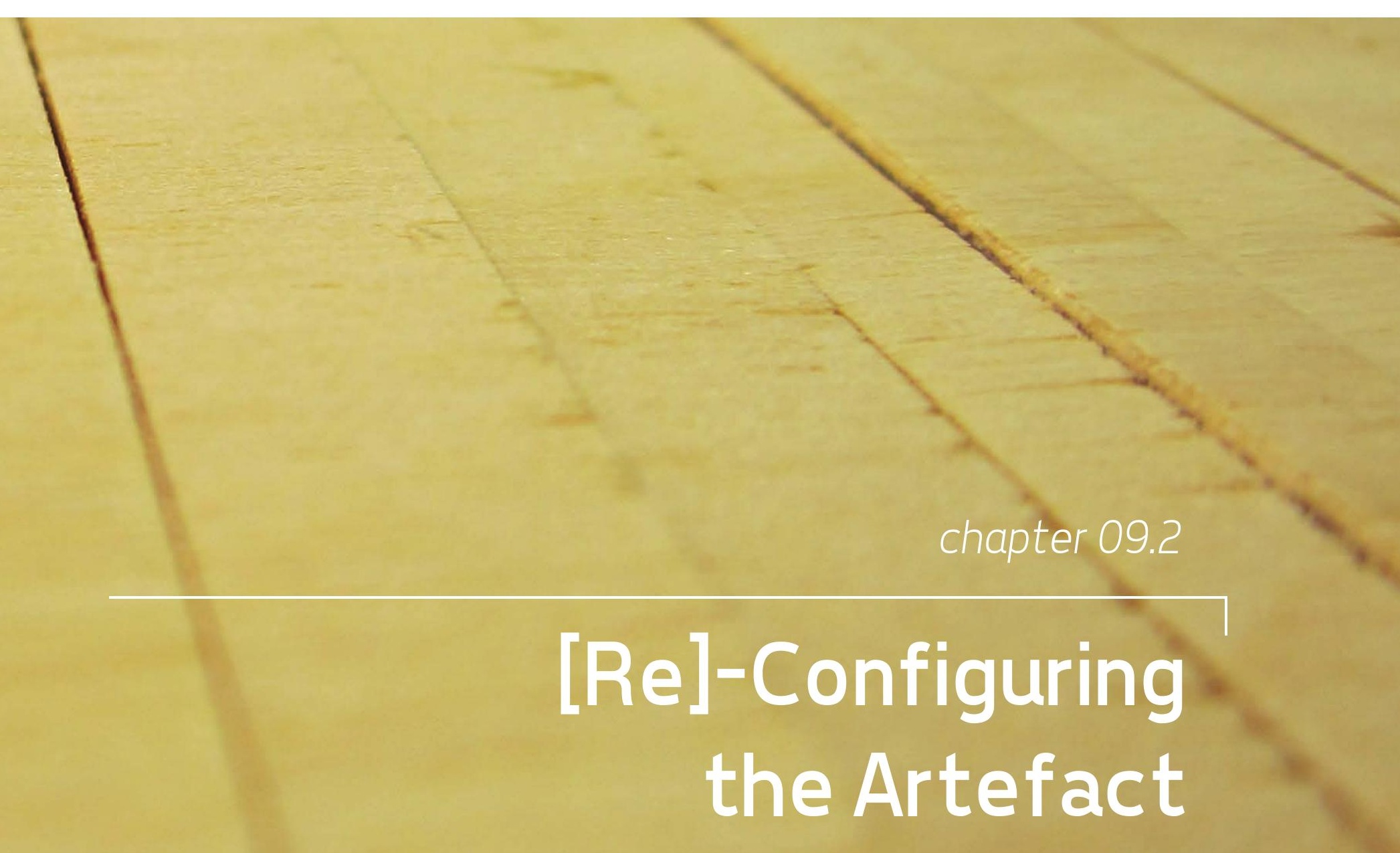


Figure 93: MV1Detail Figure 94: MV1Detail
Making Version 2: [Re]-Configuring the Artefact engaged the previously made prototypes through photography (Figures 95-113), diagrammatic analysis (Figures 114-116), and collage (Figures 117-122) as a means of drawing forth the inherent architectural conditions present. MV2 explores the affect which variances in perception of scale can be employed to visualize these artefacts materiality, components, details, connections, exterior and interior conditions, and lighting. The preconceived static understanding of the model as a tool of representation was reconfigured in order to allow these prototypes to take on an informative role for the remainder of the design and making process; exemplifying the crucial and primary role which making has in the understanding, development, and design of architecture. 


\section{Photography}

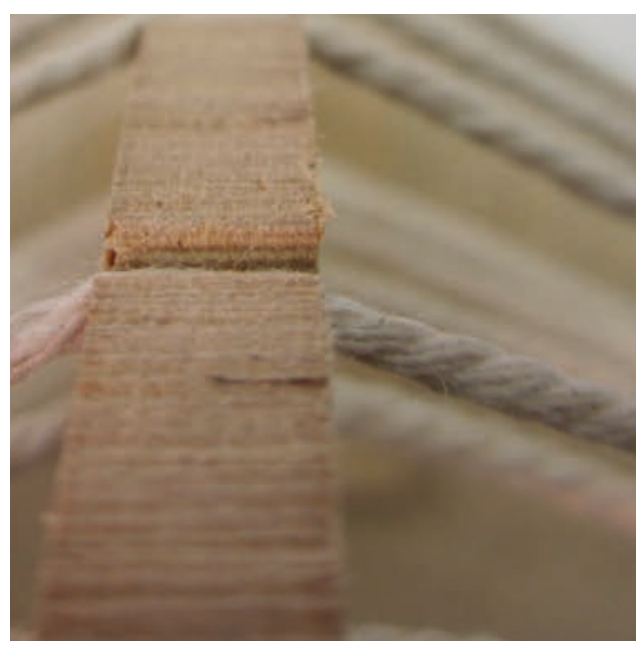

Figure 95: MV2-P1

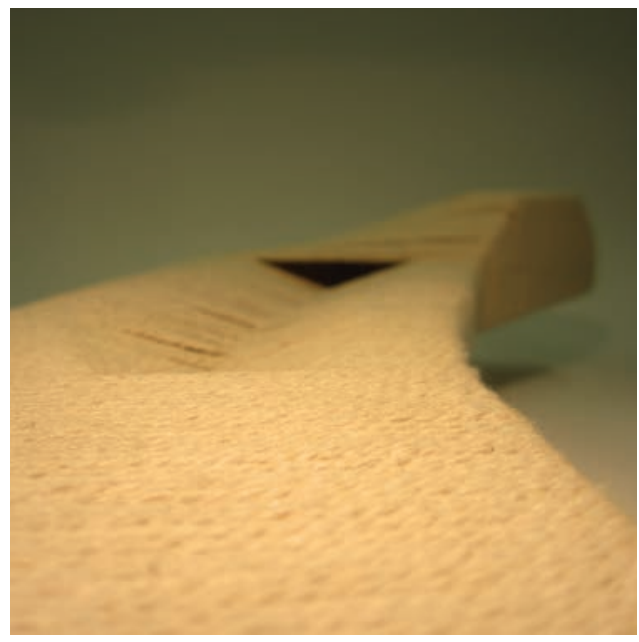

Figure 101: MV2-P7

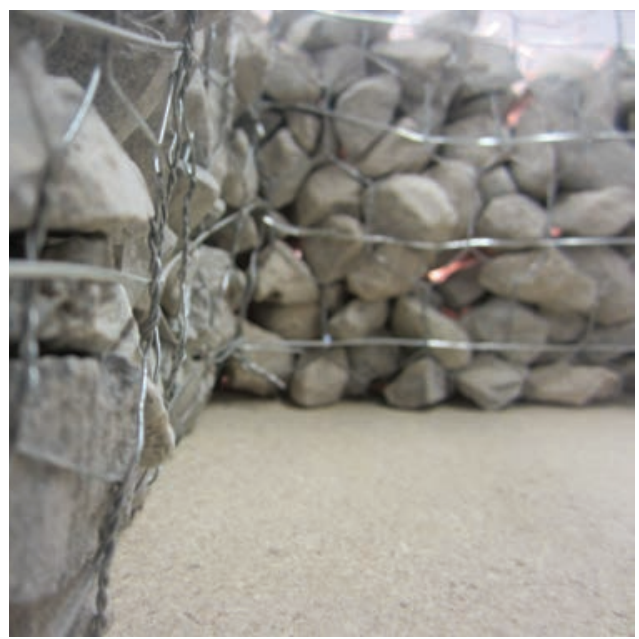

Figure 107: MV2-P13

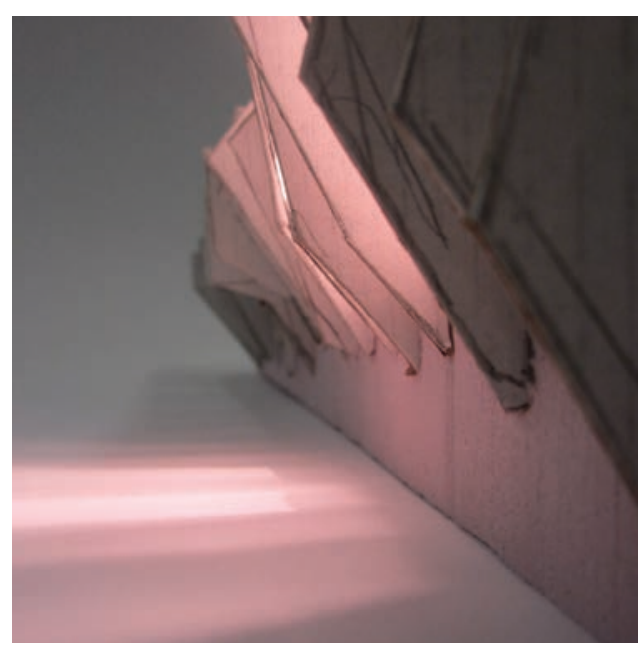

Figure 96: MV2-P2

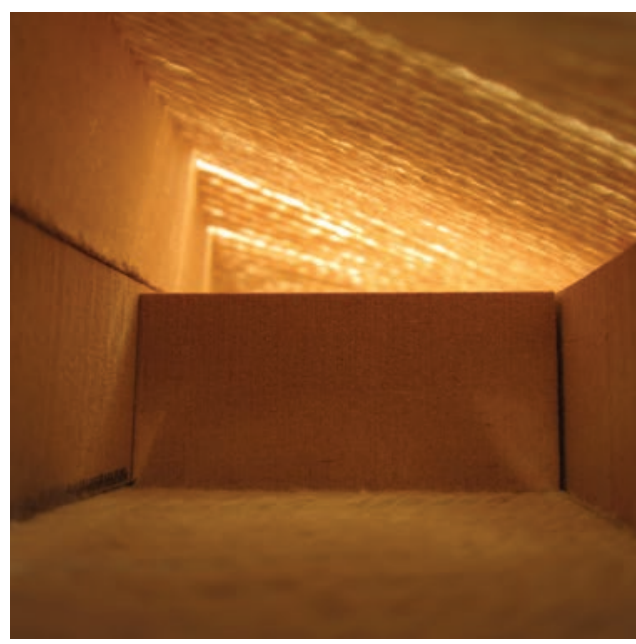

Figure 102: MV2-P8

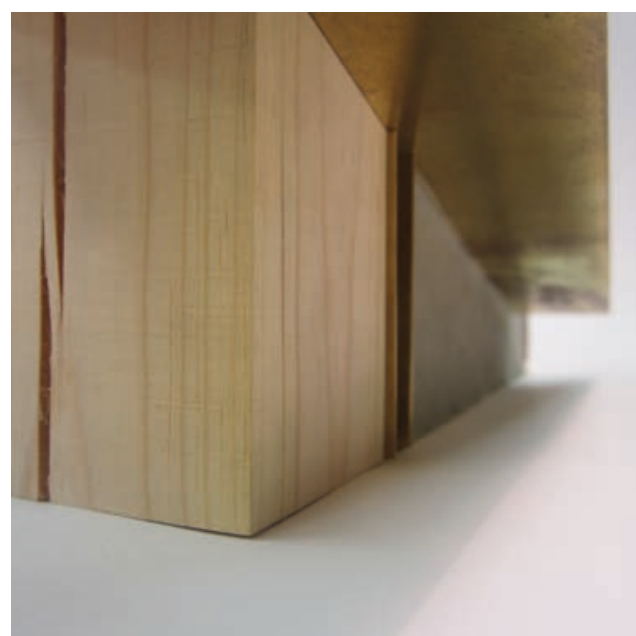

Figure 108: MV2-P14

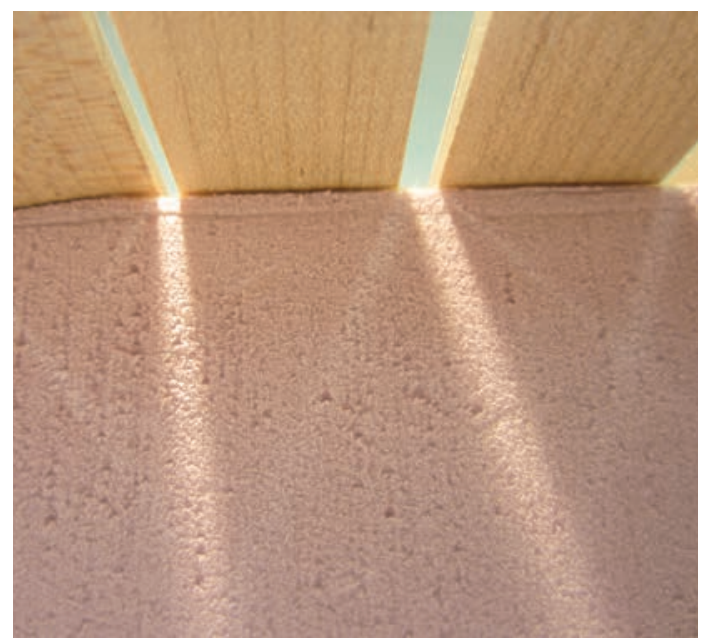

Figure 97: MV2-P3

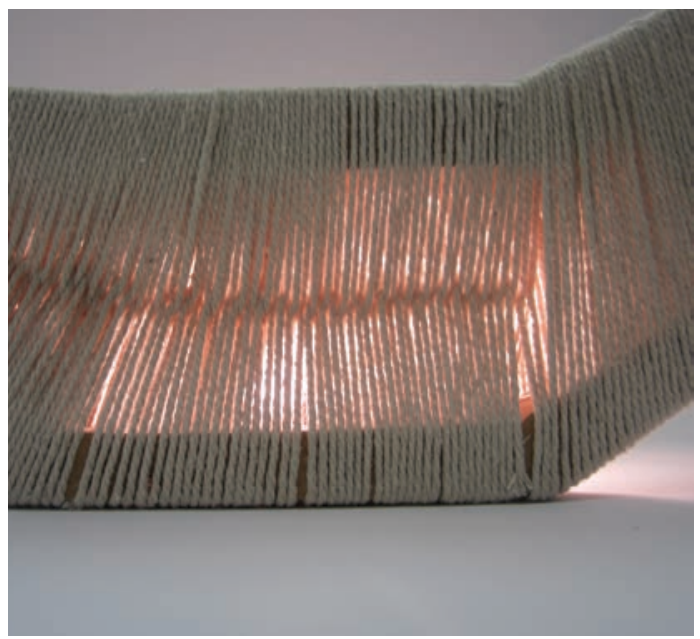

Figure 103: MV2-P9

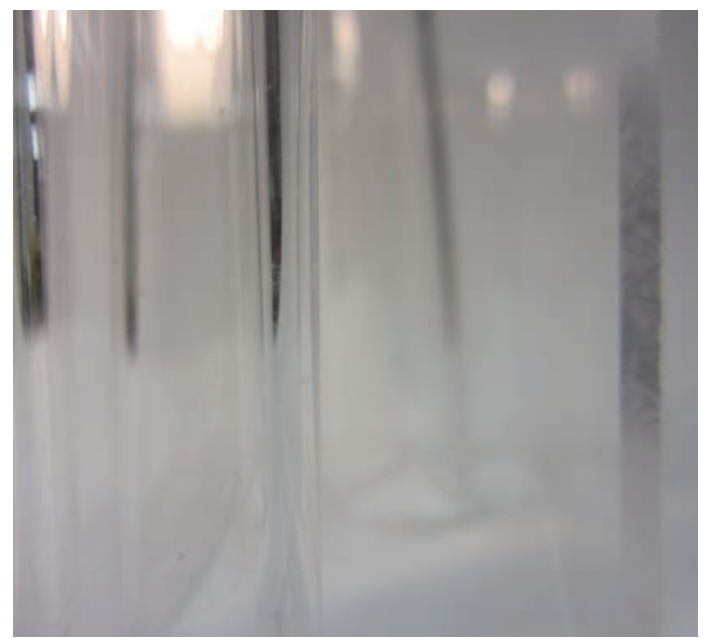

Figure 109: MV2-P15 


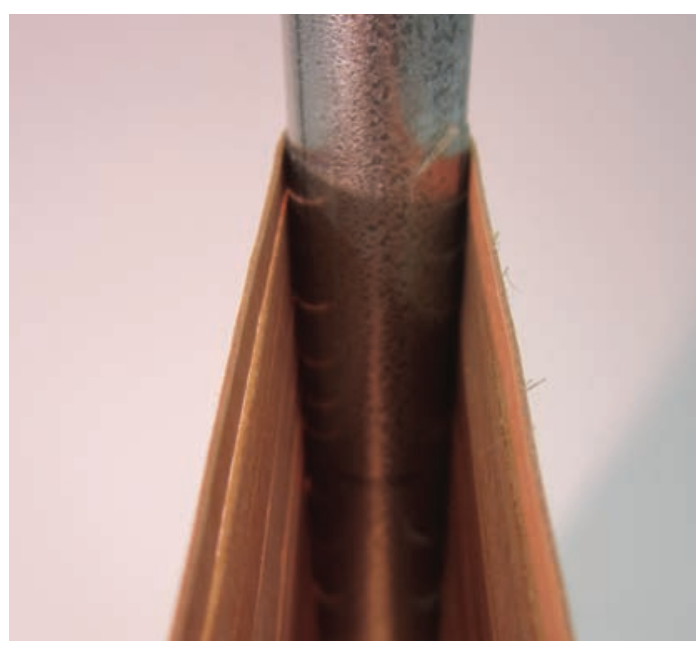

Figure 98: MV2-P4

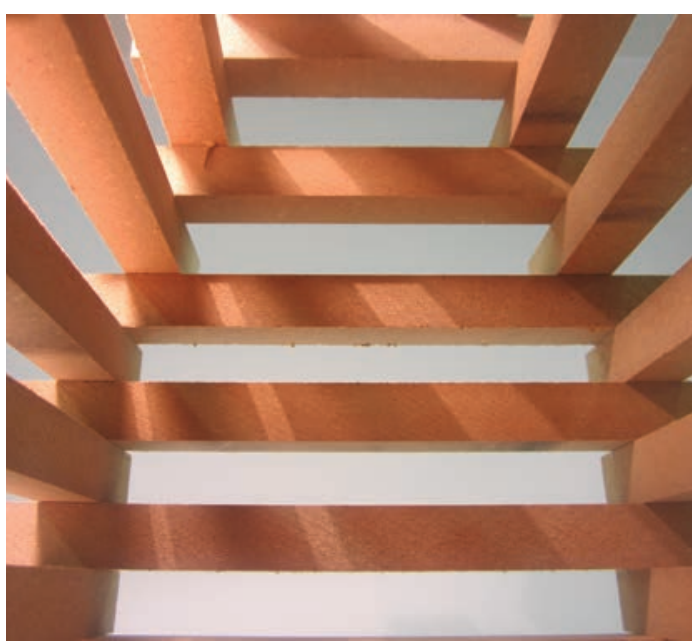

Figure 104: MV2-P10

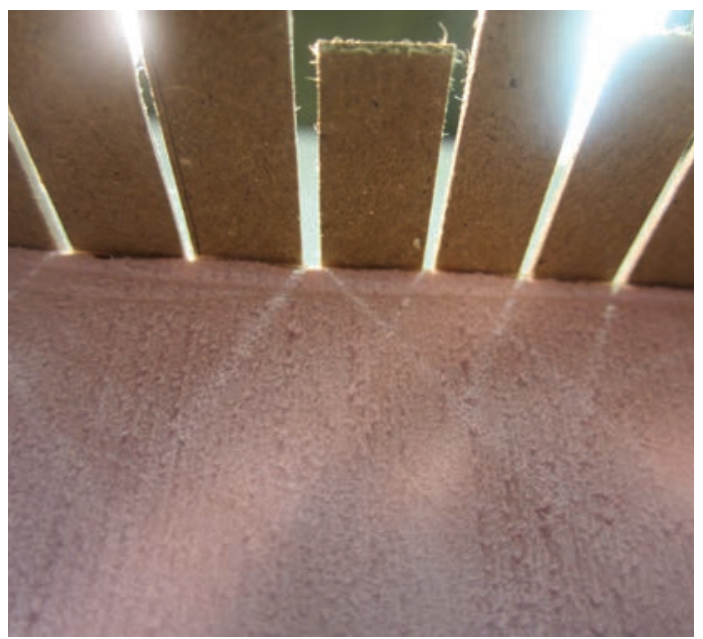

Figure 110: MV2-P16

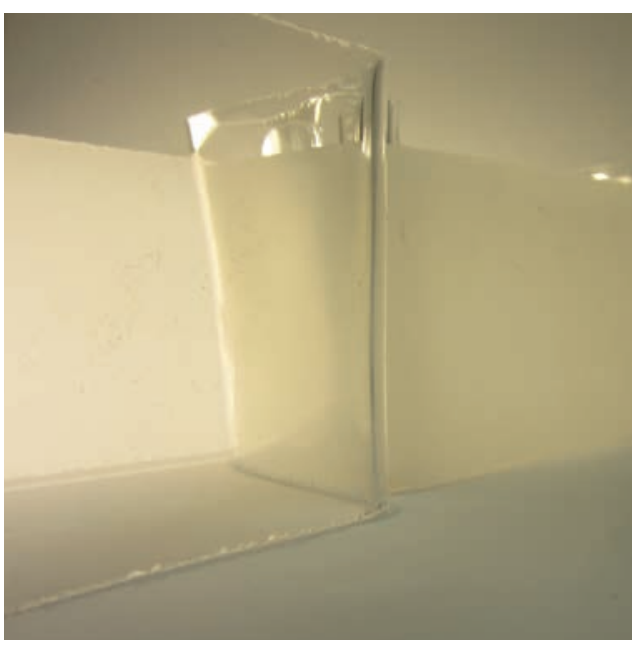

Figure 99: MV2-P5

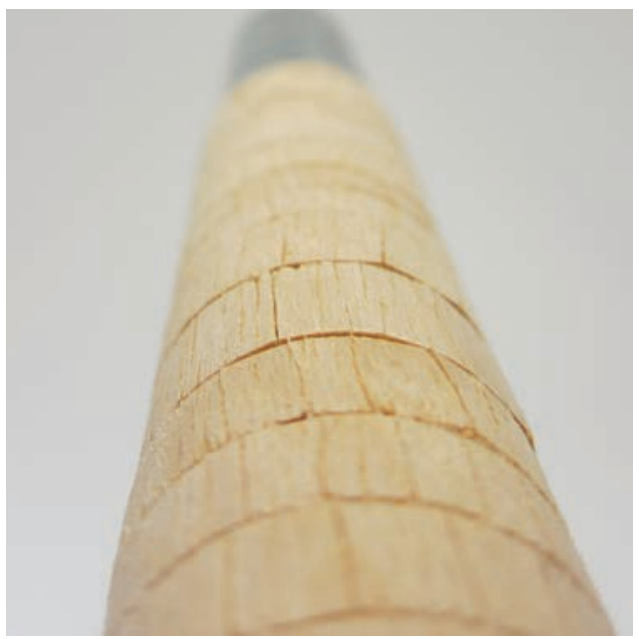

Figure 105: MV2-P1

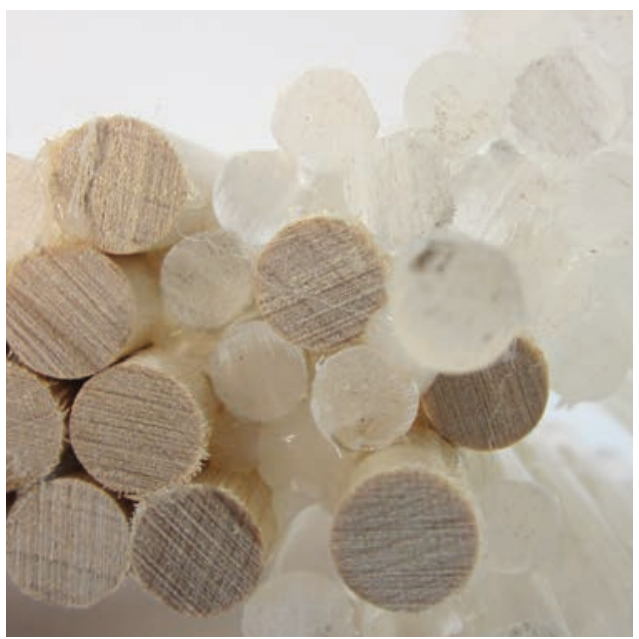

Figure 111:MV2-P17

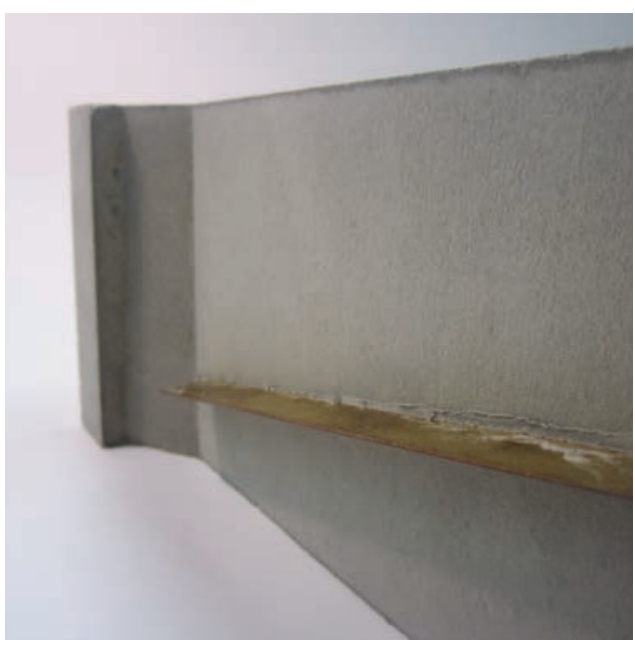

Figure 100: MV2-P6

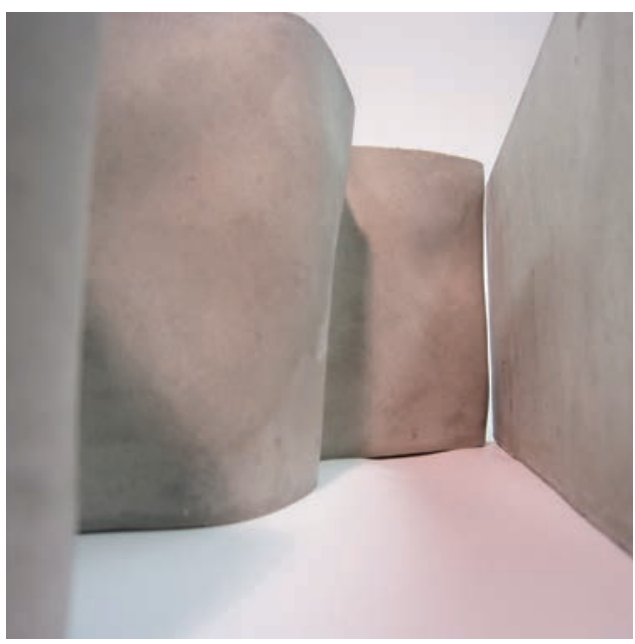

Figure 106: MV2-P12

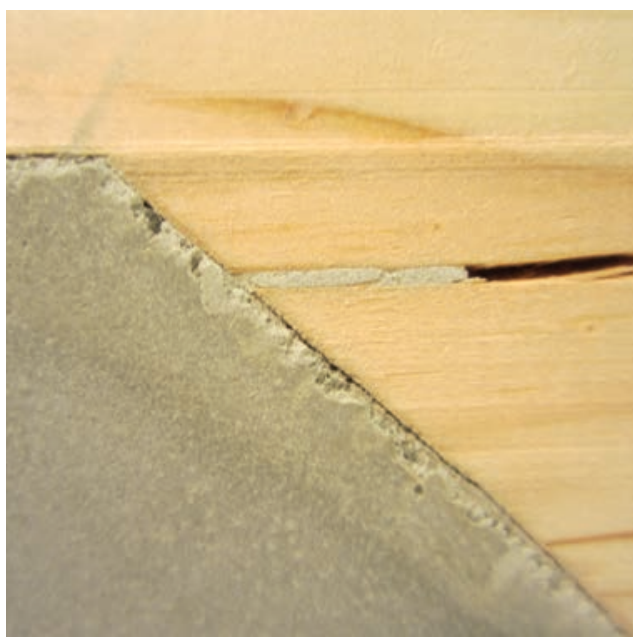

Figure 112: MV2-P18 


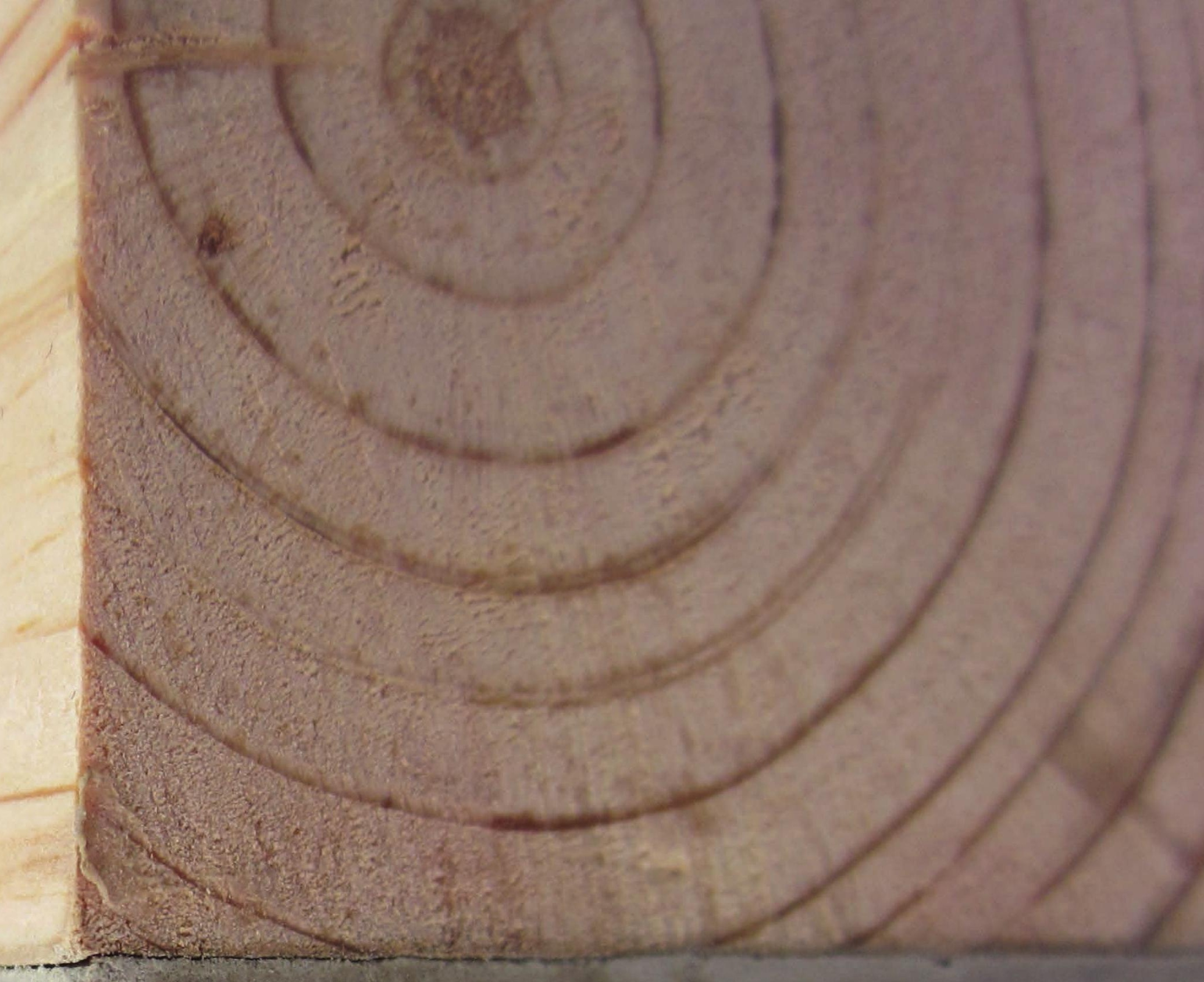

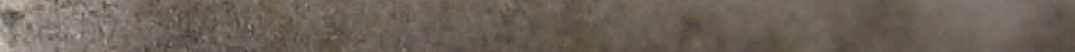

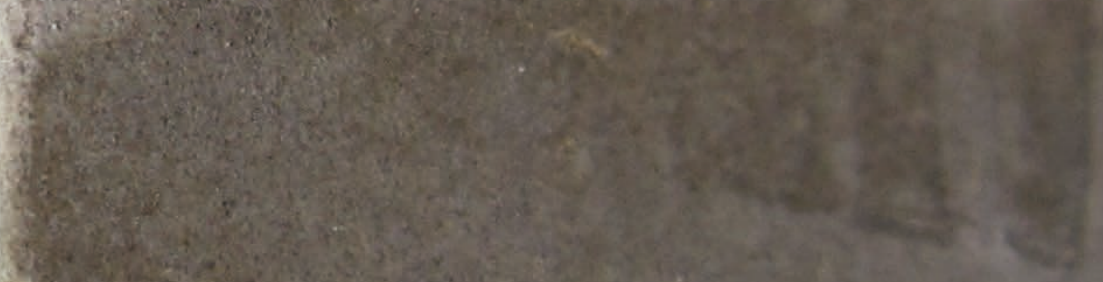

3

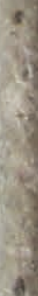




\section{Diagrammatic Analysis}

Construction Sequence

Figure 114: MV2-DA1

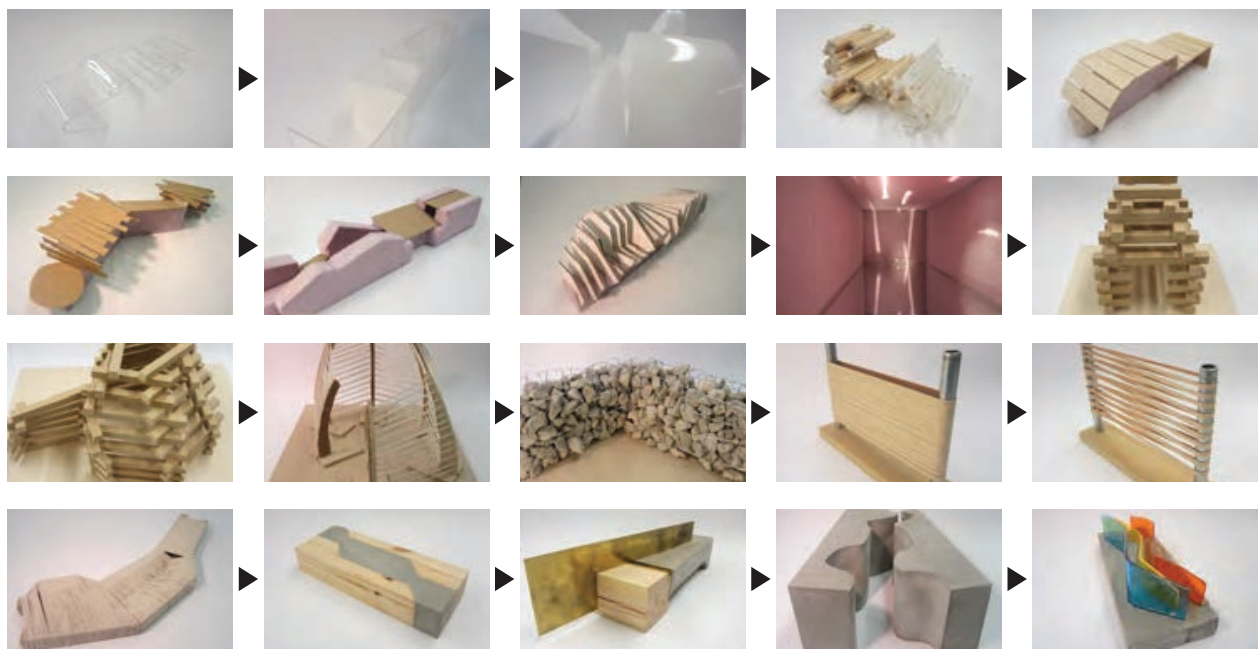

Quantity of Materials
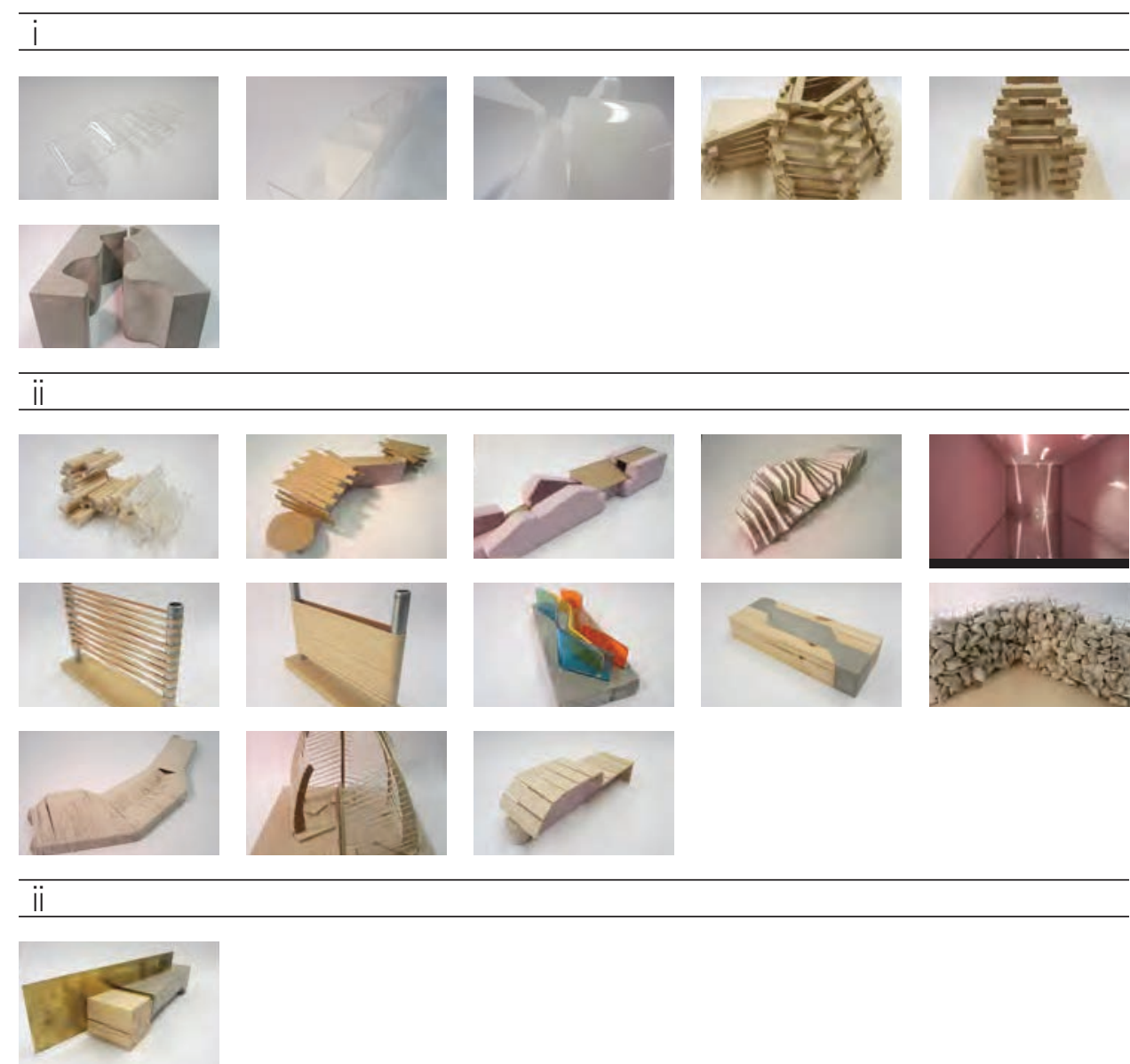


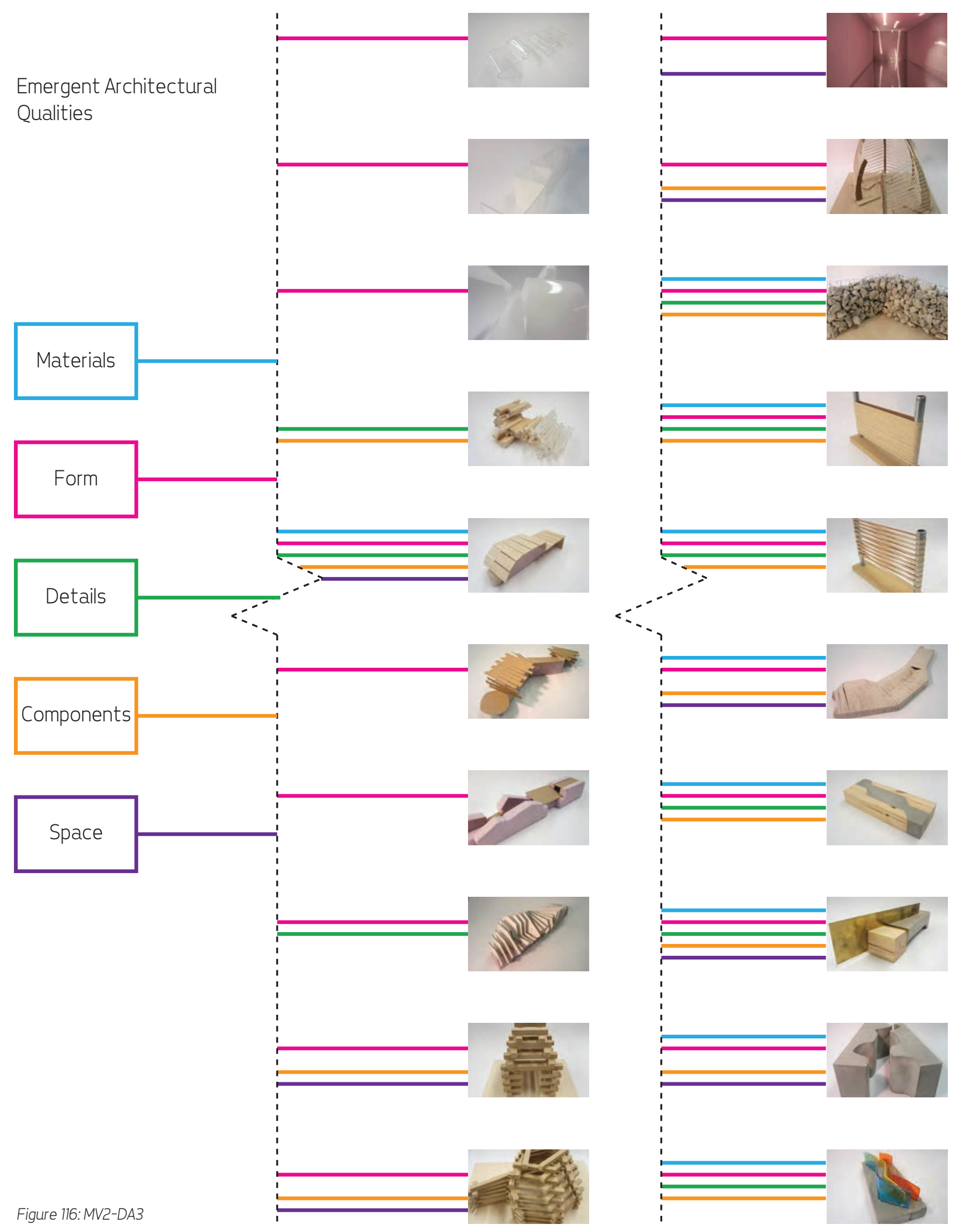




\section{Collage}

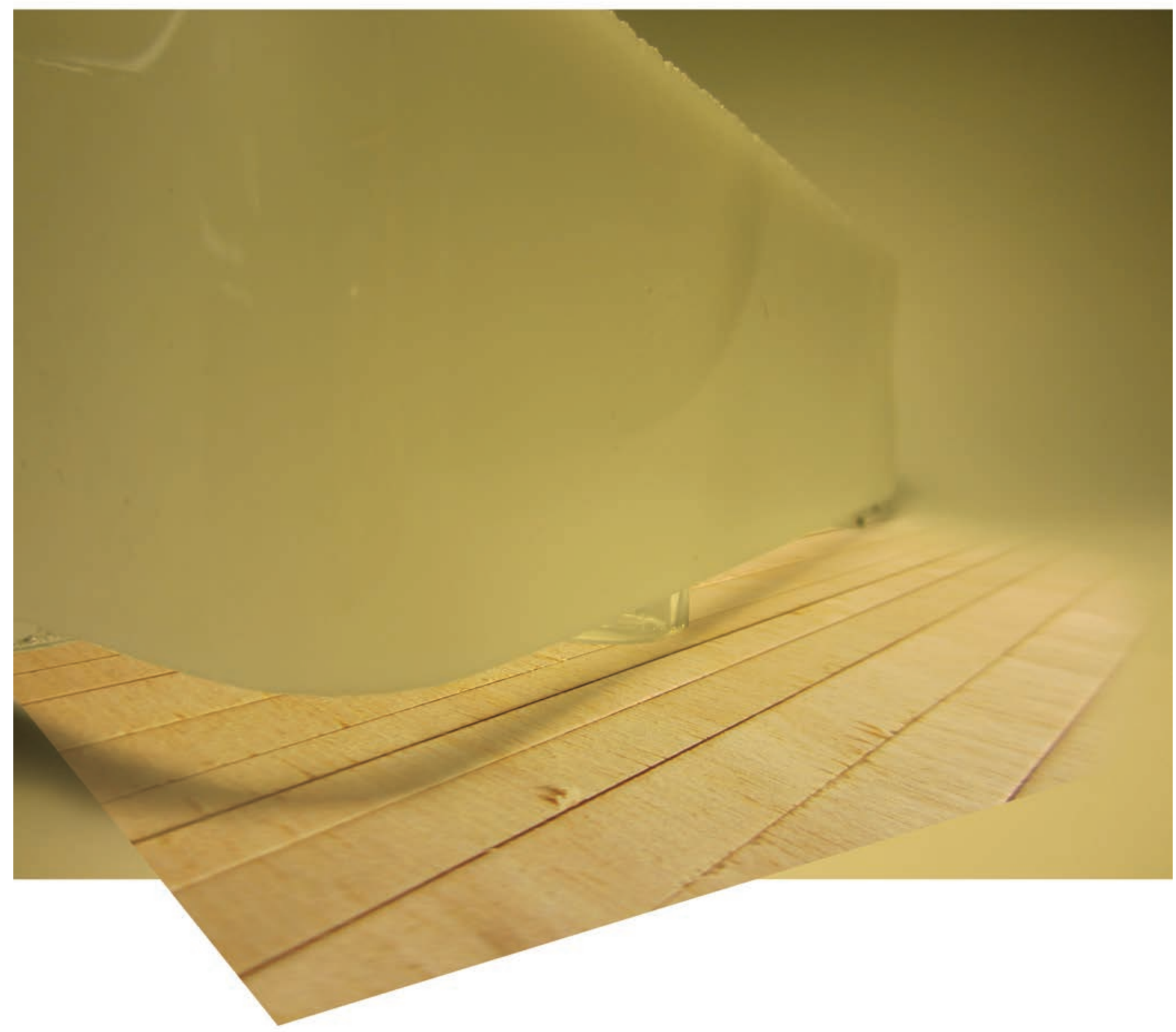

Figure 117: MV2-C1 


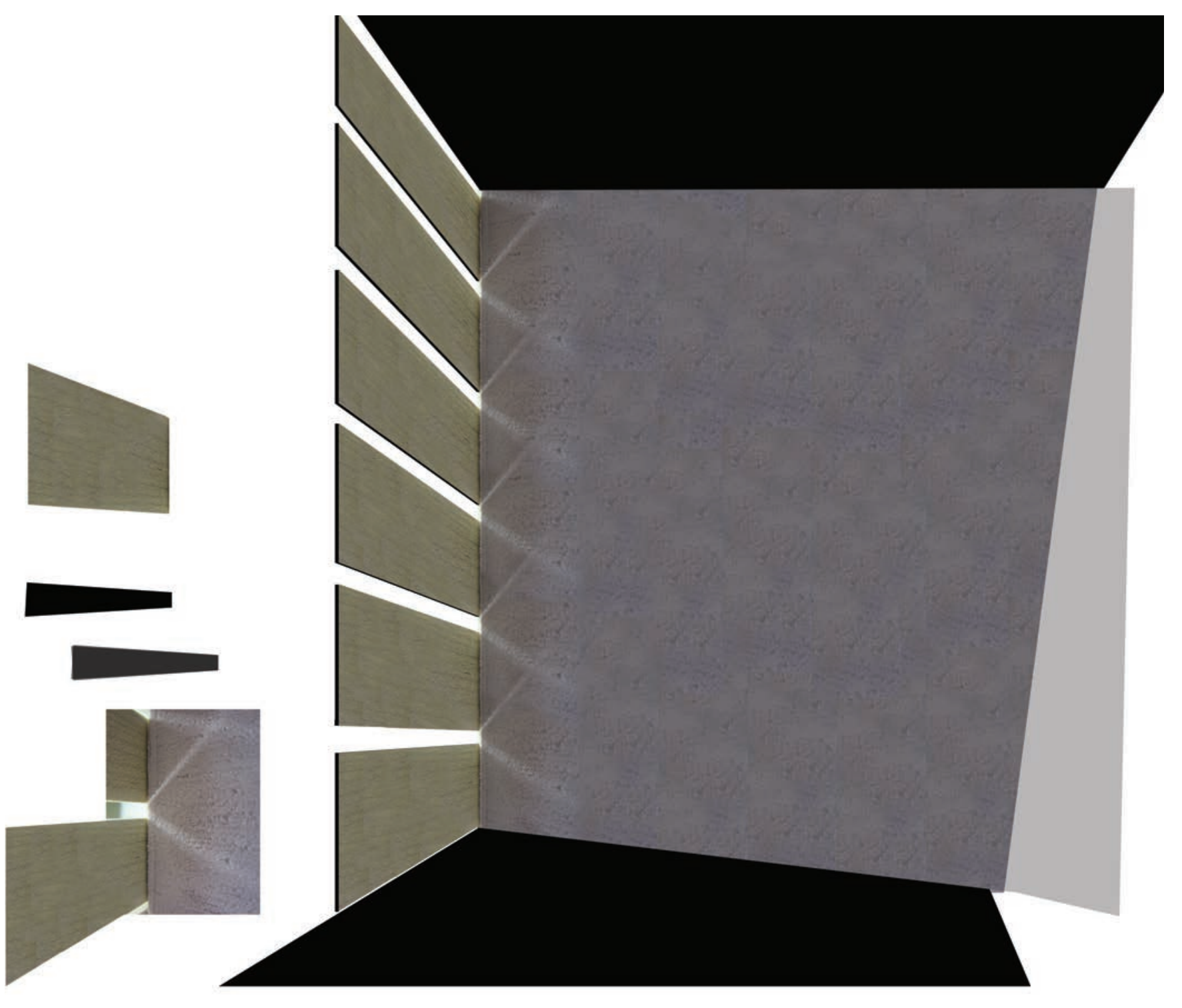

Figure 118: MV2-C2 


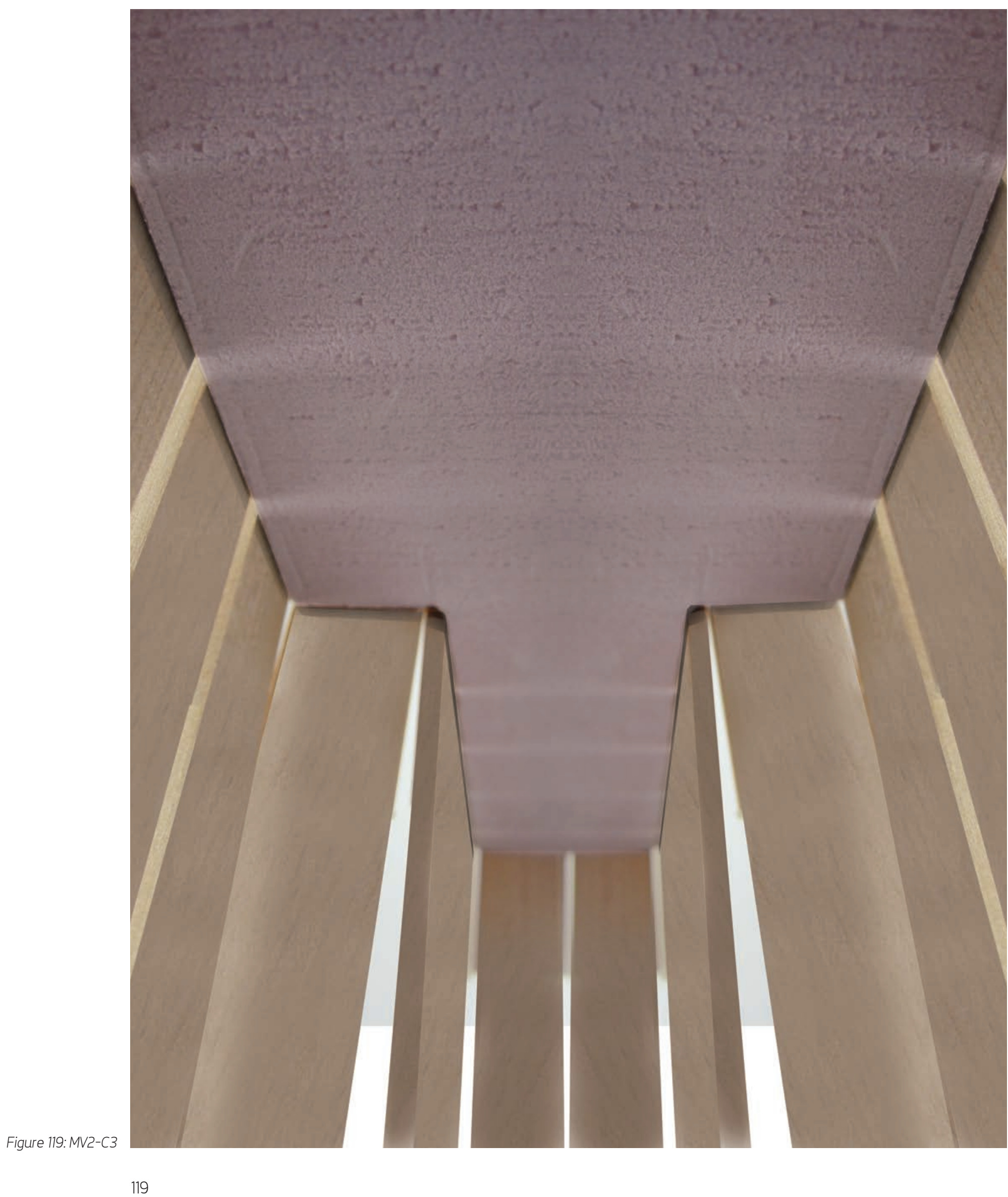




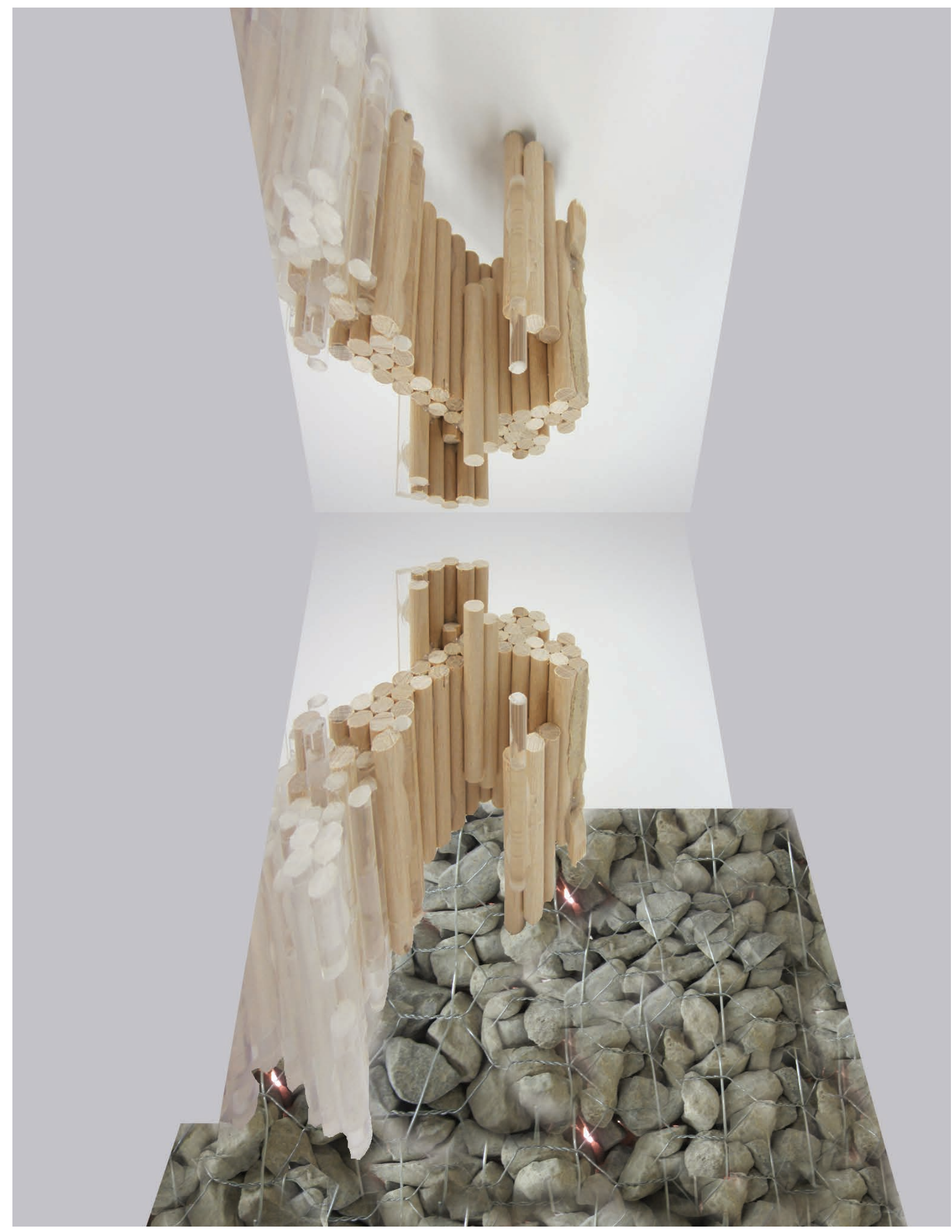

Figure 120: MV2-C4 


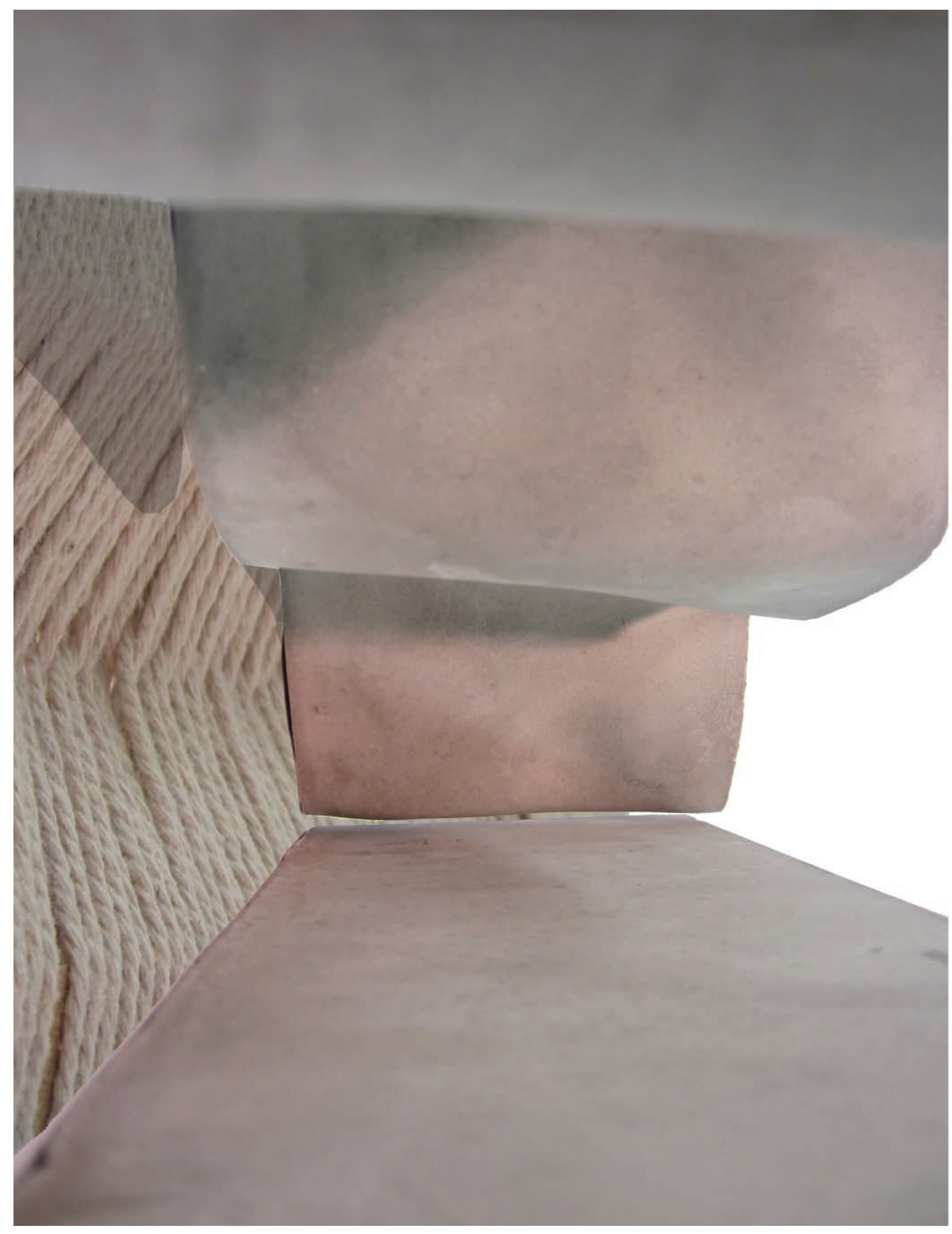

Figure 121: MV2-C5 


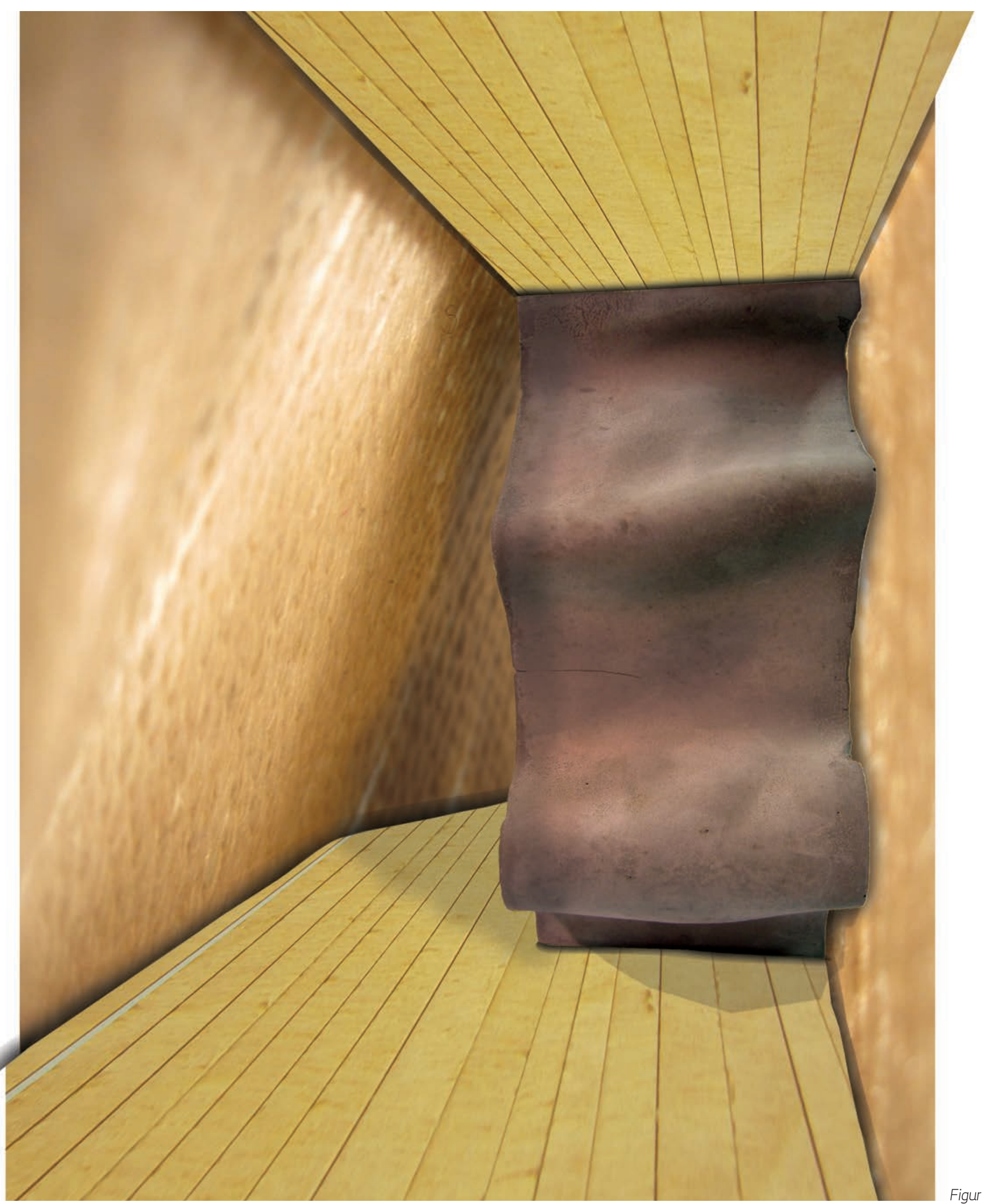

Figure 122: MV2-C6 


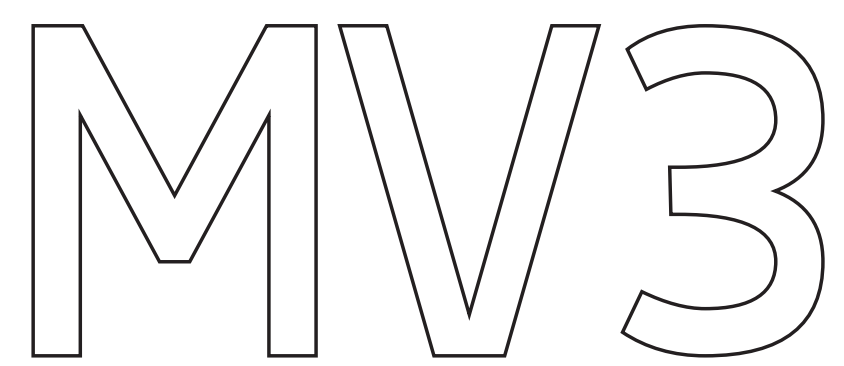

making version three 


\section{chapter 09.3}

\section{Building the Drawing}



Figure 123: MV4 Mold Detail Figure 124: MV4 Detail
Making Version 3: Building the Drawing explored the way in which making the drawing, both digitally and manually, is employed as a means of creating information to drive the making process as well as exploring design. I actively engaged drawing's role in closing the established schism between immaterial and material methods of design, employing drawing (Figures 125-127) and three-dimensional modeling (Figures 128-130) as a means of driving fabrication machinery (Figure 131) as well as guiding the manual building process. During this process, I was actively engaged in building drawings which were relevant to the model making process and less focused on the formal architectural qualities of the hut. While the drawings were relatively simple explorations of formal qualities of the design (MV1 and MV2) the majority of the drawing was undertaken in order to provide clarity, notation, and information during the building and making process. 


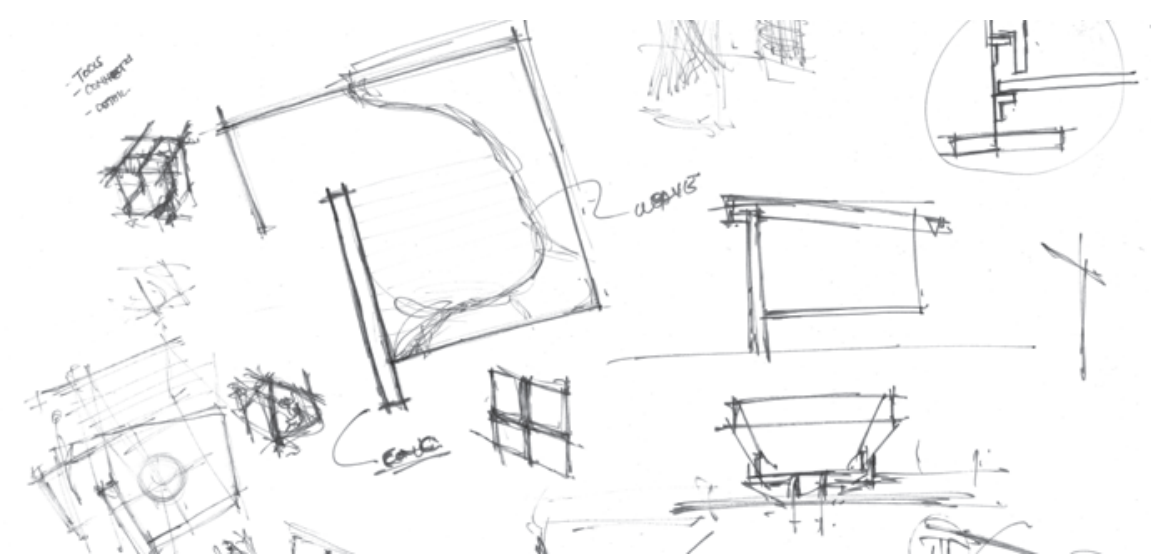

Figure 125: Primary Model Sketches
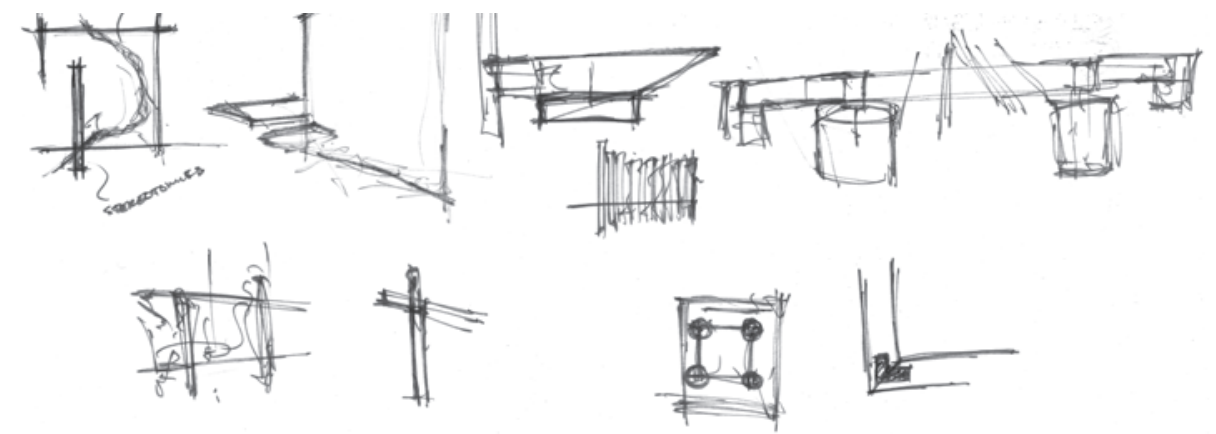

4

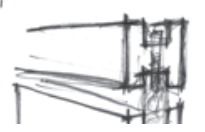

Figure 126: Primary Model Sketches

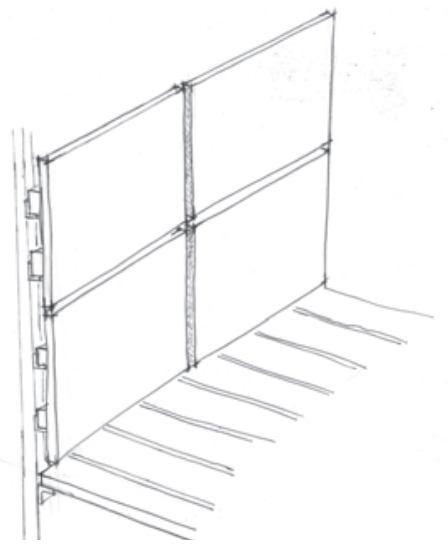

Figure 127: Concrete Panel Model Sketch

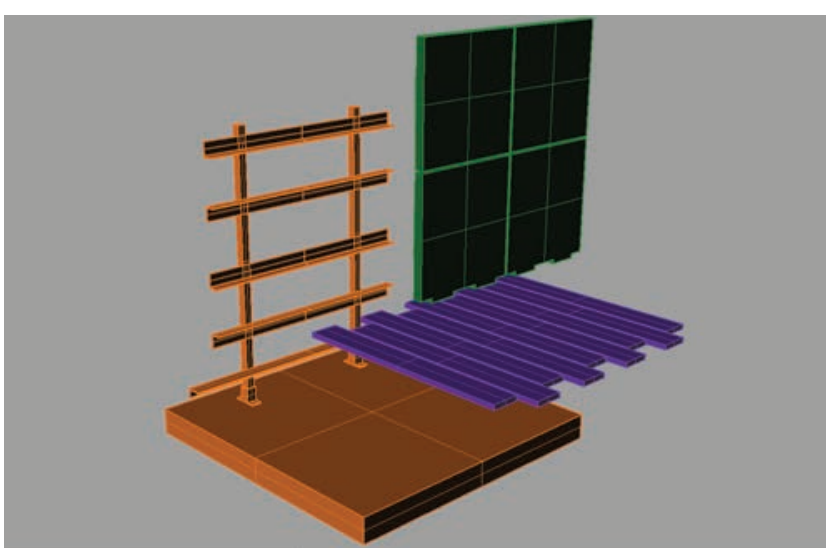

Figure 128: Concrete Panel Model Render 


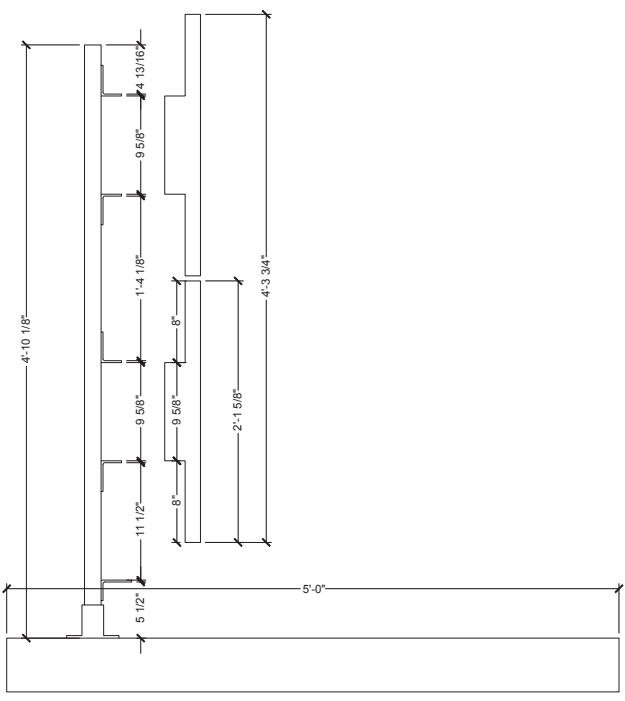
for Concrete Panels

Figure 130: Grasshopper Surface Texture Explorations
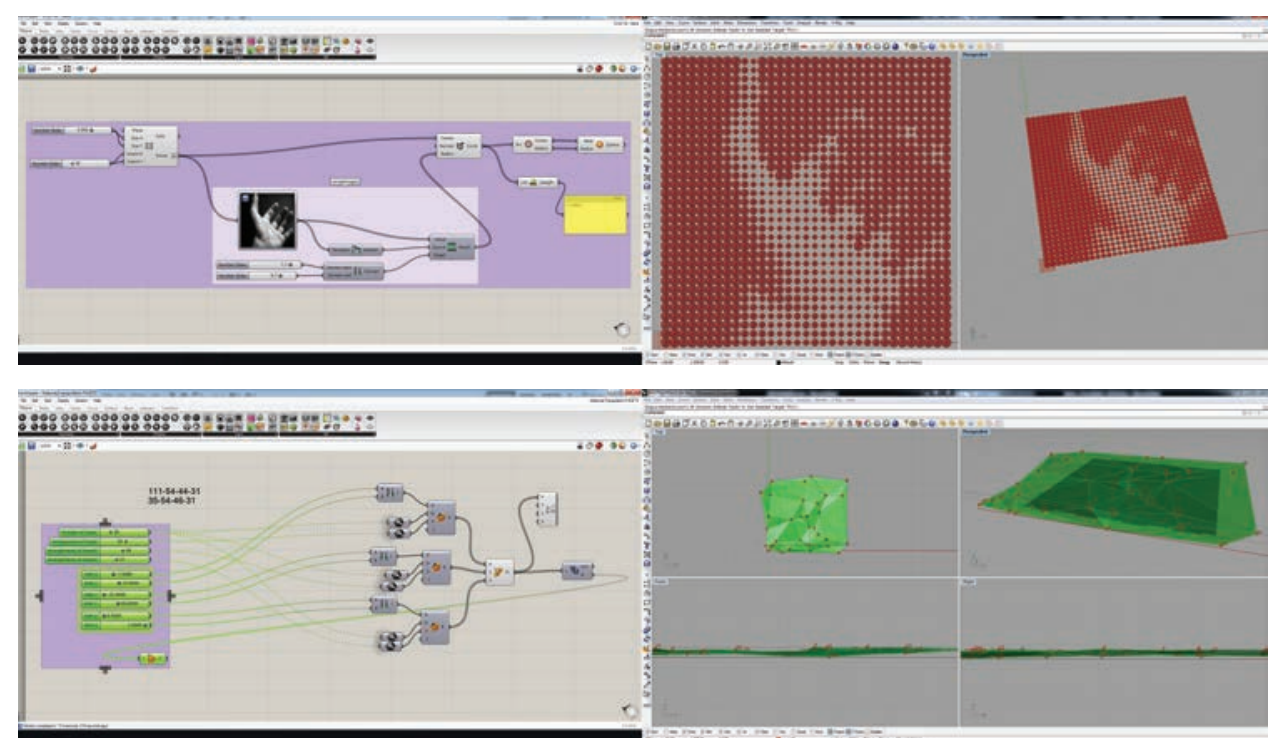

Figure 131: CNC Milling Concrete Form derived from Rhino Model

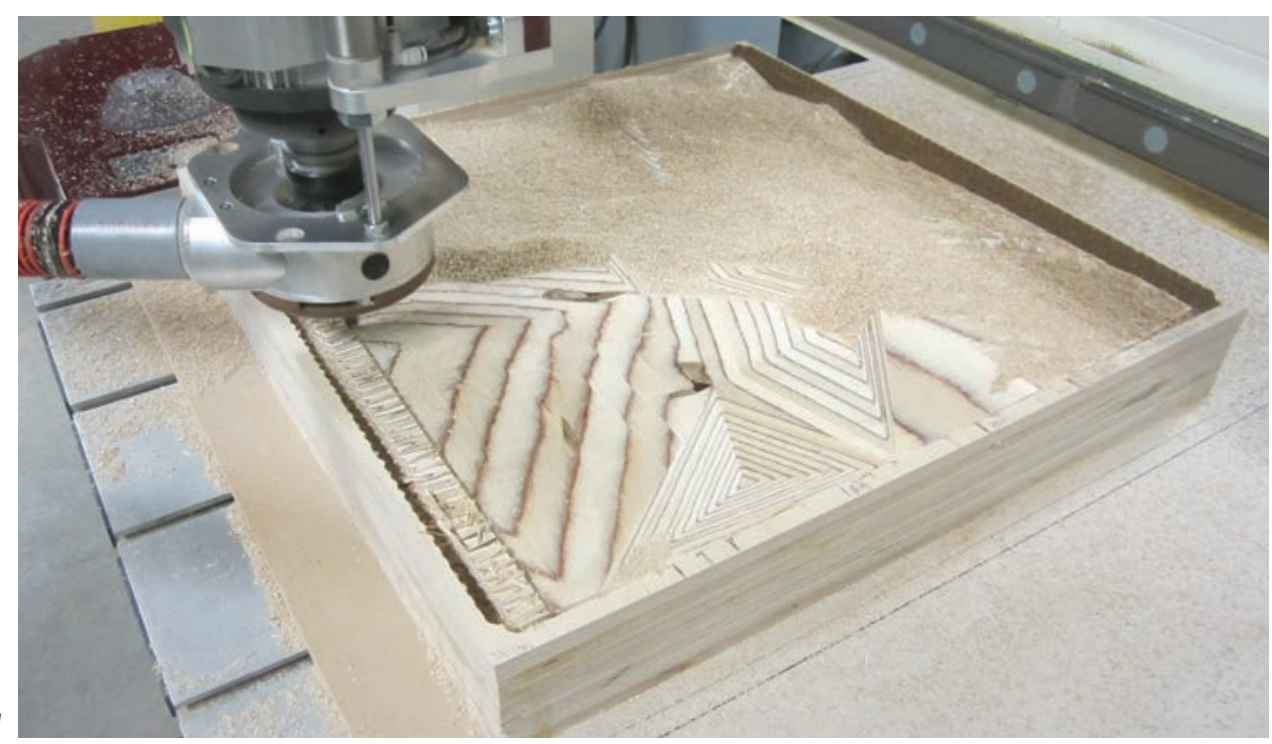



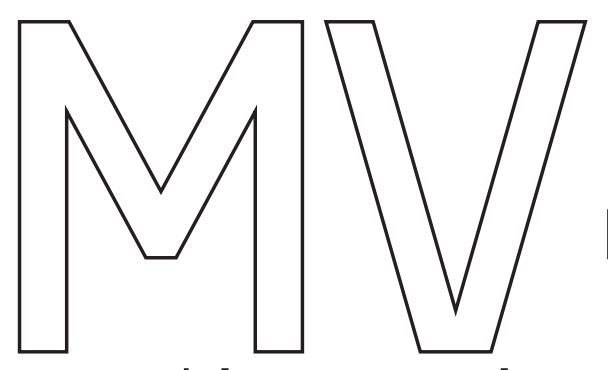

making version four

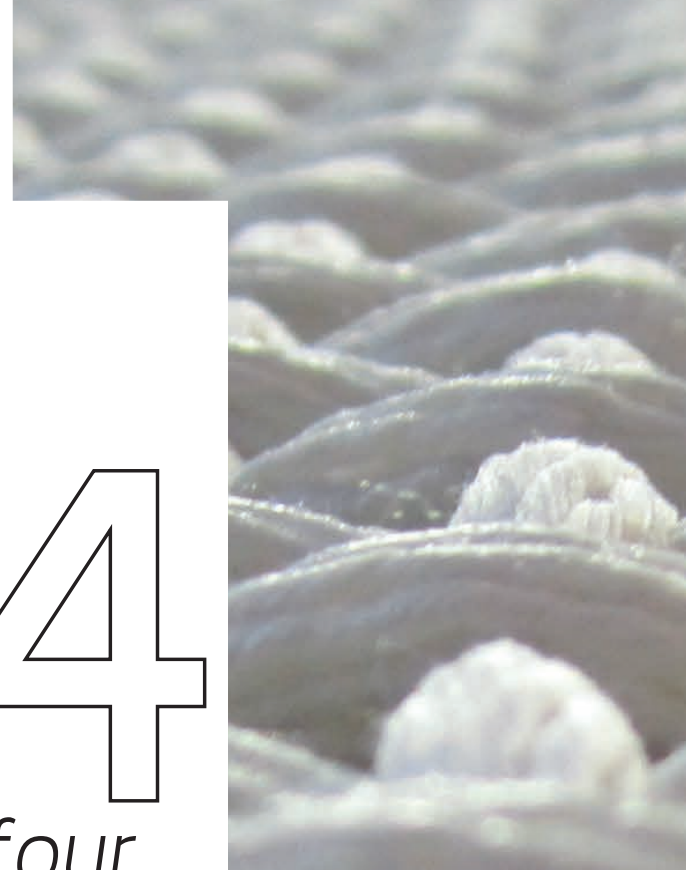




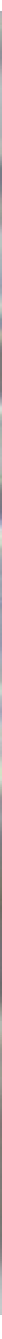


During Making Version 4: [1:1] I chose to design and construct several particular components of the Primitive Hut [Re]-Engaged at a larger scale in order to explore the way these conditions affected the subsequent design of the hut. The two particular conditions which I was able to fully explore were the concrete wall conditions (Figures 141-160) and the textile wall conditions (Figures 161-170) both of which were built through an iterative process and based (both consciously and on later examination unconsciously) on the earlier making versions. These prototypes explored the materiality, connections, and structure (Figures 134-140) of the hut physically imparting important tacit knowledge through the intimate act of making. This in turn translated into architectural considerations (such as assembly processes, building component weight, joint conditions, structural conditions, etc.) which were brought to the forefront of the design process surpassing form in terms of importance and bringing to light the complex physical conditions of architecture very early on in the design phase. 

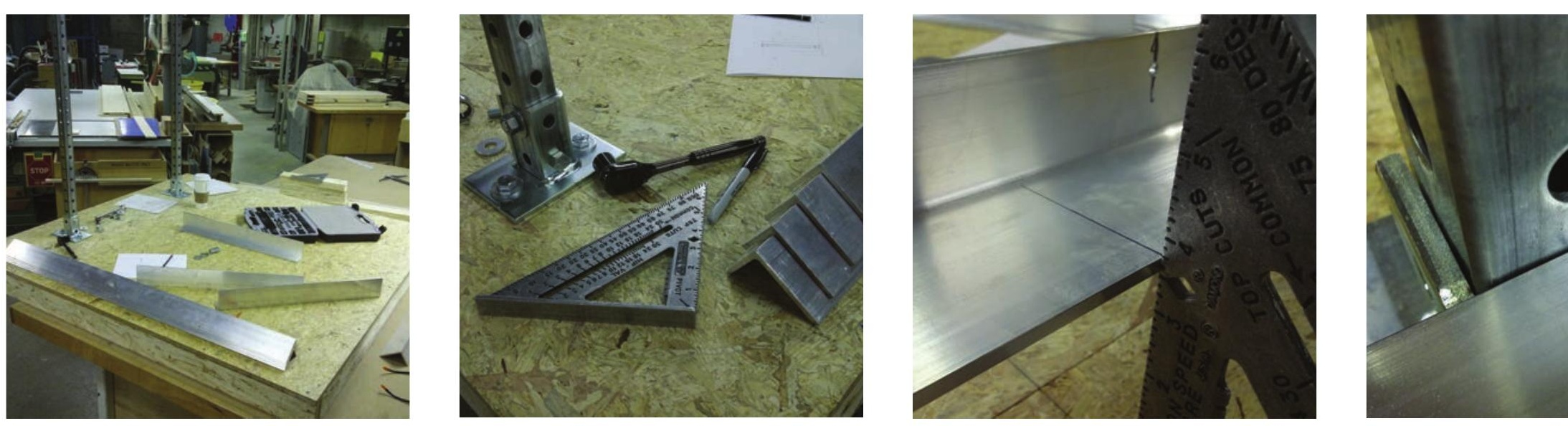

Figure 134: MV4-1 Component Assembly Figure 135: MV4-1 Tools and Materials Figure 136: MV4-1 Component Assembly Figure 137: MV4-1 Component Assembly 

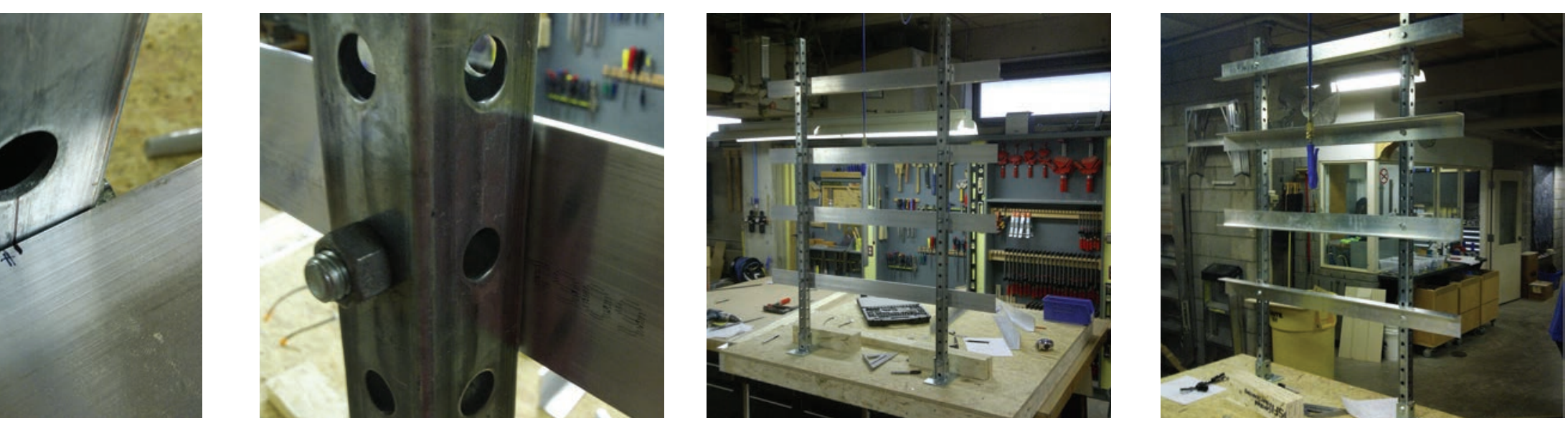

Figure 138: MV4-1 Component Assembly

Figure 139: MV4-1 Final Assembly

Figure 140: MV4-1 Completed 

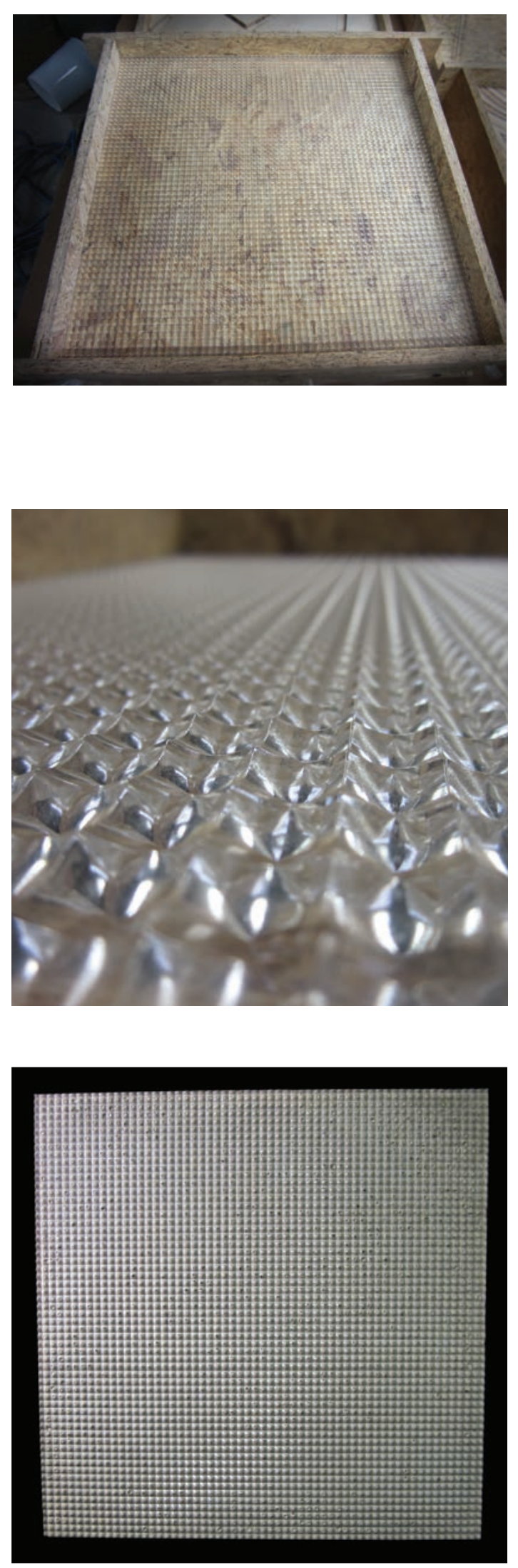

Figure 141: MV4-2 Concrete Mold

Figure 142: MV4-2 Mold Detail

Figure 143: MV4-2 Concrete Panel Figure 144:MV4-2 Concrete Panel Detail 


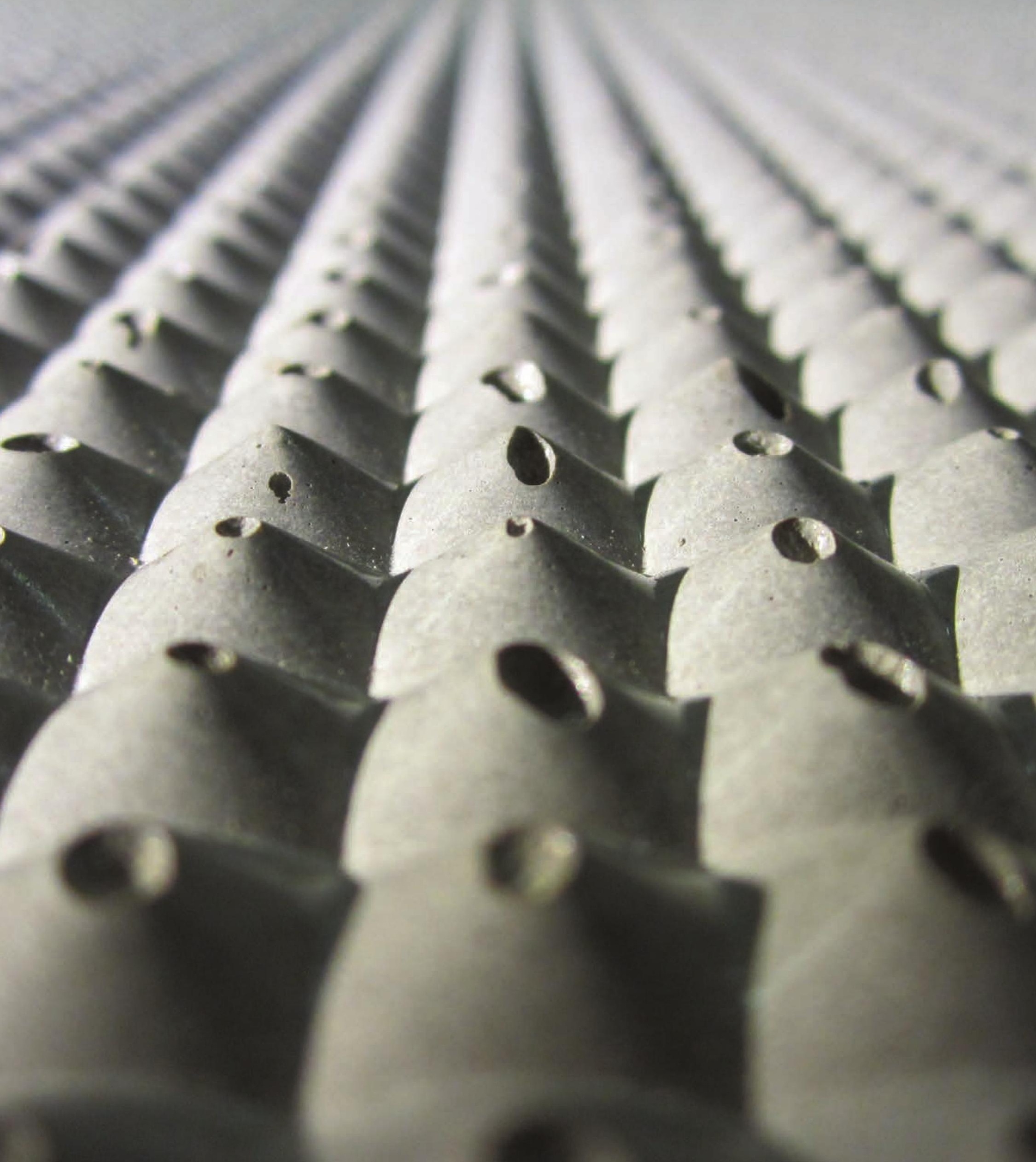



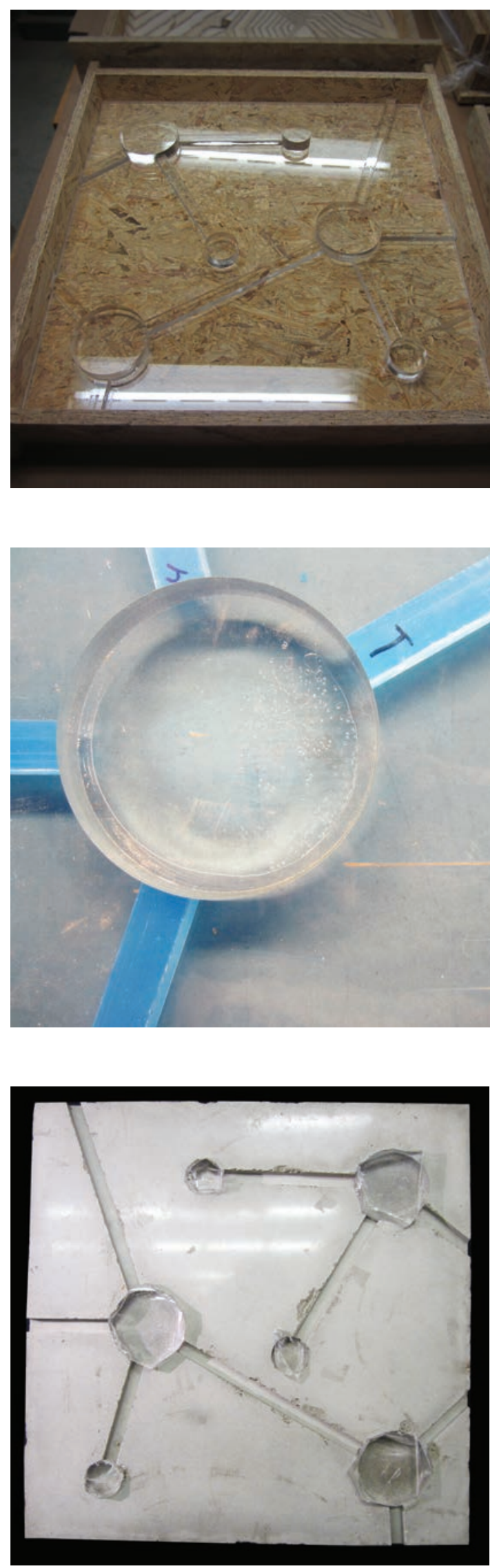

Figure 145: MV4-3 Concrete Mold Figure 146: MV4-3 Mold Detail

Figure 147: MV4-3 Concrete Panel Figure 148: MV4-3 Concrete Panel Detail 


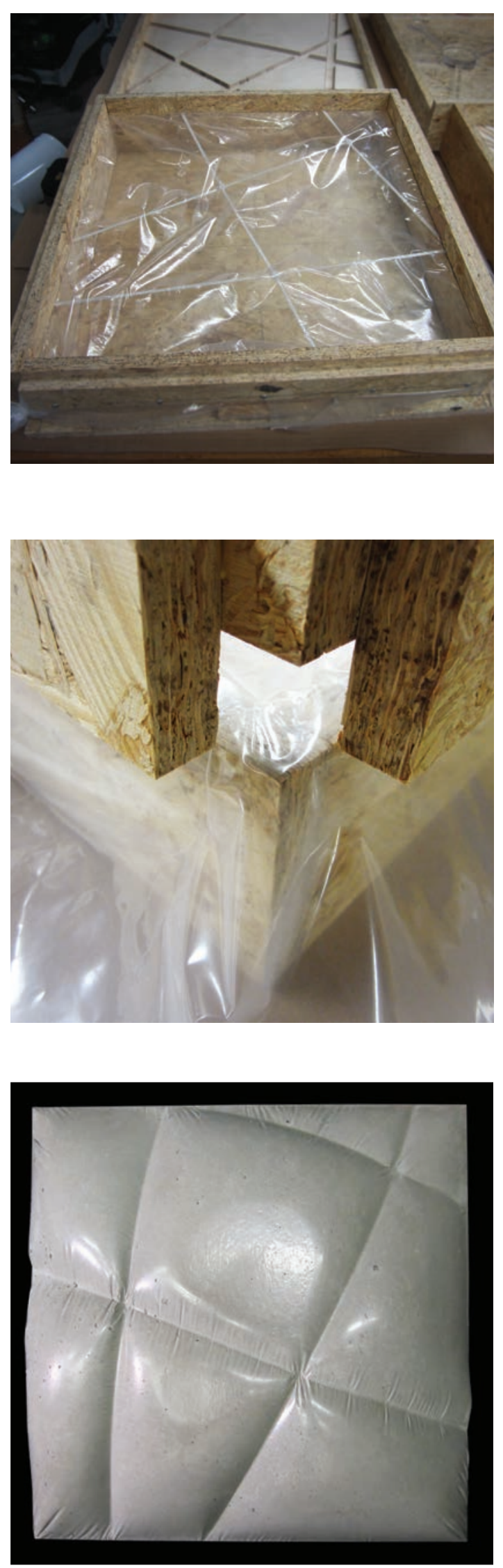

Figure 149: MV4-4 Concrete Mold Figure 150: MV4-4 Mold Detail

Figure 151:MV4-4 Concrete Panel Figure 152: MV4-4 Concrete Panel Detail 


\section{$*$}

s

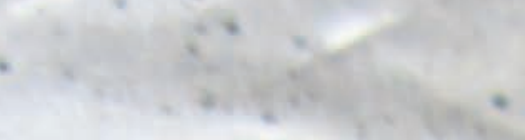

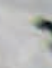
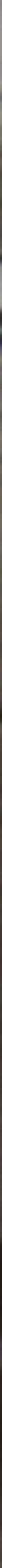

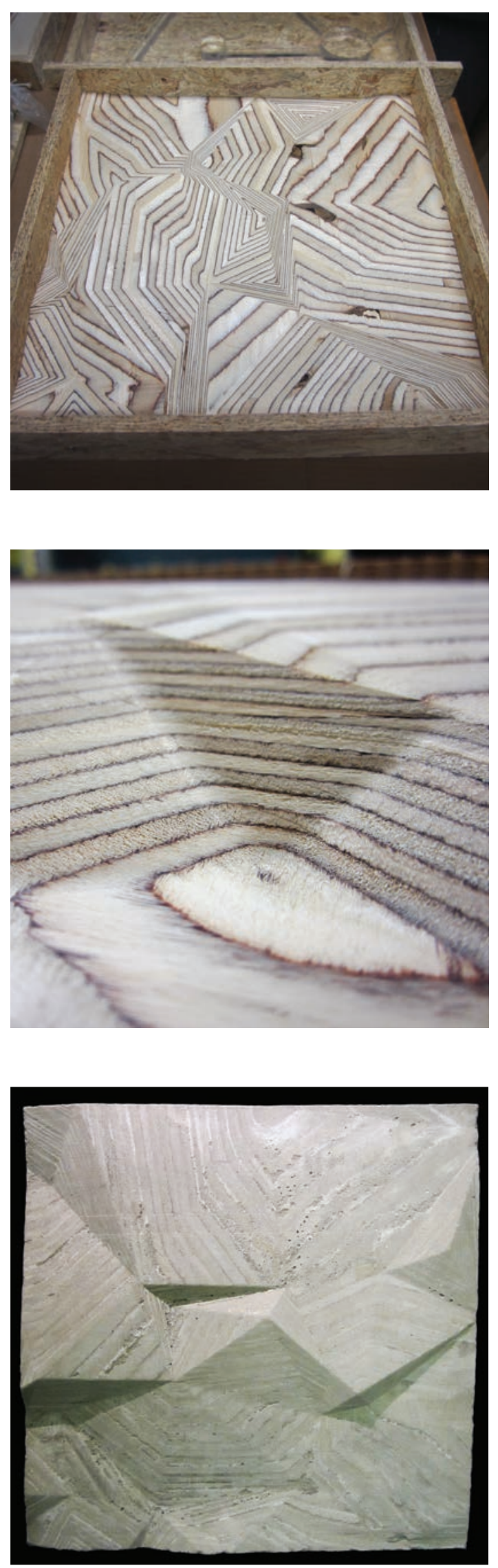

Figure 153: MV4-5 Concrete Mold

Figure 154: MV4-5 Mold Detail

Figure 155: MV4-5 Concrete Panel

Figure 156: MV4-5 Concrete Panel Detail 


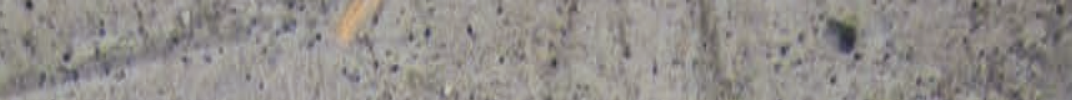

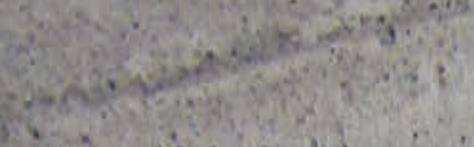

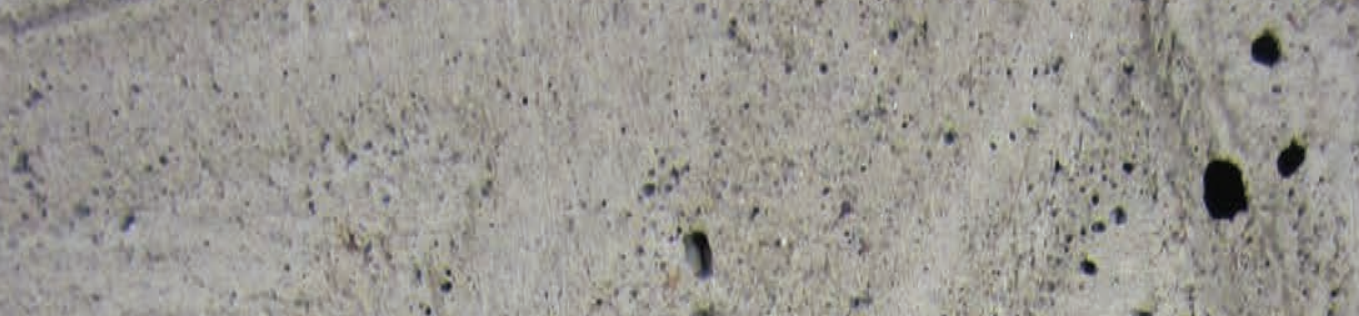

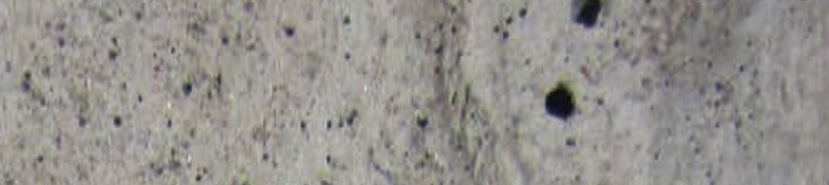

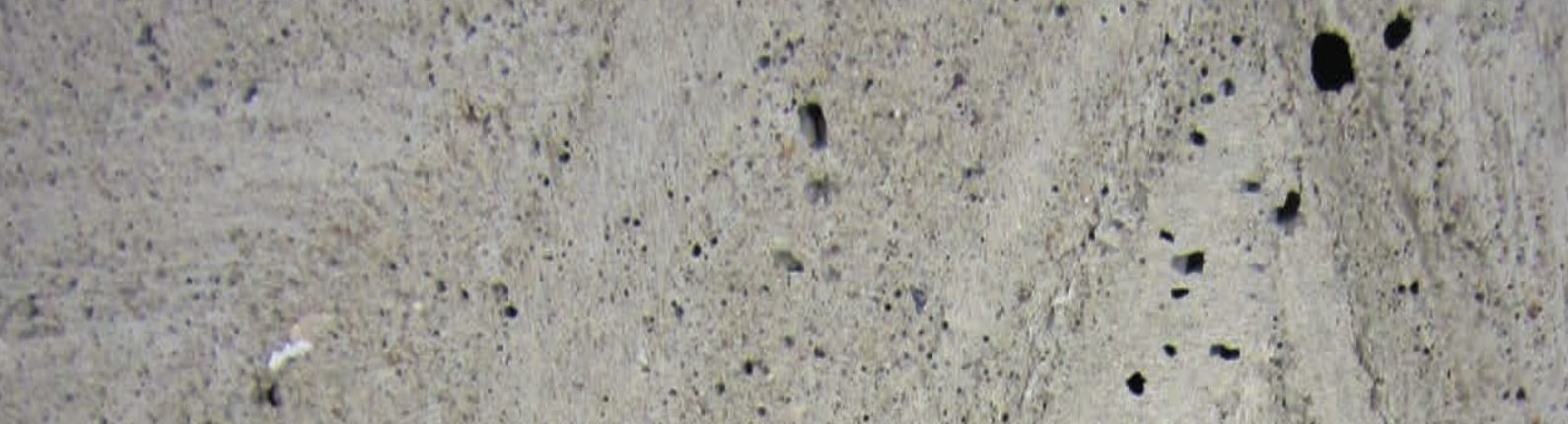

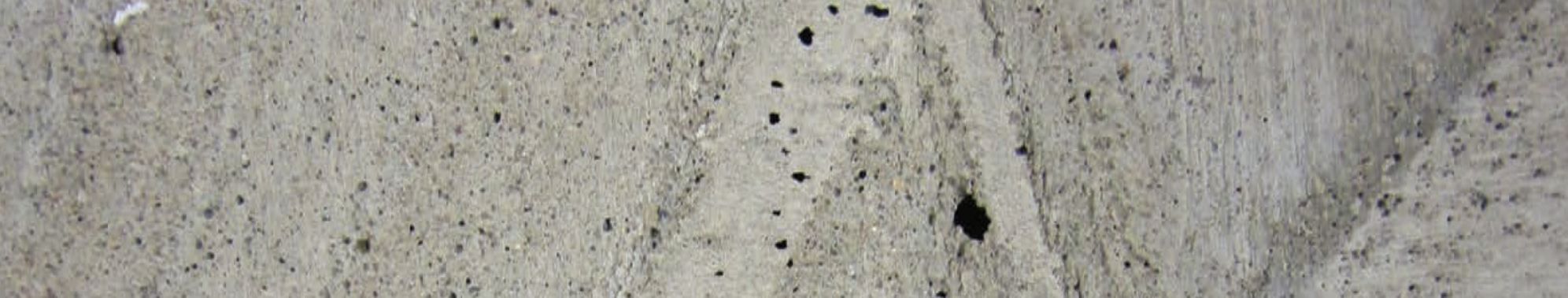

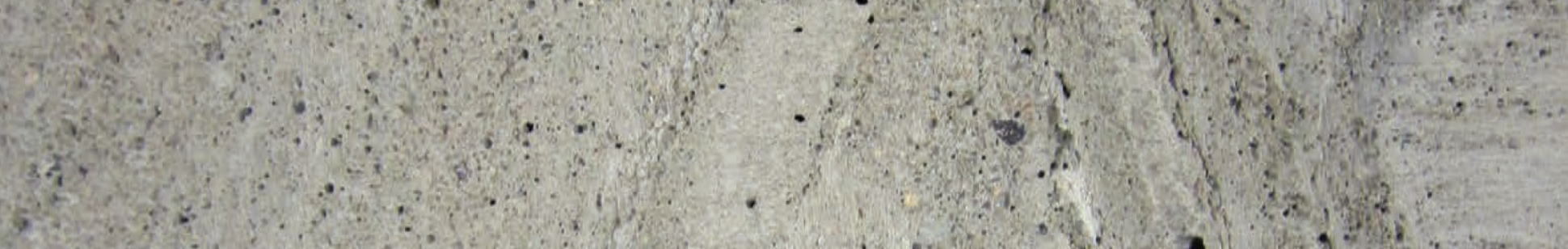

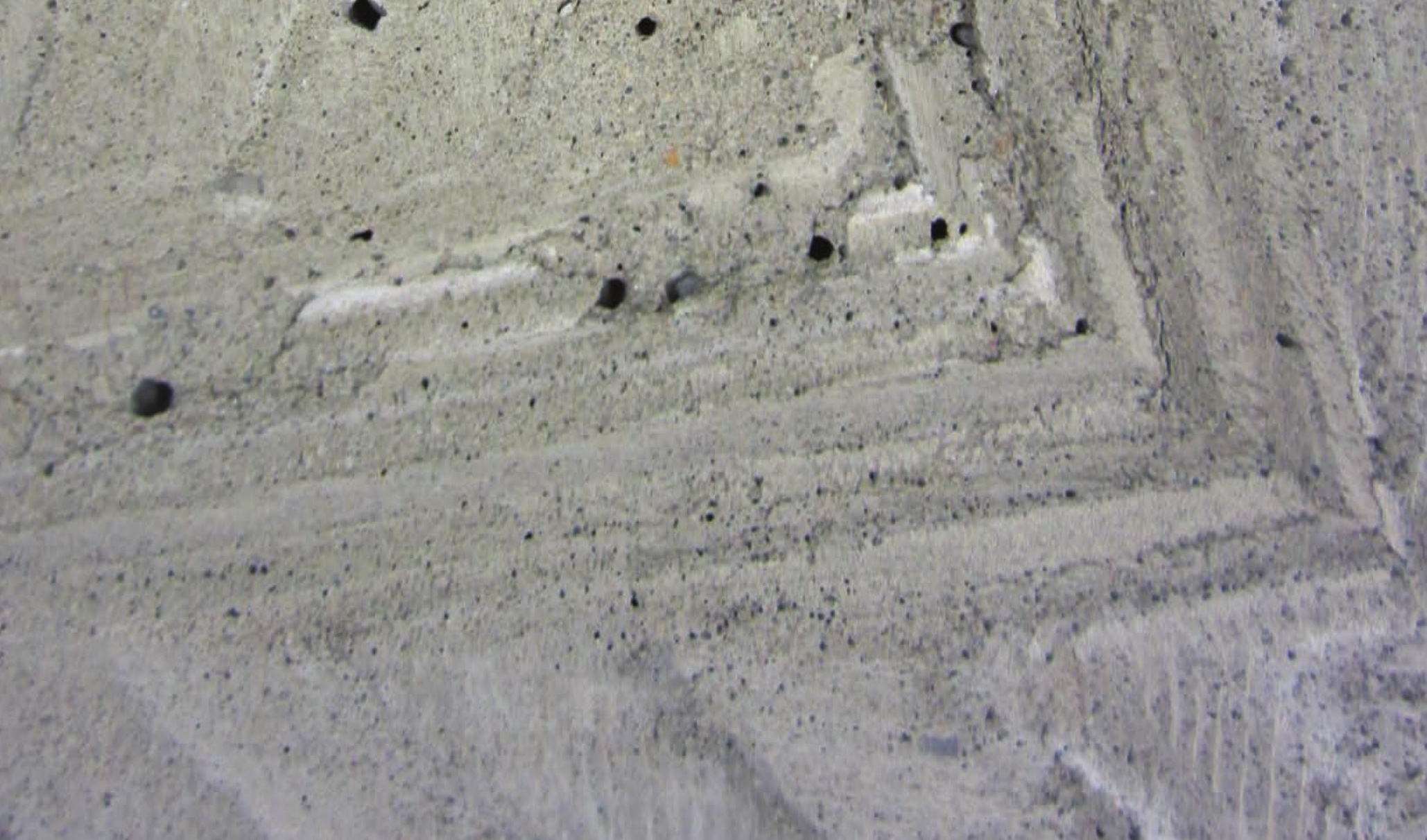



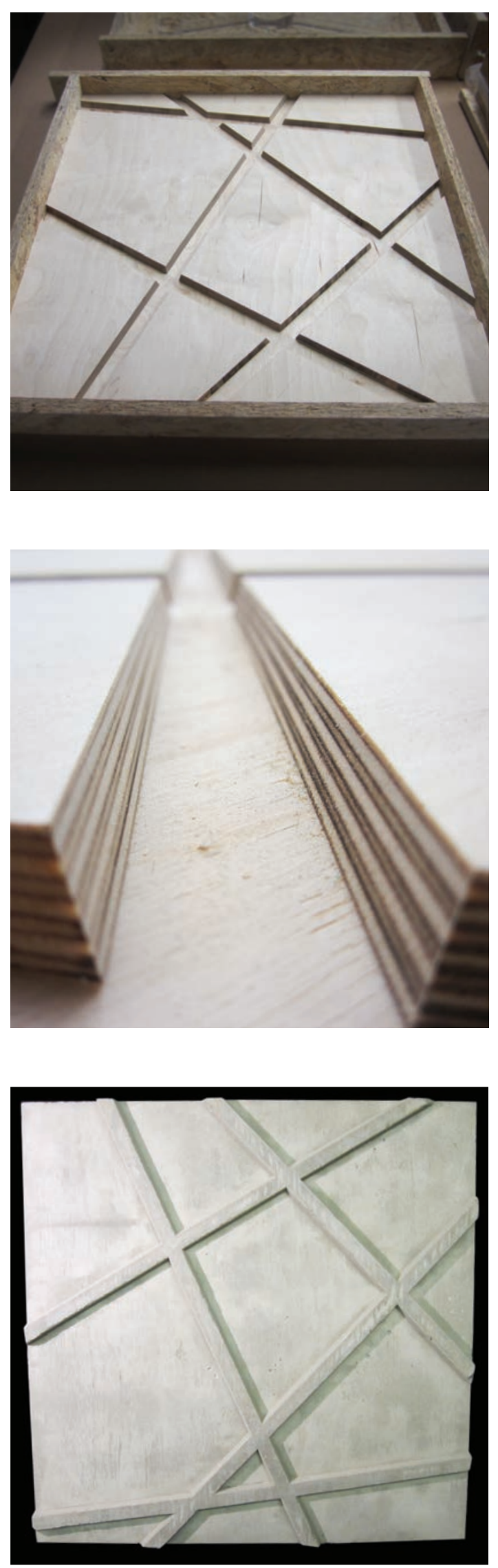

Figure 157: MV4-6 Concrete Mold Figure 158: MV4-6 Mold Detail

Figure 159: MV4-6 Concrete Panel Figure 160: MV4-6 Concrete Panel Detail 

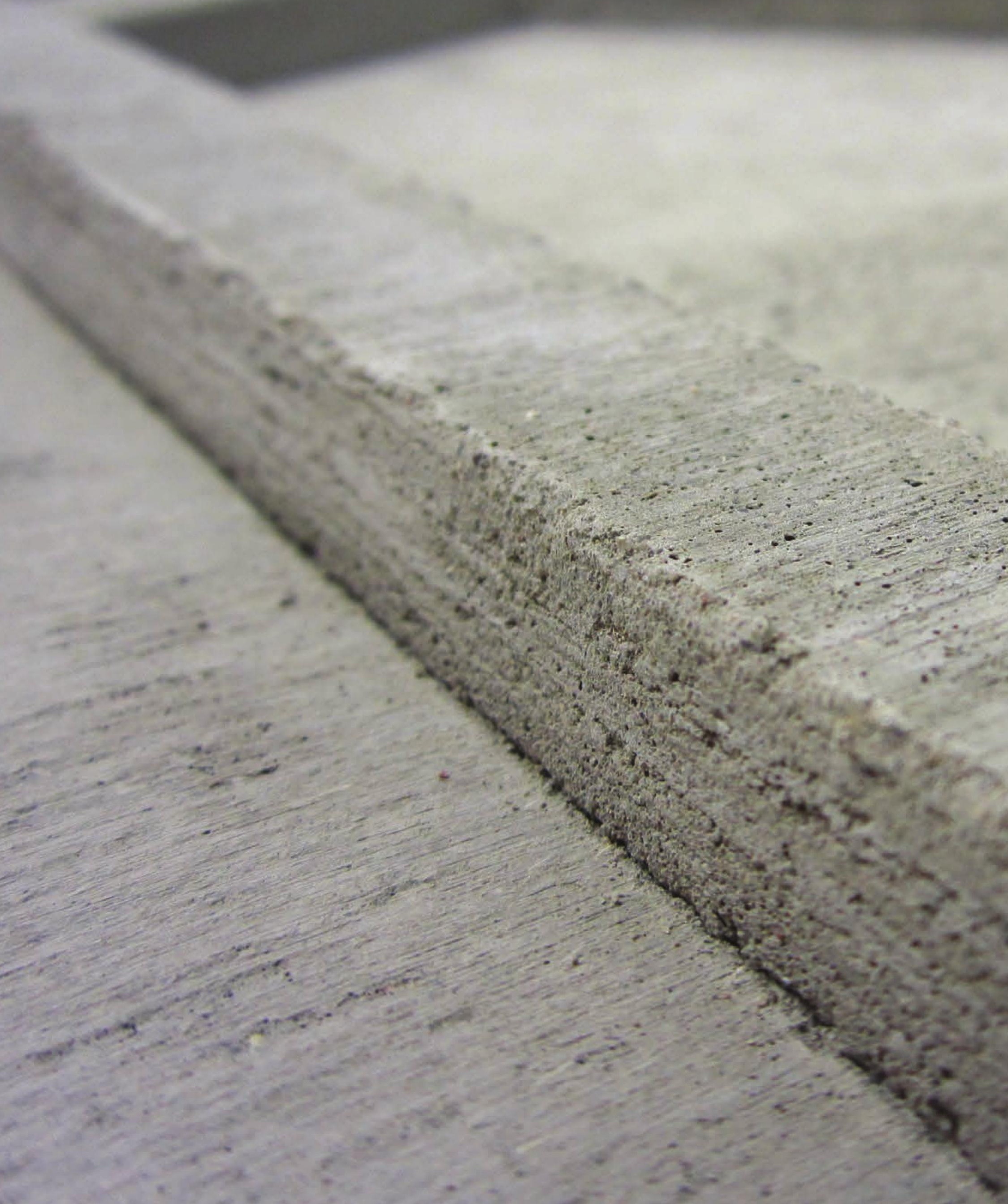


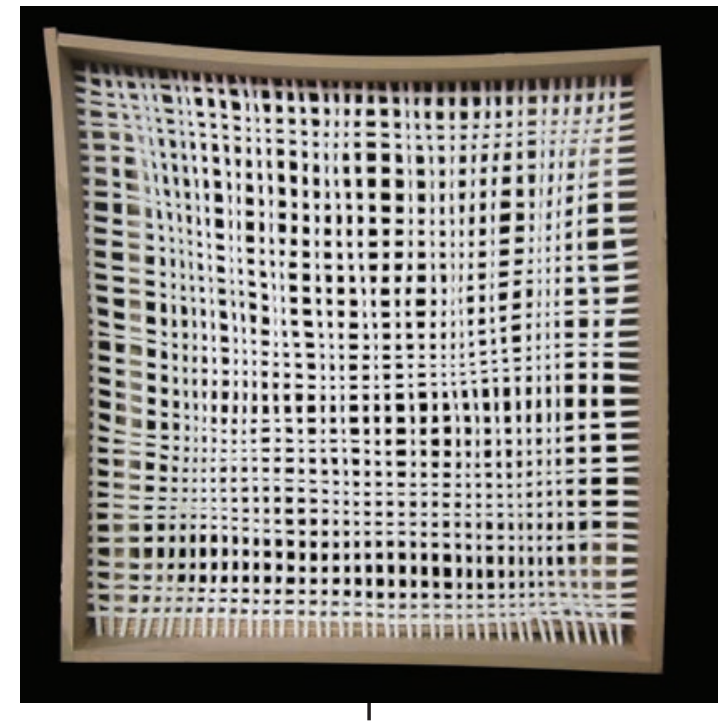

Figure 161: MV4-7

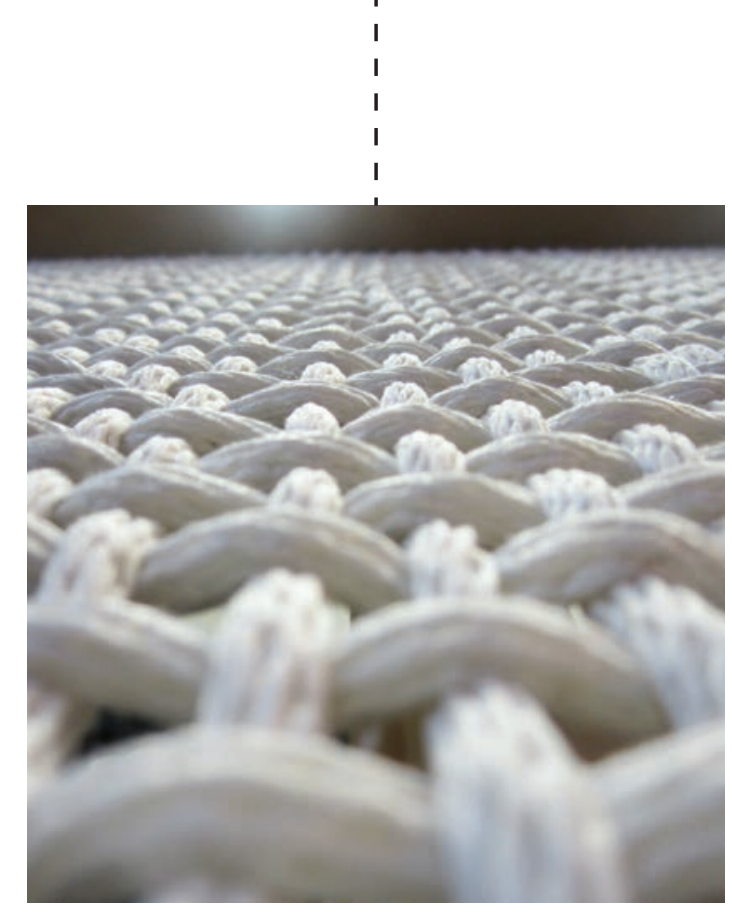

Figure 166: MV4-7 Detail

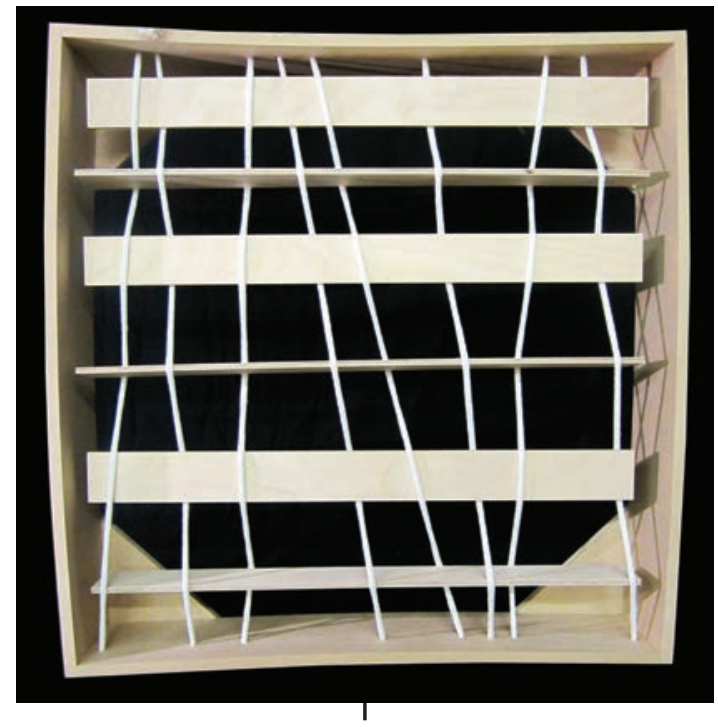

Figure 162: MV4-8

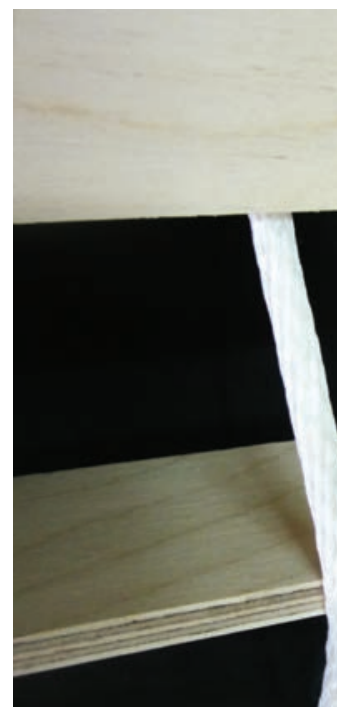

Figure 167: MV4-8 Detail

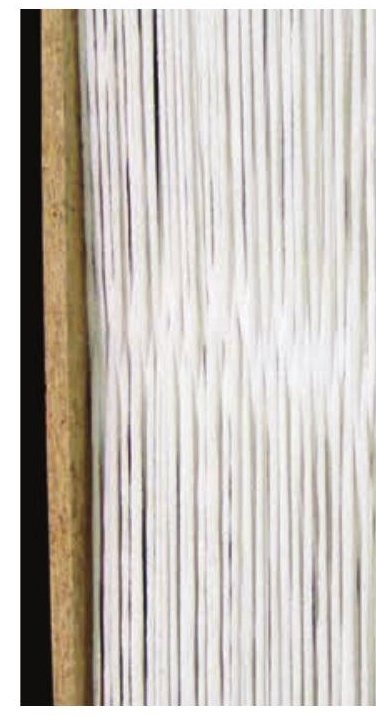

Figure 163: MV4-9

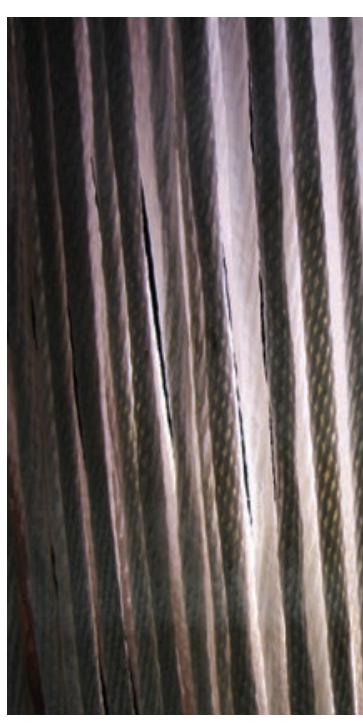

Figure 168: MV4-9 Detail 

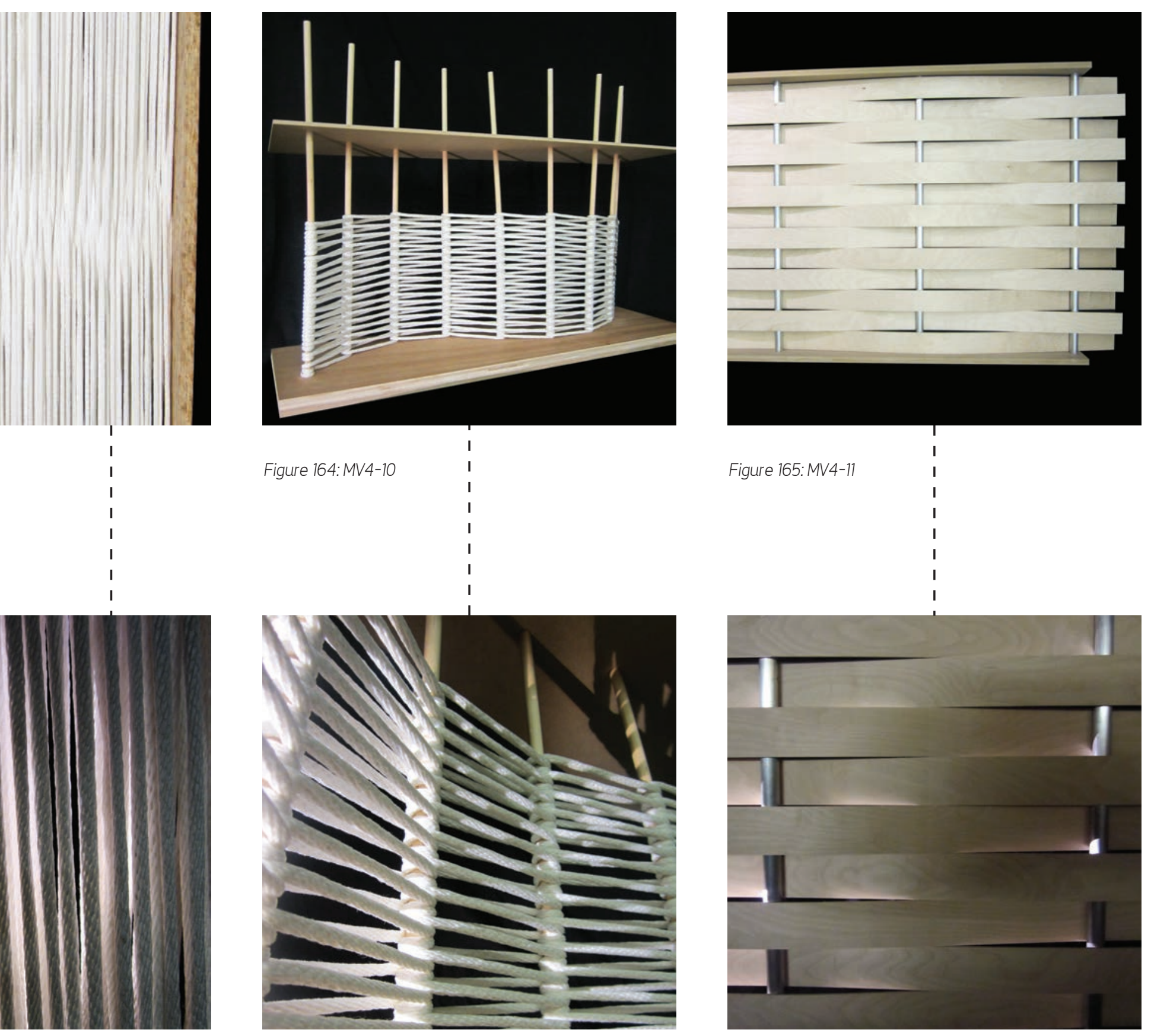

Figure 169: MV4-10 Detail

Figure 170: MV4-11Detail 


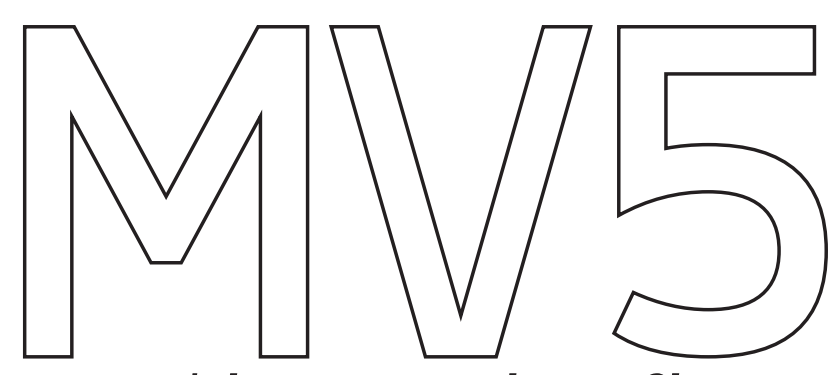

making version five 


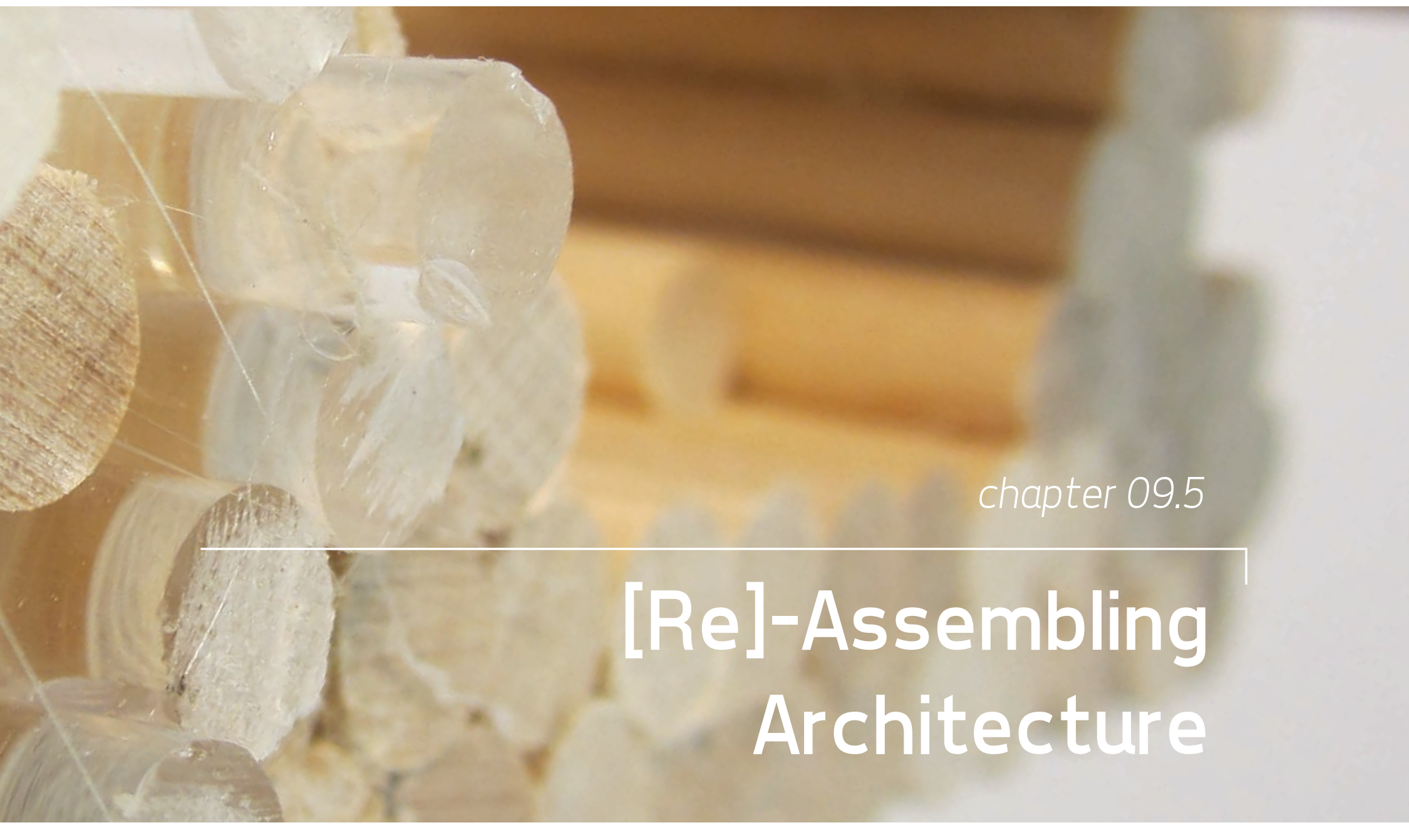




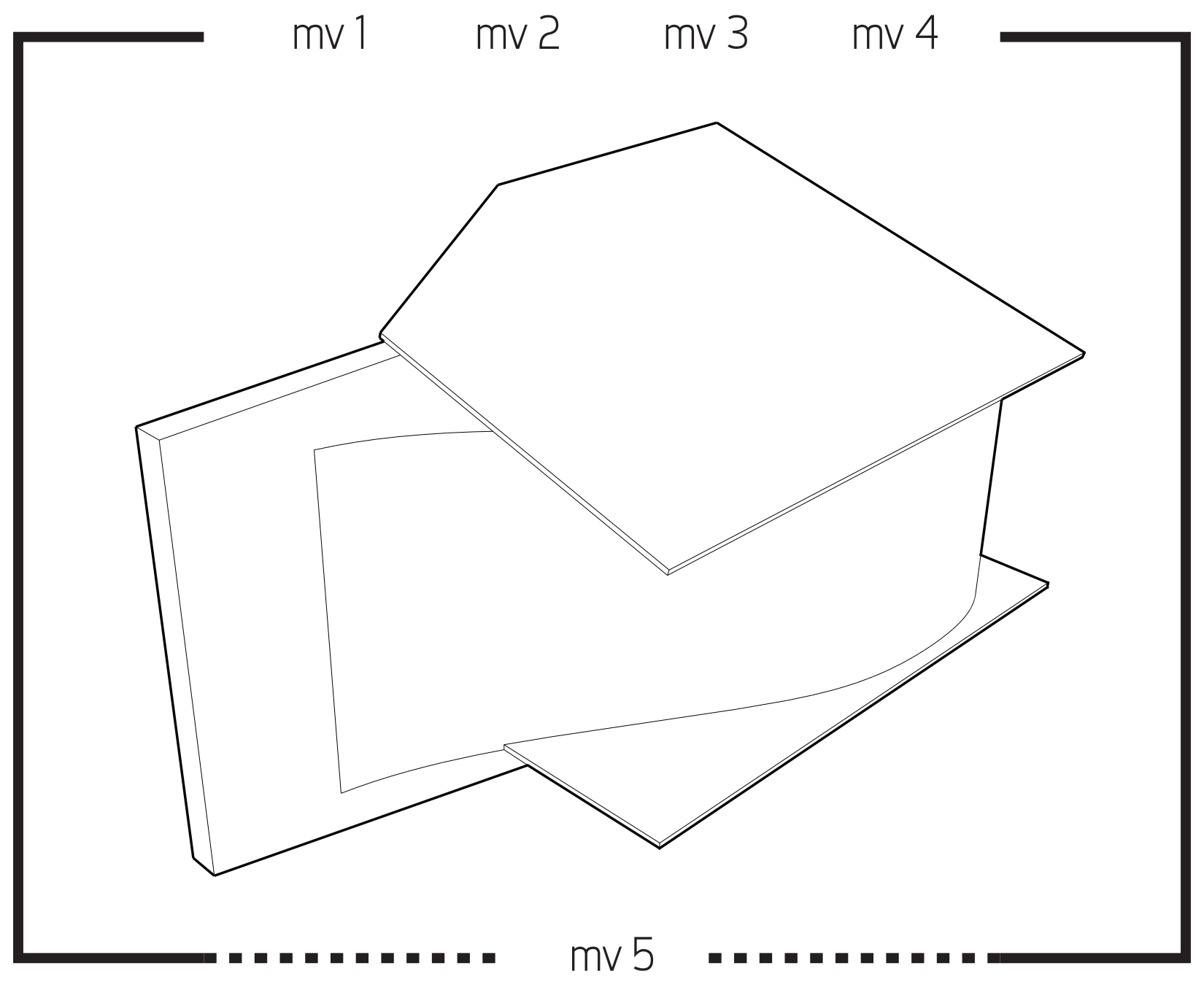


Figure 171: MV1Detail

Figure 172: MV5 Making Diagram
During Making Version 5: [Re]-Assembling Architecture, I brought together all previous versions of making in order to develop a unified design which was based on the made prototypes which I had explored. The process of this design, while somewhat intuitive (as I had been mentally drawing connections between the different artefacts produced) can be represented as an analysis, amalgamation, and integration of the made prototypes through MV1, MV2, MV3, and MV4. 


\section{MV5.1 - Architectural Genealogy}

MV5.1 - Architectural Genealogy is a visual representation of the genesis of the three conditions which I explored in the Primitive Hut [Re]-Engaged. Tracing the design development visually, each of the components post-design was an important measure of exploring my thesis position allowing a retrospective and broad understanding of the affect of making on the design process (Figures 173-175). After completing this exercise it was interesting to note particular threads of design ideas which continued to appear in each making version, in different forms but coming from the same seed.

$\mathrm{mv} 1$

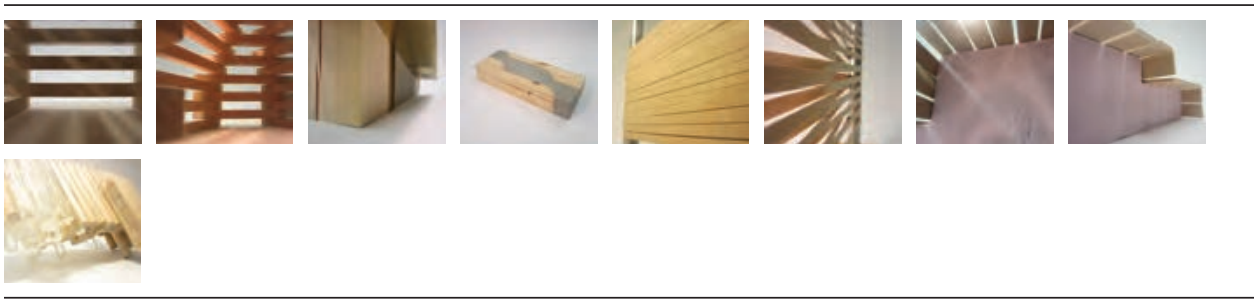

$\mathrm{mv} 2$

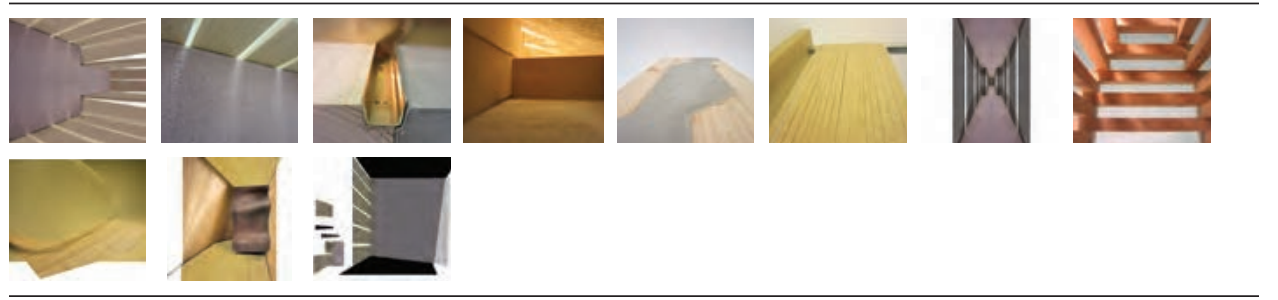

mv 3
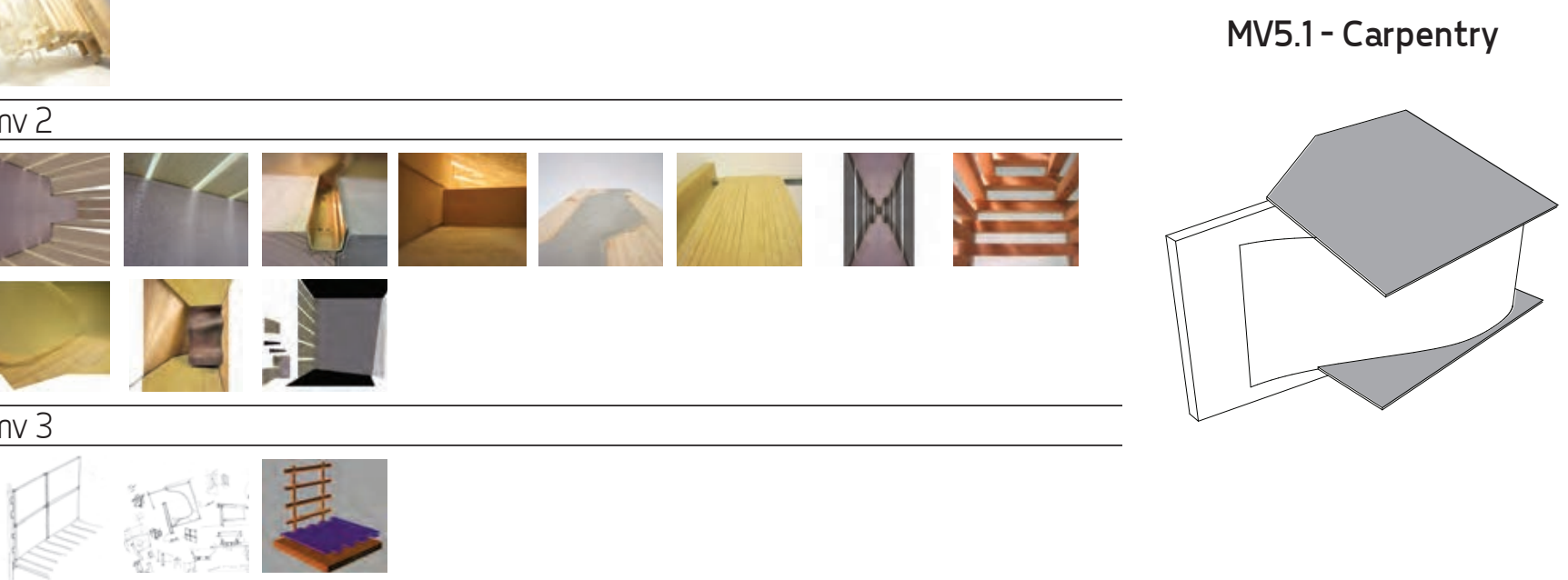

Figure 173: Carpenty Genealogy

151 


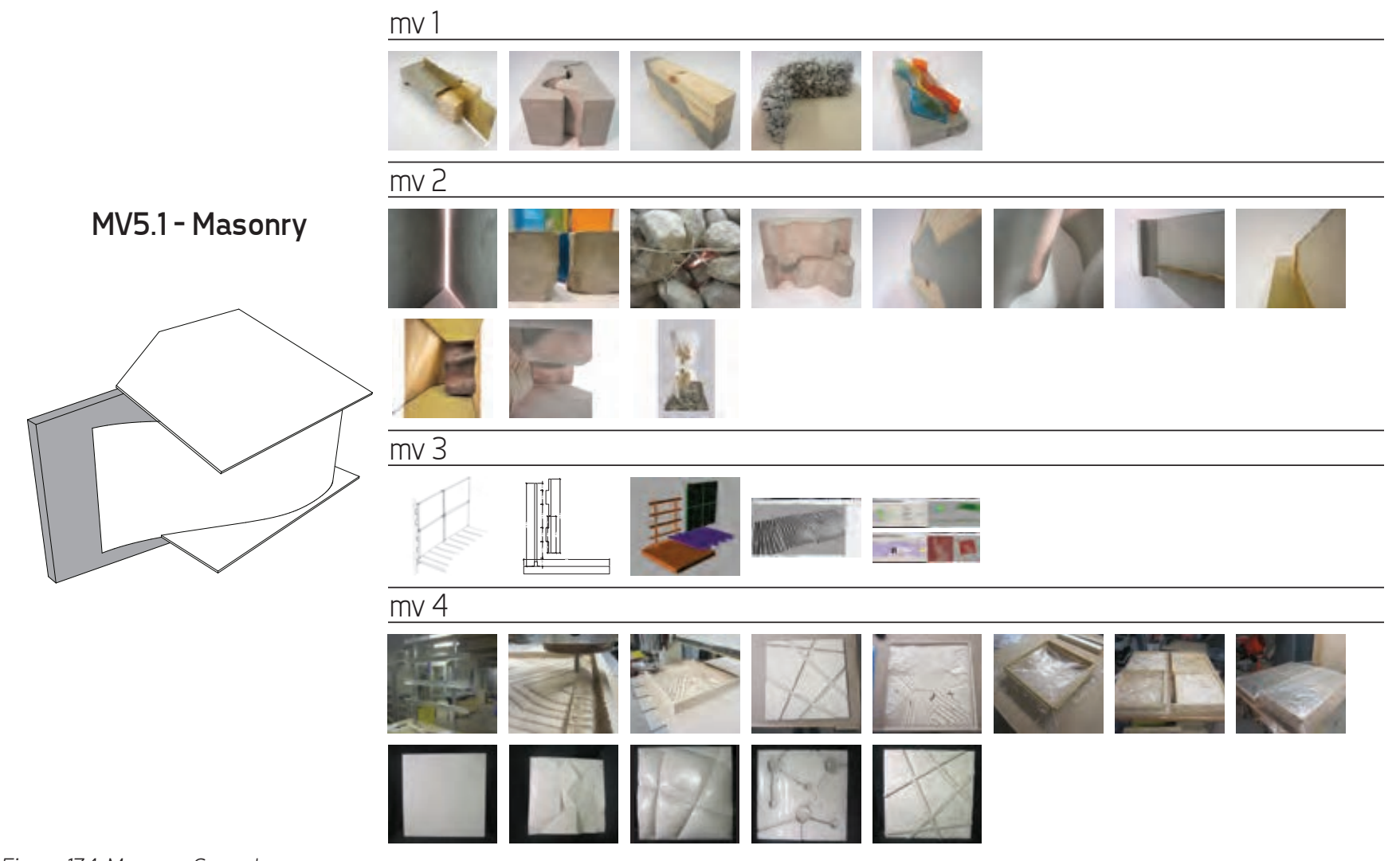

Figure 174: Masonry Genealogy

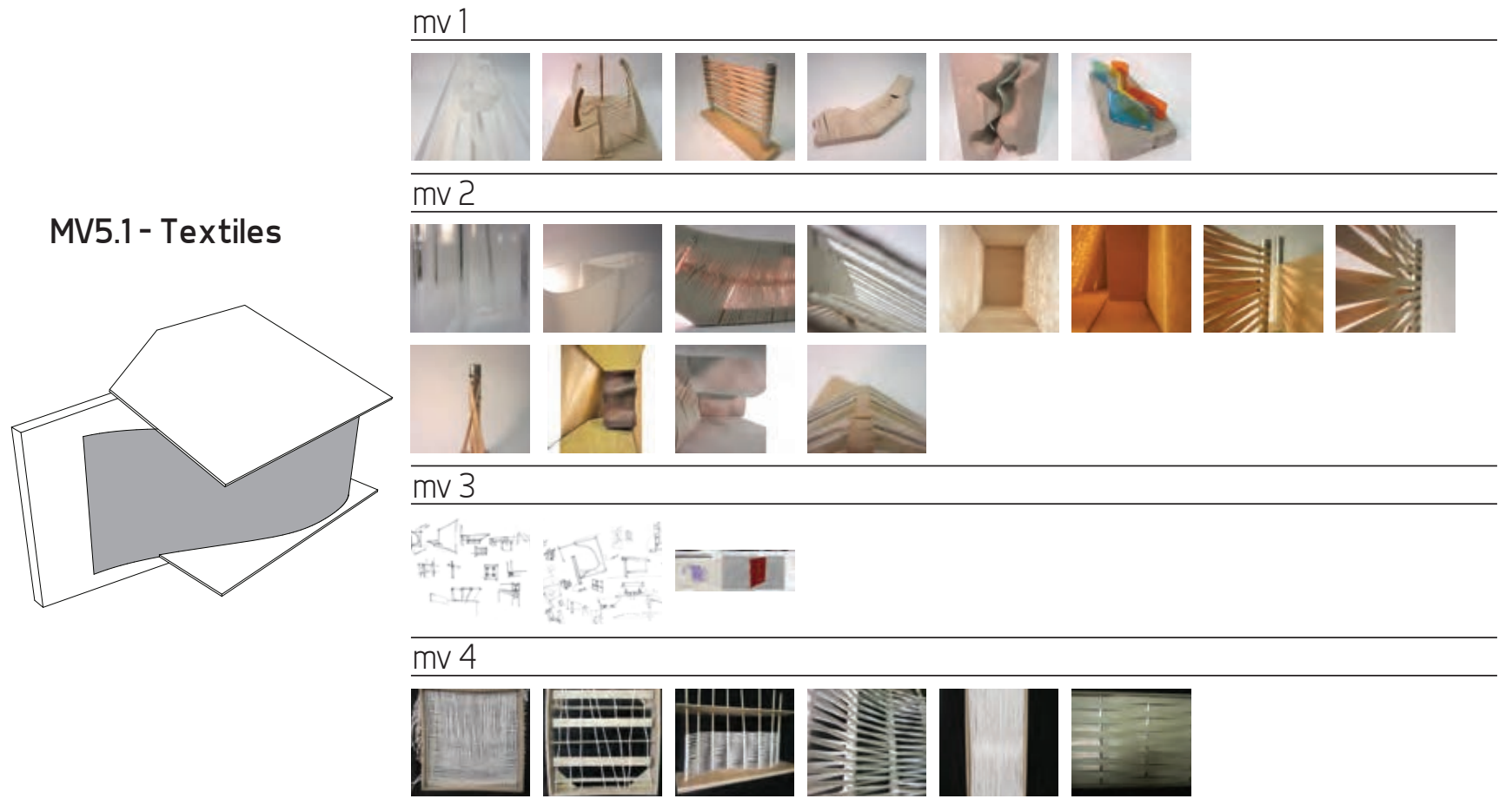

Figure 175: Textile Genealogy 


\section{MV5.2 - [Re]conciling Matter and Form}

Through analyzing MV1-4 I was able to draw finite conclusions on how the varying material palette of the prototypical artefacts created could come together in a singular cohesive design. Drawing forth these conclusions was less about picking particular aesthetics but rather were a result of continually emerging qualities which were inherently tied to the material properties of the making explorations. Critical to making these decisions was constructing these prototypes at 1:1 which allowed for an intrinsic understanding of their architectural qualities (Figures 176-179). For examples the wood-weave wall test was seminal in understanding not only how that particular condition may function but also in designing the structural components of the hut.
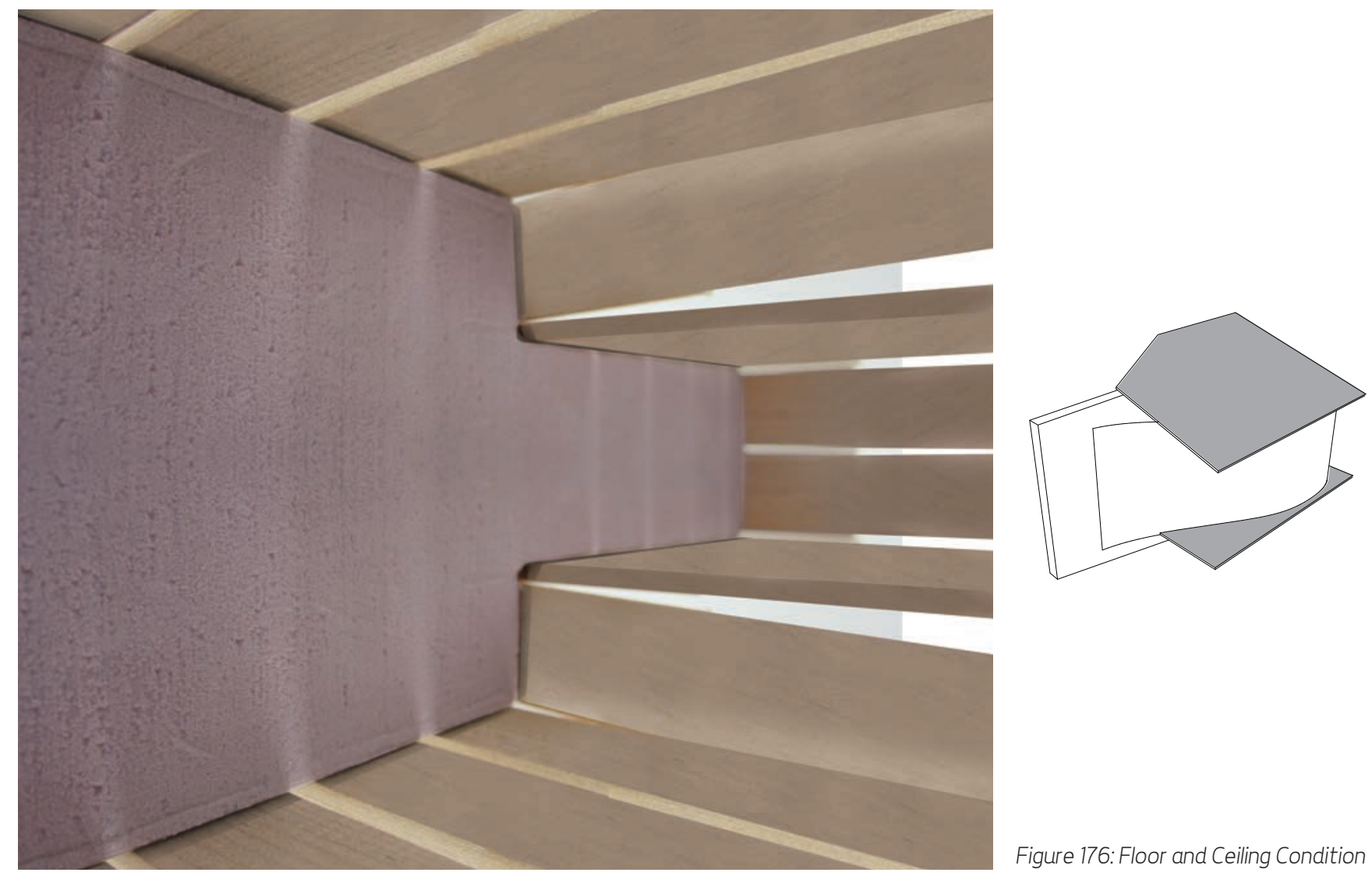

Figure 176: Floor and Ceiling Condition 

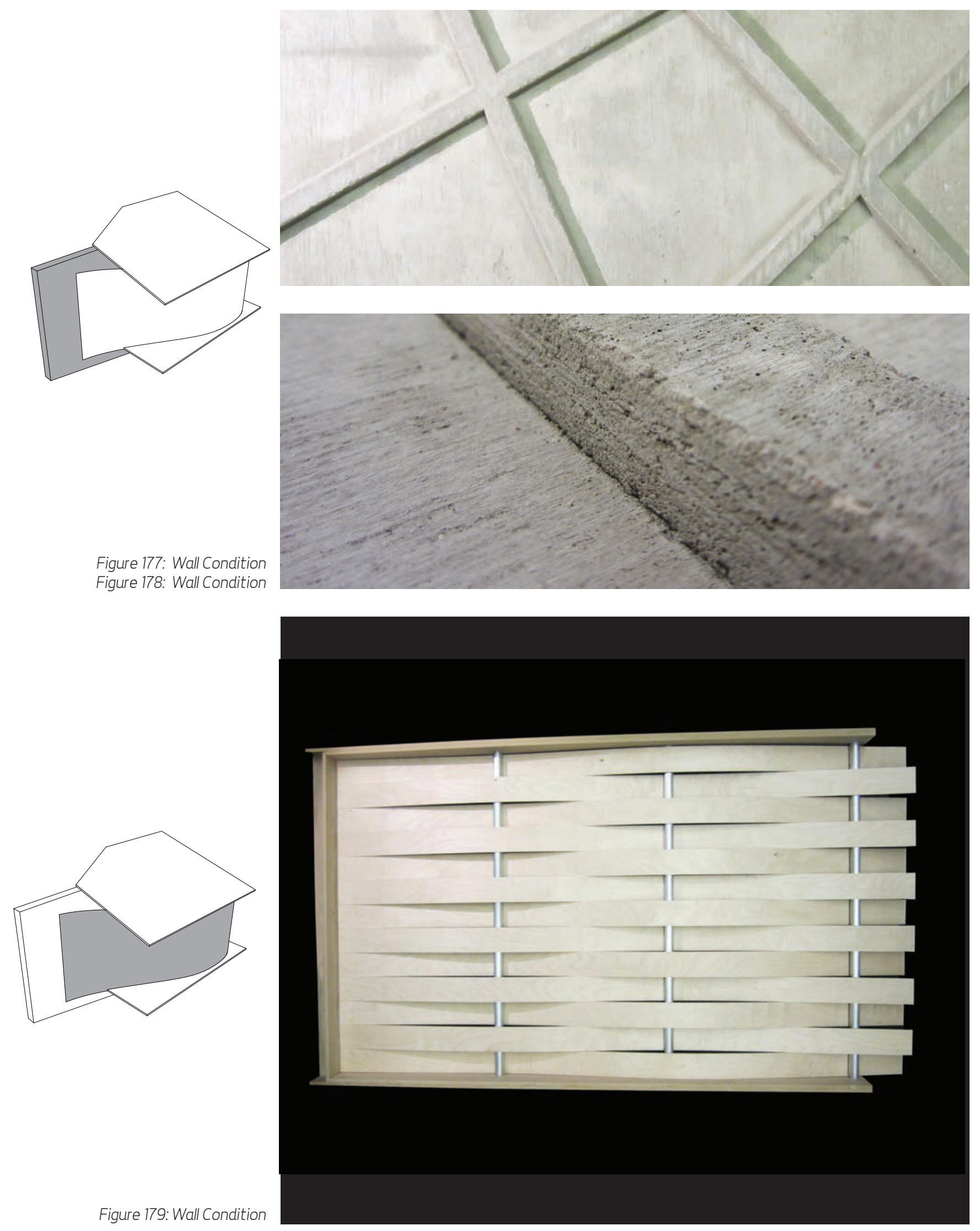


\section{MV5.3 - Details}

While the development of details prior to the rest of the hut design may seem out of place, I thought it was important that the Primitive Hut [Re]-Engaged be presented in the same manner that it was designed in, which is a direct result of engaging making as the primary design tool. As I engaged making for the entirety of the design process I was immediately drawn to and most adept at completing the detailing of the Hut, which was primarily based on the experience ascertained from constructing the larger models in MV4 (Figures 180-183). As a direct result of having personally designed and built the prototypes I was acutely aware when designing of the affects which minute changes in form and dimensions can have on materials and assembly methods of a work of architecture. This process aided in connecting the drawn line to physical form and reinforced the importance of understanding the affects of virtualized design on the built environment.
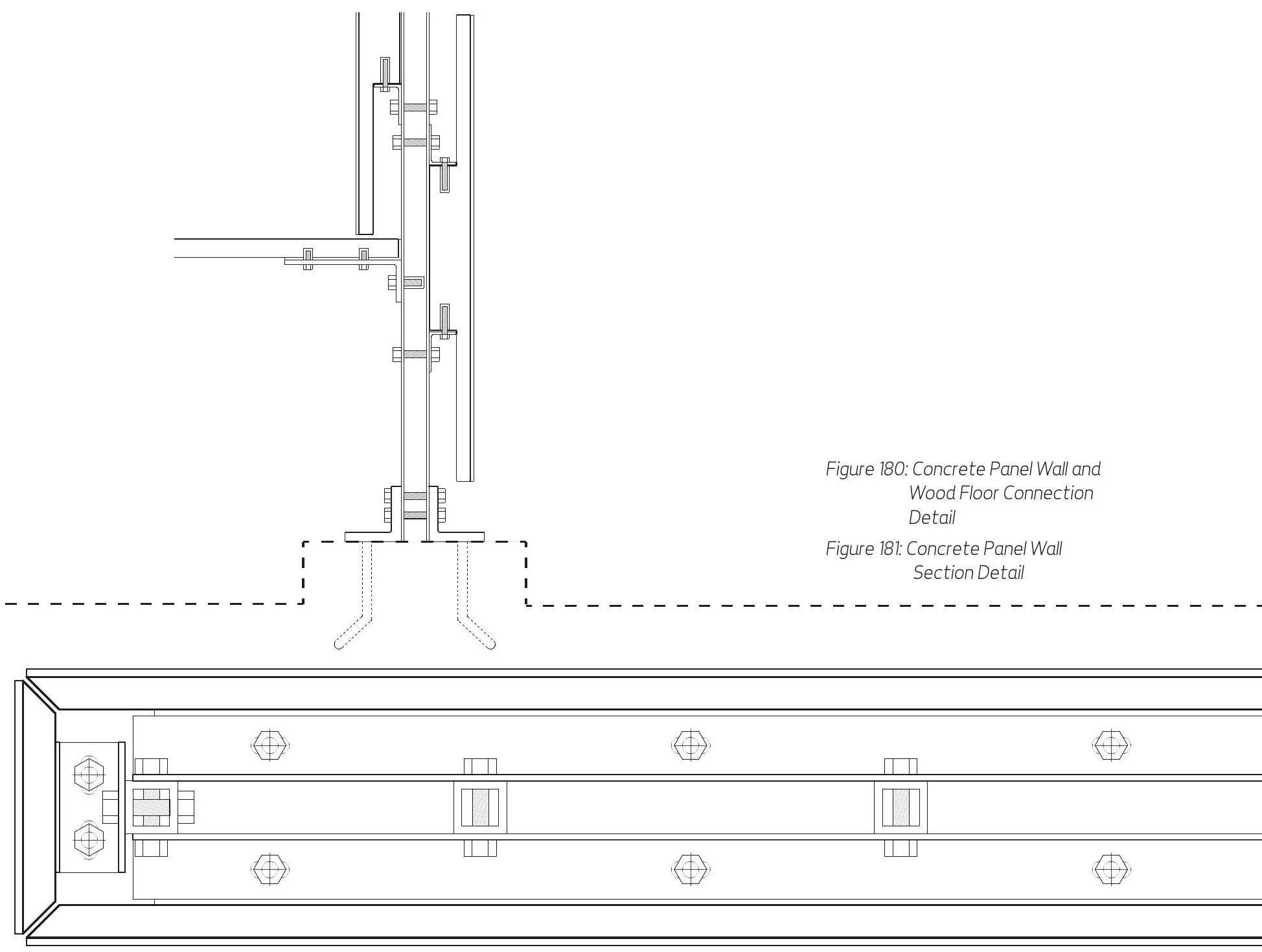


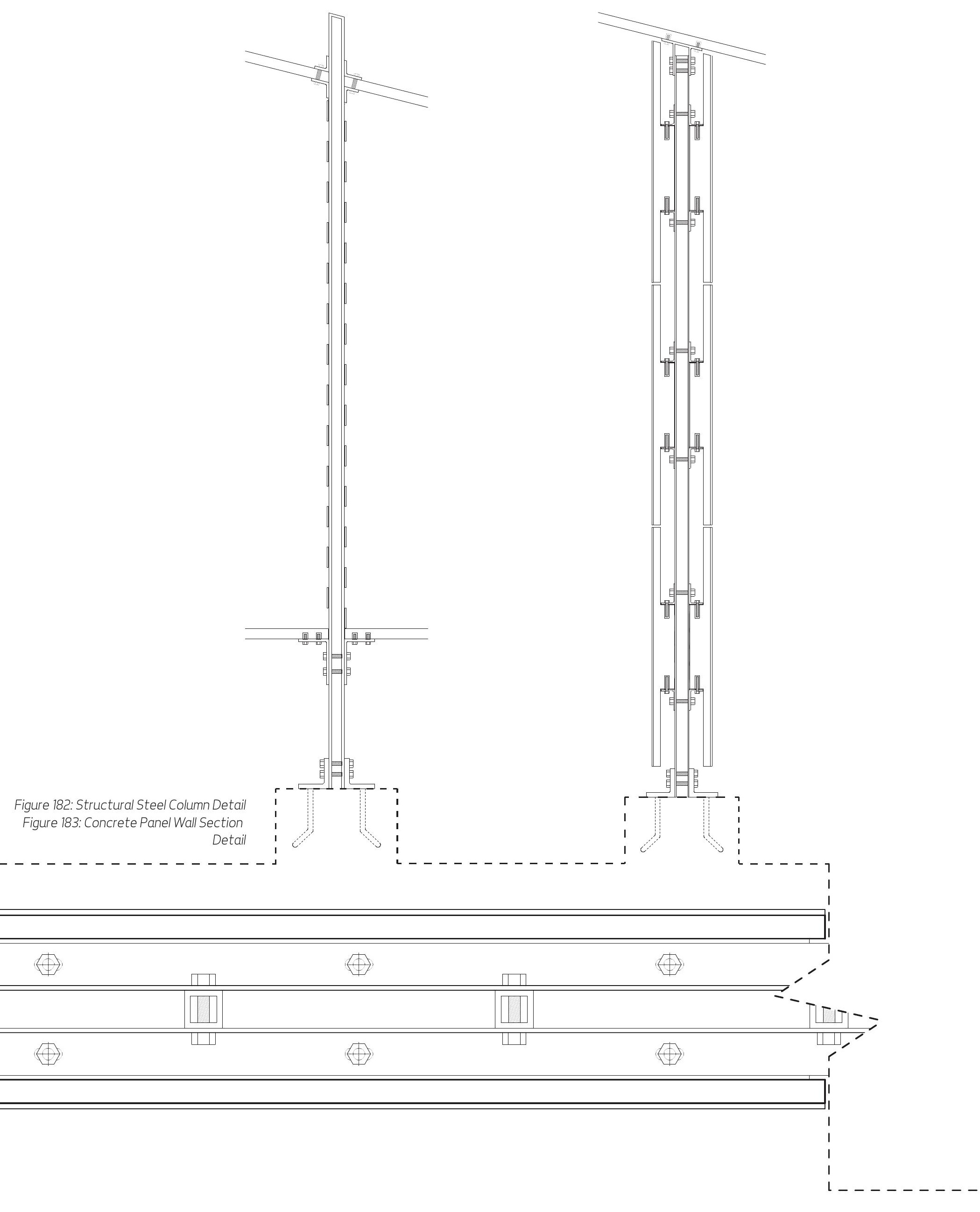




\section{MV5.4 - Making the Model}

After designing the details I immediately began to design the hut in virtual modeling software in a process which mimicked how I manually built earlier prototypes, starting not with form, but rather on the arrangement of the materials and their connections. This allowed me to integrate the material palate assembled during MV1-4 while further exploring in three dimensions the aesthetic and tectonic qualities of the Hut (Figures 184-189).

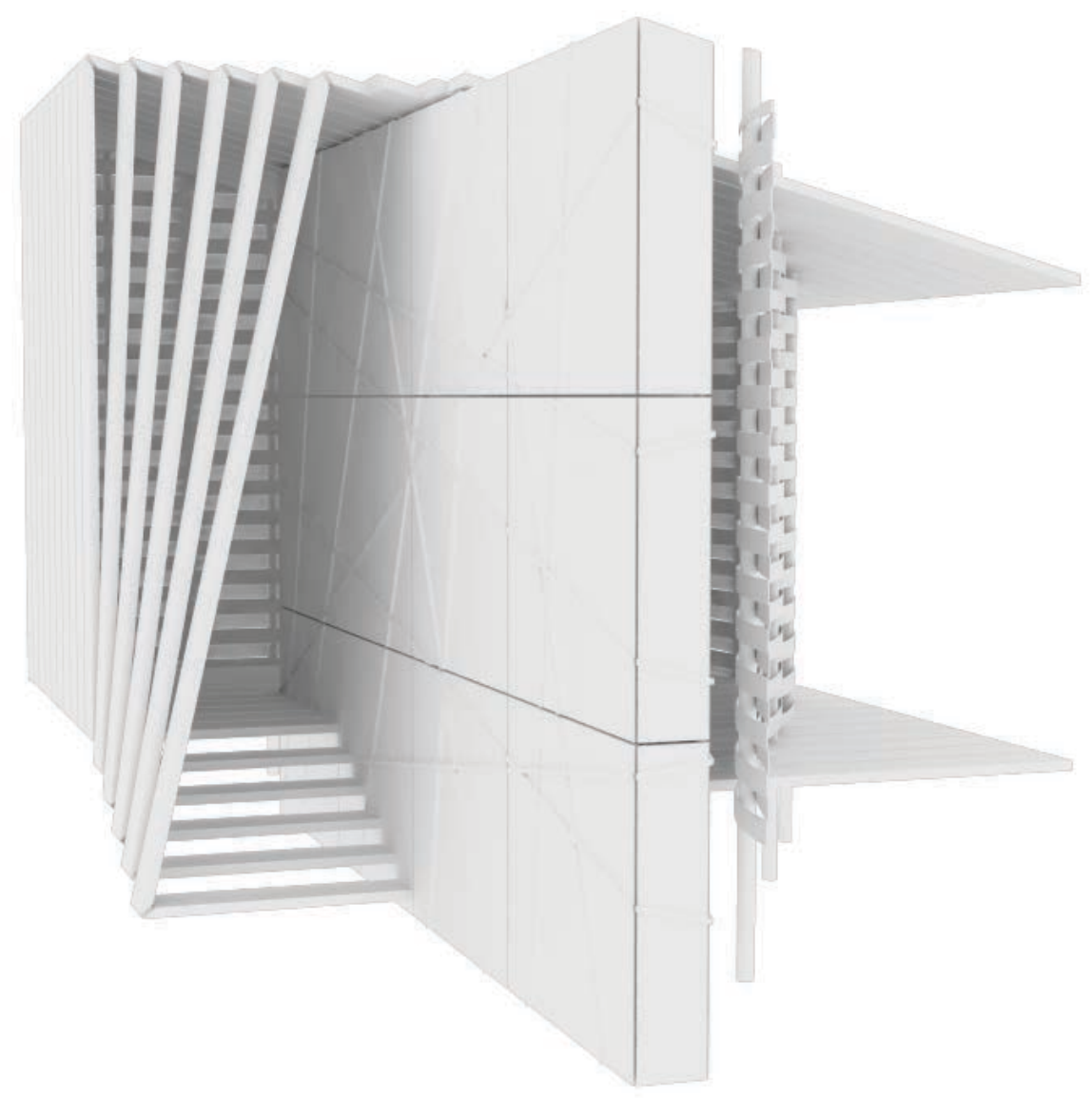

Figure 184: Exterior Render 1 Figure 185: Exterior Render 2 Figure 186: View towards Entrance

Figure 187: Interior Volume Figure 188: Interior Volume Figure 189: View towards Exterior
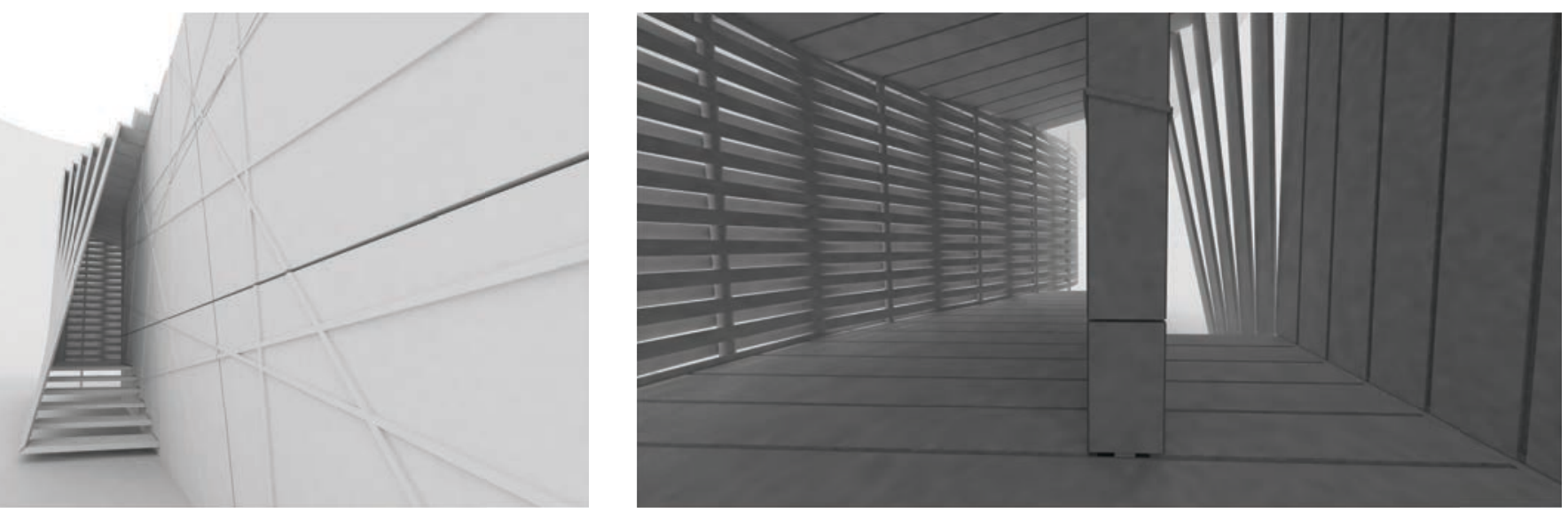

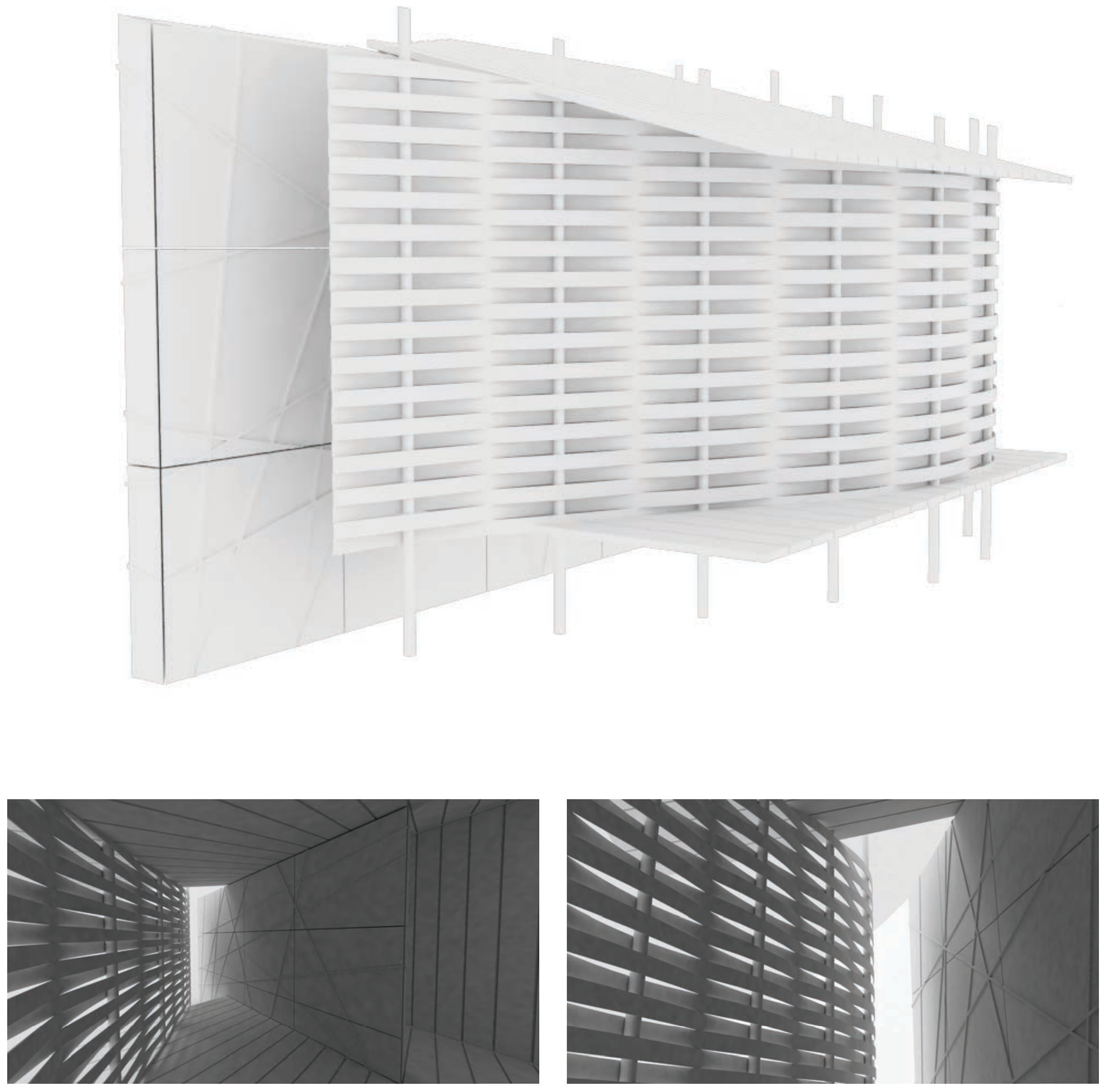


\section{MV5.5 - Plan, Section, Representation}

The conventional architectural devices of plan, elevation, and section were not engaged within the design process however were produced as a by product of the building of the three-dimensional model. They were pulled from the model as representational devices rather than exploratory artefacts (Figures 190-193).
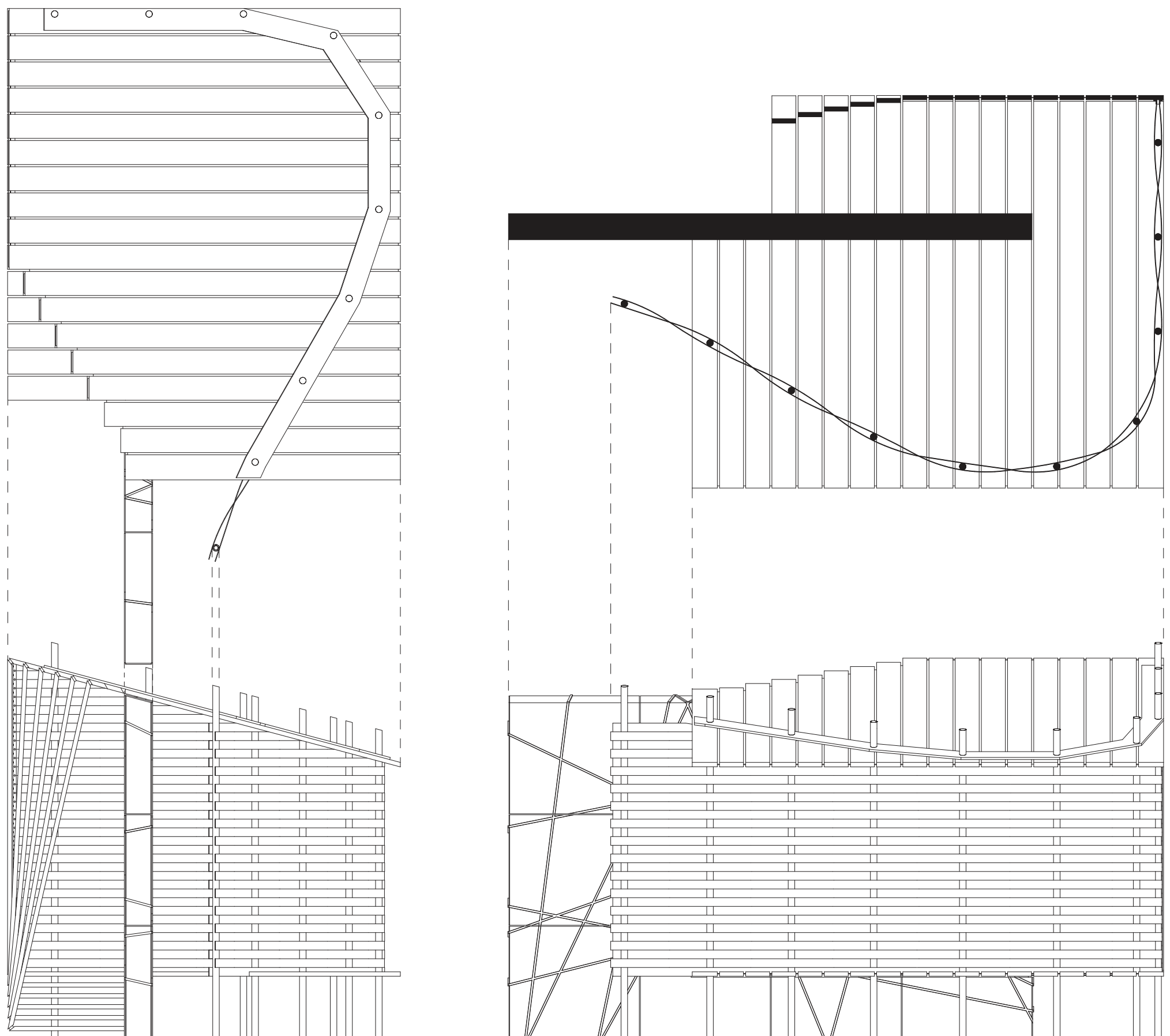
Figure 190: Roof Plan

Figure 191: Plan

Figure 192: Unfolded Section

Figure 193: Elevations
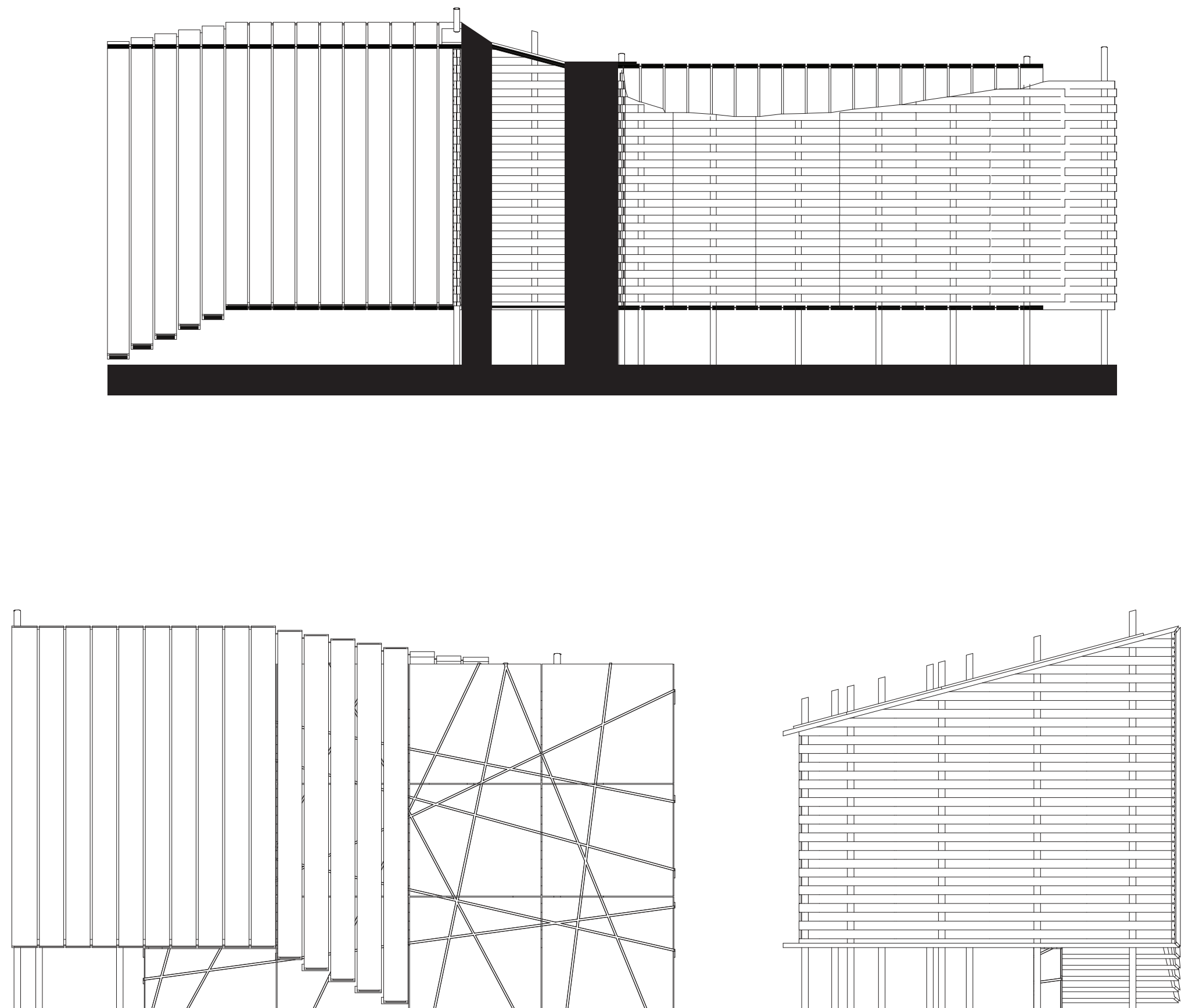


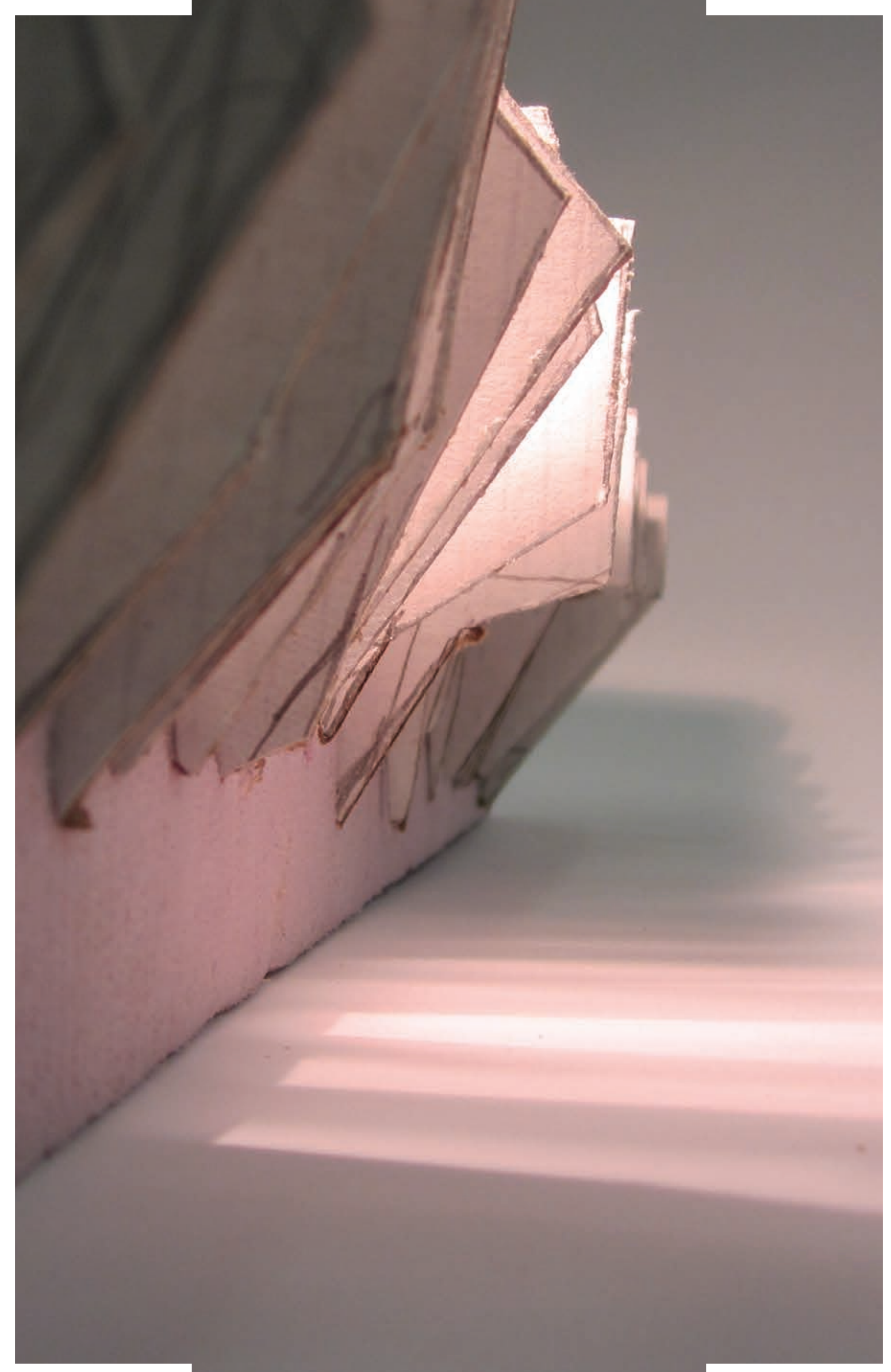




\section{A Manifesto of Architecture}

Embedded within the position that this thesis holds on the crucial role which making has within architectural design is an equally critical position on the nature and the essence of architecture. This position has been formulated as a response to the contemporary post-digital context in which architectural practice now functions. Designing in such a cultural condition, where the normative mode of design is virtualized, required a position which reconsiders the trajectory of architectural design in a post-digital ecology whereby architecture and technology are inherently linked in a mutualistic relationship. Discussing the possibility of architecture's existence sans the digital in contemporary society is a moot point as contemporary architectural praxis is wholly dependent on the digital and virtual. 
From this vantage my thesis is positioning, reconsidering, and reintegrating making as a process of design which relies more fully on the fundamentally physical nature of architecture. Engaging design through this material lens will better a designer's understanding of architecture at a remove from the highly representational. This method of design is being suggested in order to impart an experiential knowledge of architecture, one which is based on the tactile properties which are inherent to our built environment. Making is being positioned in the post-digital age as the most direct means of engaging architecture; drawing knowledge, inspiration, and an architectural intuition from its elemental material essence.

Functioning within this context there have been established a number of inherent positions on the nature of architecture which were fundamental in the conception of my core thesis position. These conditions are central to implementing and developing making as a central component of architectural design as they begin to unearth the emergent importance of the physical and tangible in the contemporary virtualized realm of architecture.

\section{In this light, what is Architecture?}

\section{Architecture is Flesh}

“...we are not just in the world, but of it." (Carman, 2008, p. 133)

This concept, which has been appropriated by Hale borrowing from Merleau-Ponty and Carman, draws a powerful parallel between the built and constructed environment and the human body through an analogy which attaches direct corporal meaning and identification with architecture (Hale, 2008, p. 514). An individual's flesh (inclusive of all its physicality and components; skin, musculature, arteries, organs, bones, etc...) is the medium through which our mind (the intangible) is connected with the external environment. Architecture fulfills a similar role becomes a quasi-prosthesis of our corporal self integrated as a means of engaging and understanding our environment. The notion of flesh is critical as it denotes a thickness, a materiality. This analogy is deliberate as it is all encompassing, disregarding notions of skin (envelope), bones (structures), or organs (building systems) but rather choosing the materiality of the 
body, its flesh, as the essence of architecture.

\section{Architecture is Material}

Architects make their mark through materials and in turn materials make their mark on humanity.

The fundamental nature of architecture is material. Even in its most intangible states (as an idea, representation, drawing, virtual model, etc...) the architect contemplates the recourse which an assemblage of materials will have on its occupants and surrounding environment. The reach of these material constructs is unending; traversing time and all facets of culture. They imprint themselves with permanence within the collective consciousness of humanity as they directly affect and shape our environment. The influence which architecture has stems from its ability to create a mark on and transcend time and space through materials.

\section{Architecture is Built}

The power of will is not enough to realize architecture. Architecture must be built, it must be constructed.

Whether simple or complex, an architectural design begs for construction. Its beauty lies in its assembly; in the meeting of materials, layering of components, integration of systems, and expression of details. These gestures imbue a work with an experience of recognition. One is able to read the touch of the craftsman's hands, feel the tension and energy embedded into materials and assemblies; acknowledging that these works are the result of great human effort, skill, and contemplation. The construction of architecture creates complex systems of shared experiences and relationships between user, maker, and designer breathing life and humanity into architecture.

\section{Architecture is Technology}

Techne + Logos to Logos + Techne. 'Knowledge of Construction' to 'Construction of Knowledge' (Hale, 2008, p. 524)

Engaging their tools the craftsman no longer differentiates between 
themselves and their technology, rather gaining an awareness of the tool as an extension of the self. This phenomenon, known as technological embodiment, occurs as a technology transforms into an artefact for both 'construction' and 'construing' (Frascari, Monsters of Architecture: Anthropomorphism in Architectural Theory, 1991, p. 107); an object which encapsulates both thinking and making. Re-conceptualizing architecture as technology draws from this critical extension. Architecture is no longer simply enclosure or shelter but rather a material edifice through which one is able to better perceive our environment. As a technology architecture allows one to create personal and corporeal adjacencies with their environment as a generative means of creating knowledge and understanding.

\section{Architecture is Tectonic}

The construction of architecture is both an art and science.

This critically inherent duality of art and science, present within all architectural works, necessitates an understanding of architecture which spans the creative and the technical. Through viewing tectonics as one of the seminal tenants of architecture a design framework can be established through which to conceive of architecture; one which prizes neither the technical or creative but rather integrates them holistically. It is therefore critical when designing architecture that a thorough experience and understanding of materiality and construction be ascertain from which it then can be applied.

\section{Architecture is Mediator}

It is through architecture's material presence in the world that humanity is able to find it's place.

The architect's capacity to bring together creative and technical abilities in the realization of architectural works is paramount to humanities ability in creating meaning within the world. Architecture is manifest as a material construct and is able to mark both time and space through its physical presence. It is through this marking that 
we attach meaning; architecture is simultaneously signifier and signified. It is through a sensorial experience of architecture that the work becomes an extension of the self, enveloping while protecting and offering permanence in a continually shifting landscape.

\section{Architecture is Process}

A realized architectural work is the sum total of a multitude of processes.

The importance of process within architectural design must not be overlooked. Each step taken, or not taken, leads the architect down a multiplicity of paths whose powerful influence is unforeseen. Given the breadth of knowledge involved in creating architecture it is critical that the designer is able to engage as many of these paths as possible in order to ensure a well-rounded architectural approach to their design. As architecture is both material and built it is crucial that these primary architectural conditions be an integral part of the design process for the lack thereof could lead down paths that are disastrous. While hindsight is 20/20, engaging a well rounded process of design sharpens the architect's foresight.

These tenents speak of developing an architectural framework through which the designer is able to conceptualize architecture as a necessarily material practice. In understanding the base essence of the profession as material, and in approaching architecture as an extended version of the self (whether initially as designer or later as occupant) a habitable artefact will emerge that embraces the sensorial and intimate connection which can be formed with architecture. This relationship is beneficially two parted; as designers we inform architecture and retrospectively architecture informs us.

The longevity of an architect's work is far greater than their own. For once the design is constructed and the endless hours of theory, conversation, explanation, and design development closed, the work must speak for itself. As a building ages and its novelty wears the architect's intentions will fade as well. Its conceptual drivers will give way to the human experience which will decide 
the success of a work regardless of its intentions and theoretical underpinnings. The architecture's history, present, and future will be contained within its materials, expressing itself for those that care to search. 


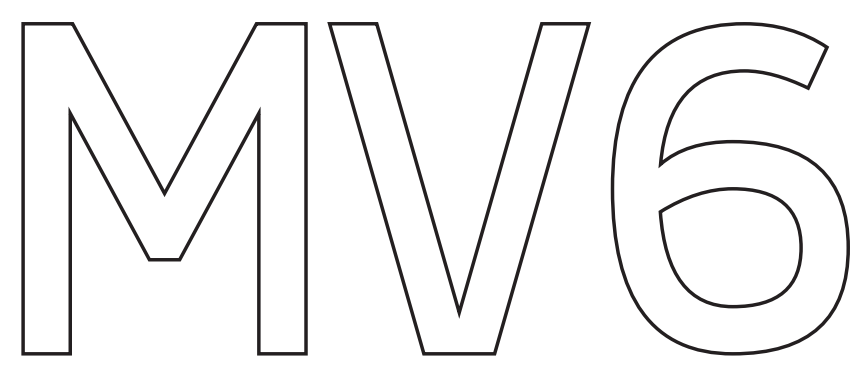

making version six

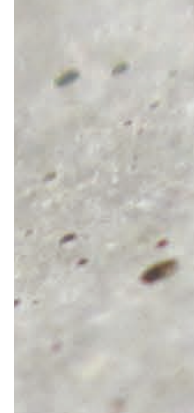


Making Version 6: An Architecture of Materiality developed three architectural conditions and an architectural typology which responded to the previous version of making (MV1-5) along with both the Manifesto of Making and Manifesto of Architecture. Deeply embedded within the processes, artefacts, and positions produced during the course of this thesis were omnipresent architectural gestures which spoke directly of an approach to architecture which draws heavily on architecture's foundation as a material craft. These conditions of thickness, immediacy, and connection are products of designing architecture through materials. They serve to imbue the emergent architecture with qualities which encourage a stimulated haptic experience.

\section{Architecture of Thickness}

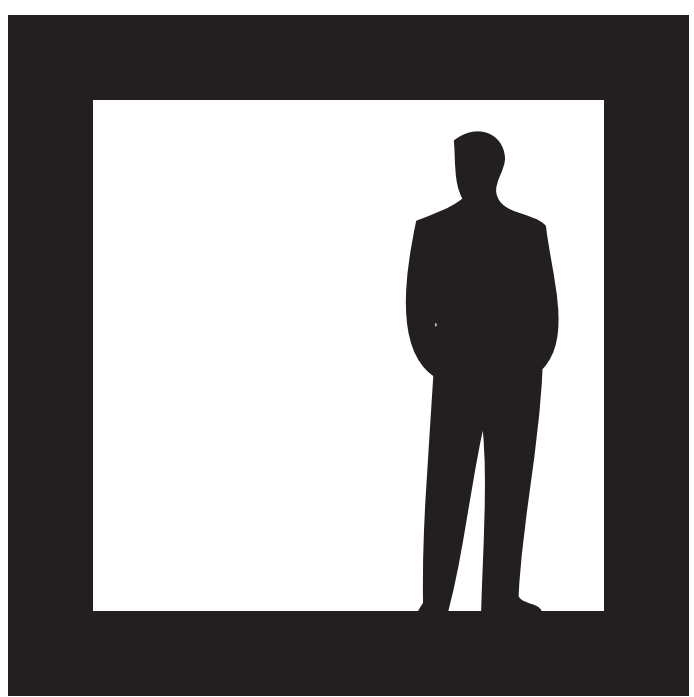

Architecture which announces itself as a material construct and engages the physicality (thickness) of materials as a formal means of expression 


\section{Architecture of Immediacy}

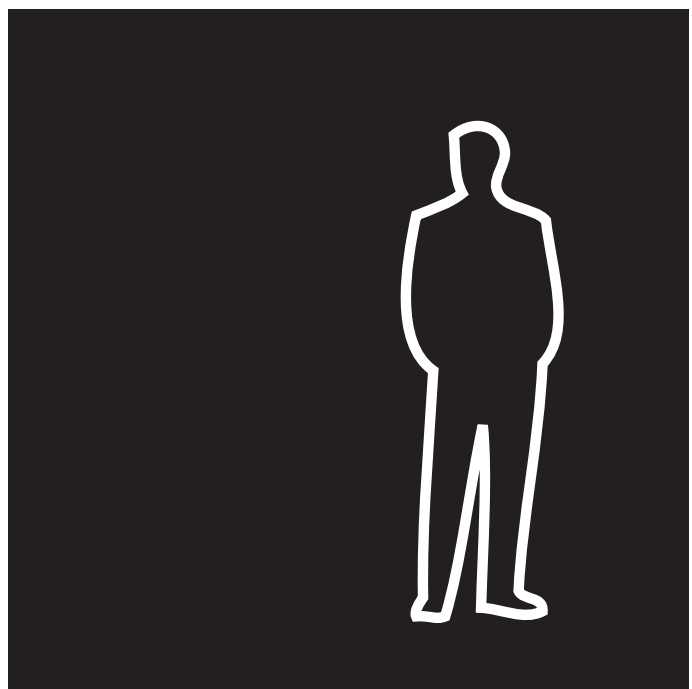

Architecture which provides opportunity for direct contact and a sensorial/tactile experience

\section{Architecture of Connection}

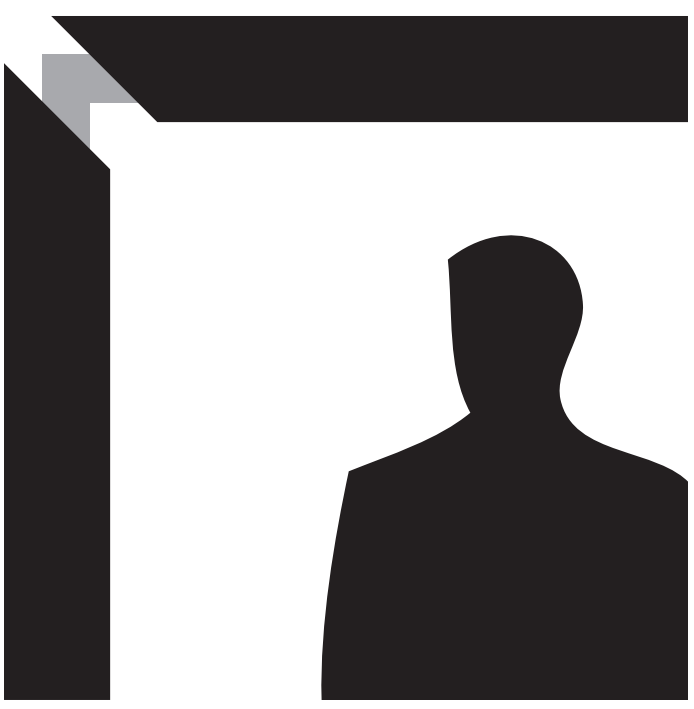

Architecture which is honest in its material and built nature, celebrating its joints, connections, details, and assembly as a tectonic craft 

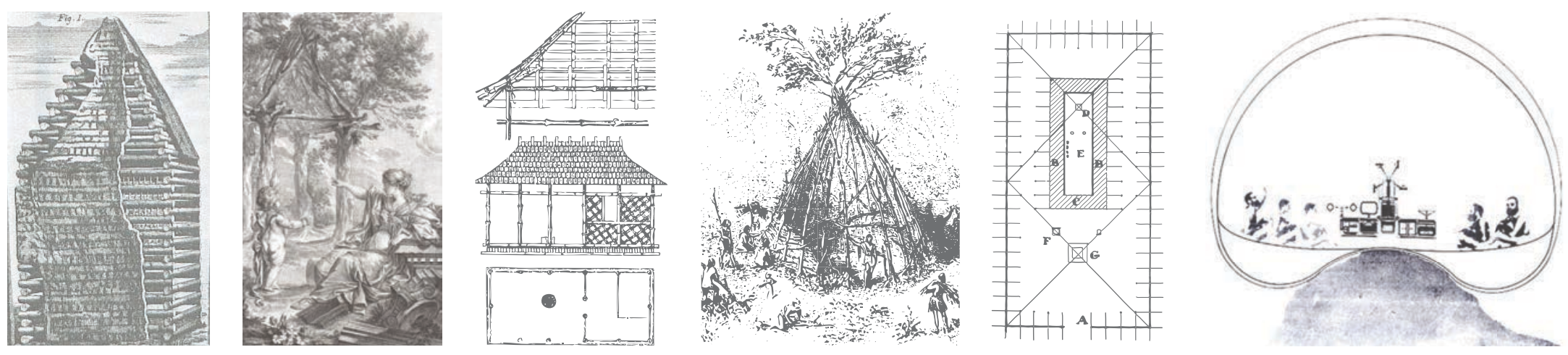


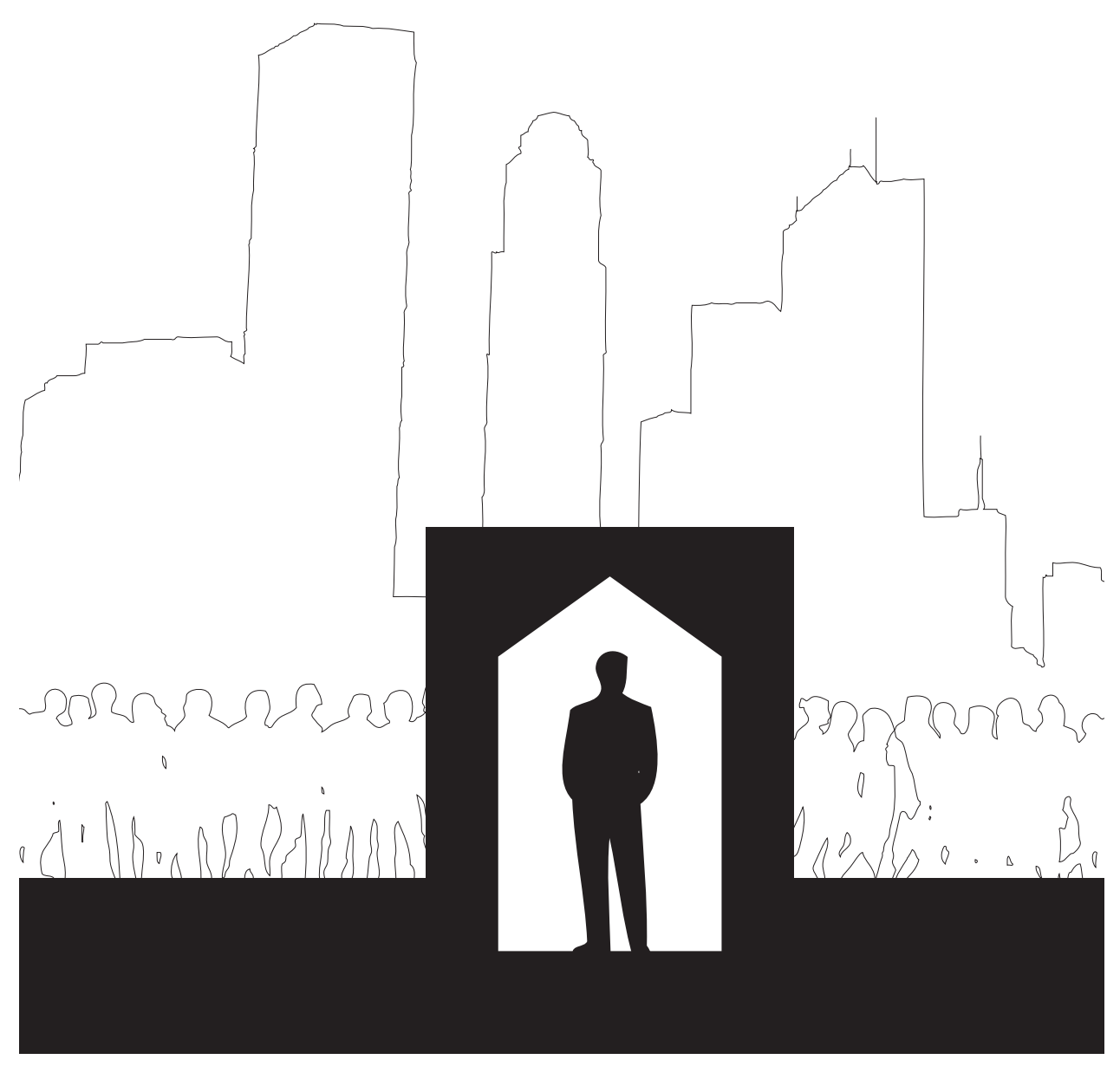

Architecture which is created in a post-digital context must remain grounded. Relying solely on digital design technology for creating architecture can lead to a shallow and naive understanding of the material foundations of the build environment. Through engaging making as a critical component of the design process a fullness of both architectural design and architectural experience can be achieved. 


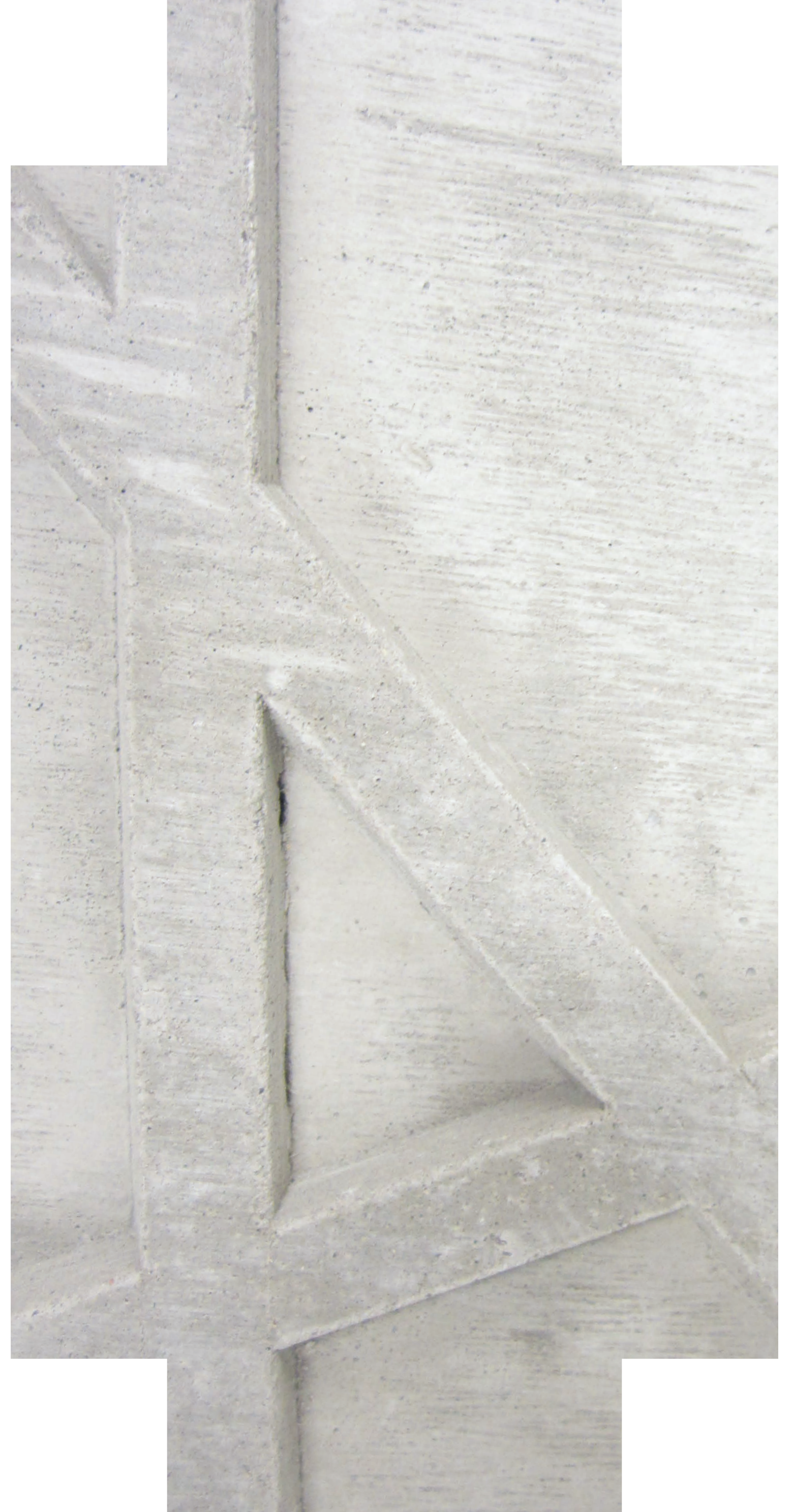


chapter 11

\section{Primitive Hut [Re]-Treat}


[Re]-Treat is the primitive hut of the post digital age.

[Re]-Treat offers refuge from the digital, virtualized, and representational

[Re]-Treat offers security and shelter

[Re]-Treat embraces

[Re]-Treat connects users with architecture through materials

[Re]-Treat is in direct contact with the user through materials

[Re]-Treat puts the user in direct contact with the flesh of architecture

[Re]-Treat puts users in direct contact with the germ of architecture 
[Re]-Treat is a space of clarity. It offers users respite from the fast-paced fleeting nature of contemporary life spurred on by the ubiquity of the digital and virtual. Achieved by developing an architecture from a design process steeped heavily in making, [Re]-Treat brings users intimately close to the fabric of the built environment. By reconnecting the users with the material foundation of architecture the development of an architectural perspective based on a haptic and sensorial immediacy is possible.

The context in which [Re]-Treat, a post-digital primitive hut, will be located is urban. The urbanite spends vast amounts of time interfacing which technologies of virtualization, experiencing the world through screens of mediation. [Re]-Treat will offer a permanent location for temporary relief and connection. 

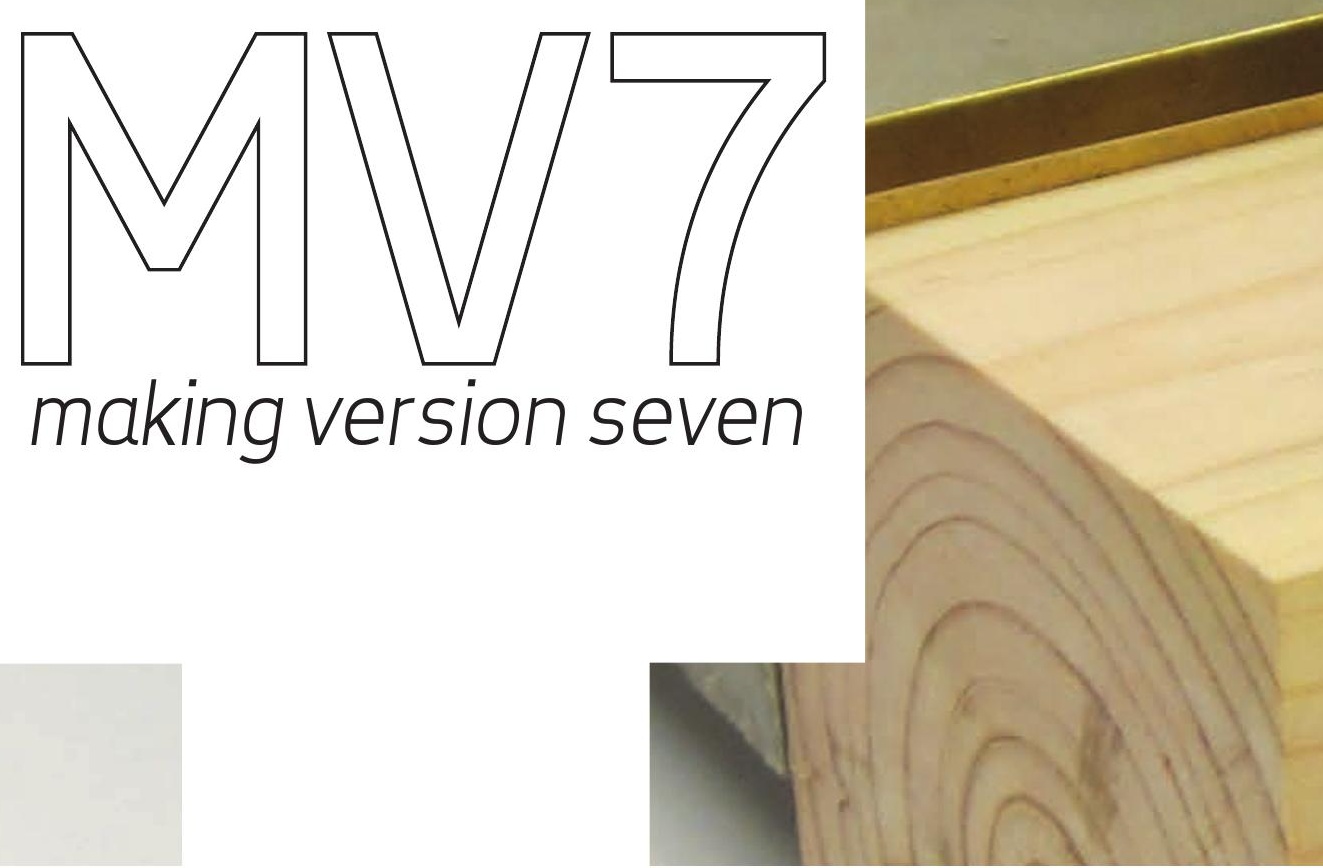


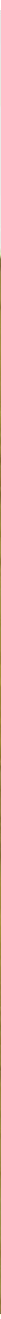



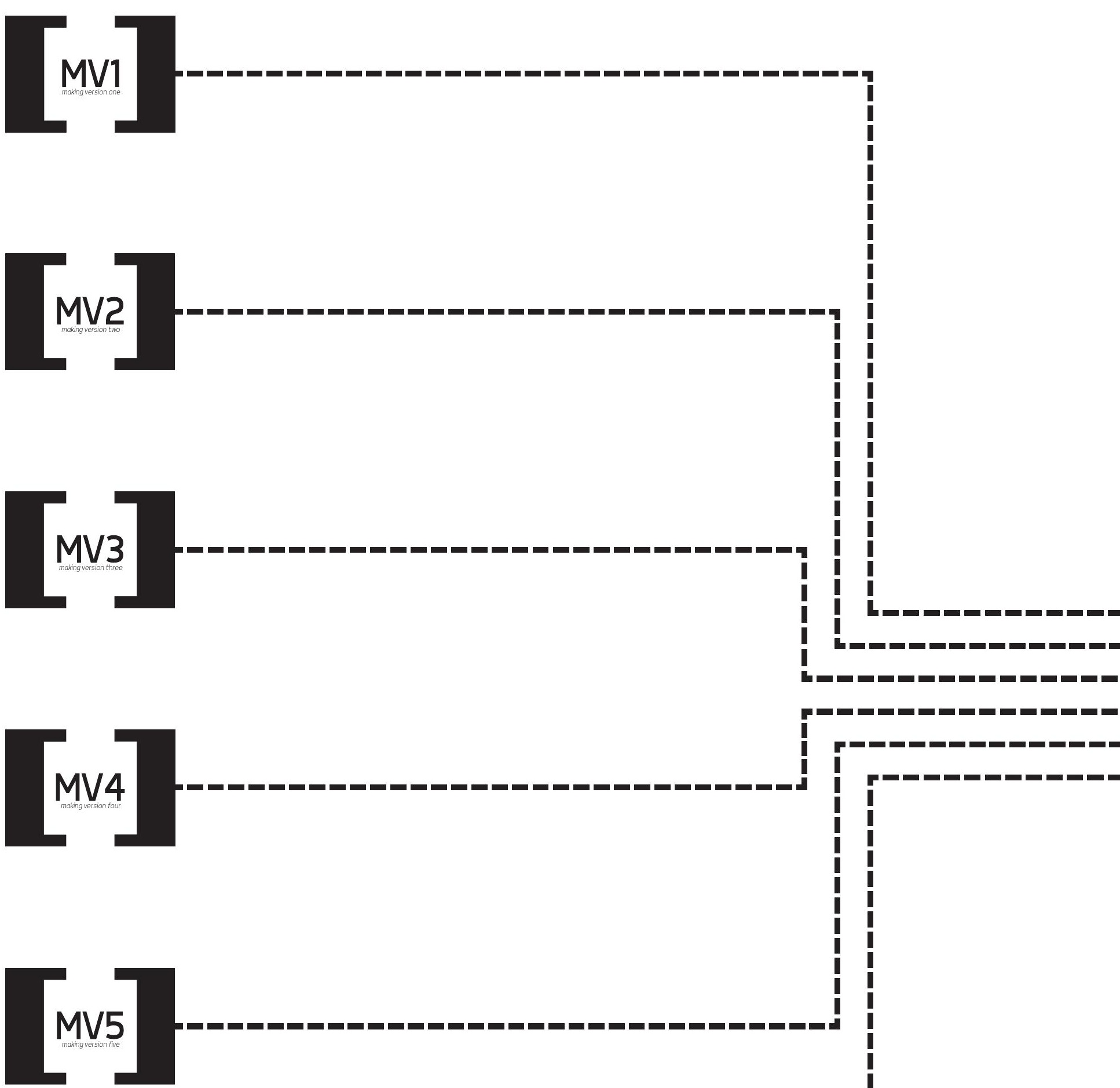

I

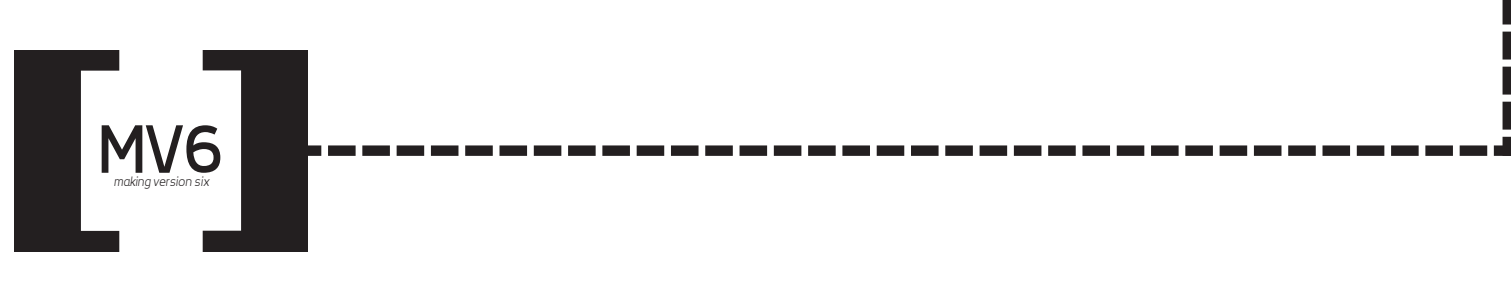

181 


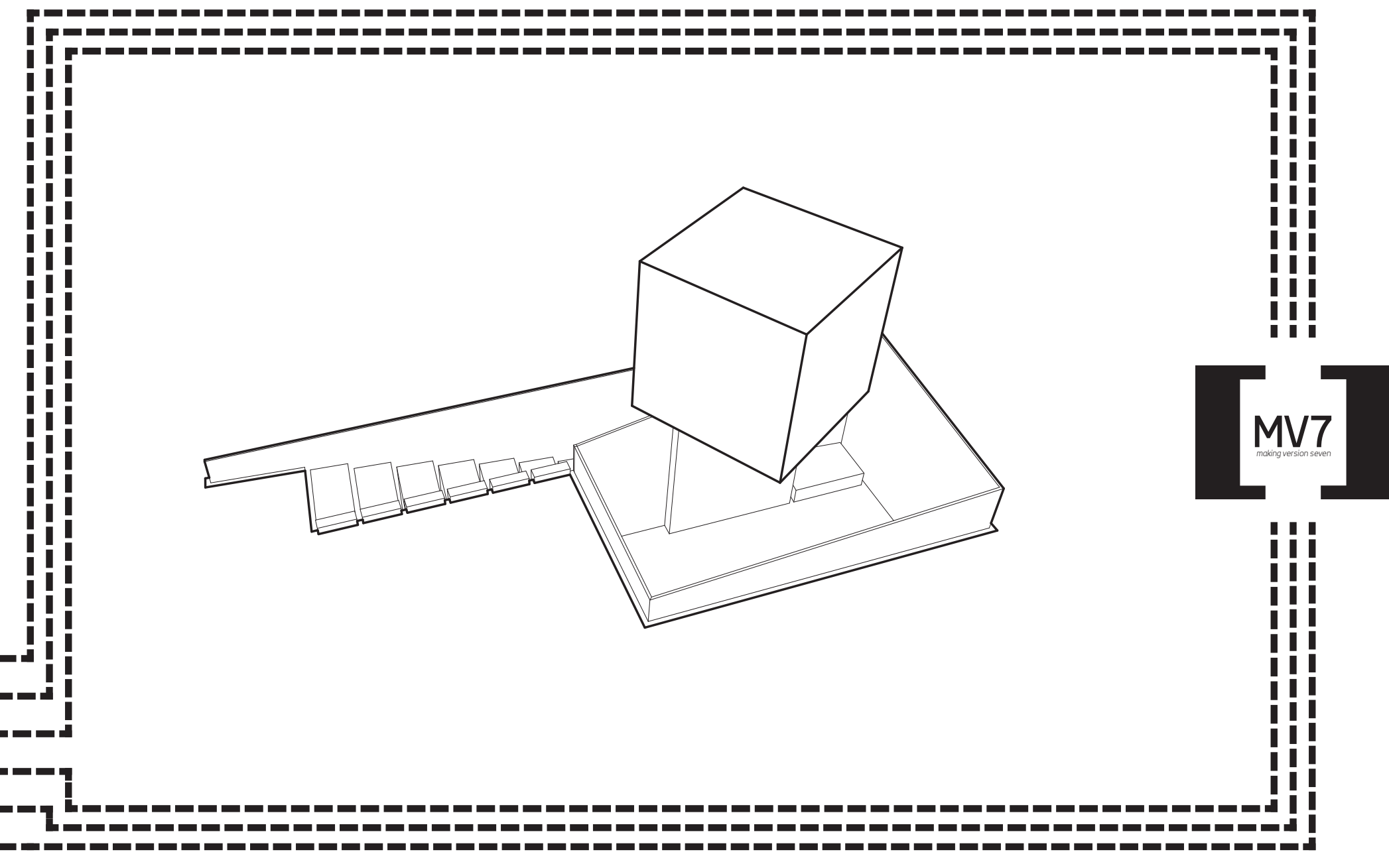

Making Version 7 [Re]-Treat is a product of all previous versions of making (one through six) as well as the manifesto explorations. [Re]-Treat reflects a methodology, process and approach to architecture that leans heavily on the richness of materials, the process of construction, and the tangible experience of designing and occupying architecture. 

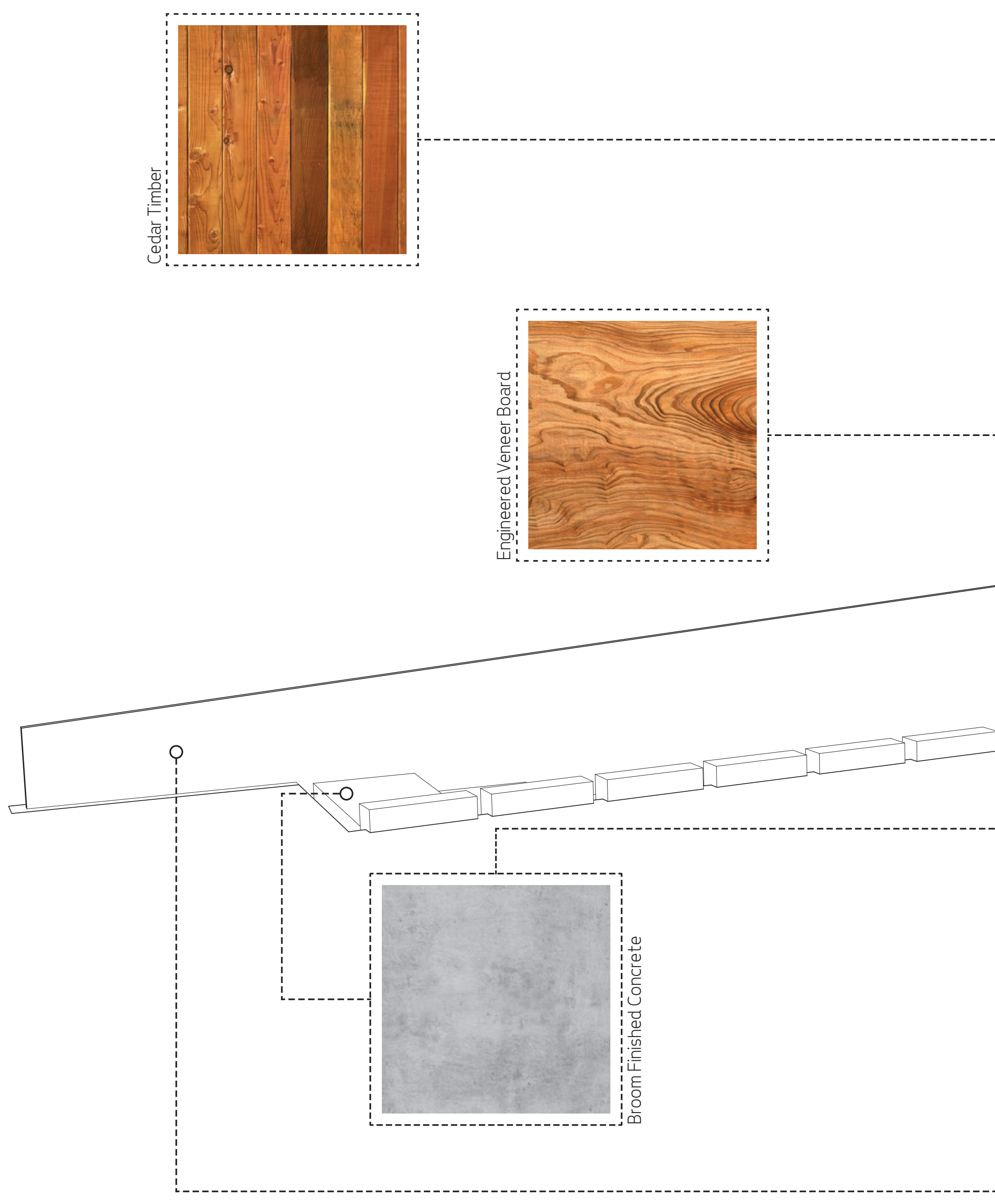


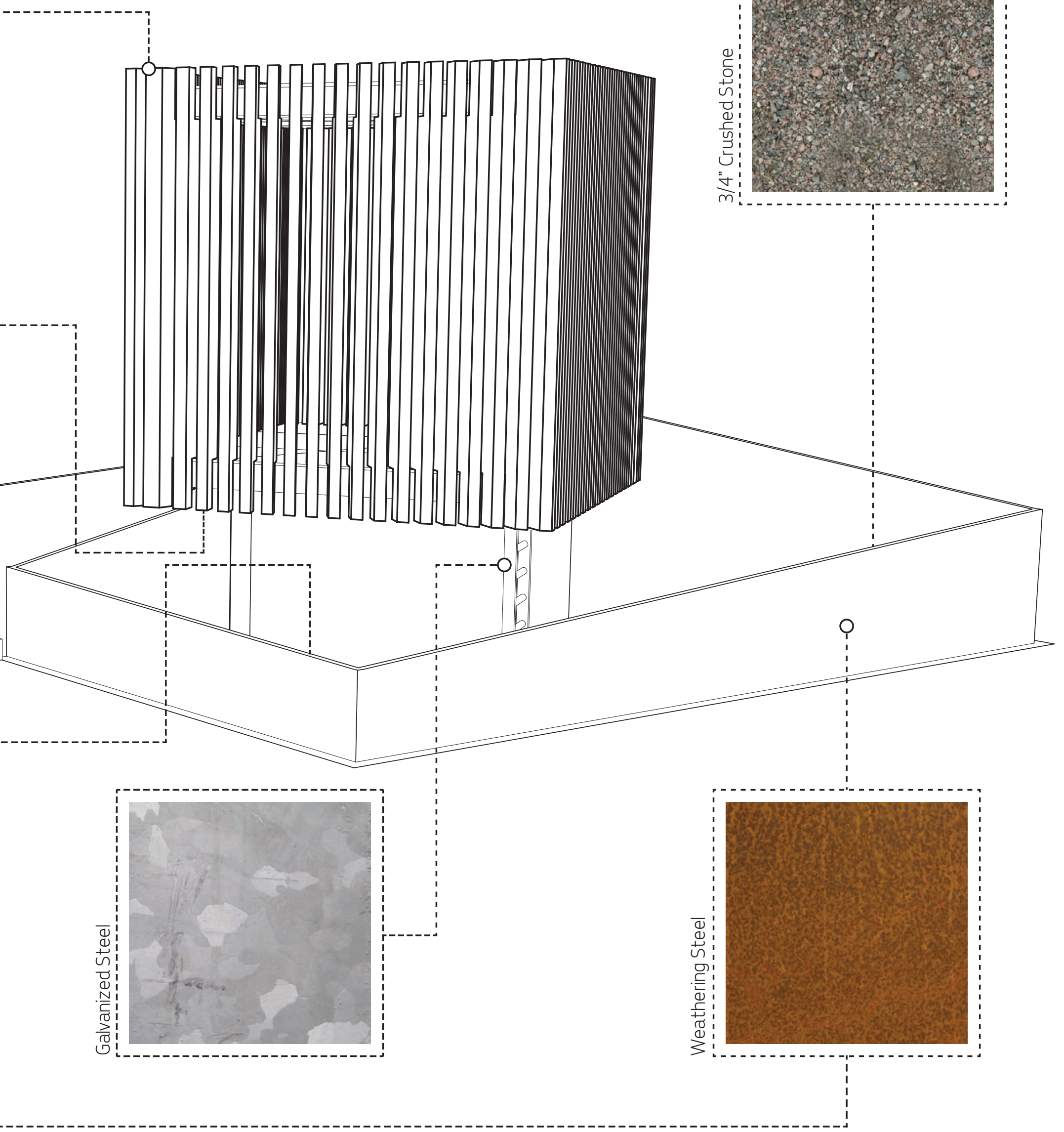




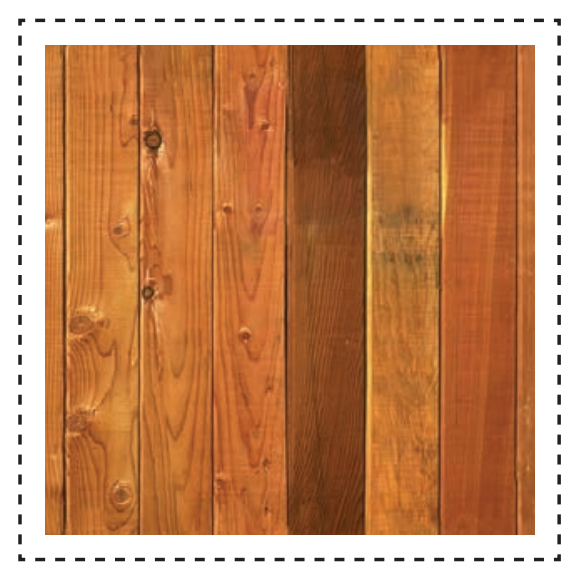

\section{Cedar Timber}

Employed exclusively for constructing the Hut portion of [Re]-Treat, cedar timber was selected for its structural and aesthetic qualities. The warmth and range of natural colours of the cedar, along with its richly textured grain, provides a contrast between the other materials employed solidifying the Hut as the occupiable focal point of [Re]-Treat. The recognizable and aromatic scent of cedar further strengthens the visceral qualities of the hut lending to a unique architectural experience within the urban context.

Weathering Steel

Framing the physical limits of [Re]-Treat, weathering steel has been used to express the formal boundaries of the project as well as enclosing the inner courtyard. Selected for its unique aging qualities the steel walls encompassing the project will mark, in a visible and tangible manner, the passage of time. This notable transformation in both material colouration and texture will shift the user experience of [Re]-Treat as it ages, becoming a permanent yet experientially ephemeral part of the urban landscape.

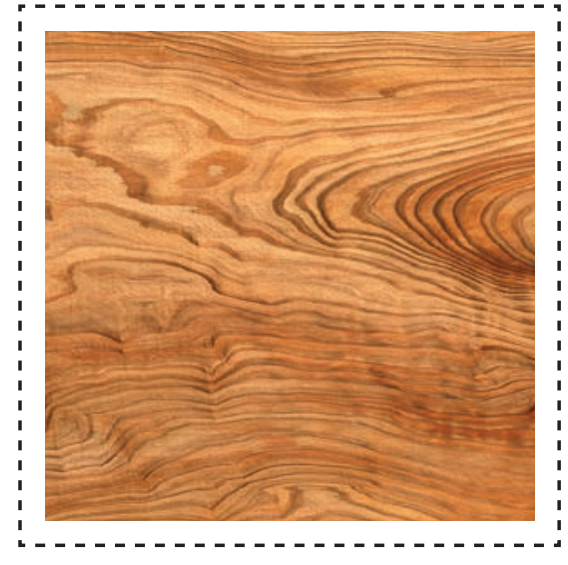

\section{Engineered Veneer Board}

Layered into the [Re]-Treat hut, engineered veneer board was selected to define both the floor and ceiling conditions. This particular material would be custom made in order for each face to show large scale wood grain. The rich textural pattern as well as the warm colouration of the board would serve to accent the spatial and material qualities of the hut. 


\section{Broom Finished Concrete}

Pre-cast for the stairs and cast-in-place for the benches, the broom finished concrete elements are grounded monoliths within [Re]-Treat. As the treading of users continually shifts the landscape of the crushed stone courtyard these solid components remain unmoved, exuding a sense of permanence.

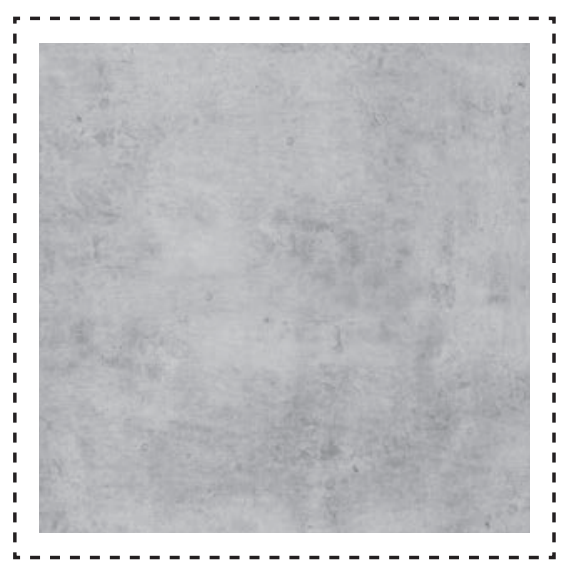

3/4" Crushed Stone

Covering the entirety of the interior courtyard, 3/4" crushed stoned provides a unique flooring surface which would normally not be encountered within the urban environment. This material has been used exclusively for the courtyard floor in order to juxtapose the solid flooring materials found elsewhere within the project and context. The textural difference as well as the acoustic changes caused by the particulate underfoot alters the aural character of the inner courtyard with each step.

Galvanized Steel

Integrated as both structure and circulation, the galvanized steel ladder leading up to the hut provides a cool and marked difference in materiality to the warmth of the wooden enclosure. The steel here acts as an intermediary between the roughness of the stone courtyard below and the finished qualities of the hut above.

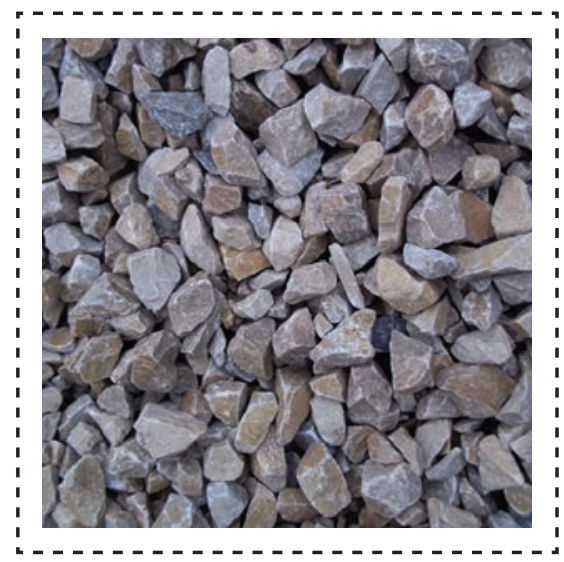




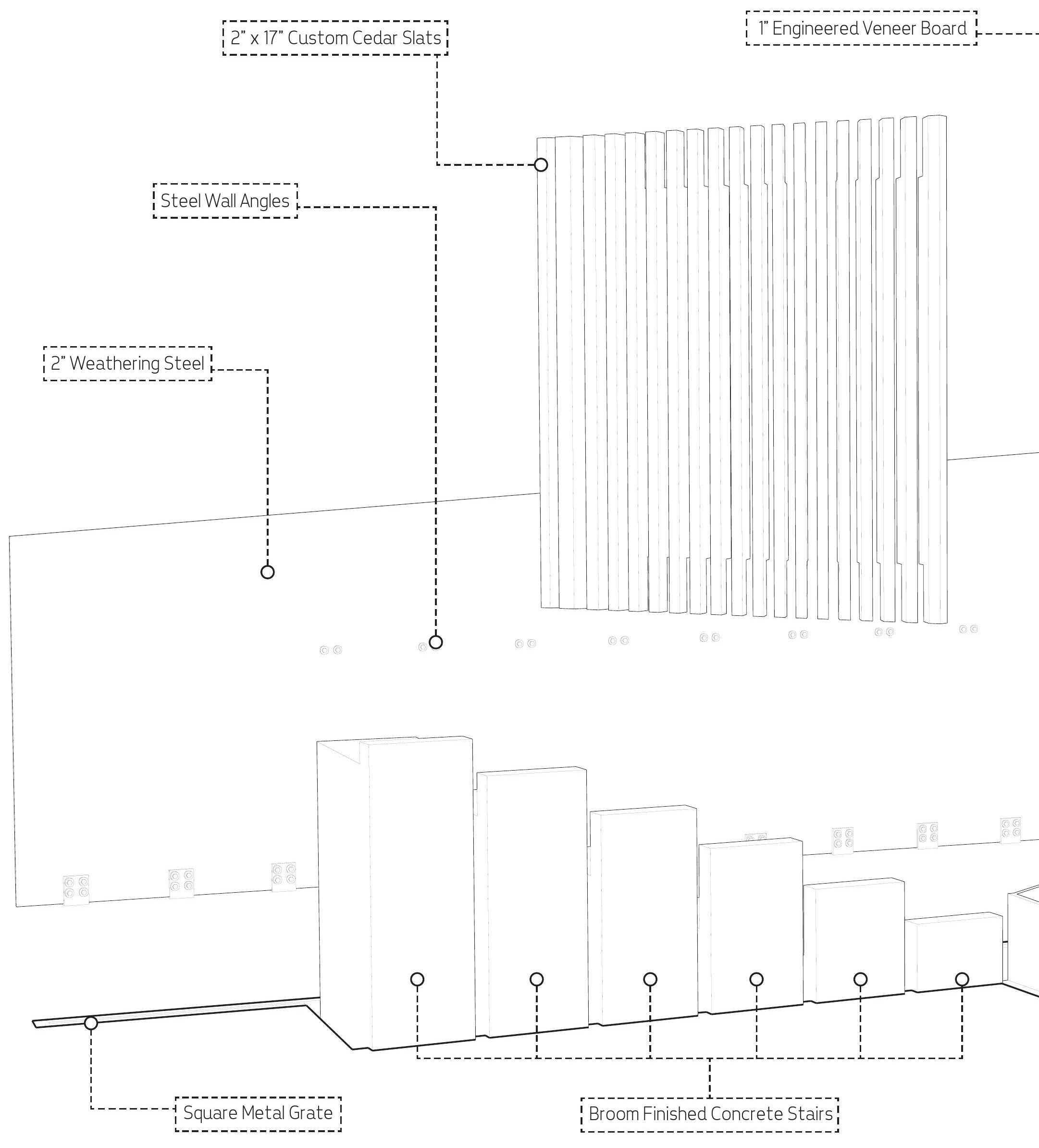


[Re]-Treat Construction Process

(1) Excavation

(2) Footings, Slab, \& Retaining Wall

(3) Cedar Timber Posts

(4) Weathering Steel Walls

(5) Concrete Stairs

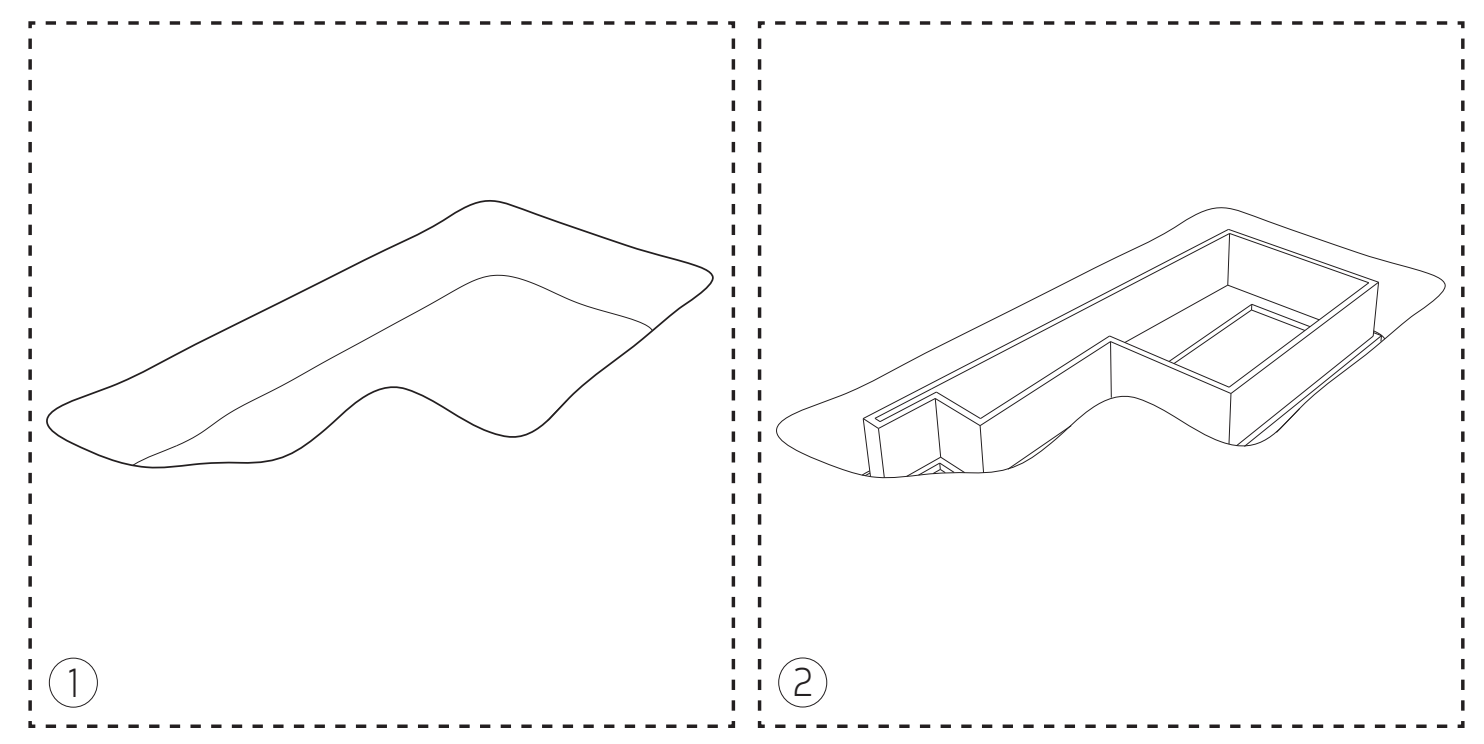

(6) Ladder Installation

(7) Cedar Timber Floor Construction

(8) Cedar Timber Wall and Ceiling Construction

(9) 3/4" Crushed Stone Placement

(10) $[$ Re]-Treat

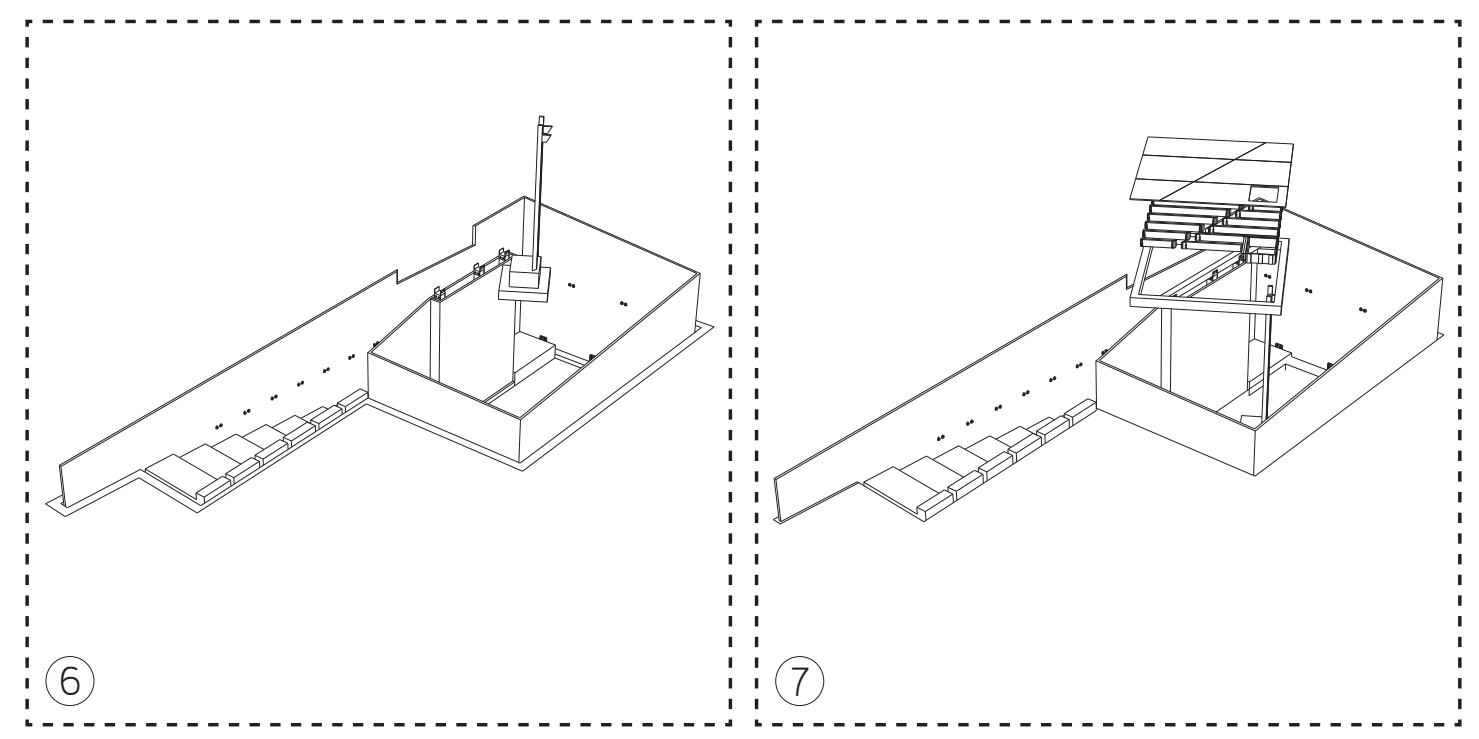



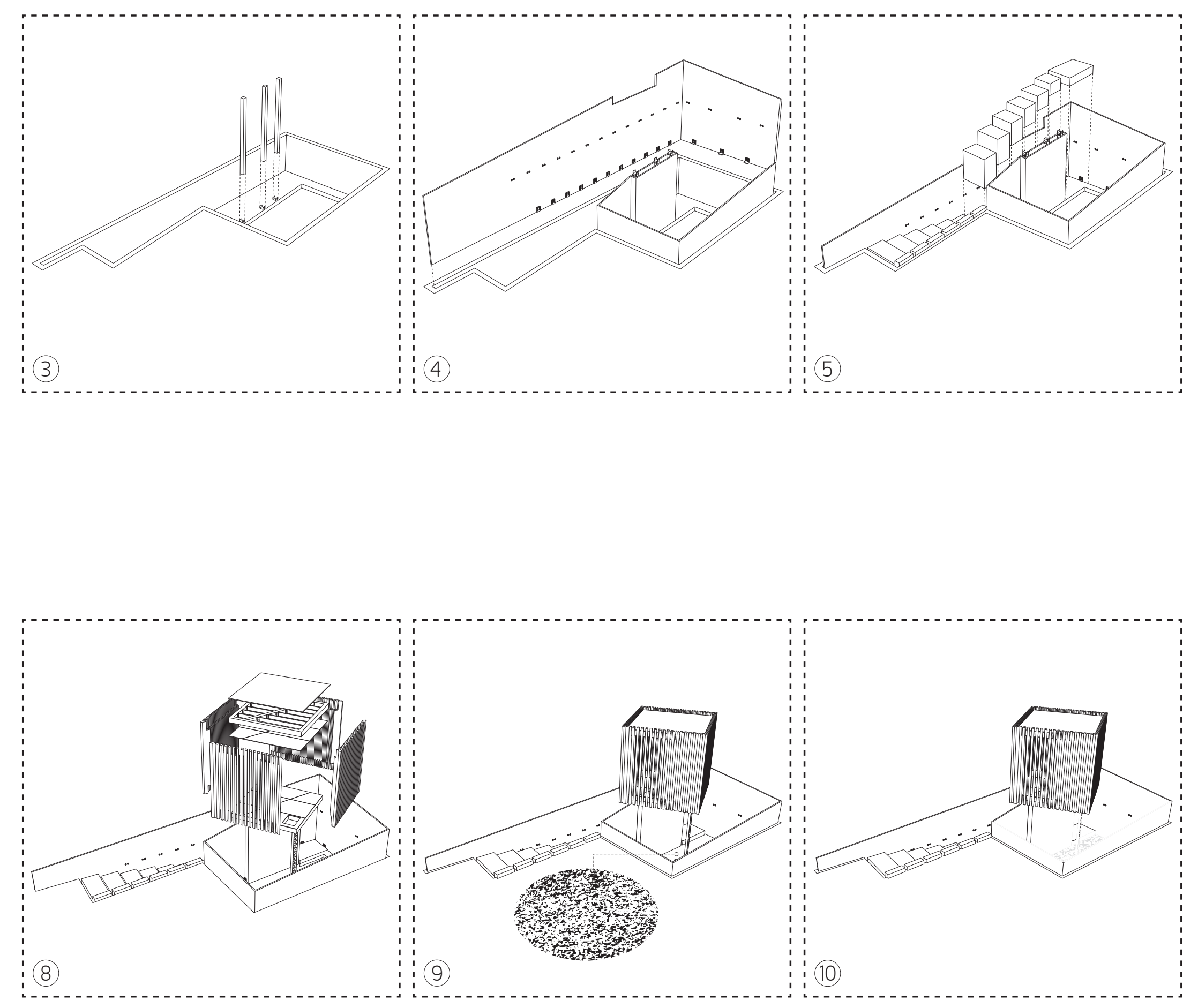

Figure 205: Construction Process Diagram 
Wood Slate Detail 目
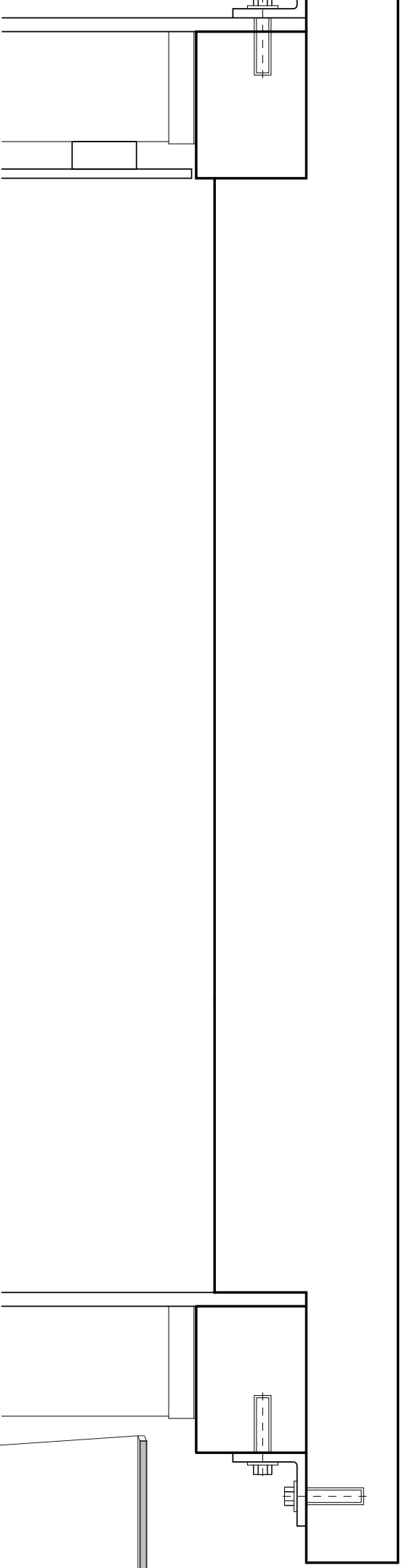

250

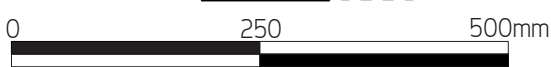

Figure 206: Section and Details
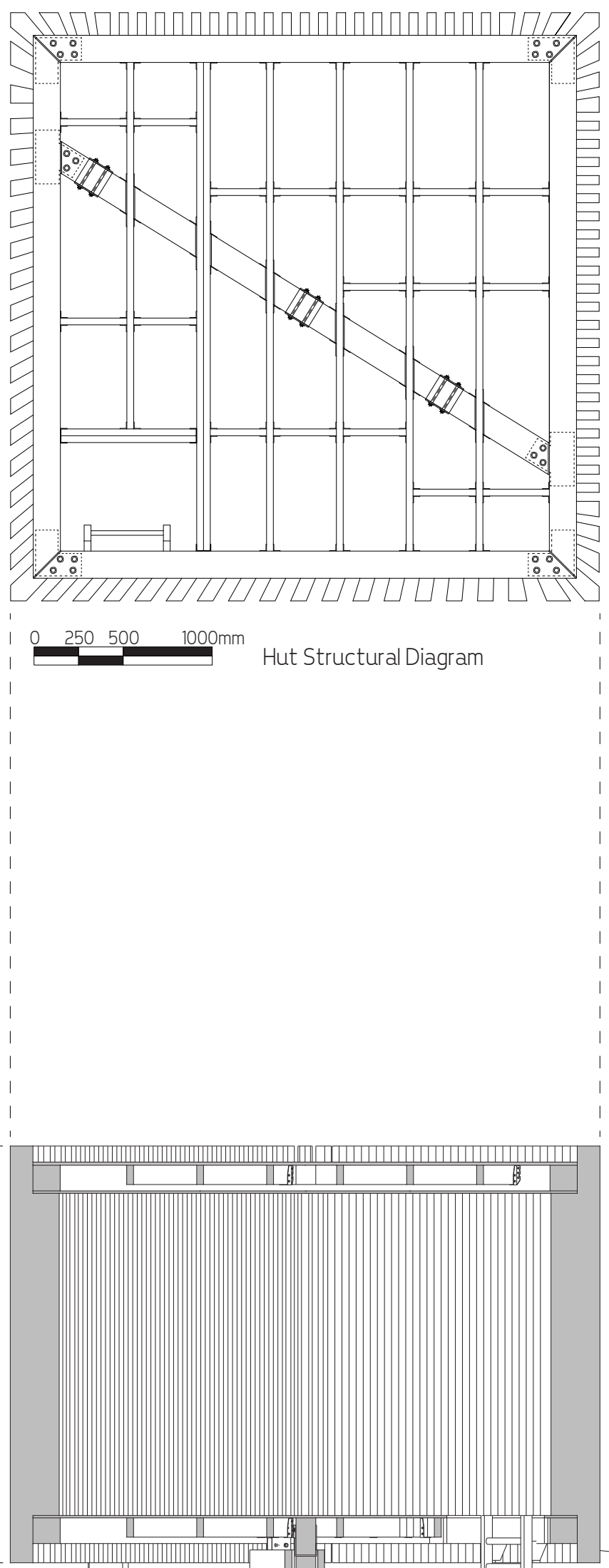

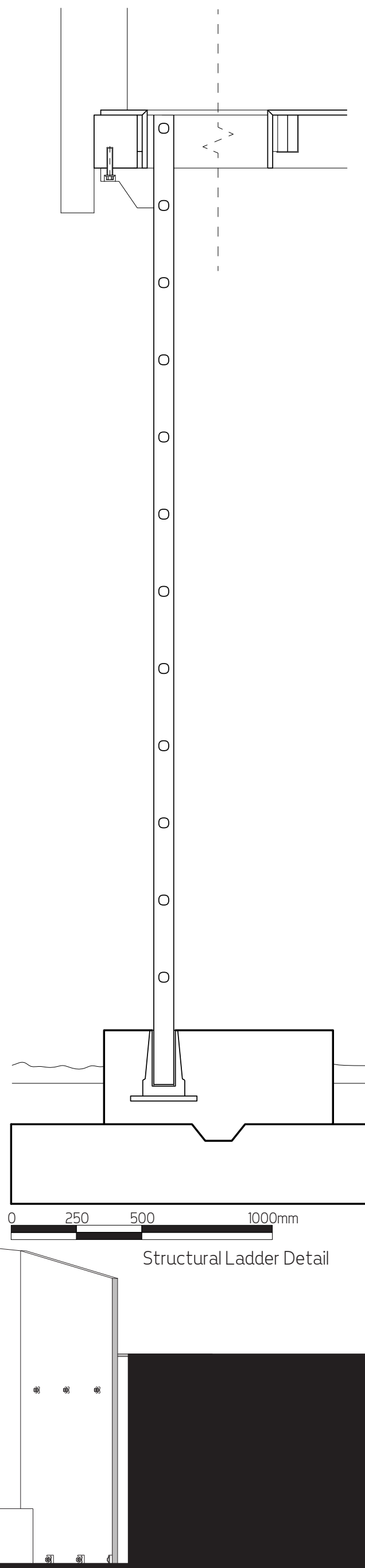


[Re]-Treat Plans

\section{(1) Approach}

Rooted within our fast-paced contemporary cityscape, [Re]-Treat presents itself as a still oasis for pause and reflection. As one encounters the weathering steel boundary walls, which rise and fall with each turned corner, and the cedar timber hut rising above them, views of the interior courtyard become readily accessible. Rounding the north elevation, the weathering steel wall breaks to allow the northern corner of the hut to push through. This singular condition allows fleeting views into the circulation of [Re]-Treat and subsequently views to the urban environment when one is descending into the courtyard. The cut-out also sets up a hierarchy of architectural elements whereby the hut is established as the focal point of [Re]-Treat.

\section{(2) Descent}

Stepping onto the broom finished concrete stairs one begins their descent into the courtyard. Each stair has been designed as an individual concrete pillar, offset from the surrounding walls and stairs in order to be properly read and experienced as a singular component. The deep crevices which form between these concrete monoliths bring the act of descending and ascending to the forefront of one's consciousness, heightening one's experience of this distinct and elongated threshold.

\section{(3) Courtyard}

Stepping off the final riser and into the courtyard one will immediately notice the textural difference underfoot. The crushed stone carpeting the floor of the courtyard serves to illuminate the processes of construction undertaken in the building of [Re]-Treat. Glancing around the courtyard evidence of the construction process has been left exposed; the visual rhythm set by the steel wall bolts, the structural framing exposed on the underside of the hut, and, through shifting the crushed stone, the bolted metal angles anchoring the weathering steel walls to the foundations. The visual and haptic accessibility of these processes cements in one's mind the tectonic craft which underscores all architectural works. Found within the south-west corner of the courtyard is a red maple tree whose continual growth, seasonal loss of foliage, and light to deep red colouration marks, in terms shorter than the weathering steel, the passage of time. 


\section{(4) Ascent}

Moving upwards into the hut space requires one to interact closely with the galvanized steel ladder, a circulatory and structural device. As one climbs, each rung brings one closer to the structural framing of the timber hut, closer to a fuller understanding of the processes behind its construction.

\section{(5) Hut}

Pulling oneself up into the hut, the striking environmental difference from the courtyard below is immediately felt. The strong scent of cedar coupled with the warm tones of the wood creates an enveloping environment. Standing within the cubic volume of the hut the views afforded towards the cityscape and the courtyard are intentionally directional. Views towards the context are provided only partially, the slating showing only glimpses of the context to the north-west and north-east. Juxtaposing this, the cedar slats have been angled in order to offer a full panorama towards the courtyard below. It is from within this intimate space that one is able to reflect and connect with architecture viscerally, experiencing its richness of materials and processes of construction.

(1)

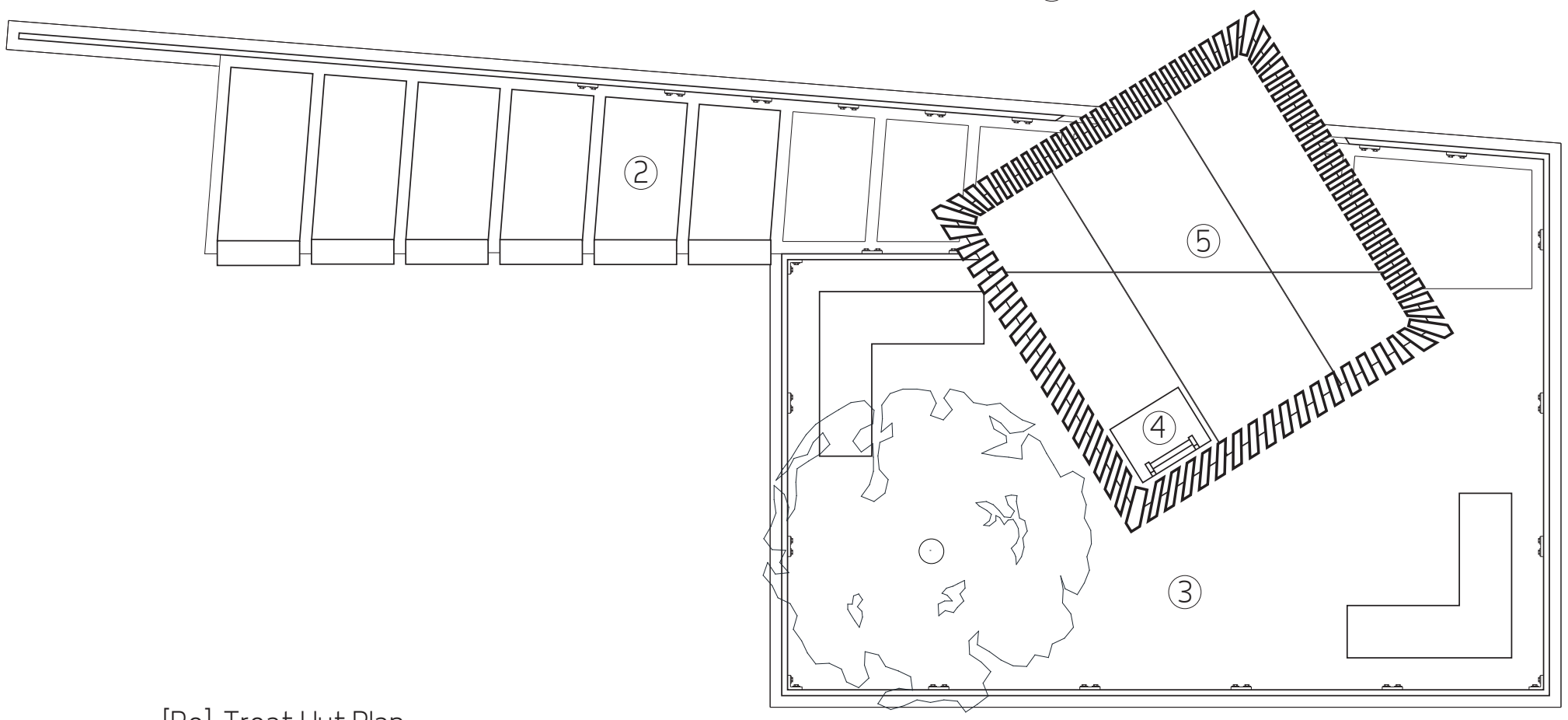

[Re]-Treat Hut Plan

(1) 


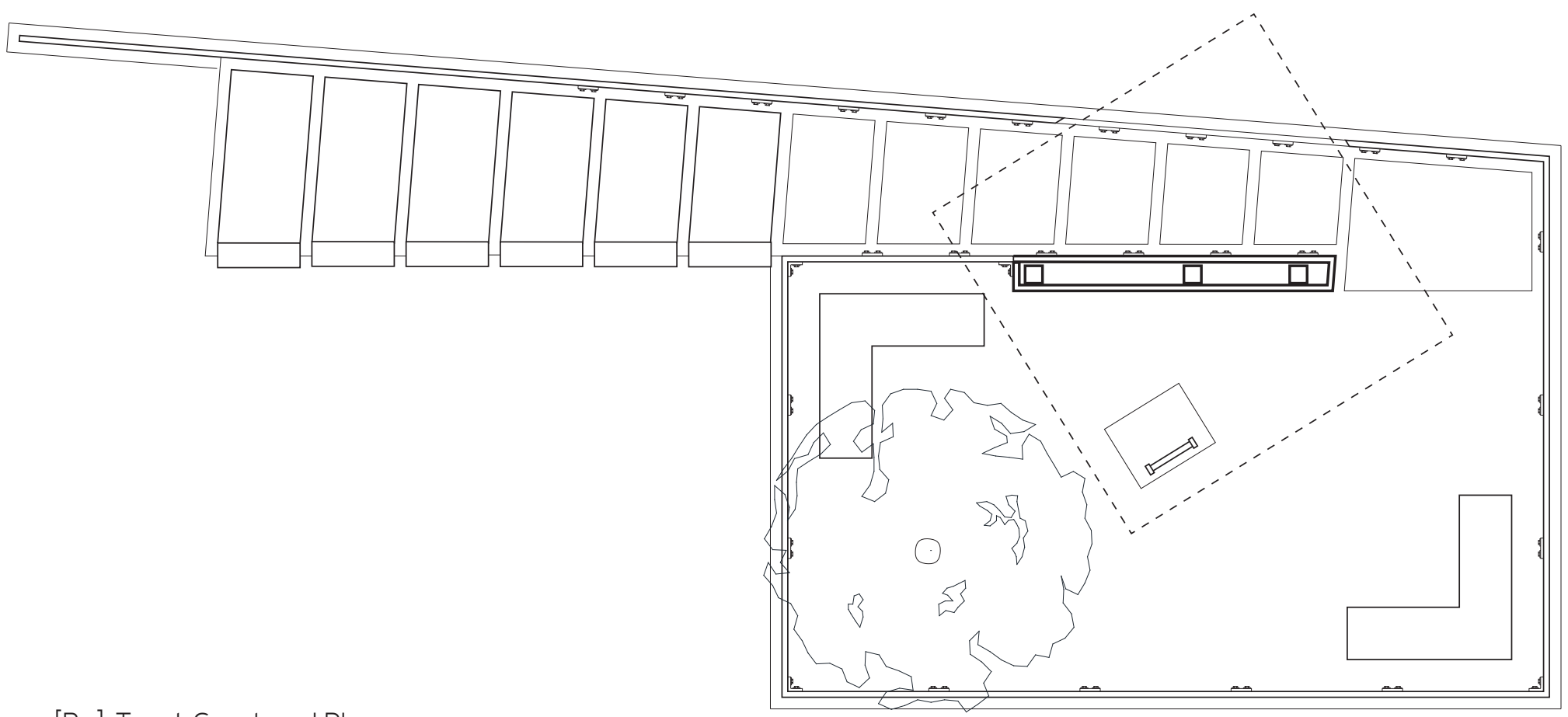

[Re]-Treat Courtyard Plan

(1) 


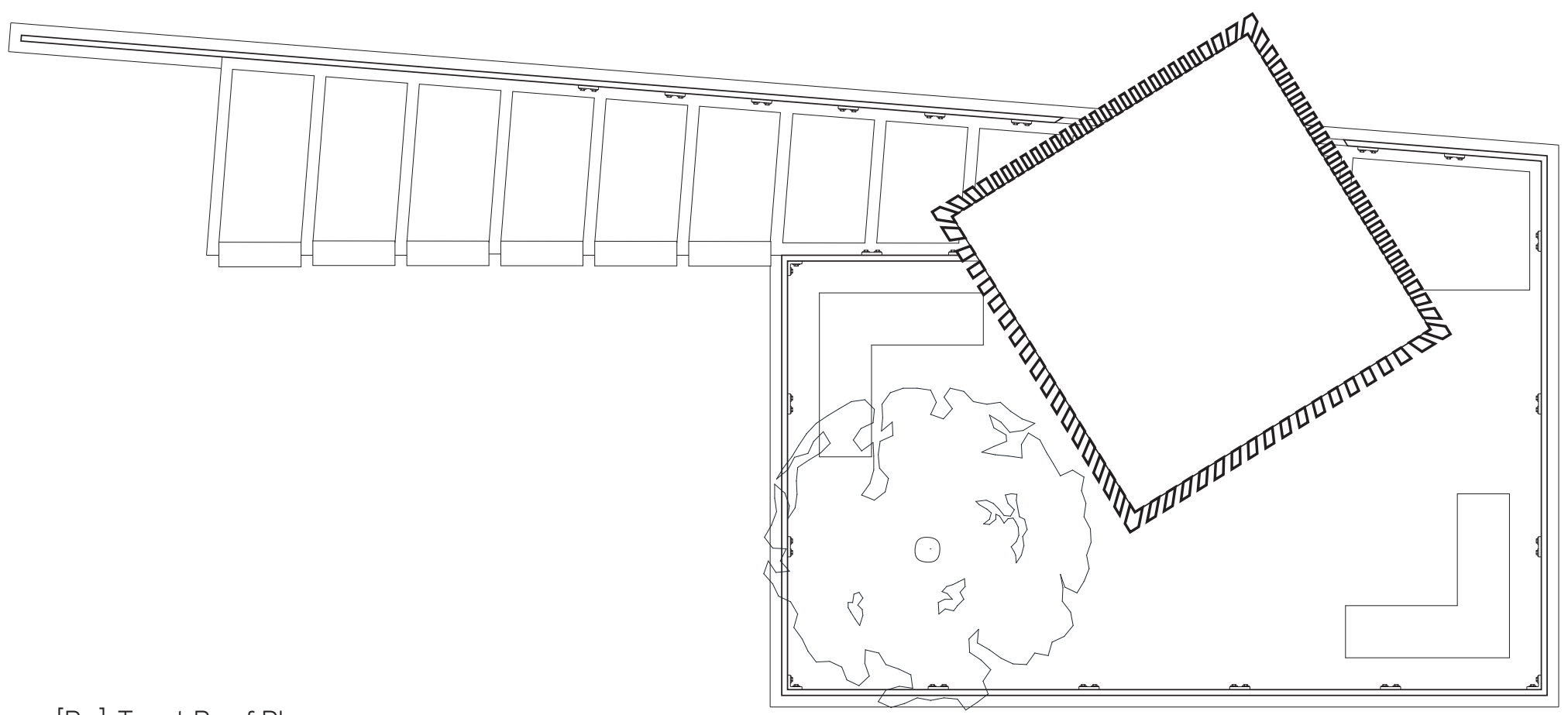

[Re]-Treat Roof Plan

(1) 


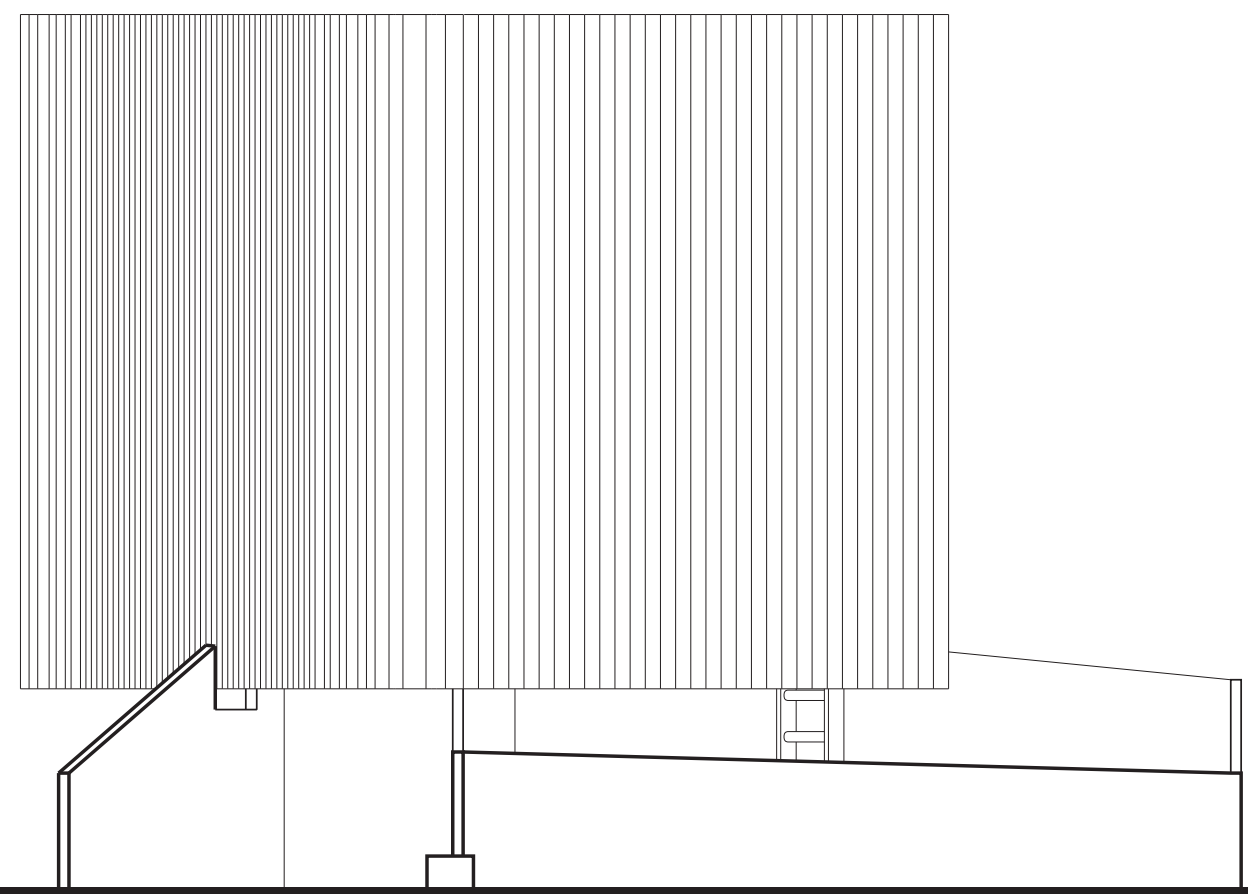

[Re]-Treat West Elevation

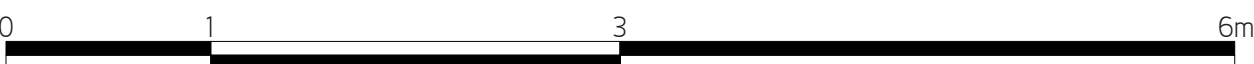

Figure 210: [Re]-Treat West Elevation 


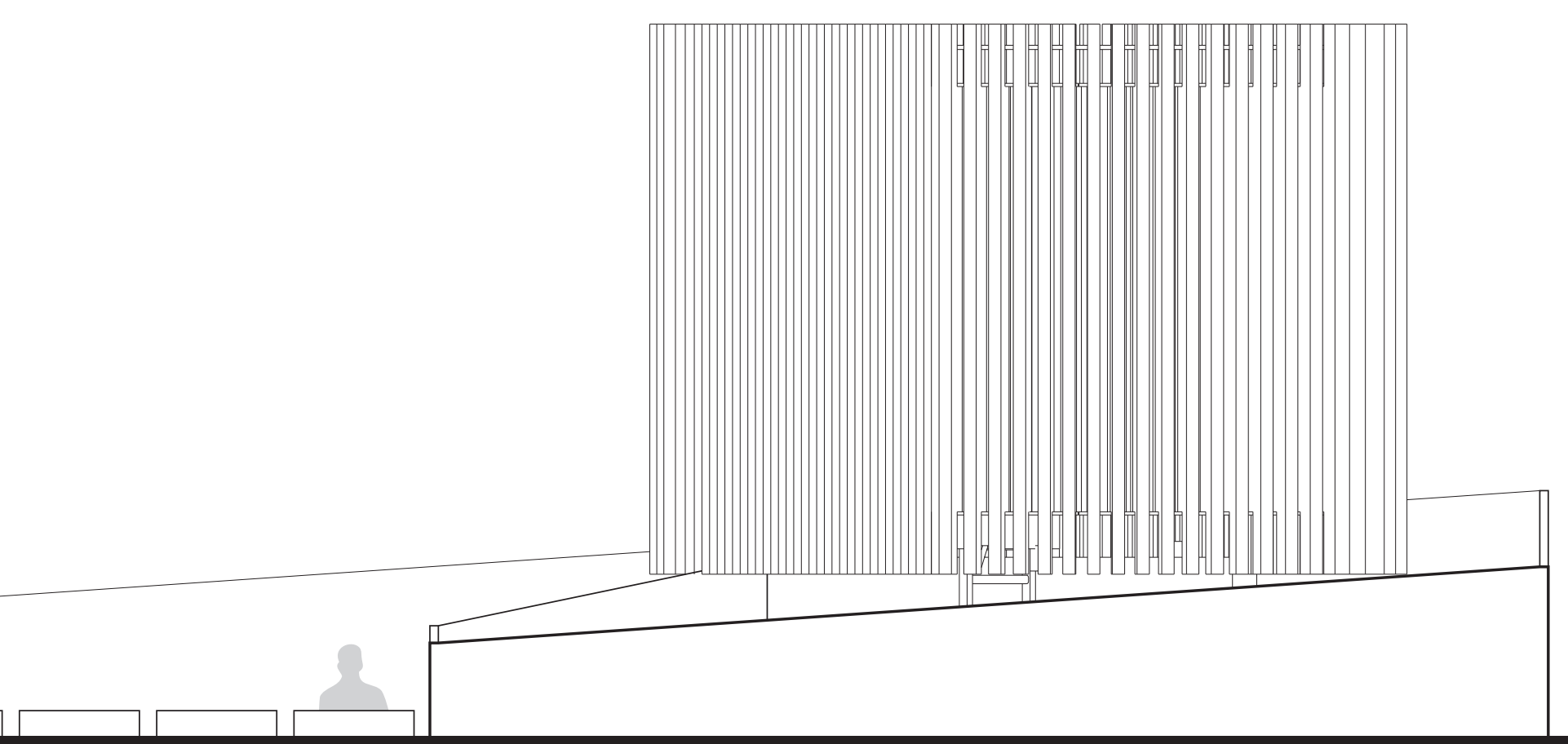

[Re]-Treat South Elevation

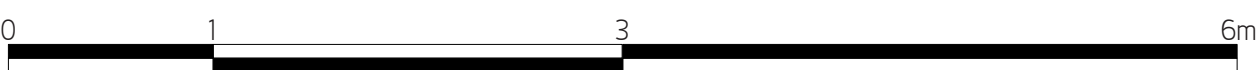

Figure 211: [Re]-Treat South Elevation 


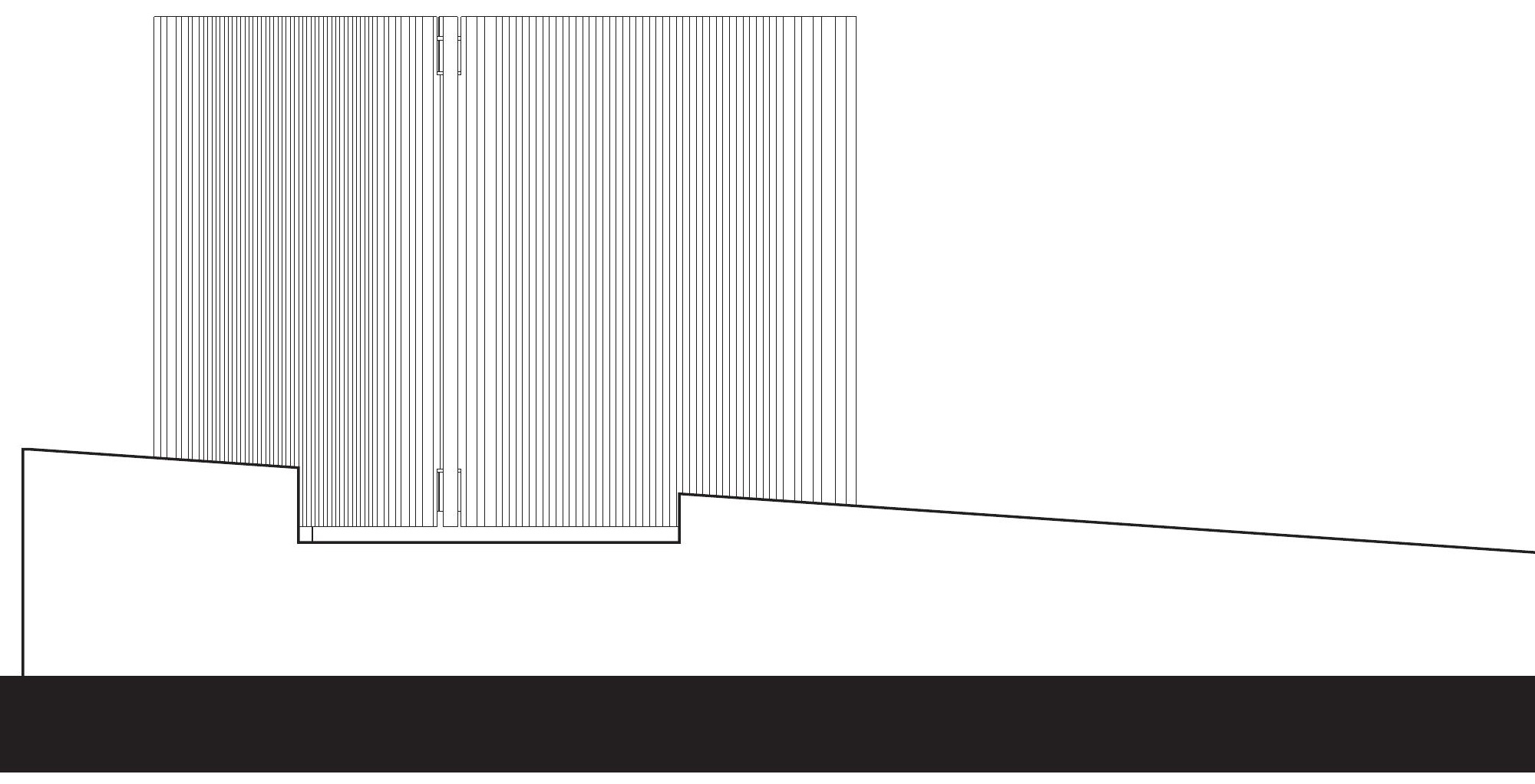

[Re]-Treat North Elevation

Figure 212: [Re]-Treat North Elevation 


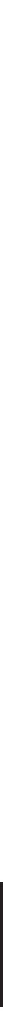

[Re]-Treat East Elevation

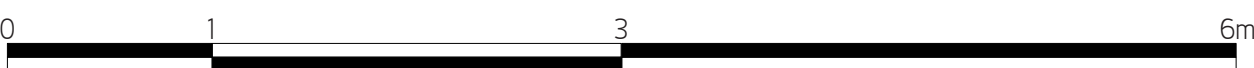

Figure 213: [Re]-Treat East Elevation 


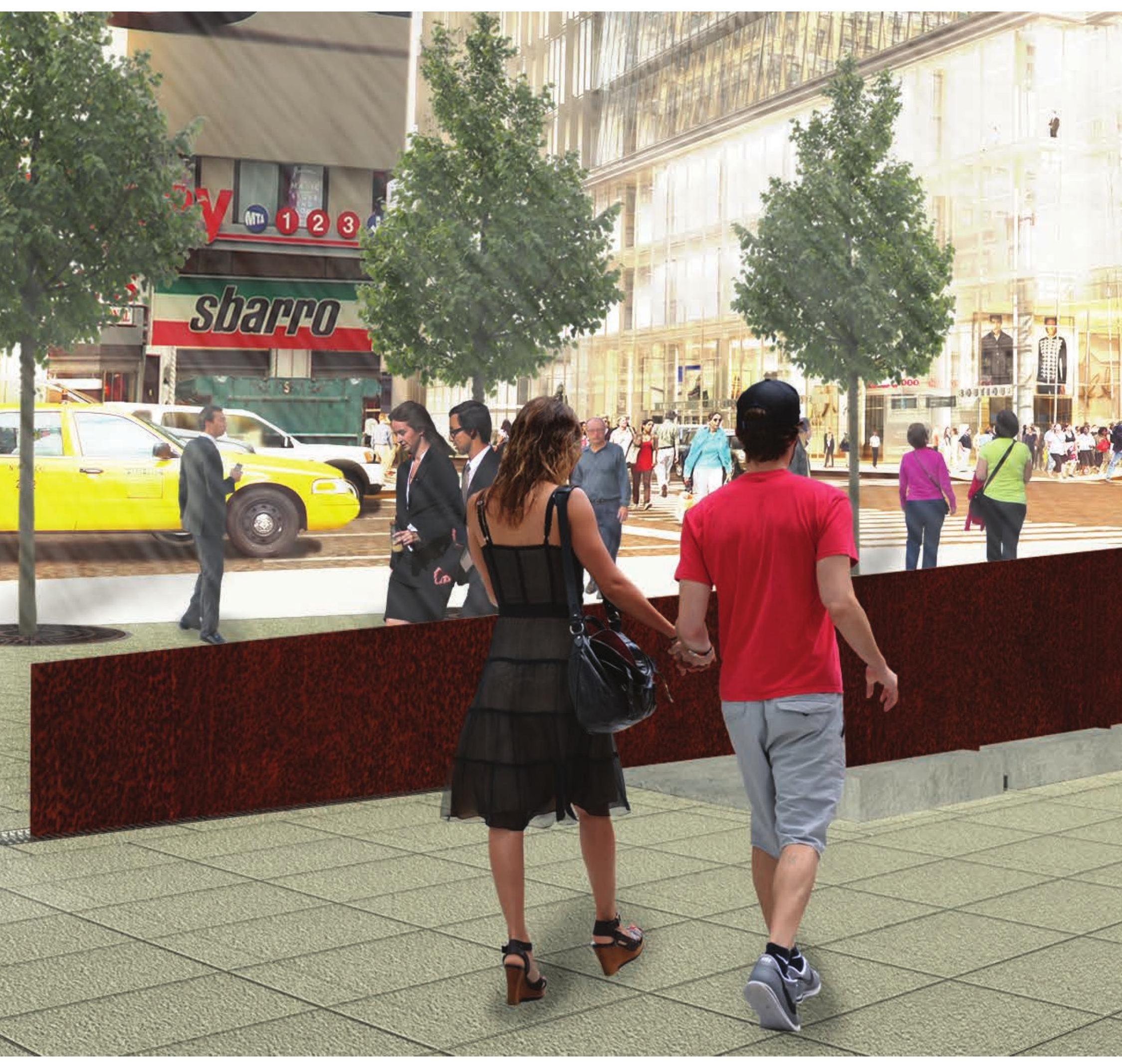




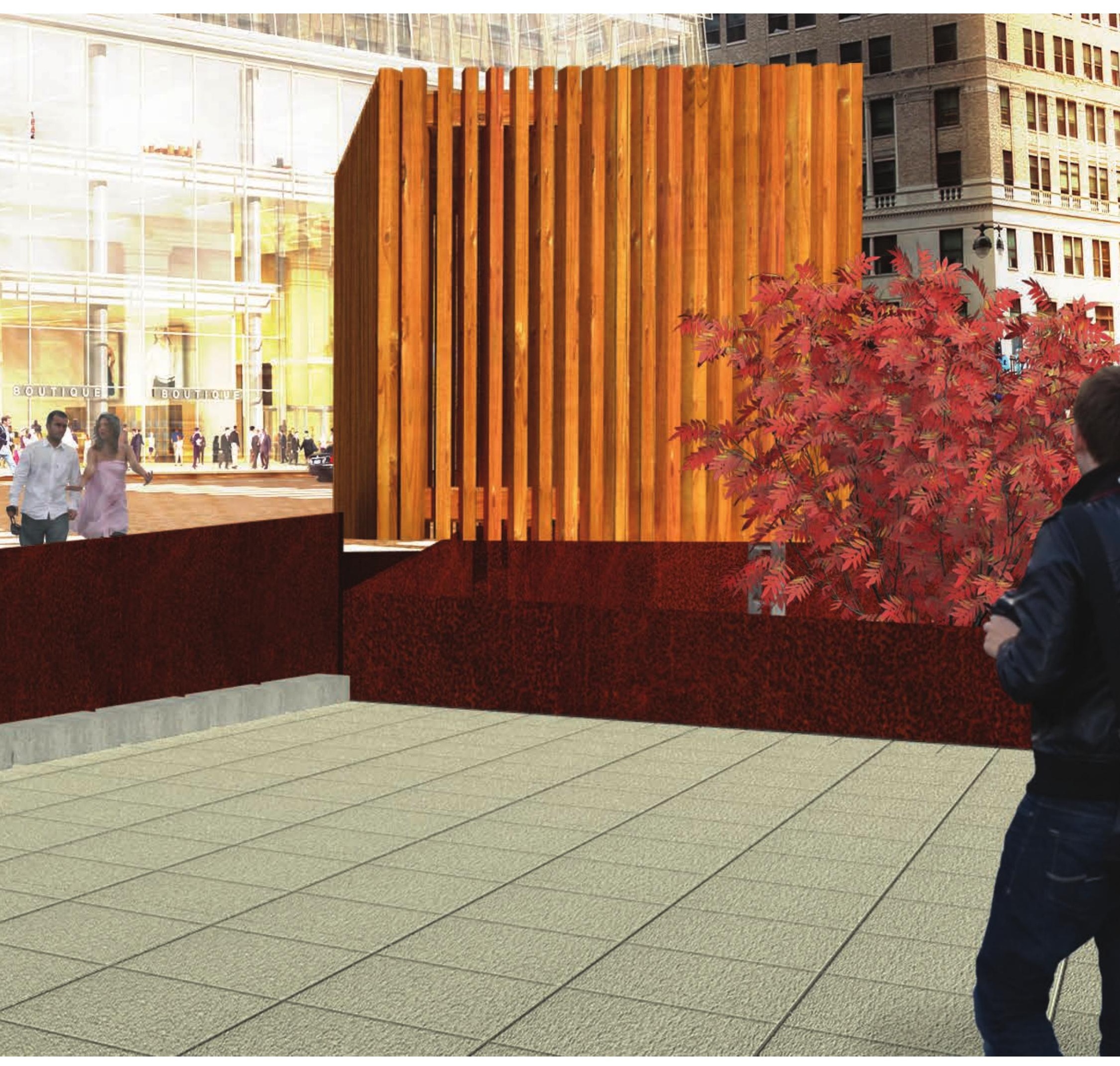

Figure 214: [Re]-Treat Approach 
Tenf 3 in

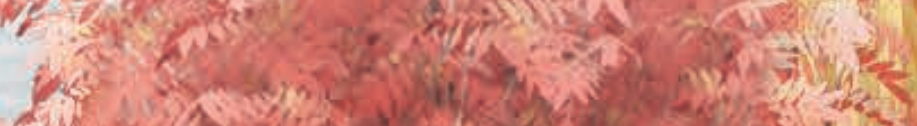

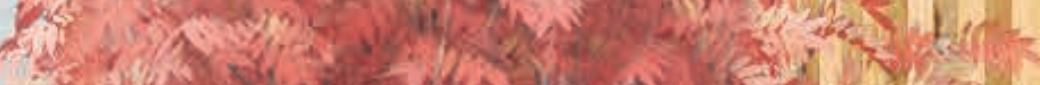

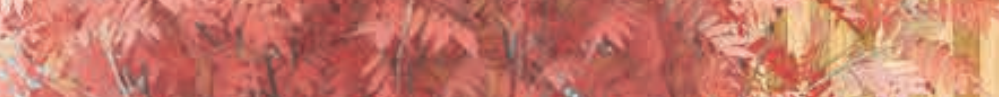

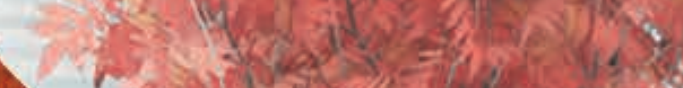

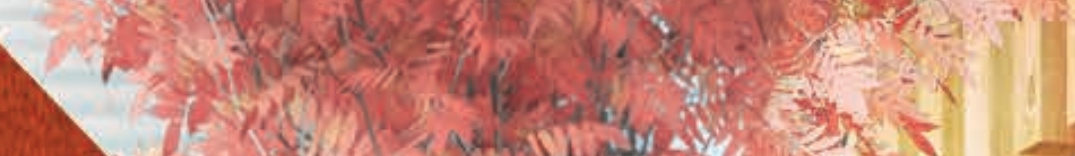

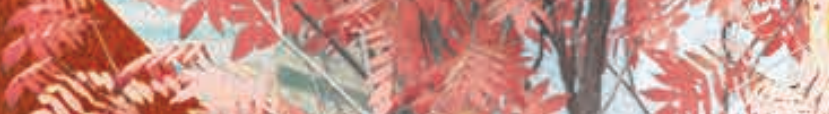
स्रफ

$\left(-\frac{x}{3}\right.$ an

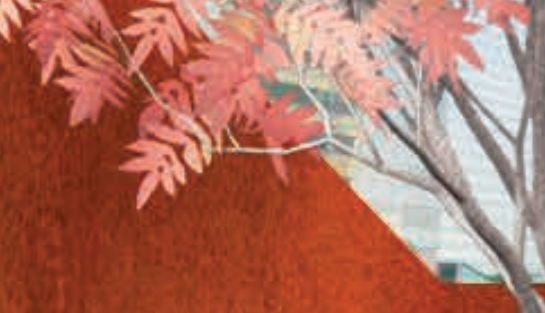

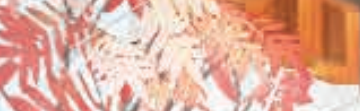

Myis

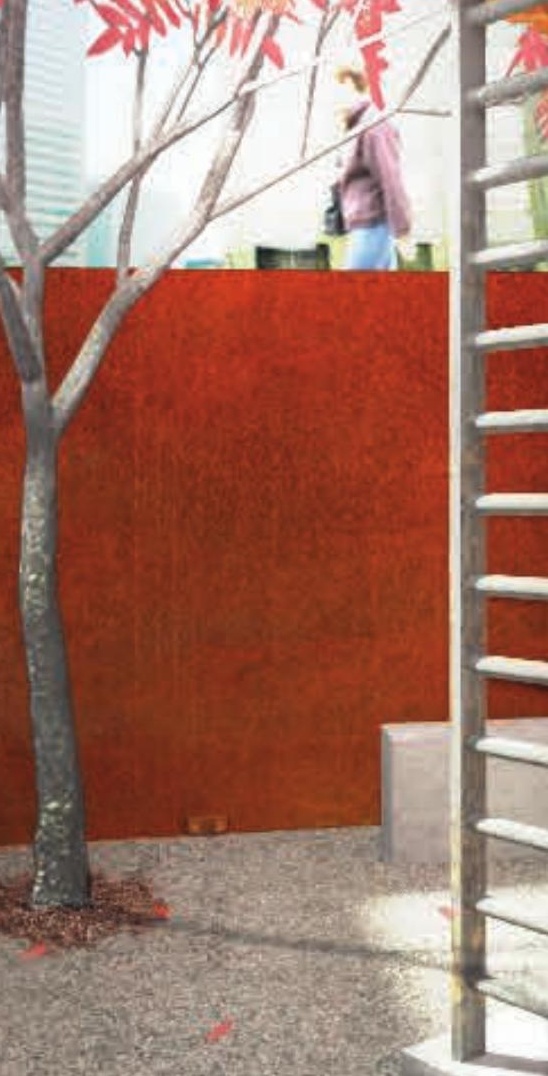




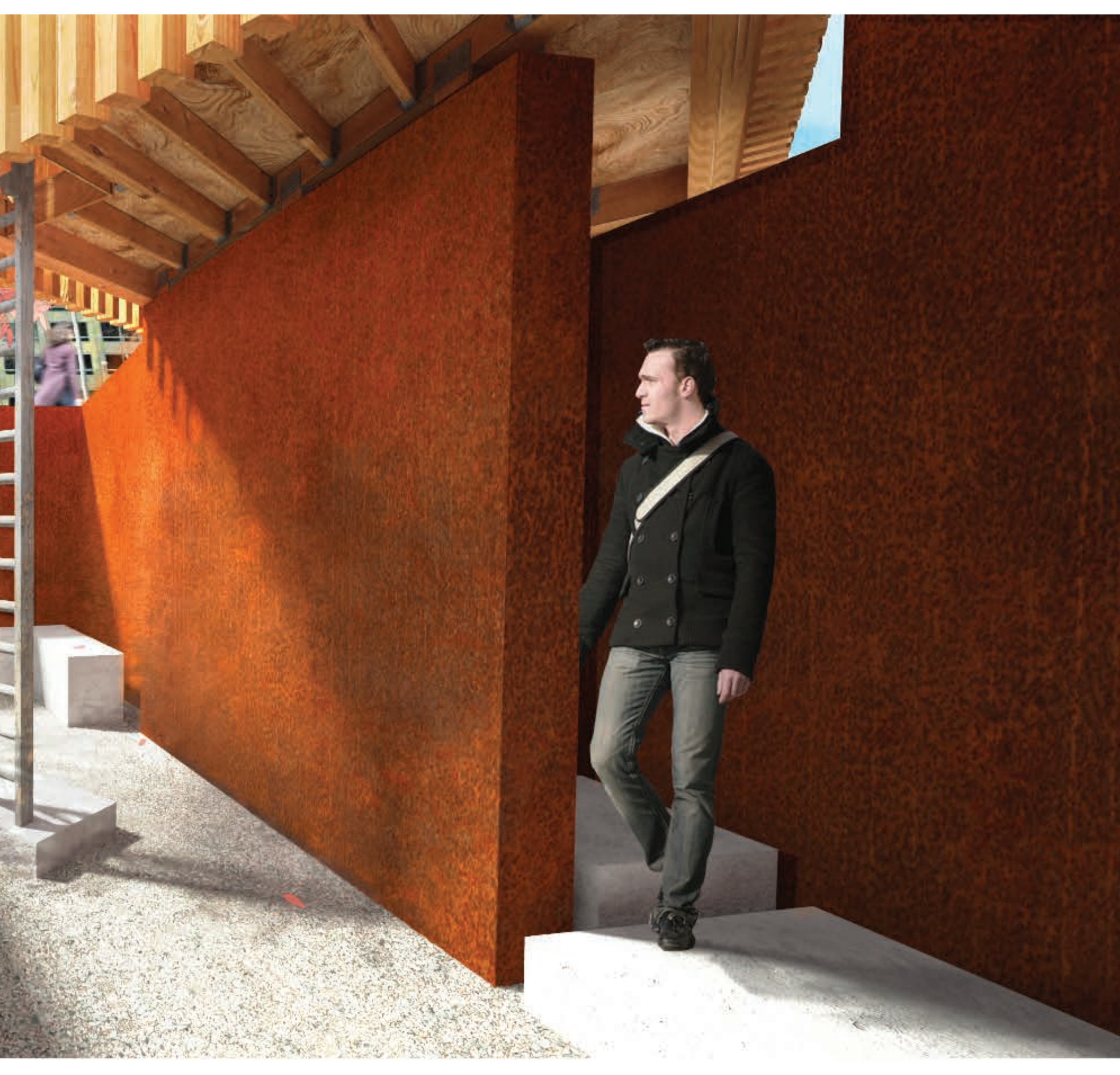

Figure 215: [Re]-Treat Courtyard 
in $x+1,4$

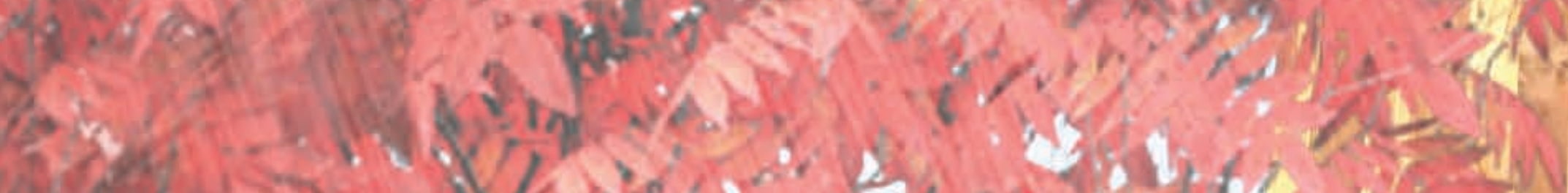

$\therefore$ n

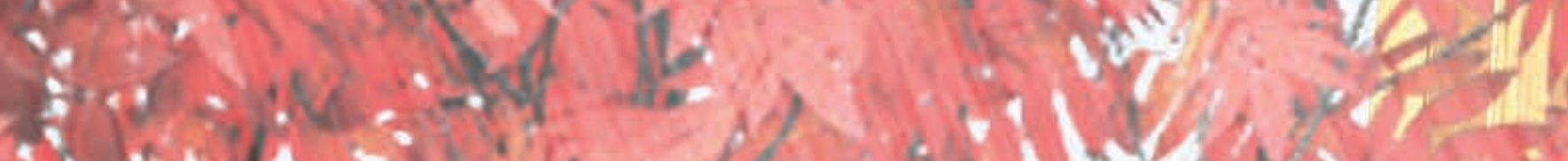

$\therefore$ a.s onne -

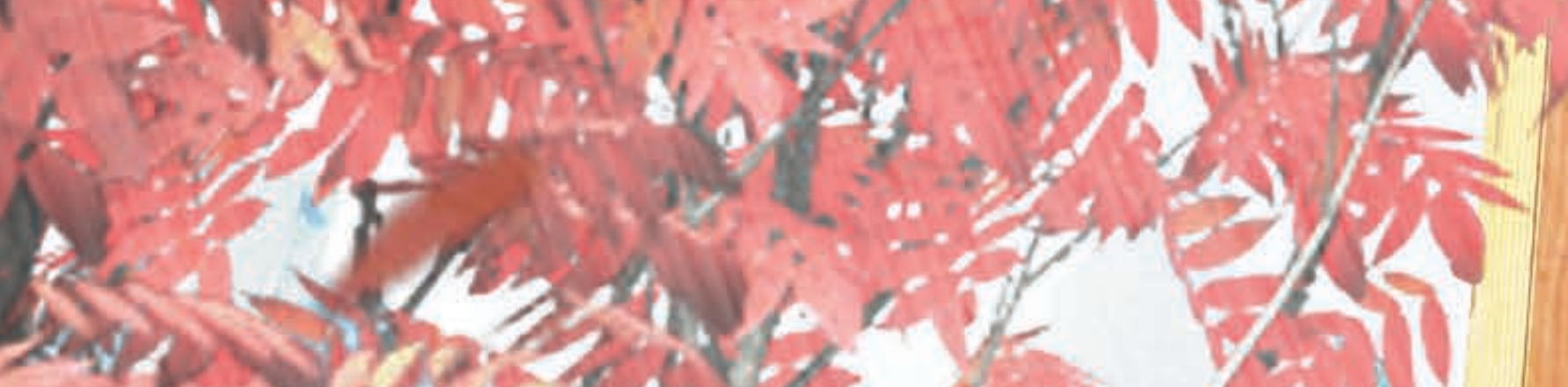

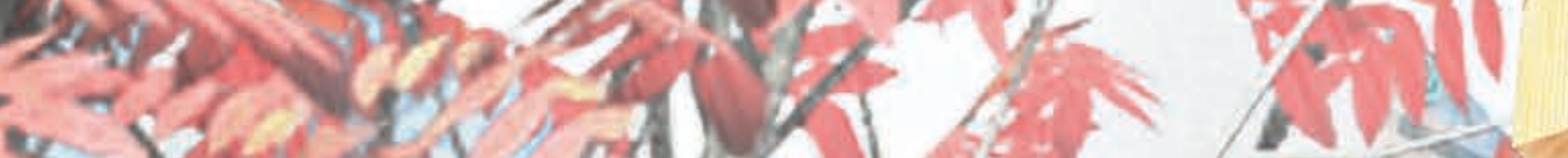

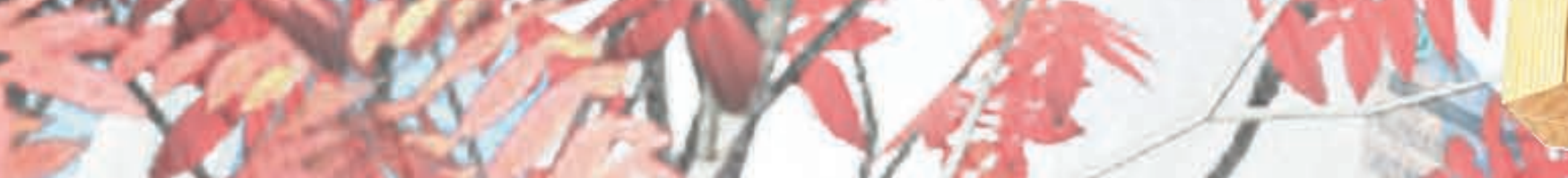

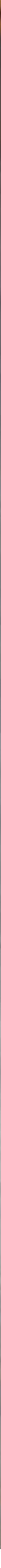




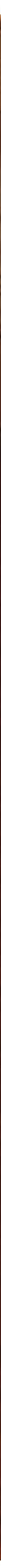




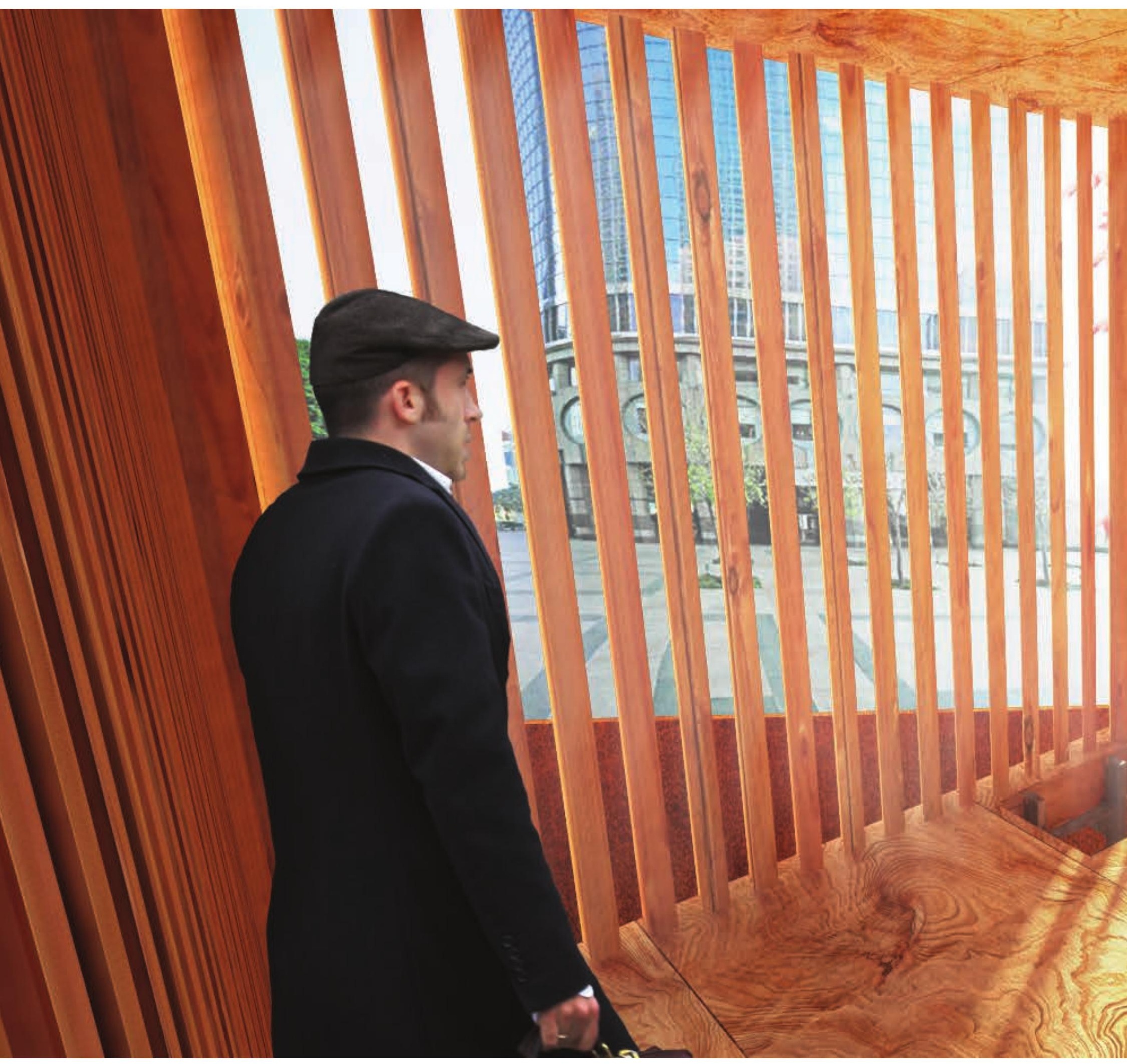




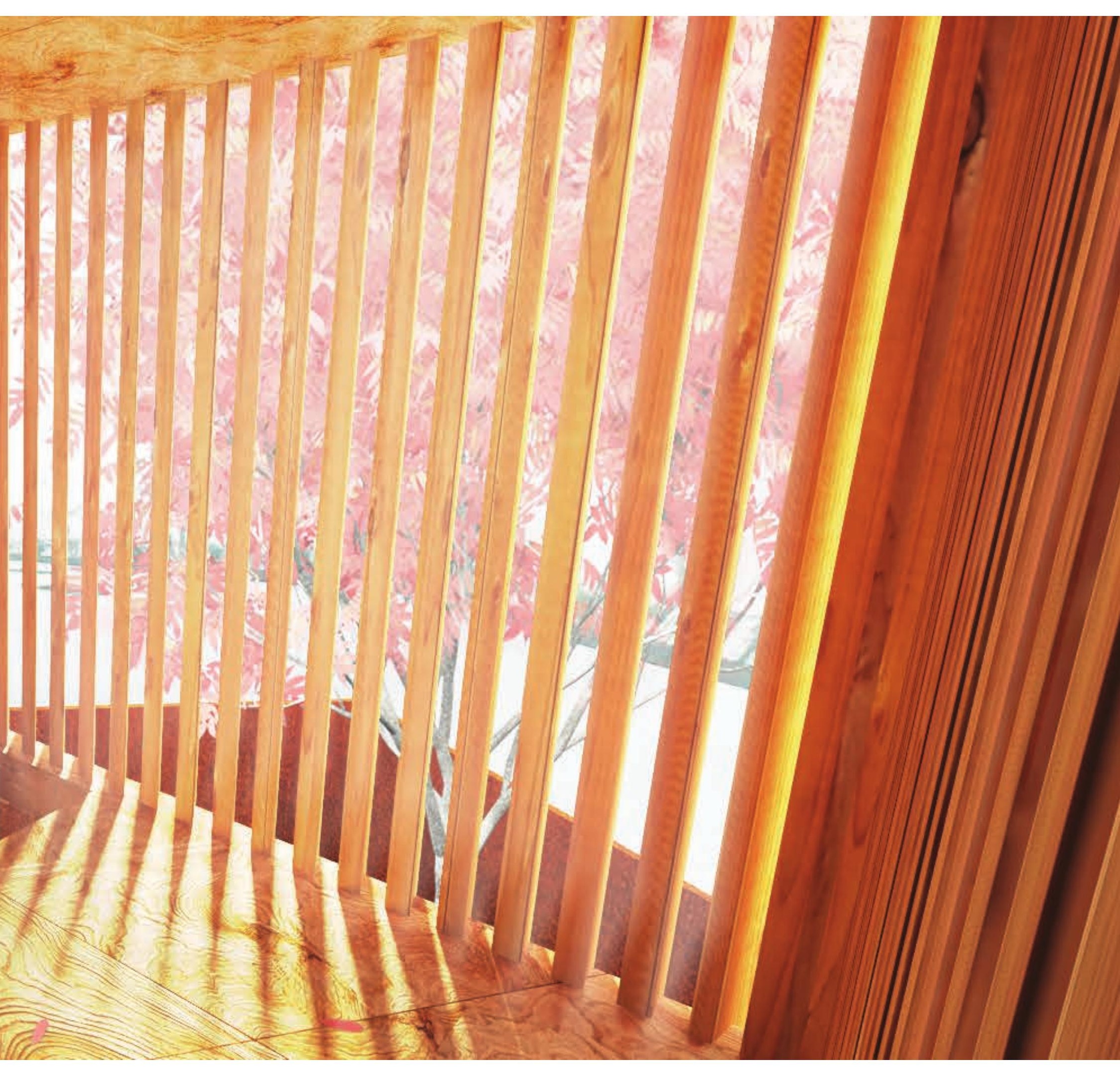

Figure 217: [Re]-Treat Hut Interior View 

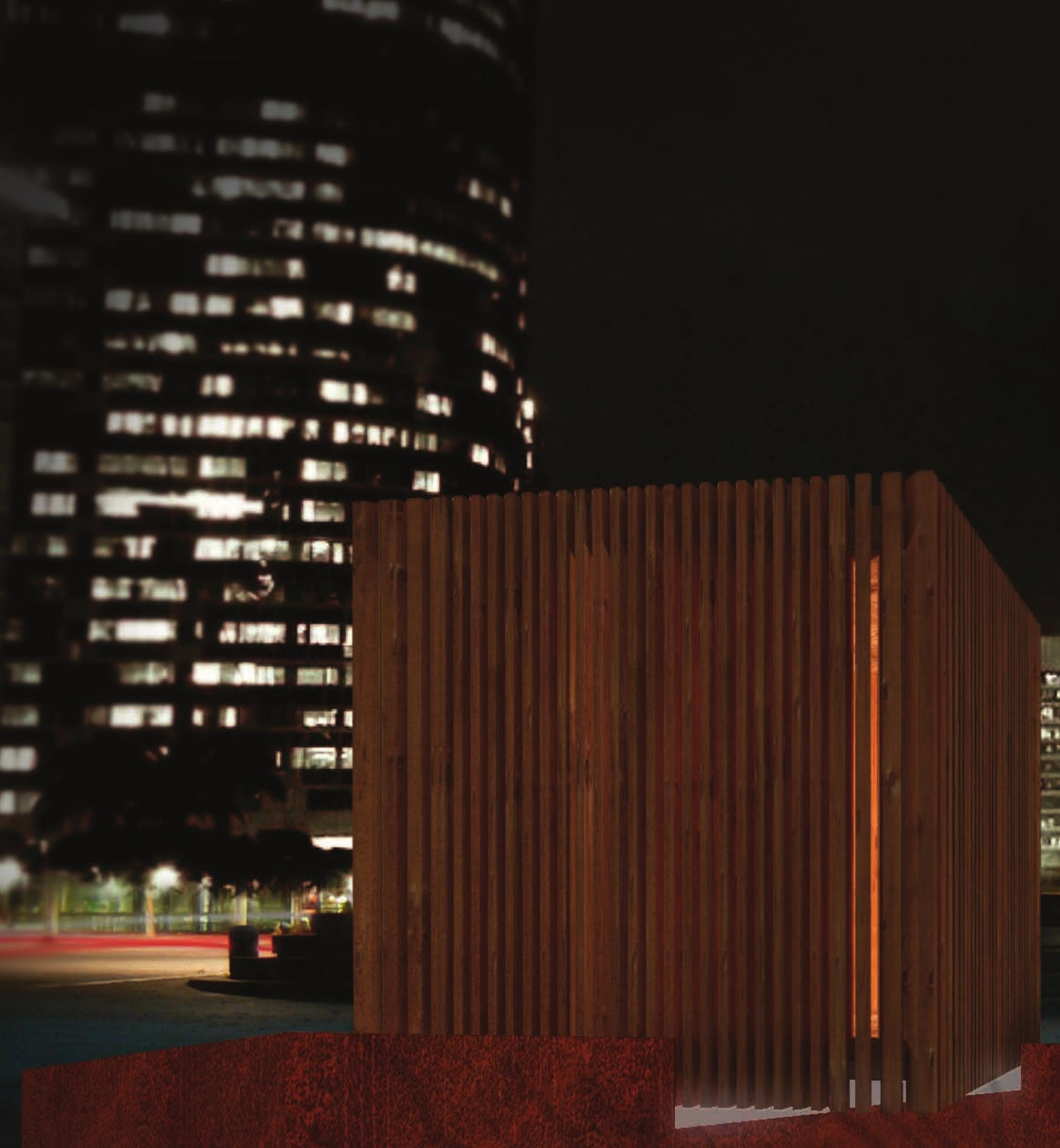


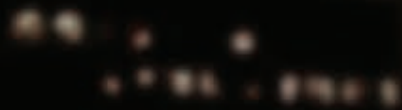

eqenceseces

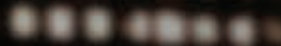
요 8
28

sis

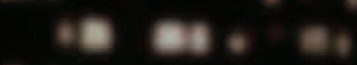

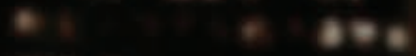

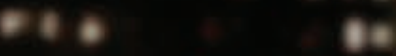

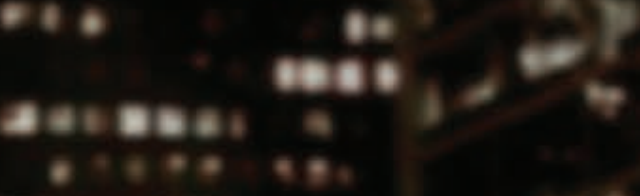

a 80

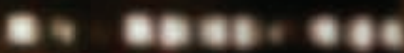
80.48

$$
\boldsymbol{P}=\mathbf{4}
$$

$+8 \mathrm{2} . \mathrm{8}$

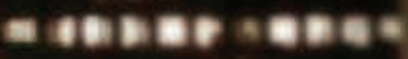

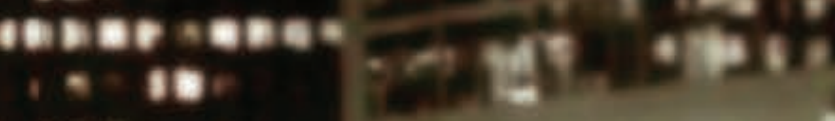

\section{0}

Ef * 8 an, e - 4. 4 ace 1 exper o v w

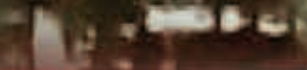
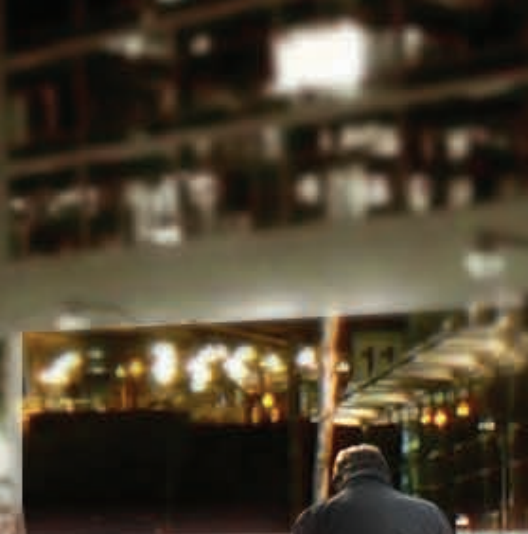

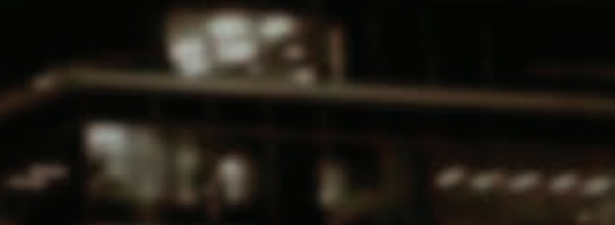

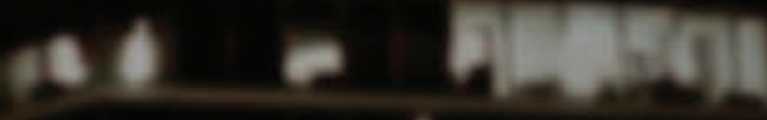
$\cos x$

cos

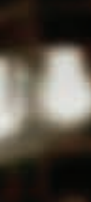

$(4)$
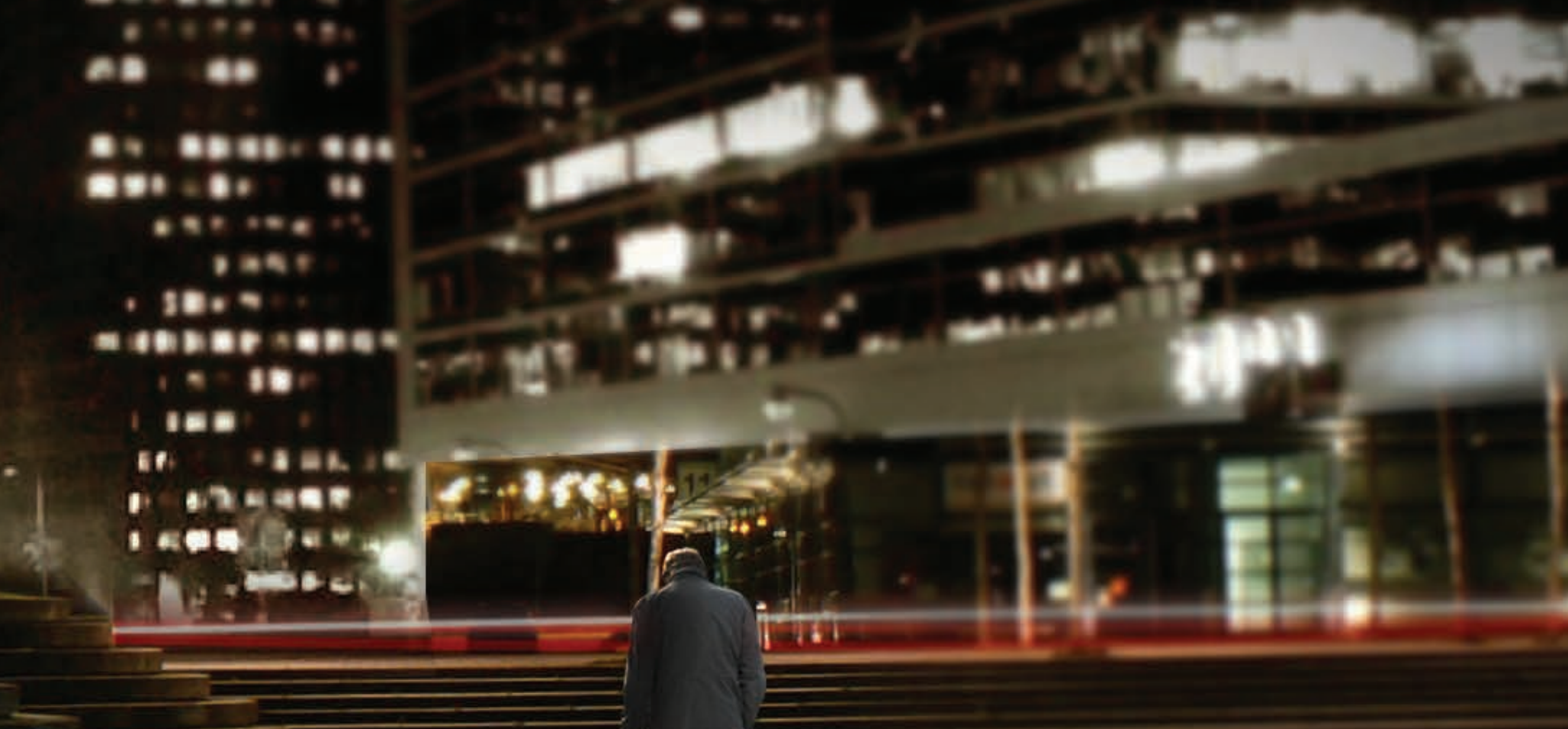

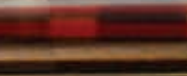




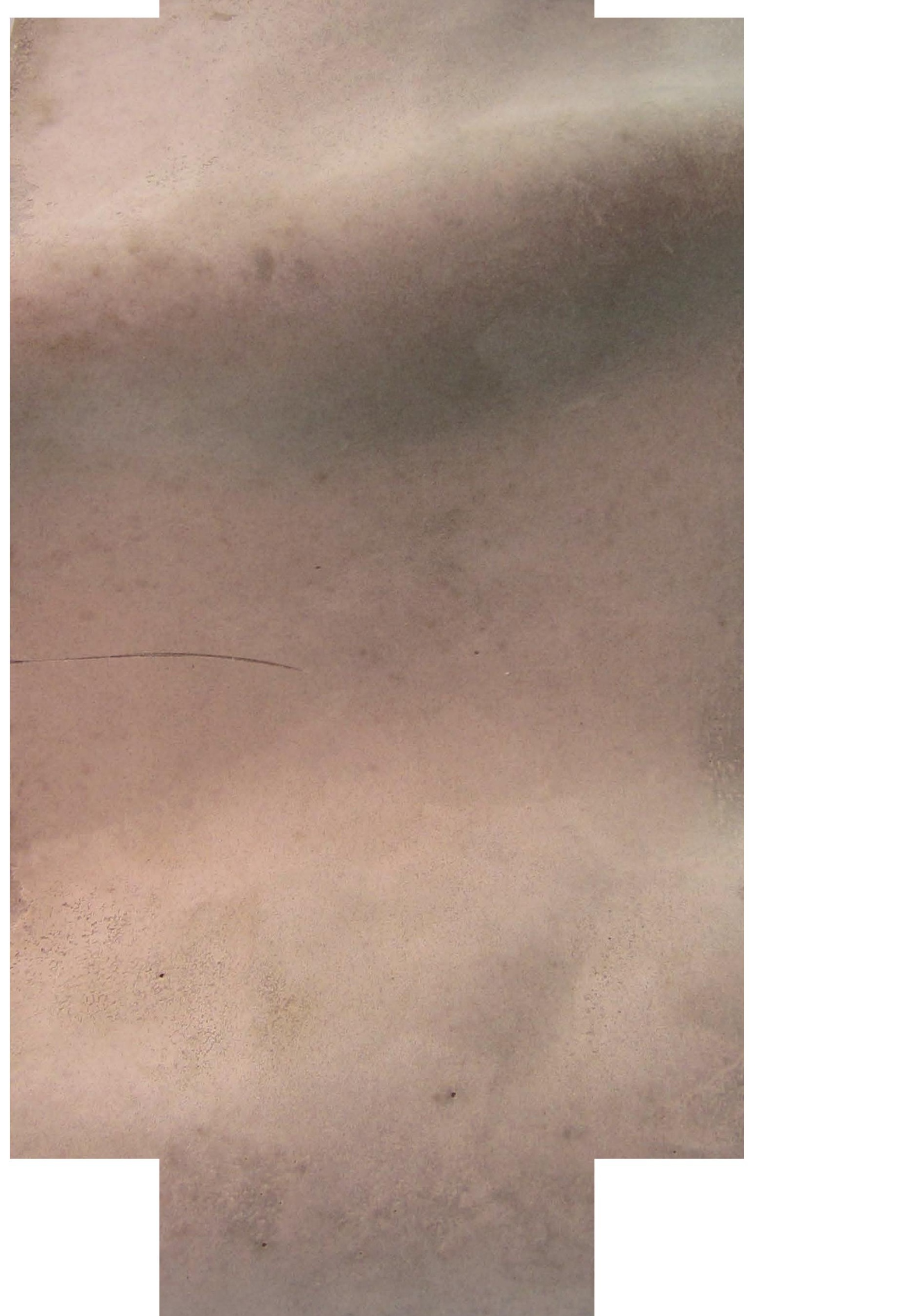




\section{Conclusion}



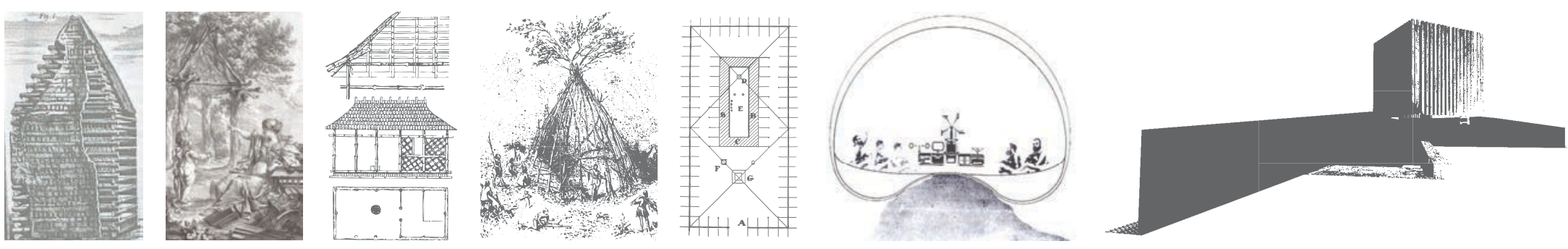
Within the continuum of the primitive hut narratives, this thesis has been employed as a machine for thinking about architecture as a uniquely material practice. This position stemmed from a critique of the virtualized context in which contemporary architectural praxis functions and was undertaken through an exploration of the critical role which fabricated prototypes hold within design. Positioning making as the central component of the design process was a complex task. It required that one suspend the deeply engrained practice of engaging architecture through virtualized means while replacing them with processes which required technical and manual skill, rigorous patience, and time.

While this elemental shift was arduous, the benefits of engaging a design process which was materially founded were unparalleled. This progression transformed the disconnected act of designing architecture through representational means into the intimate experience of designing architecture through its material foundations and their embedded constructive practices.

The notion of experience is fundamental to the position which this thesis presents. In its realized state architecture is meant to be experienced sensually. It is through the imparted experience, which a collection of materials bring, that exposes the inherent qualities of an architectural work. It thus holds that the means through which an architect creates their work must also be equally experiential. An intimate connection must be fostered between architect, material, and form.

Each version of making (MV1-MV7) established within this thesis aided in forming a framework which allowed this critical relationship to be created and strengthened. The versions varied between a directly haptic design process and diagrammatic or written research and explorations. These developmental procedures tested the hypothesis presented and recorded the outcome which culminated in the design of [Re]-Treat. Each making version was critical in building an intimate understanding of the architectural qualities which a design process steeped in making engenders.

Although this methodology of design may be limited in application within 
the context of professional practice, its core tenets can be wholly appropriated as a lens through which to create architecture. Engaging design materially, thinking and working as the intellectual craftsman, affords the architect a position which respects and responds to architecture's material nature. It is from designing within this fundamental truth that the architect and their architectural works are able to embody a practice which explores the richness of materials and the beauty of construction processes providing an unmatched experience to both designer and occupier. 




\section{Bibliography}

Adamson, G. (2007). Thinking through Craft. Oxford: Berg .

Allen, S., \& Agrest, D. I. (2000). Practice: Architecture, Technique and Representation. Amsterdam: G+B Arts International.

Banham, R. (1965, April). A Home is Not a House. Art in America, Number Two, 70-79.

Barrett, E. (2010). Aesthetic Experience and Innovation in Practice-led Research. ACUADS 2010 : Proceedings of the Australian Council of University Art and Design Schools : A View into the Future of Australian Art and Design Schools, (pp. 1-9). Launceston.

Biggs, I. (2009). Art as Research: Creative Practice and Academic Authority. Saarbrucken: VDM Verlag.

Buchanan, P. (2003). Renzo Piano Building Workshop: Complete Works (Vol. vol. 4). New York: Phiadon Press.

Burry, M. (2005). Homo Faber. In B. Sheil, Design Through Making (pp. 30-37). Chichester: Wiley.

Busch, A. (1991). The Art of the Architectural Model. New York: Design Press.

Callicott, N. (2005). Adaptive Architectural Design. In B. Sheil, Design Through Making (pp. 66-69). Chichester: Wiley.

Carman, T. (2008). Merleau-Ponty. Abingdon: Routledge.

Carranza, P. M. (2007). Out of Control: The Media of Architecture, Cybernetics and Design. In K. L. Thomas, Material Matters Architecture and Material Practice (pp. 152-162). New York: Routledge.

Carter, P. (2004). Material Thinking: The Theory and Practice of Creative Research. Carlton, Vic: Melbourne University Publishing. 
Chandler, A. (2004). Building Walls - a Philosophy of Engagement. Arq: Architectural Research Quarterly, 8, 1-11.

Chandler, A. (2007). A Philosphy of Engagement: Developing a Strategic Ability through Direct Engagement with Material, Process and Collective Action. In K. L. Thomas, Material Matters Architectural and Material Practice (pp. 115-124). New York: Routledge.

Chaplin, S. (2005). Makeshift: Some Reflections on Japanese Design Sensibility. In B. Sheil, Design Through Making (pp. 78-85). Chichester: Wiley.

Coderch, R. P., Miró, E. P., \& Carbonero, P. P. (2010). Advanced Architectural Modelmaking. New York: W.W. Norton \& Company.

Corbusier, L. (1923). Toward an Architecture. Los Angeles: Getty Research Institute.

De Freitas, N. (2009, November). Material Thinking as Document. Studies in Material Thinking, 3.

Dewey, J. (1938). Experience and Education. New York, NY, USA: Touchstone.

Dewey, J. (2005). Art as Experience. New York: Berkley Publishing Group.

D'souza, N. (2009). Revisiting a Vitruvian preface: the value of multiple skills in contemporary architectural pedagogy. Arq: Architectural Research Quarterly, 13, 173-181.

Dunn, N. (2007). The Ecology of the Architectural Model. Oxford, Bern, Berlin, Bruxelles, Frankfurt am Main, New York, Wien: Peter Lang International Academic Publishers.

Frascari, M. (1991). Monsters of Architecture: Anthropomorphism in Architectural Theory. New York: Rowman and Littlefield.

Frascari, M. (2010). Splendor and Miseries of Architectural Construction Drawings. Interstices Journal of Architecture and Related Arts(11), 107-113.

Gibson, J. J. (1966). The Senses Considered as Perceptual Systems. Boston, MA: Hougton Mifflin. 
Gray, C., \& Burnett, G. (2009). Making Sense: An Exploration of the Ways of Knowing Generated through Practice and Reflection in Craft. Proceedings of the Crafticulation \& Education Conference. Helsinki: Helsinki University Press. Retrieved from Making Sense.

Gregotti, V. (1996). Inside Architecture. Boston: The MIT Press.

Hale, J. (2008). Architecture, Technology and the Body: From the Prehuman to the Posthuman. In S. Cairns, G. C. Crysler, \& H. Heynen, The SAGE Handbook of Architectural Theory (pp. 513-533). London: SAGE.

Harper, D. (n.d.). Prototype. Retrieved from Online Etymology Dictionary: http://www.etymonline.com/index.php?term=prototype

Harper, D. (n.d.). Tectonic. Retrieved from Online Etymology Dictionary: http://www.etymonline.com/index.php?term=tectonic

Hein, G. E. (1998). Learning in the Museum. London, UK: Routledge.

Hill, J. (2005). Building the Drawing. In B. Sheil, Design through Making (pp. 13-22). Chichester: Wiley.

Jetsonen, J. (2001). Little Big Houses: Working with Architectural Models. Helsinki: Building Information.

Kolarevic, B. (2005). Information Master Builders. In B. Kolarevic, Architecture in the Digital Age: Design and Manufacturing (pp. 55-62). New York: Spon Press.

Kolarevic, B. (2008). Manufacturing Material Effects: Rethinking Design And Making in Architecture. New York: Routledge.

Kolarevic, B. (2008). The (Risky) Craft of Digital Making. In B. Kolarevic, Manufacturing Material Effects: Rethinking Design and Making in Architecture (pp. 119-128). New York: Routledge.

Kolb, D. A. (1984). Experiential Learning: Experience as The Source of Learning and Development. Englewood Cliffs, N.J.: Prentice-Hall.

Krasny, E. (2008). The Force is in the Mind: The Making of Architecture. Vienna: Holzhausen Druck \& Medien GmbH.

Kundera, M. (1995). Slowness. (L. Asher, Trans.) New York: HarperCollins. 
Laugier, M.-A. (1977). An Essay on Architecture. Los Angeles: Hennessey \& Ingalls Inc.

Lawson, B. (2002). The Subject That Won't Go Away But Perhaps We Are Ahead of the Game. Design as Research. Arq: Architectural Research Quarterly, 6, 109-114.

Makela, M. (2007, 10 01). Knowing Through Making: The Role of the Artefact in Practise-Based Research. Knowledge, Technology \& Policy, 20(3), 157-163. doi:10.1007/s12130-007-9028-2

Mills, C. (2011). Designing with Models: A Studio Guide to Architectural Process Models. Ft. Laderdale; FL: Ross Publishing.

Mousette, C., \& Banks, R. (2011). Designing Through Making: Exploring the Simple Haptic Design Space. Proceedings of the fifth international conference on Tangible, Embedded, and Embodied Interaction. TEl '11, pp. 279-282. New York, NY, USA: ACM. doi:10.1145/1935701.1935763

Niedderer, K. (2009). Relating the Production of Artefacts and the Production of Knowledge in Research. In N. Nimkulrat, \& T. O'Riley, Relfections and Connections On the relationship between creative production and academic research (pp. 59-68). Helsinki: Helsinki University Press.

Nimkulrat, N., \& O'Riley, T. (2009). Reflections and Connections On the relationship between creative production and academic research. Helsinki: University of Art and Design Helsinki.

Oxford University Press. (2010, April). Craft. Retrieved from Oxford Dictionaries: http://oxforddictionaries.com/definition/english/craft

Oxford University Press. (2010, April). Design. Retrieved from Oxford Dictionaries: http://oxforddictionaries.com/definition/english/design

Oxford University Press. (2010, April). Make. Retrieved from Oxford Dictionaries: http://oxforddictionaries.com/definition/english/make

Pallasmaa, J. (2005). Hapticity Vision. In B. Sheil, Design through Making (pp. 137-138). Chichester: Wiley.

Pallasmaa, J. (2005). The Eyes of the Skin: Architecture and the Senses. Chichester: Wiley-Academy. 
Piano, R. (1994). The Building Workshop. In E. Robbins, Why Architects Draw (pp. 125-150). Cambridge: The MIT Press.

Polanyi, M. (1968). The Body-Mind Relation. In W. R. Coulson, \& C. R. Rogers, Man and the Sciences of Man (pp. 85-102). Columbus, Ohio: Charles E. Merrill Publishing Company.

Poole, S. (2007). Pumping Up: Digital Steroids and the Design Studio. In K. L. Thomas, Material Matters Architecture and Material Practice (pp. 103-114). New York: Routledge.

Schon, D. A. (1983). The Reflective Practitioner: How Professionals Think in Action. New York: Basic.

Semper, G. (1989). The Four Elements of Architecture. New York: Cambridge University Press.

Semper, G. (2004). Style: Style in the Technical and Tectonic Arts; or, Practical Aesthetics. Los Angeles: Getty Publications.

Sennett, R. (2008). The Craftsman. New Haven: Yale University Press.

Sheil, B. (2005). Design Through Making: An Introduction. In B. Sheil, Design through Making (pp. 4-5). Chichester: Wiley.

Sheil, B. (2005). Transgression from Drawing to Making. Arq: Architectural Research Quarterly, 9, 21-32.

Sheil, B., \& Packman, R. (2005). Making a Bang. In B. Sheil, Design through Making (pp. 70-77). Chichester: Wiley.

Shotton, E. (2007). Material Imprecision. In K. L. Thomas, Material Matters Architecture and Material Practice (pp. 91-102). New York: Routledge.

Smith, A. C. (2004). Architectural Model as Machine: A New View of Models from Antuquity to the Present Day. Boston: Elsevier Ltd.

Smith, M. (2008). Associative Design in Fabrication. In B. Kolarevic, \& K. Klinger, Manufacturing Material Effects: Rethinking Design and Making in Architecture (pp. 223-234). New York, NY: Routledge.

Stacey, M. (2005). In My Craft and Sullen Art or Sketching the Future by Drawing on the Past. In B. Sheil, Design through Making (pp. 38-45). Chichester: Wiley. 
Starkey, B. (2005). Architectural models: material, intellectual, spiritual. Arq: Architectural Research Quarterly, 9(3/4), 265-272.

Sutherland, I., \& Acord, S. K. (2007, October). Thinking with Art: From Situated Knoweldge to Experiential Knowledge. Journal of Visual Art Practice, 6(2).

Tallis, R. (2003). The Hand: A Philosophical Inquiry in Human Being. Edinburgh: Edinburgh University Press.

Thomas, K. L. (2007). Introduction: Architecture and Material Practice. In K. L. Thomas, Material Matters Architecture and Material Practice (pp. 1-12). New York: Routledge.

Thornton, J. (2005). Fabrication Research. In B. Sheil, Design through Making (pp. 100-103). Chichester: Wiley.

Tonkwise, C. (2009, April). Knowing by Being-There Making: Explicating the Tacit Post-Subject in Use. Studies in Material Thinking, 1(2).

Tozer, W. (2008). A Theory of Making: Methodology and Process in Architectural Practice. Arq: Architectural Research Quarterly, 12, 134-138.

Viollet-le-Duc, E. (1876). The Habitations of Man in All Ages. Boston: J.R. Osgood and Company.

Vitruvius, P. (1999). Vitruvius: Ten Books of Architecture. (I. D. Rowland, T. N. Howe, \& M. Dewar, Eds.) New York: Cambridge University Press.

Werner, M. (2011). Model Making. New York: Princeton Architectural Press.

Williams, A. (2002). Architectural Modelling as a Form of Research. Arq: Architectural Research Quarterly, 6, 337-347.

Winnicott, D. W. (1971). Playing and Reality. London: Tavistock Publications.

Wright, E. (1984). Psychoanalytic Criticism: Theory in Practice. London: Routledge.

Young, A. (2011, December). Editorial. Studies in Material Thinking, 6, 1-6. 
